\title{
Oxy-coal Combustion Studies
}

Task 3 Topical Report, Utah Clean Coal Program

Reporting Period Start Date: October 2008

Report Period End Date: July 2011

Principal Authors: J.O.L. Wendt, E.G. Eddings, J.S. Lighty, T. Ring, P.J. Smith, J. Thornock, Y. Jia, W. Morris, J. Pedel, D. Rezeai, L. Wang, J. Zhang, K. Kelly

Issue date: January 6, 2012

DOE Award Number: DE-NT0005015

Project Officer: David Lang

University of Utah

Institute for Clean \& Secure Energy

380 INSCC

155 South, 1452 East

Salt Lake City, UT 84112 


\section{DISCLAIMER}

This report was prepared as an account of work sponsored by an agency of the United States Government. Neither the United States Government nor any agency thereof, nor any of their employees, makes any warranty, express or implied, or assumes any legal liability or responsibility for the accuracy, completeness, or usefulness of any information, apparatus, product, or process disclosed, or represents that its use would not infringe privately owned rights. Reference herein to any specific commercial product, process or service by trade name, trademark, manufacturer, or otherwise does not necessarily constitute or imply its endorsement, recommendation, or favoring by the United States Government or any agency thereof. The views and opinions of authors expressed herein do not necessarily state or reflect those of the United States Government or any agency thereof. 


\section{ABSTRACT}

The objective of this project is to move toward the development of a predictive capability with quantified uncertainty bounds for pilot-scale, single-burner, oxy-coal operation. This validation research brings together multi-scale experimental measurements and computer simulations. The combination of simulation development and validation experiments is designed to lead to predictive tools for the performance of existing air fired pulverized coal boilers that have been retrofitted to various oxy-firing configurations. In addition, this report also describes novel research results related to oxy-combustion in circulating fluidized beds. For pulverized coal combustion configurations, particular attention is focused on the effect of oxy-firing on ignition and coal-flame stability, and on the subsequent partitioning mechanisms of the ash aerosol. To these ends, the project has focused on the following:

- The development of reliable Large Eddy Simulations (LES) of oxy-coal flames using the Direct Quadrature Method of Moments (DQMOM) (Subtask 3.1). The simulations were validated for both non-reacting particle-laden jets and oxy-coal flames.

- The modifications of an existing oxy-coal combustor to allow operation with high levels of input oxygen to enable in-situ laser diagnostic measurements as well as the development of strategies for directed oxygen injection (Subtask 3.2). Flame stability was quantified for various burner configurations. One configuration that was explored was to inject all the oxygen as a pure gas within an annular oxygen lance, with burner aerodynamics controlling the subsequent mixing.

- The development of Particle Image Velocimetry (PIV) for identification of velocity fields in turbulent oxy-coal flames in order to provide high-fidelity data for the validation of oxy-coal simulation models (Subtask 3.3). Initial efforts utilized a laboratory diffusion flame, first using gas-fuel and later a pulverized-coal flame to ensure the methodology was properly implemented and that all necessary data and image-processing techniques were fully developed. Success at this stage of development led to application of the diagnostics in a large-scale oxy-fuel combustor (OFC).

- The impact of oxy-coal-fired vs. air-fired environments on $\mathrm{SO}_{\mathrm{x}}\left(\mathrm{SO}_{2}, \mathrm{SO}_{3}\right)$ emissions during coal combustion in a pilot-scale circulating fluidized-bed (CFB) (Subtask 3.4). Profiles of species concentration and temperature were obtained for both conditions, and profiles of temperature over a wide range of $\mathrm{O}_{2}$ concentration were studied for oxy-firing conditions. The effect of limestone addition on $\mathrm{SO}_{2}$ and $\mathrm{SO}_{3}$ emissions were also examined for both air- and oxy- firing conditions.

- The investigation of $\mathrm{O}_{2} / \mathrm{CO}_{2}$ and $\mathrm{O}_{2} / \mathrm{N}_{2}$ environments on $\mathrm{SO}_{2}$ emissions during coal combustion in a bench-scale single-particle fluidized-bed reactor (Subtask 3.5). Moreover, the sulfation mechanisms of limestone in $\mathrm{O}_{2} / \mathrm{CO}_{2}$ and $\mathrm{O}_{2} / \mathrm{N}_{2}$ environments were studied, and a generalized gassolid and diffusion-reaction single-particle model was developed to study the effect of major operating variables.

- The investigation of the effect of oxy-coal combustion on ash formation, particle size distributions (PSD), and size-segregated elemental composition in a drop-tube furnace and the $100 \mathrm{~kW}$ OFC (Subtask 3.6). In particular, the effect of coal type and flue gas recycle (FGR, OFC only) was investigated.

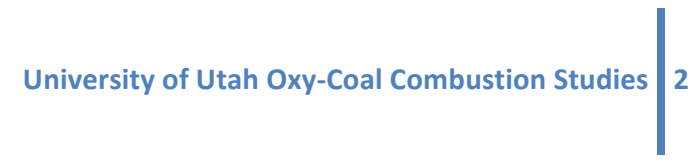




\section{TABLE OF CONTENTS}

DISCLAIMER

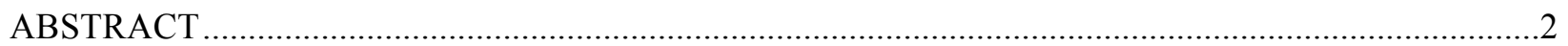

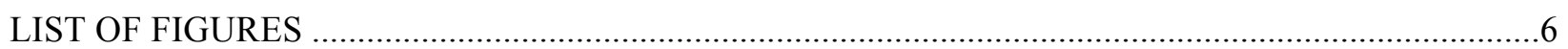

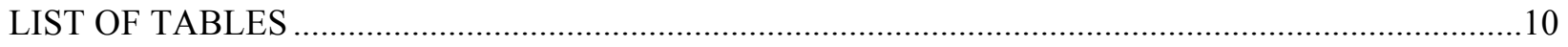

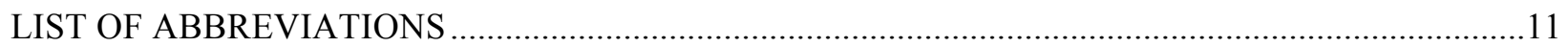

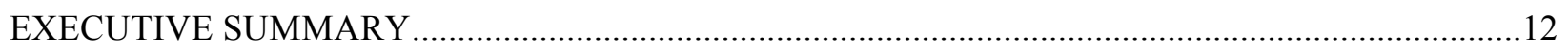

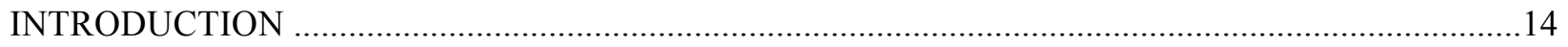

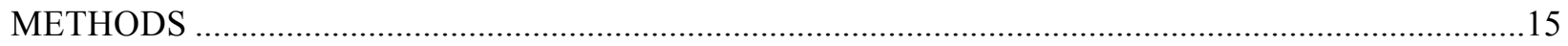

Subtask 3.1 - Oxy-Coal Combustion Large Eddy Simulations ..................................................... 15

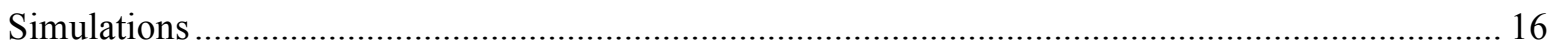

Subtask 3.2 - Near-Field Aerodynamics of Oxy-Coal Flames with Directed Oxygen and Minimum

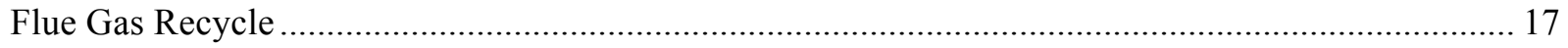

Furnace modifications and burner designs for directed oxygen tests......................................... 18

Furnace modifications for improved laser diagnostics............................................................. 20

Subtask 3.3 - Advanced Diagnostics for Oxy-Coal Combustion .................................................... 22

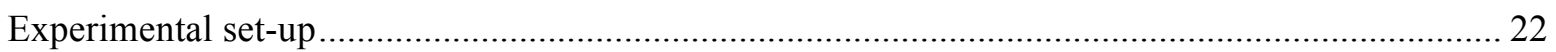

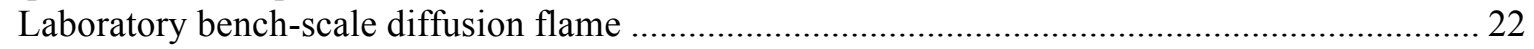

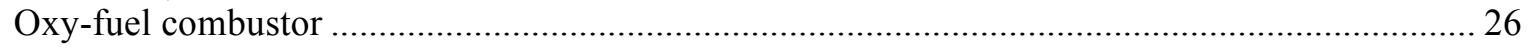

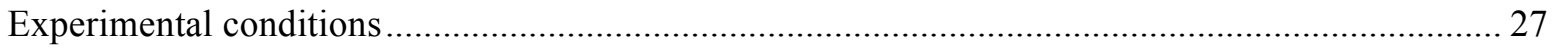

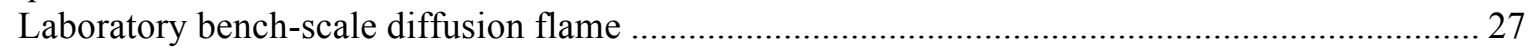

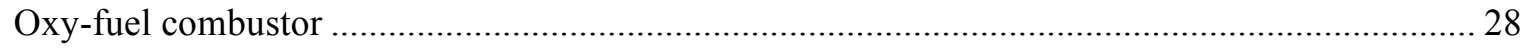

Subtask 3.4 - Oxy-Coal Combustion in Circulating Fluidized Beds ................................................ 28

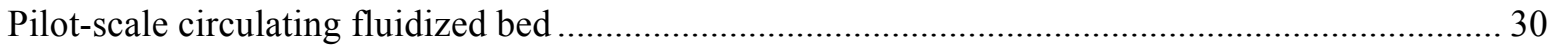

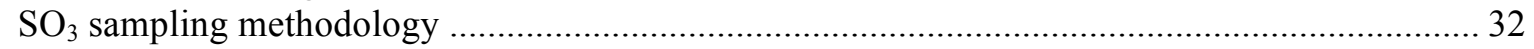

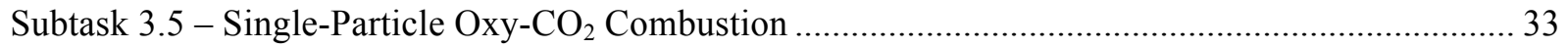

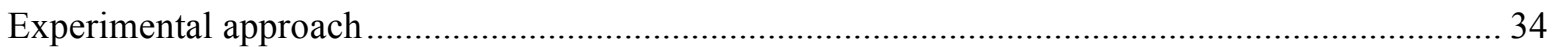

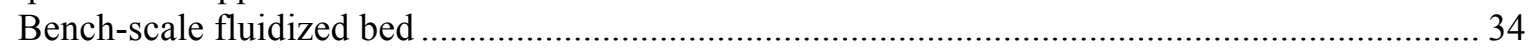

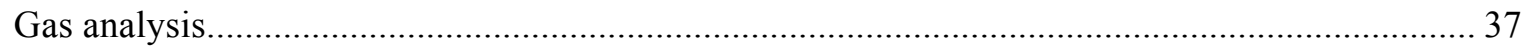

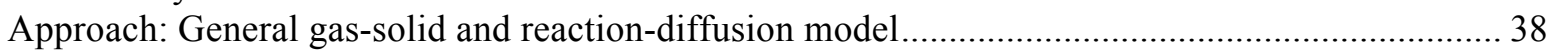

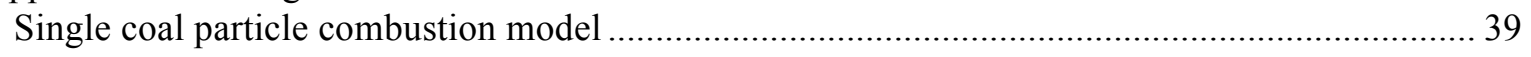

Subtask 3.6 - Ash Partitioning Mechanisms for Oxy-Coal Combustion with Varied Amounts of Flue

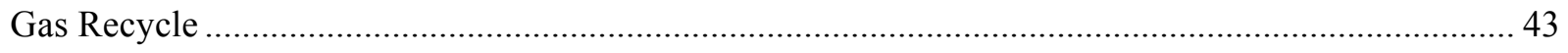

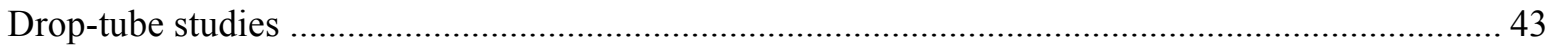

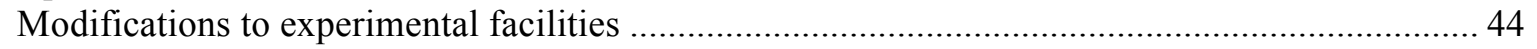




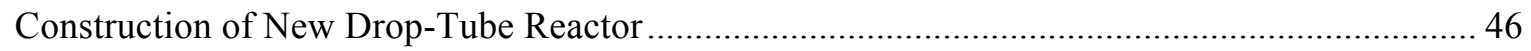

Experiments with simulated flue gases for Utah Skyline, PRB and Illinois \#6 coals .................. 48

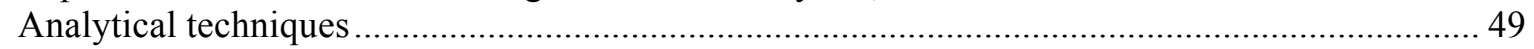

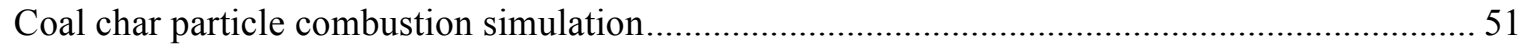

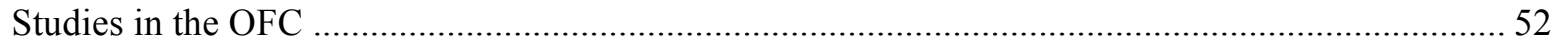

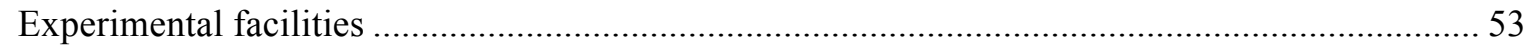

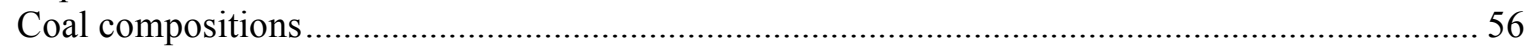

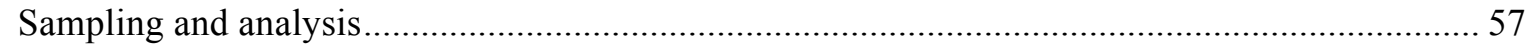

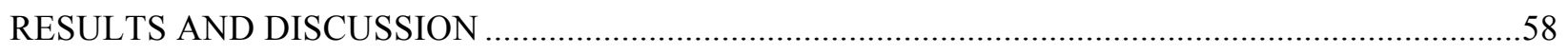

Subtask 3.1 - Oxy-Coal Combustion Large Eddy Simulations ........................................................ 58

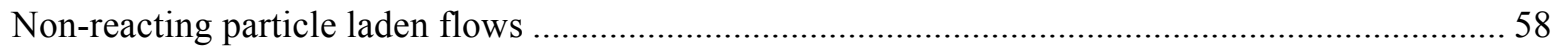

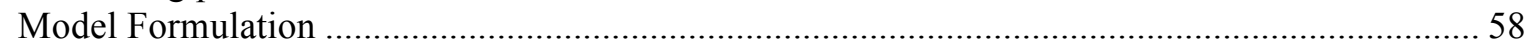

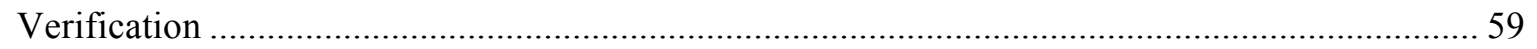

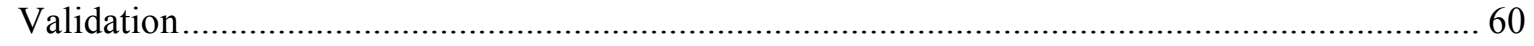

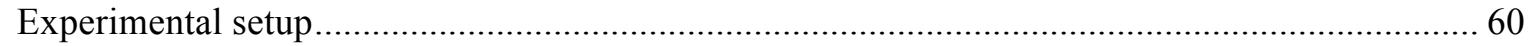

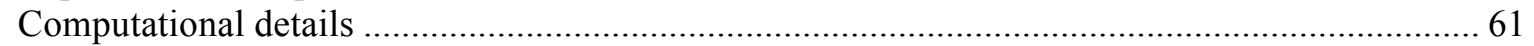

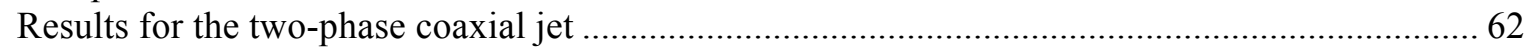

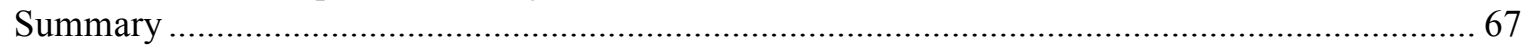

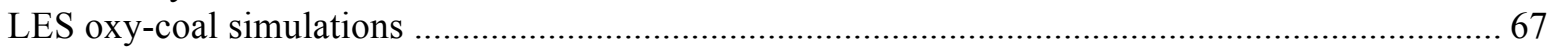

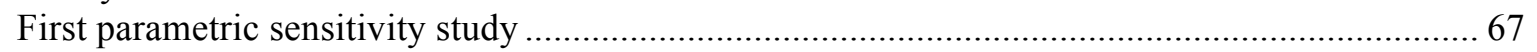

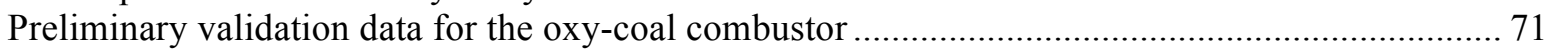

Subtask 3.2 - Near-Field Aerodynamics of Oxy-Coal Flames with Directed Oxygen and Minimum

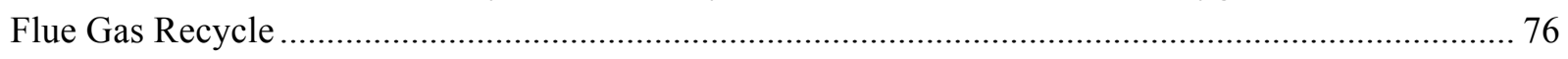

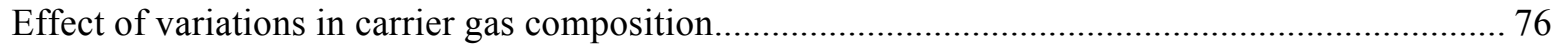

Subtask 3.3 - Advanced Diagnostics for Oxy-Coal Combustion …................................................ 85

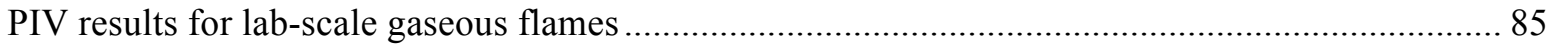

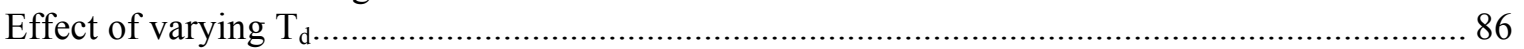

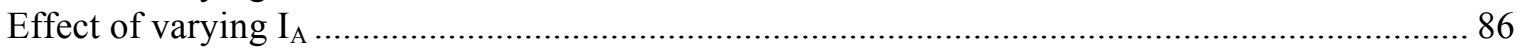

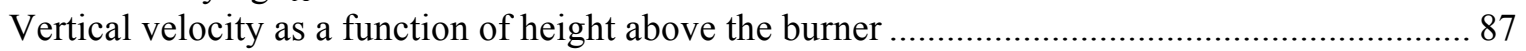

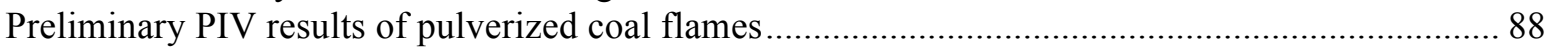

Effects of coal particle size and global equivalence ratio on PIV results of pulverized coal flames

PIV results of pulverized coal flame in the OFC

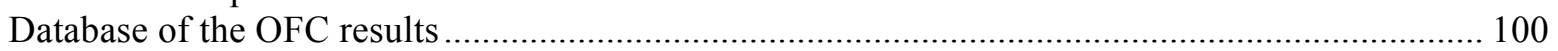

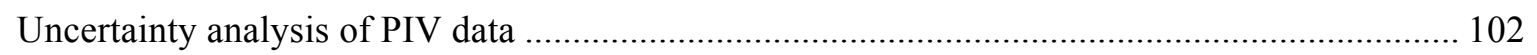

Subtask 3.4 - Oxy-Coal Combustion in Circulating Fluidized Beds ............................................... 104

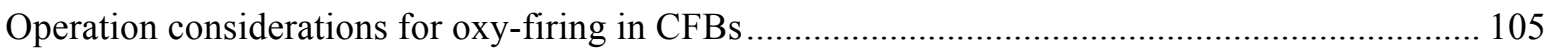

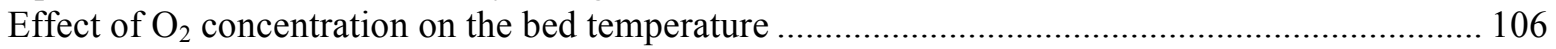

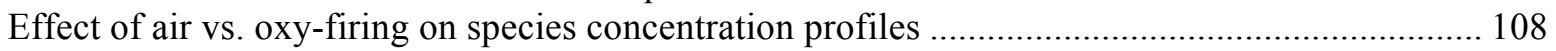

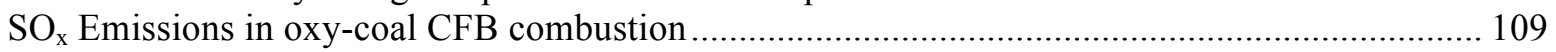

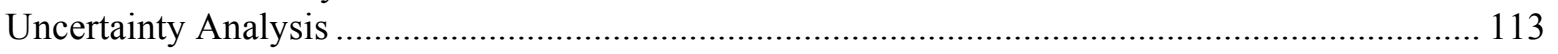

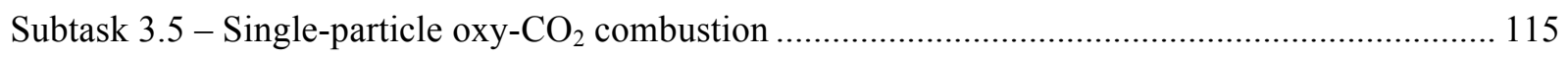




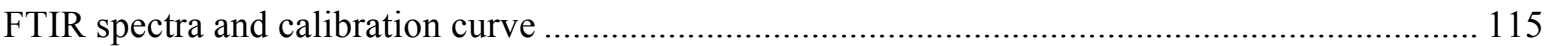

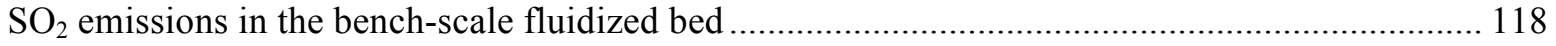

Sulfur removal by limestone during coal combustion process ................................................. 125

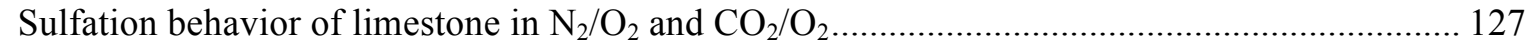

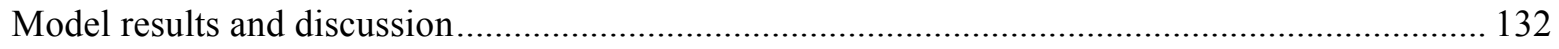

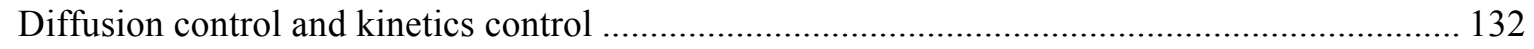

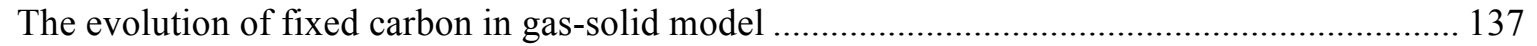

Subtask 3.6 - Ash Partitioning Mechanisms for Oxy-Coal Combustion with Varied Amounts of Flue

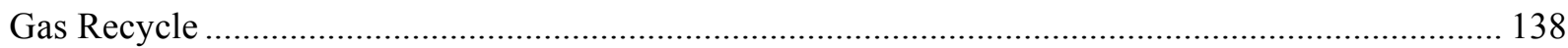

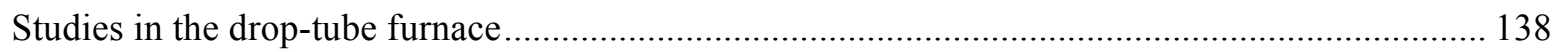

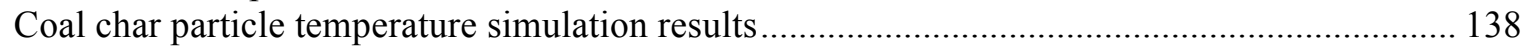

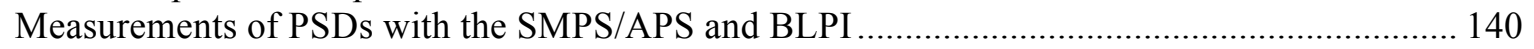

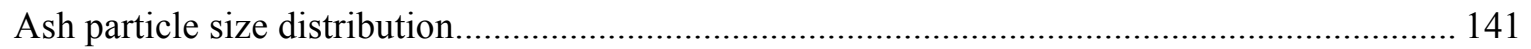

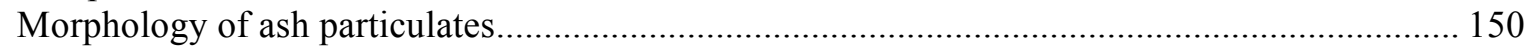

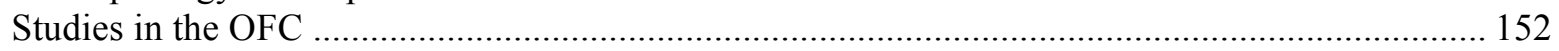

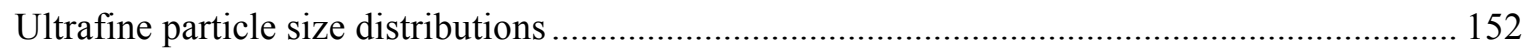

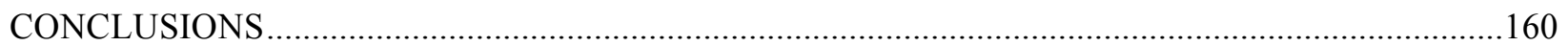

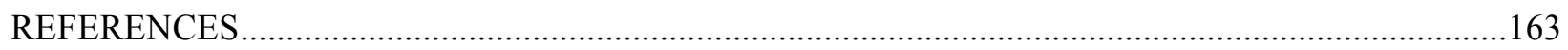




\section{LIST OF FIGURES}

Figure 1. Triple concentric coaxial burner used for directed oxygen studies........................................ 18

Figure 2. Set of burners 0 (bottom row left) through 6 (top row right)................................................. 20

Figure 3. New quartz window and high speed camera for PIV application. .......................................... 21

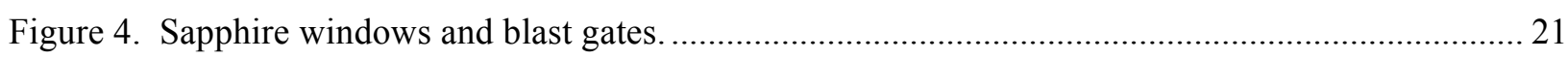

Figure 5. Diagram of the laboratory diffusion flame set-up. …............................................................. 22

Figure 6. Diagram of the coal burner for PIV measurements. The central tube is the coal jet while ......... 23

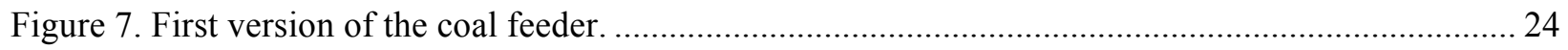

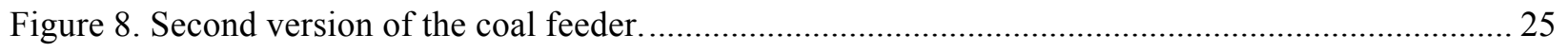

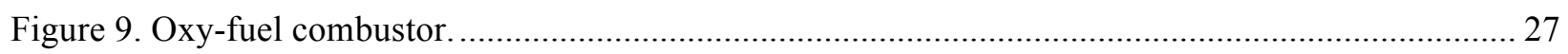

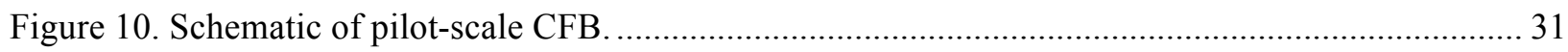

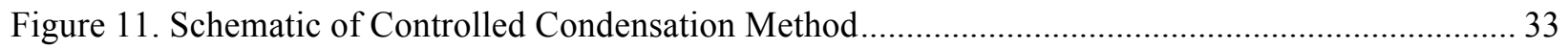

Figure 12. Schematic setup of bench-scale fluidized bed combustor........................................................ 35

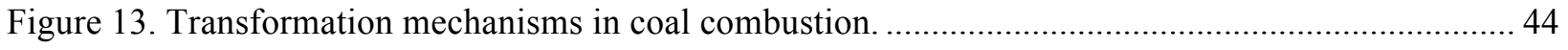

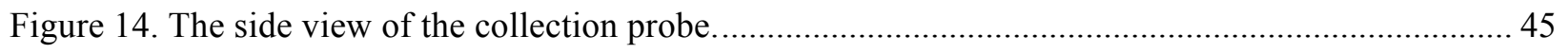

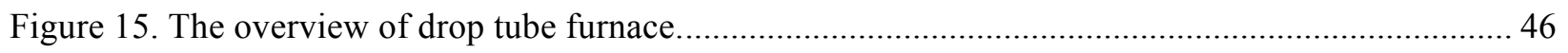

Figure 16. Clam shell furnace open to show insulation and heating elements. ...................................... 47

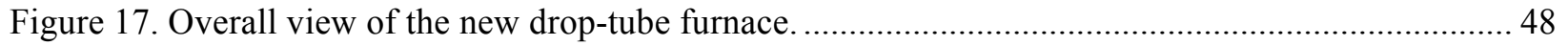

Figure 18. OFC prior to modifications for flue gas recycle ............................................................... 53

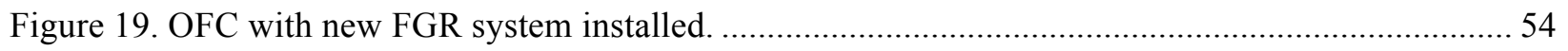

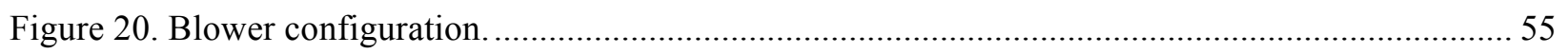

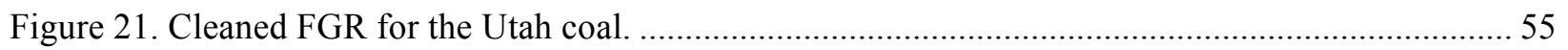

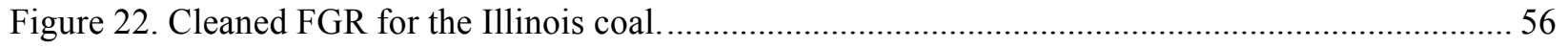

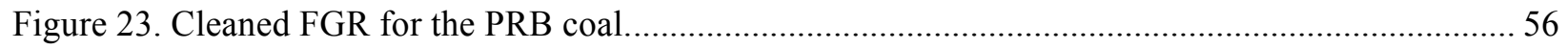

Figure 24. Water cooled, water quenched isokinetic sampling probe with additional dilution for SMPS

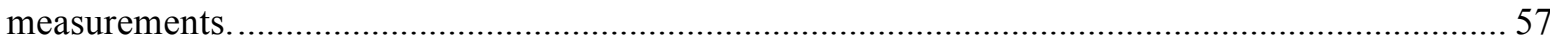

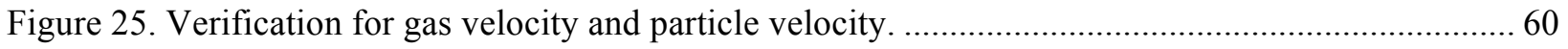

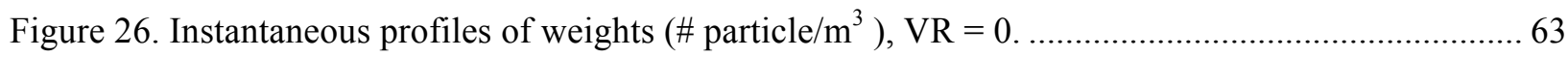

Figure 27. Instantaneous profiles of total particle concentration $\mathrm{W}_{\text {sum }}\left(\#\right.$ particle $\left./ \mathrm{m}^{3}\right)$.......................... 64

Figure 28. Comparison between simulations and experimental data of time-averaged gas and particles velocities along the centerline for $25 \mathrm{um}$ particles [(a) (c) (e)] and $70 \mathrm{um}$ particles [(b) (d) (f)]...... 66

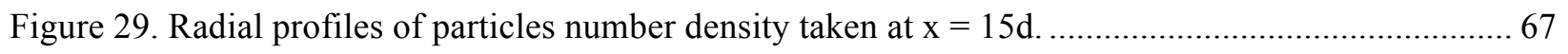

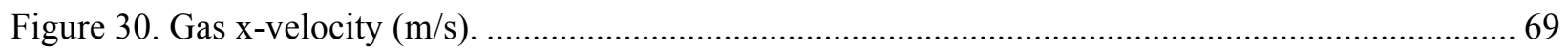

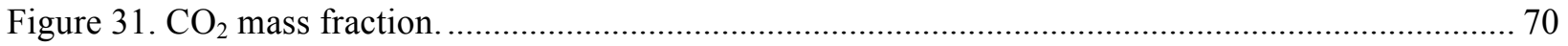




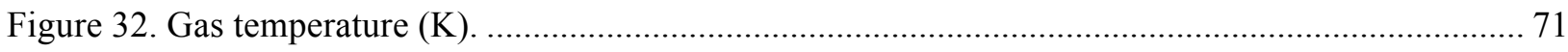

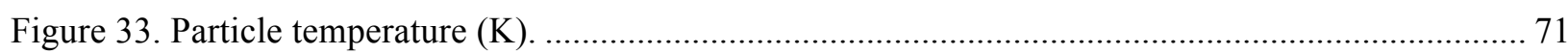

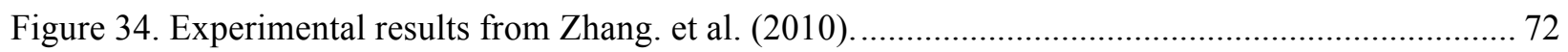

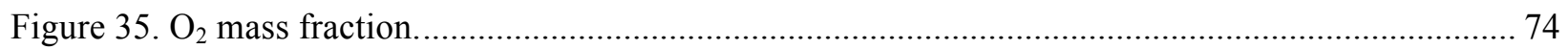

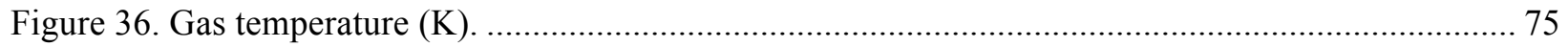

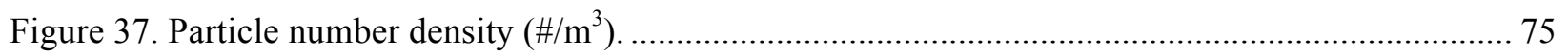

Figure 38. Comparison of flame stand-off distance statistics between simulations and experiments for

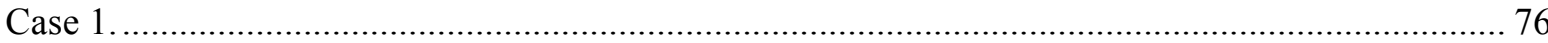

Figure 39. Flames with $\mathrm{N}_{2}$ as the coal transport fluid. Replacement of transport fluid $\mathrm{CO}_{2}$ by $\mathrm{N}_{2}$ greatly increases flame stability. $\mathrm{MM}=$ matched momentum. $\mathrm{MV}=$ matched velocity. Previous data with

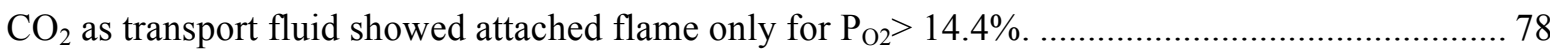

Figure 40. Flame stand-off PDFs for tests with $\mathrm{N}_{2}$ as transport fluid................................................... 79

Figure 41. Simple model to correlate data on effect of transporting fluid. Model assumes that time to ignition is controlled by molecular diffusion of $\mathrm{O}_{2}$ from secondary fluid through stagnant film of

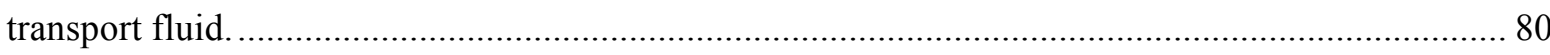

Figure 42. Correlation of data on effect of transport medium, using simple molecular diffusion film

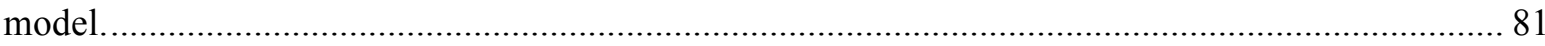

Figure 43. PDFs of stand-off distance for directed oxygen tests (Burners 0-9) ................................... 84

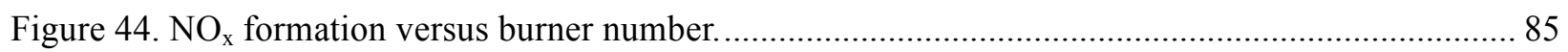

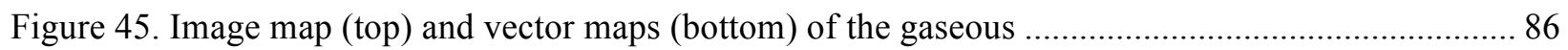

Figure 46. PIV vector maps of the gaseous flame using two different IAs. Camera frame rate was 3000 fps

Figure 47. Vertical velocity, as measured by PIV, at five different heights above the burner. 88

Figure 48. Example of an image map of the laboratory pulverized coal flame and the corresponding velocity field from two consecutive image maps using PIV (coal flow rate $150 \mathrm{mg} / \mathrm{min}, \phi=0.92$ ).. 89

Figure 49. Particle size distribution in a pulverized coal flame, $\phi=0.92$. 89

Figure 50. Image maps (left), and the corresponding velocity fields (right) of a pulverized coal flame.

Viewing the flame from burner head to a height $3.5 \mathrm{~cm}$ (bottom,), $3.5-7 \mathrm{~cm}$ (middle), and 7-10.5 cm

(top). $\phi=0.92$ and coal particle sizes $<38 \mu \mathrm{m}$. 91

Figure 51. Fluctuation in axial velocity at 3 different heights (left plot) and corresponding power .......... 92

Figure 52. Image maps of pulverized coal flames at different $\phi$. Coal particle size $<38 \mu \mathrm{m}$................. 92

Figure 53. Mean axial velocities taken at a height of $3 \mathrm{~cm}$ vs. mean particle size of pulverized coal....... 93

Figure 54. Two examples of PIV taken at two locations in the $100 \mathrm{KW}$ OFC, (a) near ......................... 95

Figure 55. Instantaneous image maps at three runs in the near-burner region ....................................... 95

Figure 56. Mean-time velocity fields using image maps in Figure 16. Averaged over 75 images. ........... 96

Figure 57. Instantaneous axial velocity at a point on the axis $7.6 \mathrm{~cm}$ from the burner tip ...................... 96 University of Utah Oxy-Coal Combustion Studies 7 
Figure 58. Instantaneous axial velocity at a point on the axis $30.1 \mathrm{~cm}$ from the burner tip 97

Figure 59. Standard deviation of instantaneous axial velocities for ...................................................... 98

Figure 60. Time-mean axial velocity along the combustor axis ..... 99

Figure 61. Time-mean axial velocity along the combustor axis at different $\mathrm{P} \mathrm{O}_{2} \%$ for the far-burner region. 100

Figure 62. An example output of the 'visualize.m' function. 101

Figure 63. PDFs constructed from $X$ velocity magnitude data from the bottom_A_1 experiment.......... 103

Figure 64. PDFs constructed from Y velocity magnitude data from the bottom_A_1 experiment.......... 103

Figure 65. Temperature profile of CFB using Utah bituminous coal for air-firing and oxy-firing. ......... 107

Figure 66. The effect of $\mathrm{O}_{2}$ concentration on the profile of bed temperature for oxy firing. .................. 107

Figure 67. Emission profiles measured under air-fired conditions in the $330 \mathrm{~kW} \mathrm{CFB}$ combustor........ 108

Figure 68. Emission profiles measured under oxy-fired conditions in the $330 \mathrm{~kW}$ CFB combustor....... 109

Figure 69. The effect of bed temperature on the $\mathrm{SO}_{2}$ emissions for oxy-firing and air-firing................ 110

Figure 70. $\mathrm{SO}_{2}$ emissions based on concentration ( $\mathrm{ppm}$ ) with different $\mathrm{Ca}: \mathrm{S}$ ratio for air-firing and oxyfiring (50 lbs/hr Utah coal, $3 \%$ excess $\mathrm{O}_{2}$ in exit flue gas, $80 \%$ primary $/ 20 \%$ secondary).

Figure 71. $\mathrm{SO}_{3}$ emissions based on concentration (ppm) with different $\mathrm{Ca}$ :S ratio for air-firing and oxyfiring (50 lbs/hr Utah coal, $3 \%$ excess $\mathrm{O}_{2}$ in exit flue gas, $80 \%$ primary $/ 20 \%$ secondary). .....

Figure 72. $\mathrm{SO}_{2}$ emissions based on mass (lbs/MMBtu) with different $\mathrm{Ca}: \mathrm{S}$ ratio for air-firing and oxyfiring (50 lbs/hr Utah coal, 3\% excess $\mathrm{O}_{2}$ in exit flue gas, $80 \%$ primary $/ 20 \%$ secondary). ........... 112

Figure 73. $\mathrm{SO}_{3}$ emissions based on mass (lbs/MMBtu) with different $\mathrm{Ca}: \mathrm{S}$ ratio for air-firing and oxyfiring (50 lbs/hr Utah coal, 3\% excess $\mathrm{O}_{2}$ in exit flue gas, $80 \%$ primary $/ 20 \%$ secondary). ............ 112

Figure 74. $\mathrm{SO}_{2}$ spectra by FTIR with a $\mathrm{SO}_{2}$ concentration of $1000 \mathrm{ppm}$.......................................... 116

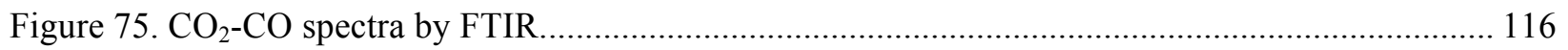

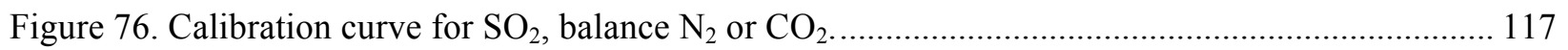

Figure 77. $\mathrm{SO}_{2}$ emissions in oxy-fuel combustion and air combustion from a single particle fluidized bed.

Figure 78. The evolution of $\mathrm{SO}_{2}$ with an increasing temperature in bench-scale fluidized bed.............. 122

Figure 79. Three sulfur releasing regions in single coal particle ..................................................... 123

Figure 80. Schema of diffusion control domination in single coal particle combustion. ........................ 123

Figure 81.The evolution of $\mathrm{SO}_{2}$ emission with an increasing temperature using equilibrium calculation

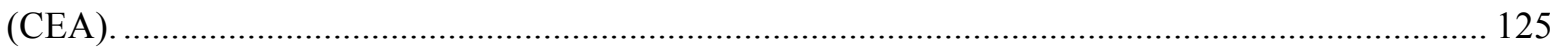

Figure 82. $\mathrm{SO}_{2}$ capture with limestone in oxy-fuel combustion and air combustion in the bench-scale

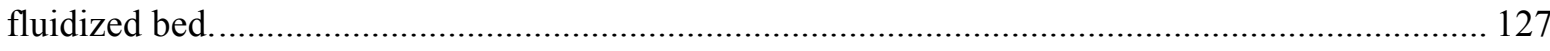

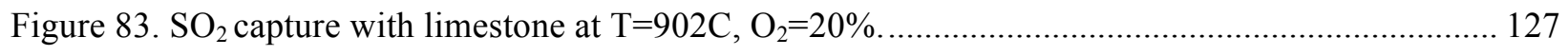

Figure 84. Effect of temperature on the sulfation degree of limestone under $\mathrm{N}_{2} / \mathrm{O}_{2} / \mathrm{SO}_{2}$ condition. ....... 130

Figure 85. Effect of temperature on the sulfation degree of limestone under $\mathrm{CO}_{2} / \mathrm{O}_{2} / \mathrm{SO}_{2}$ conditions. ... 130 
Figure 86. Comparison of sulfation degree of limestone between $\mathrm{N}_{2} / \mathrm{O}_{2} / \mathrm{SO}_{2}$ and $\mathrm{CO}_{2} / \mathrm{O}_{2} / \mathrm{SO}_{2}$ at $\mathrm{T}=765 \mathrm{C}$.

Figure 87. Comparison of the sulfation degree of limestone between $\mathrm{N}_{2} / \mathrm{O}_{2} / \mathrm{SO}_{2}$ and $\mathrm{CO}_{2} / \mathrm{O}_{2} / \mathrm{SO}_{2}$ at

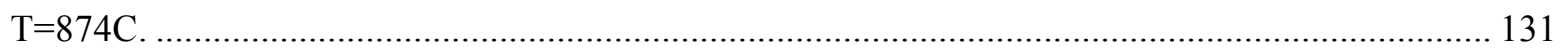

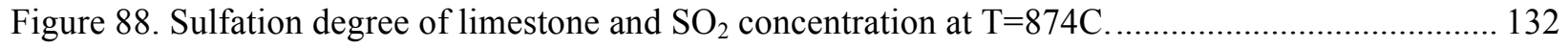

Figure 89. The effect of particle sized on evolution of temperature (top-50 microns; bottom-1500

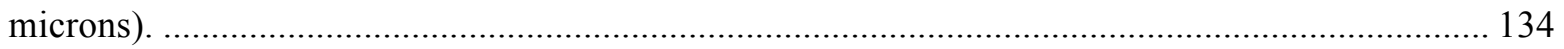

Figure 90. The effect of particle sized on evolution of $\mathrm{O}_{2}$ (top-50 microns; bottom-1500 microns). ...... 135

Figure 91. The effect of particle sized on evolution of CO (top-50 microns; bottom-1500 microns)..... 136

Figure 92. The effect of particle sized on evolution of $\mathrm{CO}_{2}$ (top-50 microns; bottom-1500 microns)..... 137

Figure 93. The evolution of fixed carbon in single coal particle combustion model. ............................ 138

Figure 94. Utah Skyline coal char combustion temperature simulation profiles.................................... 139

Figure 95. The BLPI and SMPS/APS PSDs of Utah Skyline under $21 \% \mathrm{O}_{2} / \mathrm{CO}_{2}$ at $1500 \mathrm{~K} \ldots \ldots \ldots \ldots \ldots . . . . .141$

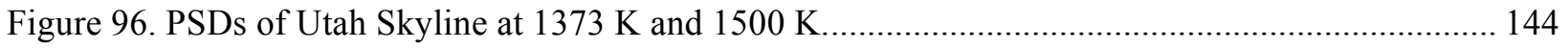

Figure 97. Elemental mass fraction size distribution of Utah Skyline at $1500 \mathrm{~K}$. Temperatures are

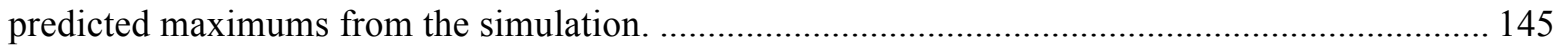

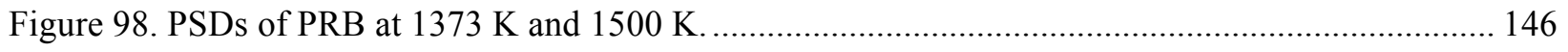

Figure 99. Elemental mass fraction size distribution of PRB at $1500 \mathrm{~K}$. Temperatures are predicted

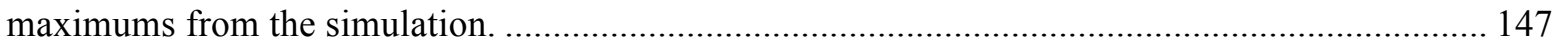

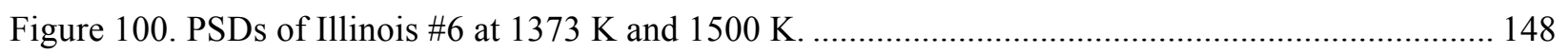

Figure 101. Elemental mass fraction size distribution of Illinois \#6 at $1500 \mathrm{~K}$. Temperatures are predicted

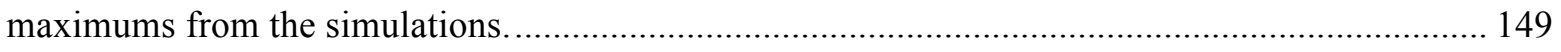

Figure 102. Morphology of Utah Skyline, PRB and Illinois \#6 combusted under $31.5 \% \mathrm{O}_{2} / \mathrm{CO}_{2}$ and $31.5 \%$

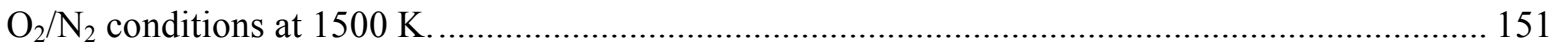

Figure 103. Ultrafine PSDs for once-through $\mathrm{CO}_{2}$ and cleaned and dirty FGR as diluent for oxidant.... 153

Figure 104. Same data as in Figure 103, showing effects of coal composition..................................... 154

Figure 105. Size distributions of the oxides in the Utah coal ash..................................................... 156

Figure 106. Size distributions of the oxides in the Illinois coal ash. .................................................... 158

Figure 107. Size distributions of the oxides in the PRB coal ash....................................................... 160 


\section{LIST OF TABLES}

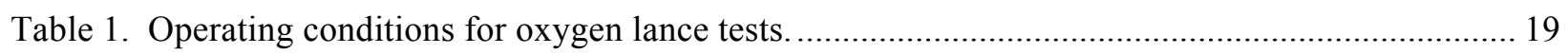

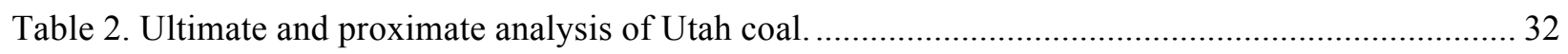

Table 3. Experimental matrix for $\mathrm{SO}_{2}$ formation in air- vs. oxy-combustion......................................... 36

Table 4. Experimental matrix for single coal particles with limestone. .................................................. 36

Table 5. Experimental matrix for known $\mathrm{SO}_{2}$ concentration in $\mathrm{N}_{2} / \mathrm{CO}_{2}$ with limestone. ......................... 37

Table 6. Coal analysis data for Utah Skyline, PRB and Illinois \#6 coals.............................................. 49

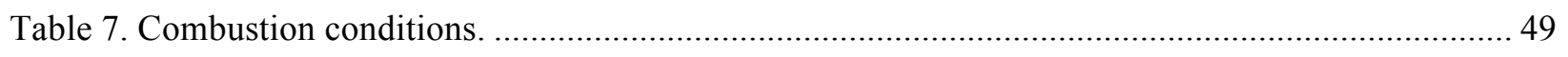

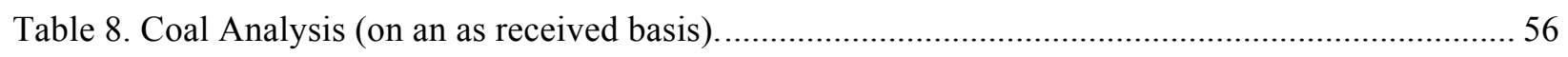

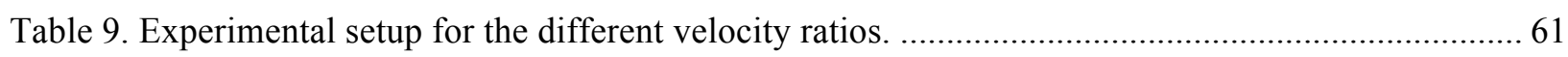

Table 10. Quadrature approximation for 25-micron particles (inlet values). ........................................ 61

Table 11. Quadrature approximation for 70-micron particles (inlet values). ......................................... 62

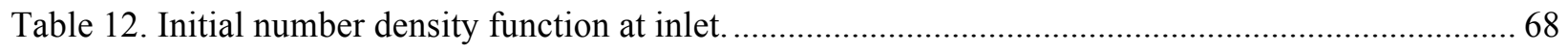

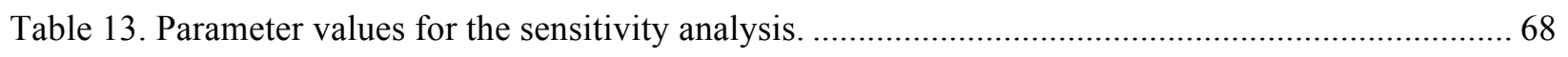

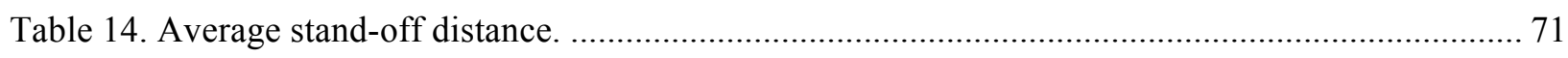

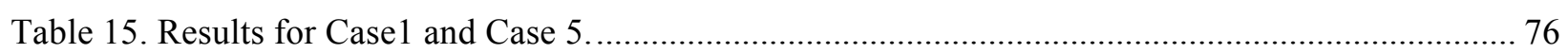

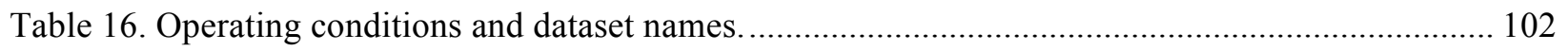

Table 17. The mean and standard deviation values of $\mathrm{X}$ and $\mathrm{Y}$ components of velocity for all experiments.

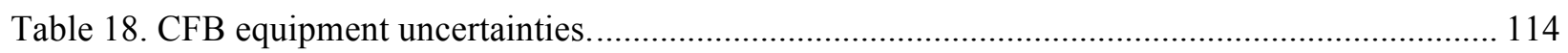

Table 19. Physical and chemical property of fix carbon and organic and inorganic sulfur.................... 124

Table 20. Coal char combustion peak temperature $(\mathrm{K})$ for particle diameter of $65 \mu \mathrm{m} . \ldots \ldots \ldots \ldots \ldots \ldots \ldots \ldots . . . . . . . . . . .140$

Table 21. Total collected mass distribution. ......................................................................................... 142 


\section{LIST OF ABBREVIATIONS}

\begin{tabular}{|c|c|}
\hline APS & Aerodynamic particle sizer \\
\hline BLPI & Berner Low Pressure Impactor \\
\hline $\mathrm{CCM}$ & Controlled Condensation Method \\
\hline CFB & Circulating Fluidized Bed \\
\hline$D_{\text {eff }}$ & Effective Diffusivity \\
\hline DQMOM & Direct Quadrature Method of Moments \\
\hline E & Activation Energy \\
\hline EDS & Electron Dispersive Spectroscopy \\
\hline FGD & Flue Gas Desulfurization \\
\hline FGR & Flue Gas Recycle \\
\hline Fps & Frames per second \\
\hline FTIR & Fourier Transform Infrared \\
\hline IA & Interrogation Area \\
\hline HHV & Higher Heating Value \\
\hline HTDT & High Temperature Drop Tube \\
\hline LES & Large Eddy Simulations \\
\hline LOD & Moisture Content \\
\hline NDIR & Nondispersive Infrared \\
\hline OFC & Oxy-fuel Combustor \\
\hline PA & Photoacoustic Analyzer \\
\hline PRB & Powder River Basin \\
\hline PIV & Particle Image Velocimetry \\
\hline PDF & Probability Density Function \\
\hline $\mathrm{P} \mathrm{O}_{2}$ & Primary Oxygen Concentration \\
\hline PSD & Particle Size Distribution \\
\hline SEM & Scanning Electron Microscopy \\
\hline SLPM & Standard Liters Per Minute \\
\hline SMPS & Scanning Mobility Particle Sizer \\
\hline $\mathrm{T}_{\mathrm{d}}$ & Time delay \\
\hline VR & Velocity Ratio \\
\hline $\mathrm{W}_{\text {sum }}$ & Time-Averaged Total Concentration of Particles \\
\hline$X_{c}$ & Carbon conversion degree \\
\hline$\delta$ & Stephen Boltzmann constant \\
\hline$\Delta \mathrm{H}$ & Heat of reaction \\
\hline$\lambda$ & Thermmal conductivity \\
\hline$\phi$ & Equivalence ratio \\
\hline$\rho$ & Density \\
\hline
\end{tabular}




\section{EXECUTIVE SUMMARY}

Oxy-coal combustion is a promising near-term, low-cost strategy for carbon capture, with current estimates of \$55/tonne $\mathrm{CO}_{2}$ avoided. DOE's FutureGen 2.0 project will employ advanced oxycombustion technology. This project supports DOE's efforts to apply advanced oxy-combustion technology by reducing the uncertainty associated with its scale up and deployment, especially to existing air-fired configurations. Our experimental and simulation work has focused on ignition, coal flame stability, ash partitioning and ash deposition under pulverized oxy-coal conditions, with a smaller companion effort on application of circulating fluidized beds to oxy-coal combustion conditions. Additional highlights for each of the subtasks follow:

Oxy-coal combustion large eddy simulations. The University of Utah expanded its high-performance LES simulation tools coupled with DQMOM to quantitatively predict oxy-coal conditions. This work employed experimental data from the University of Utah's $100 \mathrm{~kW}$ OFC and has focused on predicting flame stability at the $100 \mathrm{~kW}$ scale. This work showed that the LES with DQMOM approach can lead to accurate simulations of particle-laden flows. A validation study was performed on a coaxial jet and showed that for several operating conditions, simulations were able to predict both gas and particle velocities. Simulations also proved able to replicate particle clustering and particle segregation.

LES simulations were able to model several complex ignition phenomena, whereas an approach employing RANS, a more common, widely used CFD approach was not. The LES similations indicated that the predicted flame stand-off distance was sensitive to wall temperature but not to the partial pressure of oxygen in the primary. The observed trend of stand-off distance decreasing with increasing primary $\mathrm{P}_{\mathrm{O} 2}$ was not predicted by the simulations, but might possibly be explained by uncertainties in the experimental operating condition. Simulations also dismissed the possibility of heterogeneous ignition in those conditions.

Near-field aerodynamics of oxy-coal flames. As described in the previous topical report on oxy-coal combustion, the University of Utah built a $100 \mathrm{~kW}$ OFC for studying the effect of various operating parameters on flame stability under oxy-combustion conditions (Zhang and Wendt 2009). During this project, modifications to the $\mathrm{OFC}$ were completed to enable increased heat removal as required for the reduced $\mathrm{CO}_{2}$ recycle during oxy-coal operation and to prepare for optical diagnostics including PIV and high-speed infrared imagery. This required replacement of existing vertical quartz windows, and also installation of sapphire windows with blast gates.

An initial strategy that exploits directed oxygen stratification to allow operation at lower $\mathrm{CO}_{2}$ recycle rates was developed. This strategy involved three concentric coaxial streams, with pulverized coal transported by $\mathrm{CO}_{2}$ in the center tube, pure $\mathrm{O}_{2}$ transported in the adjacent annulus (the "lance"), and a mix of $\mathrm{O}_{2}$ and $\mathrm{CO}_{2}$ in the secondary oxidant in the annulus adjacent to the "lance". This configuration prevented any upstream contact between oxygen and fuel, which is a potential safety issue. Of interest was to determine how the fraction of total input oxygen transported in the lance affected flame stability,

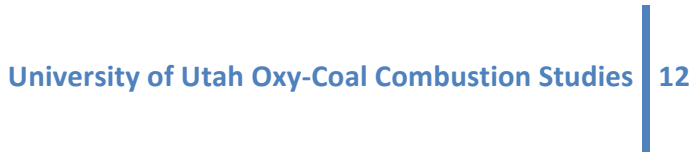


as quantified by flame stand-off distances, keeping all exit velocities and the ensuing flame aerodynamics unchanged.

Data from special tests of the dual concentric burner, in which flame attachment with $\mathrm{N}_{2}$ as the transport fluid was compared to that with $\mathrm{CO}_{2}$ as the transport medium, could be correlated through a simple model in which molecular diffusion of oxygen from the secondary jet to the particle surface controlled the time to particle ignition.

Advanced diagnostics for oxy-coal combustion. The advanced diagnostics team developed the capability for applying PIV to laboratory coal burners and began to apply this to the $100 \mathrm{~kW}$ OFC for the measurement of planar velocity fields in turbulent oxy-coal flames. Image analysis techniques were used in conjunction with the PIV system to provide detailed image maps and velocity information of particles in the flame, as well as for providing information about overall particle-size distribution. The results of the lab-scale experiments show the effect of coal particle size, global equivalence ratio and height location in the flame on the dynamics and velocity fields in the pulverized coal flames. Results in the large-scale OFC highlight the differences in the velocity fields of coal particles at different concentrations of the oxidizer and at various locations in the reaction zone.

Oxy-coal combustion in circulating fluidized beds. This work is aimed at developing an understanding of the process dynamics, and the impact of key process variables on bed temperature, bed agglomeration, solids recycle rate, and sulfur capture. The recently modified oxy-fired pilot-scale CFB is being used to study the impact of oxy-coal-fired vs. air-fired environments on $\mathrm{SO}_{\mathrm{x}}\left(\mathrm{SO}_{2}, \mathrm{SO}_{3}\right)$ emissions. Profiles of species concentration and temperature were obtained for both conditions, and profiles of temperature over a wide range of $\mathrm{O}_{2}$ concentration was studied for oxy-firing conditions. The effect of limestone addition on $\mathrm{SO}_{2}$ and $\mathrm{SO}_{3}$ emissions were also examined for both air- and oxy- firing conditions. The results suggest that native capture of $\mathrm{SO}_{2}$ by coal ash is possible under both air- and oxy-fired conditions. The performance was primarily a function of bed temperature, with sulfur capture decreasing with increasing bed temperature. In addition, $\mathrm{SO}_{2}$ and $\mathrm{SO}_{3}$ emissions on a concentration basis (ppm) for oxy-firing are much higher than that for air firing, while $\mathrm{SO}_{2}$ and $\mathrm{SO}_{3}$ emissions based on mass (lbs/MMBtu) in are not significantly different between air- and oxy-firing.

Single-particle oxy-CO $\mathrm{CO}_{2}$ combustion. This work focused on the impact of an $\mathrm{O}_{2} / \mathrm{CO}_{2}$ environment on carbon, nitrogen and sulfur release from coal and coal char in a bench-scale single-particle fluidized-bed reactor. Measurements focused on both rate determination with detailed uncertainty quantification for use in model development, as well as the identification of the influence on major operating variables such as oxygen concentration and bed temperature on the release of nitrogen and sulfur impurities.

Ash Partitioning Mechanisms for Oxy-Coal Combustion. Research at the University of Utah is focused on understanding ash partitioning under oxy-coal combustion conditions by considering experiments on two scales: (1) at the bench-scale using a drop-tube reactor with coal flow rates of $\sim 1-4 \mathrm{~g} / \mathrm{h}$, to determine fundamental ash partitioning mechanisms using simulated flue gases; (2) at 100kW self sustained combustor scale (coal flow rates of $\sim 10 \mathrm{~kg} / \mathrm{h}$ ) where the focus is on how the amount of recycled flue gas

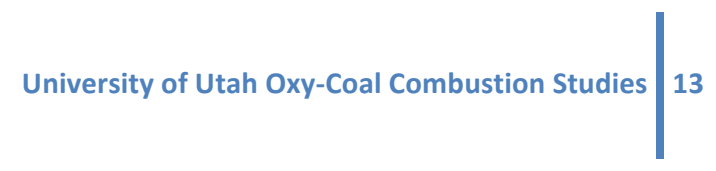


affects ash partitioning mechanisms. In both experiments ash aerosol PSDs and size segregated ash compositions are obtained using aerosol mobility and impaction techniques.

In the drop-tube studies study, ash formation was studied as a function of temperature, coal type and gasphase conditions, namely $\mathrm{CO}_{2}$ versus $\mathrm{N}_{2}$. A tri-modal particle-size distribution (PSD), including an ultrafine mode, a fine mode and a coarse mode was identified. Furthermore, the results showed that in the presence of $\mathrm{CO}_{2}$ less ultrafine particles were formed, as compared to a $\mathrm{N}_{2}$ environment. These results support the hypothesis that refractory oxide formation is governed by the equation: $\mathrm{MO}(\mathrm{s})+\mathrm{CO}(\mathrm{g}) \leftrightarrow$ $\mathrm{CO}_{2}(\mathrm{~g})+\mathrm{M}(\mathrm{g})$, where $\mathrm{MO}$ indicates a refractory oxide.

In the OFC studies, the following modifications were completed: installation of a new FGR system, a baghouse to remove particulates, and a scrubber to remove sulfur oxides and moisture. The FGR system is unique in that it allows either "dirty" flue gas, without particulate or sulfur removal, or "cleaned" flue gas, with removal of particulates and/or $\mathrm{SO}_{2}$ and water, to be employed. Reported here are results of studies focused on a single "baseline", flue gas recycle rate (inlet composition $32 \% \mathrm{O}_{2}, 68 \%$ flue gas), which matches adiabatic flame temperatures with air-fired combustion with the same exit $\mathrm{O}_{2}(\sim 3 \%$ dry). Experiments were completed for three coals, namely a Utah Skyline bituminous coal, a Powder River Basin (PRB) coal and a high-sulfur Illinois coal. Results indicate that it is erroneous to use once-through synthetic $\mathrm{CO}_{2}$ to simulate the recycled flue gas in practical situations. Recycled flue gas leads in general to higher levels of ultrafine particles in the combustor, and this can have important influences on fouling and radiant heat transfer.

\section{INTRODUCTION}

Oxycoal combustion is a promising near-term, low-cost strategy for carbon capture from pulverized coalfired power plants (Buhre et al. 2005, Nsakala et al. 2001). Oxygen mixed with recycled flue gas replaces air combustion resulting in a flue gas that consists primarily of $\mathrm{CO}_{2}$, which is readily $\mathrm{CO}_{2}$ captureable. DOE's FutureGen 2.0 project will employ advanced oxy-combustion technology, and the University of Utah's project will support DOE's efforts by facilitate scale up, reduce deployment time, and reduce risk, thus lowering deployment cost of oxy-coal combustion for $\mathrm{CO}_{2}$ capture. The efforts to facilitate scale up currently center on the development of a validated simulation tool to predict flame stability. Efforts to reduce risk focus on an improved understanding $\mathrm{SO}_{\mathrm{x}}$ and particulate emissions as well as safety and operability issues associated with oxy-coal combustion.

Consistent with DOE's Carbon Capture and Sequestration Initiative, the University of Utah's simulation work will facilitate scale up, reduce deployment time, and reduce risk, thus lowering deployment cost. Tightly coupling experimental data with the development of a validated simulation tool will accelerate deployment of this carbon-capture technology. For example, in the short term, oxy-coal combustion will be applied, and hopefully retrofitted, to steam generation systems that look very much like current airfired boilers. These require recycling about four times the exhaust gas stream in order to maintain similar heat fluxes and/or adiabatic flame temperatures in the boiler firebox. Recycling this large amount of mass is expensive and inefficient. This near-flame aerodynamic and the simulation subtasks (3.1 and 3.2) are

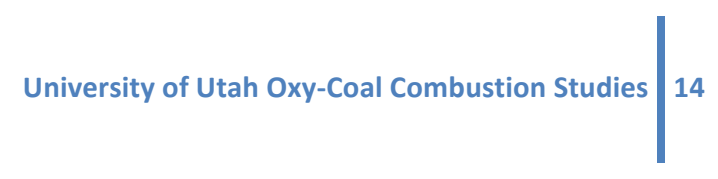


directed towards understanding flame stability and the intermediate-term application of oxy-coal combustion, where i) pure oxygen is injected in directed streams, ii) the amount of recycled flue gas is minimized, and iii) local regions of very high temperature are permitted, although the system is still derived from, and can, potentially, still be retrofitted to, conventional air fired steam boilers. Insight obtained the experimental and simulation work will provide the scientific background that would enable technology employing directed pure oxygen flows and minimum $\mathrm{CO}_{2}$ recycle to be used for secondgeneration applications to (both new and retrofit) oxy-coal combustion systems.

Subtasks 3.3 - 3.6 address some of the environmental, safety, and operability concerns associated with oxy-coal combustion. For example, $\mathrm{SO}_{2}$ emissions from coal combustion have several harmful effects on the environment, including their contribution to acid rain. A variety of approaches, including wet and dry scrubbing and direct sorbent injection, have been developed to control sulfur pollution, and direct dry sorbent injection is a relatively simple and low-cost process. Another important environmental issue associated with coal combustion is the emission of ash particulates containing iron and other refractory metals, which have various harmful effects on human health (Bachmann et al. 1996, Dockery et al. 1993). However, the effects of oxy-fuel combustion on mechanisms of $\mathrm{SO}_{2}$ and particulate matter (PMP emissions are not well understood.

\section{METHODS}

\section{Subtask 3.1 - Oxy-Coal Combustion Large Eddy Simulations}

The purpose of this research is to perform reliable LES of oxy-coal flames. To achieve it, several milestones have been defined. Initially, Arches, the LES tool developed at the University of Utah, only included gaseous-phase simulations, so implementation of particle modeling capabilities was required. The DQMOM has been chosen to represent particles in an Eulerian-Eulerian framework. This method allows the transport of multi-dimensions probability density functions (PDFs) in a computationally cheap manner. The first step was thus to implement DQMOM in Arches in a stable and efficient way. Predicting particle behavior in coal flames is a key point for this research. To ensure that DQMOM is able to model particles correctly, a validation study was conducted. Since few data on particles in coal flames are available, experimental data of non-reacting turbulent flows with particles were used. The next milestone was to implement all the physical models related to coal particles combustion within the DQMOM approach and couple them with the gaseous phase. A non-exhaustive list of those models includes mass, momentum and heat transfer between the gas and solid phases, devolatilization and char oxidation. Once this step was completed, it was possible to simulate oxy-coal flames. One issue of interest is to understand and predict the effects of near-burner zone environment, now consisting of $\mathrm{O}_{2}$ and $\mathrm{CO}_{2}$ instead of $\mathrm{N}_{2}$, on flame stability and ignition. Flame stability, which can be measured by the stand-off distance, is an important issue in designing burners because it affects the lifespan of the burner as well as pollutant formation and heat fluxes in the furnace. Previous work has shown that stability of coal flames was sensitive to many factors such as wall temperature, coal type, inlet streams composition, temperature and velocities. The final objective is thus to perform simulations of oxy-coal flames in the near-burner region

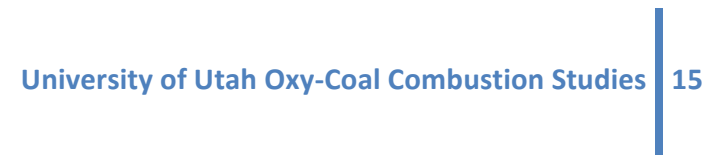


in order to assess the capability of LES with DQMOM to predict flame stability and to conduct a validation and uncertainty quantification analysis against experimental data.

The approach can be summarized as:

1. Implementation of DQMOM in Arches.

2. Optimization of DQMOM accuracy, stability and efficiency.

3. Implementation of models for non-reacting particle-laden flows.

4. Implementation of coal combustion models.

5. Models verification.

6. Benchmark validation for non-reacting, particle laden, coaxial jets.

7. Validation of oxy-coal flames / Prediction and sensitivity analysis on flame stand-off distance.

This report will mostly focus on the simulations and the results. A description of the DQMOM equations and the physical models can be found in Pedel (2010).

\section{Simulations}

As a general rule, simulations results should be compared to experimental data to assess the validity and accuracy of the models. This process, called validation and uncertainty quantification, can be achieved be selecting relevant experimental data and comparing them with the predictions made by the simulations. This research has two main objectives.

The first one is to show that DQMOM can be used in combination with LES to model complex particleladen flows. It was proposed to use Budilarto's data (2003) to validate this approach. Budilarto investigated the effect of fluid aerodynamics on particle motion in the near-field region of coaxial particle-laden jets. The fluid aerodynamics were modified by varying the inlet velocity ratio of the annular to central jet velocity at $0,1.0$, and 1.5 . The dispersion of particles was enhanced with decreasing particle size and with increasing the velocity ratio greater than 1.0. The particle-phase radial velocity fluctuation was determined as an important parameter to characterize the particle turbulence interaction and the spatial distribution of particles in coaxial laden jets. The investigation of PSD effects showed that the radial spreading of the coarse particles was reduced by the presence of the fine particles. Performing simulations of Budilarto's cases can determine the ability of this approach to model the following phenomena: particle dispersion, particle clustering and gas-solid interactions.

The second objective aims to show that LES with DQMOM can be used to perform reliable simulations of oxy-coal flames in the near-burner region. More specifically, LES should be able to predict aerodynamics, kinetics and ignition characteristics of the flame. Experimental data on oxy-coal flames that would meet the criteria for LES simulations are very limited. Zhang et al. (2010) studied how composition of the coal transport medium (primary $\mathrm{CO}_{2}$ and $\mathrm{O}_{2}$ ) affects the observed ignition stand-off distance in co-axial turbulent diffusion, oxy-coal flames. Results show that flame stability is affected by primary $\mathrm{PO}_{2}$, wall temperature, secondary preheat temperature, secondary $\mathrm{PO}_{2}$, and transport medium. The burner and the furnace geometry were chosen to be simple enough for LES simulations. It was thus

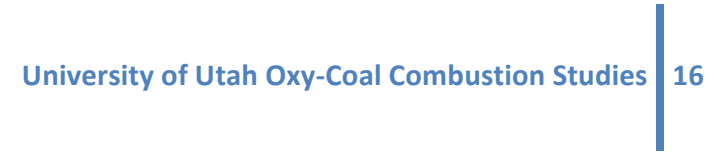


chosen to perform simulations of Zhang's cases and to compare predictions on the flame stand-off distance with the experimental data.

Since the flame stand-off distance is sensitive to many parameters, which can have large uncertainties associated with them, a set of two parameters - wall temperature and primary $\mathrm{PO}_{2}$ - was identified to establish a response surface and perform a first sensitivity study.

Wall temperature has been chosen because experiments show a high sensitivity of the flame stand-off distance to the temperature of the walls, but also because the uncertainty of this parameter is important. The uncertainty on the temperature of the walls ranges from $1100 \mathrm{~K}$ to $1800 \mathrm{~K}$.

The $\mathrm{PO}_{2}$ in the primary was chosen because in some conditions, the flame stand-off is highly sensitive to it. Zhang et al. (2010) showed that by increasing the primary $\mathrm{PO}_{2}$ from $0 \%$ to $40 \%$, the averaged flame stand-off distance can decrease from $30 \mathrm{~cm}$ to $12 \mathrm{~cm}$. The phenomena behind this trend are not understood, and LES simulations could possibly help to understand why oxygen concentration affects the stand-off distance. One hypothesis is that the coal reactions are controlled by the diffusion of oxygen. Another explanation would be that heterogeneous ignition is occurring.

\section{Subtask 3.2 - Near-Field Aerodynamics of Oxy-Coal Flames with Directed Oxygen and Minimum Flue Gas Recycle}

The overall objectives of this task are to:

- Develop fundamental strategies for directed $\mathrm{O}_{2}$ injection with minimum $\mathrm{CO}_{2}$ recycle in oxy-coal flames. A system with directed $\mathrm{O}_{2}$ injection will still, most likely, be contained in a conventional firebox, with conventional heat transfer mechanisms to effect steam generation. The expectation is that insight obtained from experimental work, together with advances in simulation, will provide the scientific background that would enable technology employing directed pure oxygen flows and minimum $\mathrm{CO}_{2}$ recycle to be used for second- generation applications to (both new and retrofit) oxycoal combustion systems.

- Provide validation data for near-field aerodynamic simulations of well defined oxy-coal flames with non-uniform injection of $\mathrm{O}_{2}$ and minimum $\mathrm{CO}_{2}$ recycle. This included preparation of the OFC to allow non-intrusive laser diagnostic techniques to measure velocities, temperatures, and species concentrations.

Previous work under this program has focused on how $\mathrm{O}_{2}$ and $\mathrm{CO}_{2}$ can best be distributed between (conventional) primary and secondary streams for oxy-coal burners designed for retrofit use, where the $\mathrm{O}_{2}$ and $\mathrm{CO}_{2}$ are uniformly mixed (to make two different concentrations) in not more than two streams. The objective of that work was also to allow systematic validation of simulations of well defined axial oxycoal turbulent diffusion flames. This current work is different in that it is designed to expand our understanding of coal ignition/combustion processes to systems with sharp local non-uniformities of temperature and composition, caused by introduction of directed flows of pure oxygen into fuel flows

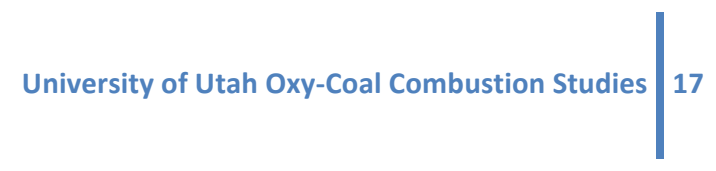


containing little or no oxygen. Velocities, compositions, and local non-uniformities in temperature and composition will be very different from the previous case, where care was exercised to maintain some similarity to traditional burner flows. Simulation of these non-uniform systems will be very useful in determining scale up criteria for new units and for retrofit, and the proposed research is therefore also directed towards obtaining validation data for such simulations.

\section{Furnace modifications and burner designs for directed oxygen tests}

For the oxy-coal directed oxygen tests described here, once-through $\mathrm{CO}_{2}$ drawn from a storage tank, rather than recycled flue gas, was used to replace the nitrogen in the air. This considerably simplified both the operation of the system and also the piping modifications required at the burner. The only significant impact on flame stability was expected to be due to the absence of water vapor in the diluent. Oxygen flows were metered into the pure oxygen "lance" (described below) and into the secondary oxidant mixture with $\mathrm{CO}_{2}$. An example of the triple concentric coaxial burner designed for the directed oxygen tests is shown on Figure 1.

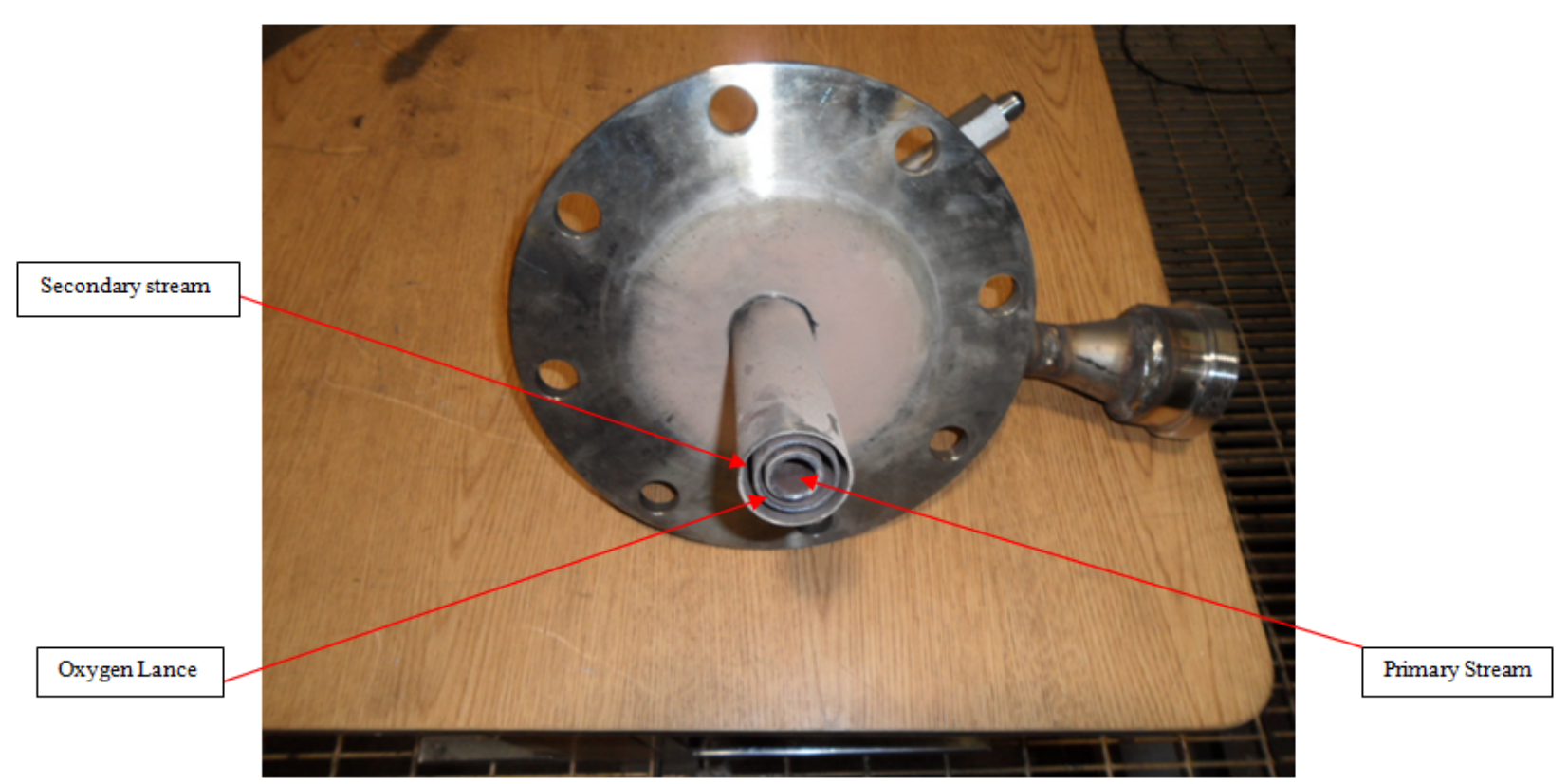

Figure 1. Triple concentric coaxial burner used for directed oxygen studies.

Pulverized coal transported by pure $\mathrm{CO}_{2}$ flows through the central pipe. The adjacent annulus comprises the "lance" that transports only pure $\mathrm{O}_{2}$, while the outer annulus contains the $\mathrm{O}_{2} / \mathrm{CO}_{2}$ mixture comprising the "secondary oxidant". Flame stability is examined as oxygen is systematically diverted from the outer annulus to the inner pure $\mathrm{O}_{2}$ "lance" annulus. We wished to vary the oxygen in the pure oxygen lance to comprise amounts from $0 \%$ to $100 \%$ of the total oxygen into the system, which was kept constant at $40 \%$ 
volume in the total input $\mathrm{O}_{2} / \mathrm{CO}_{2}$ mixture. A total of $40 \% \mathrm{O}_{2}$ in the input mixture reflects higher input $\mathrm{O}_{2}$ than the customary $32 \%$, which matches adiabatic flame temperature for air firing. Development of a directed oxygen injection strategy with $100 \%$ of the oxygen in the lance was of special practical interest.

In order to keep the velocities approximately the same and thus systematically limit effects on ignition and flame stability to those caused by increasing the pure oxygen in the lance, without causing aerodynamic changes, a different triple coaxial burner was required for each of the ten experimental conditions examined, as shown on Table 1 and Figure 2. Velocities are matched approximately, rather than exactly because of the need to use available pipe schedules.

In Case 9 all the oxygen is introduced through the annular lance. This is of practical significance, since it simplifies safety considerations because this configuration allows oxygen to be kept separate from all other flows and lines.

Table 1. Operating conditions for oxygen lance tests.

\begin{tabular}{ccccccccc}
\hline Case & $\begin{array}{c}\mathrm{O}_{2} \% \text { in } \\
\text { Lance }\end{array}$ & $\begin{array}{c}\text { Pri Vel } \\
(\mathrm{m} / \mathrm{s})\end{array}$ & $\begin{array}{c}\text { Lance Vel } \\
(\mathrm{m} / \mathrm{s})\end{array}$ & $\begin{array}{c}\mathrm{Sec} \mathrm{Vel} \\
(\mathrm{m} / \mathrm{s})\end{array}$ & $\begin{array}{c}\text { Pri } \mathrm{CO}_{2} \\
(\mathrm{lb})\end{array}$ & $\begin{array}{c}\text { Lance } \mathrm{O}_{2} \\
(\mathrm{lb})\end{array}$ & $\begin{array}{c}\mathrm{Sec} \mathrm{O}_{2} \\
(\mathrm{lb})\end{array}$ & $\begin{array}{c}\mathrm{Sec}^{\mathrm{CO}_{2}} \\
(\mathrm{lb})\end{array}$ \\
\hline 0 & $0.0 \%$ & 6.373 & 0.00 & 14.9 & 15.11 & 0 & 24.4 & 35.2 \\
1 & $8.5 \%$ & 6.373 & 6.12 & 14.98 & 15.11 & 2.08 & 22.38 & 35.2 \\
2 & $18.0 \%$ & 6.37 & 6.17 & 15.15 & 15.11 & 4.4 & 20.05 & 35.2 \\
3 & $23.5 \%$ & 6.373 & 6.11 & 15.87 & 15.11 & 5.75 & 18.71 & 35.2 \\
4 & $30.0 \%$ & 6.390 & 6.53 & 15.8 & 15.11 & 7.34 & 17.12 & 35.2 \\
5 & $41.0 \%$ & 6.410 & 6.57 & 16.6 & 15.11 & 10.03 & 14.43 & 35.2 \\
6 & $55.0 \%$ & 6.340 & 6.40 & 16.85 & 15.11 & 13.45 & 11 & 35.2 \\
7 & $75.0 \%$ & 6.380 & 6.39 & 14.6 & 15.11 & 18.3 & 6.1 & 35.2 \\
8 & $85.0 \%$ & 6.380 & 6.70 & 14.6 & 15.11 & 20.74 & 3.66 & 35.2 \\
9 & $100.0 \%$ & 6.380 & 6.30 & 14.82 & 15.11 & 24.4 & 0 & 35.1 \\
\hline
\end{tabular}




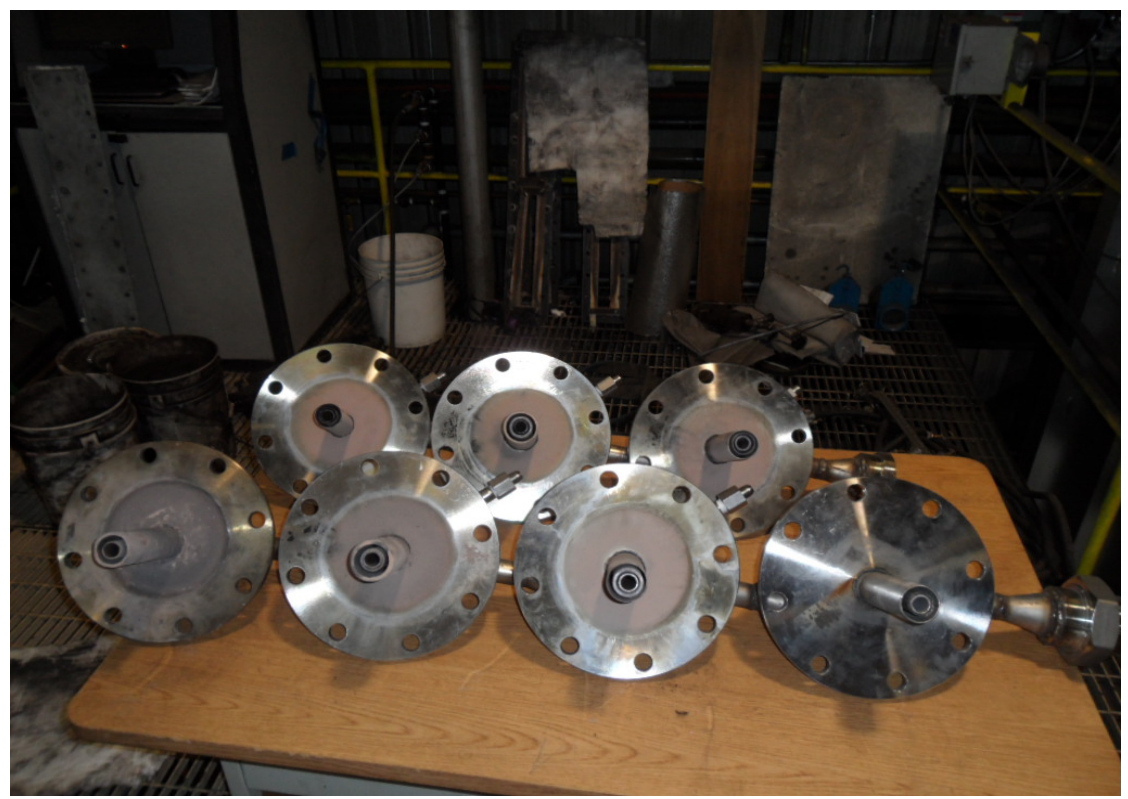

Figure 2. Set of burners 0 (bottom row left) through 6 (top row right).

\section{Furnace modifications for improved laser diagnostics}

Modifications to the furnace were made to employ laser PIV and high-speed infrared photo imagery to yield velocities, temperatures, and species $\left(\mathrm{CO}_{2}\right)$ concentrations within the oxy-fuel furnace (OFC), firing coal. Details regarding PIV can be found in the advanced diagnostics sections of this topical report. This section focuses solely on changes made to the OFC to accommodate these technologies. New vertical windows were installed on the three quadrants of the OFC. This enabled us to use PIV equipment (highspeed camera and laser) and existing CMOS camera for luminous zone position, simultaneously. Each vertical window consisted of two quartz panels as shown in Figure 3. 


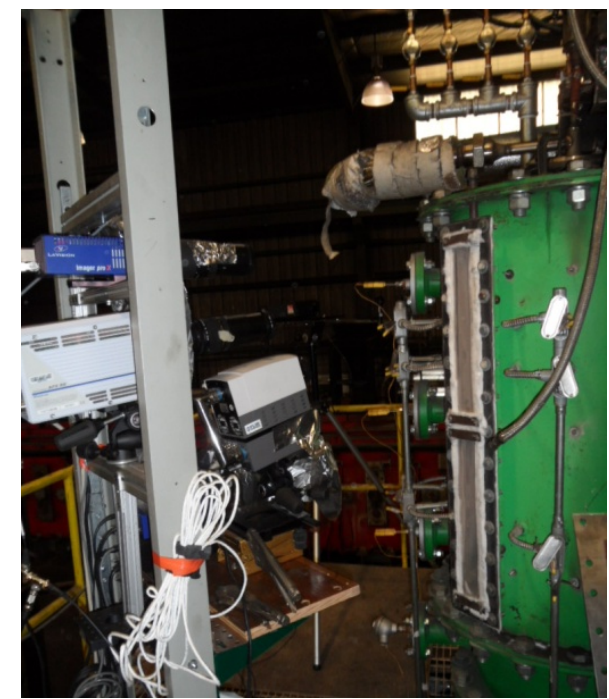

Figure 3. New quartz window and high speed camera for PIV application.

Two ports have been adapted for visual access through sapphire windows with blast gates, as shown on Figure 4. These were required for high-speed infrared photo-imaging that was performed by a team from the University of Naples, Italy.

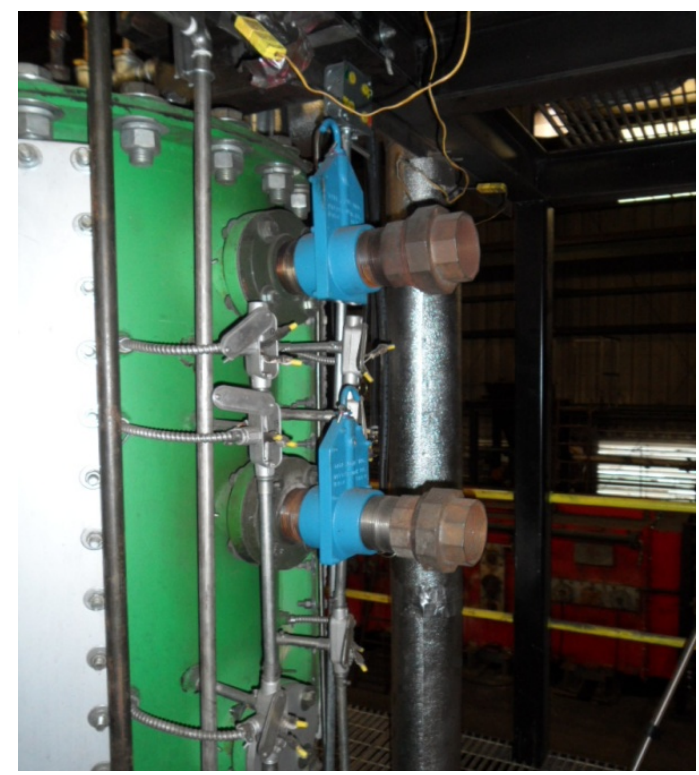

Figure 4. Sapphire windows and blast gates. 


\section{$\underline{\text { Subtask 3.3 - Advanced Diagnostics for Oxy-Coal Combustion }}$}

A non-intrusive laser diagnostic technique, PIV, has been used in the past to analyze the velocity field of flames under various combustion conditions. In this technique a laser sheet, formed using a combination of spherical and cylindrical lenses, illuminates seeding particles in the flow at two different times and images are recorded on a camera that is synchronized with the laser. Using PIV software, the images are divided into interrogation areas and cross-correlated to determine the displacement between the two images. Knowing the time between the two laser pulses, velocity components and all velocity-derived quantities are calculated. Although PIV has seen considerable application in laboratory flames, there has been limited application of this technique to large-scale pulverized-coal flames.

\section{Experimental set-up}

\section{Laboratory bench-scale diffusion flame}

Figure 5 shows the main components of the laboratory-scale set-up for the gaseous and pulverized coal flames, which include a coal burner, a coal feeder and the PIV system.

Coal burner. A burner that is capable of moving in three dimensions using metered movable stages was designed and built for implementation with the PIV system. The burner utilizes four concentric streams to control the ignition and flame shape, see Figure 6.

\section{Burner}
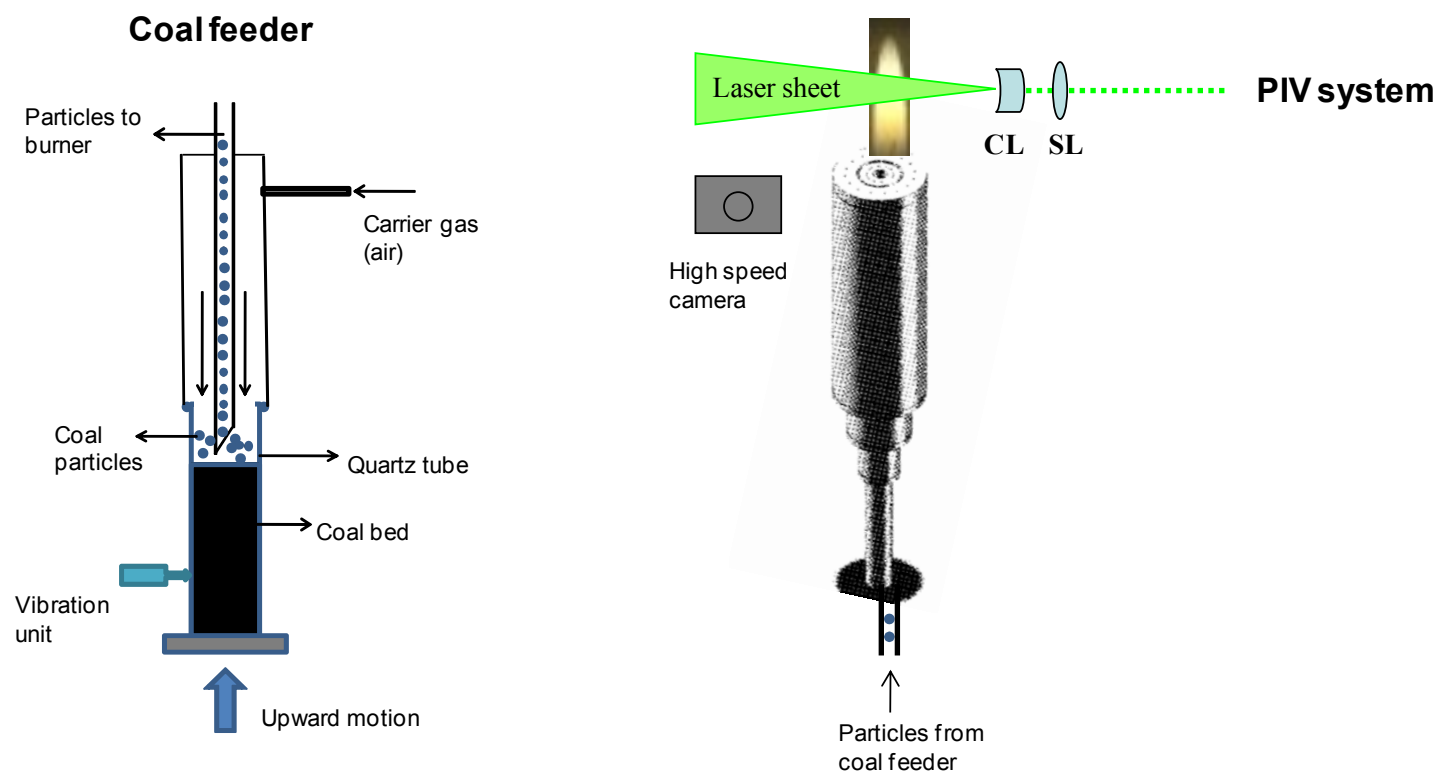

Figure 5. Diagram of the laboratory diffusion flame set-up. 

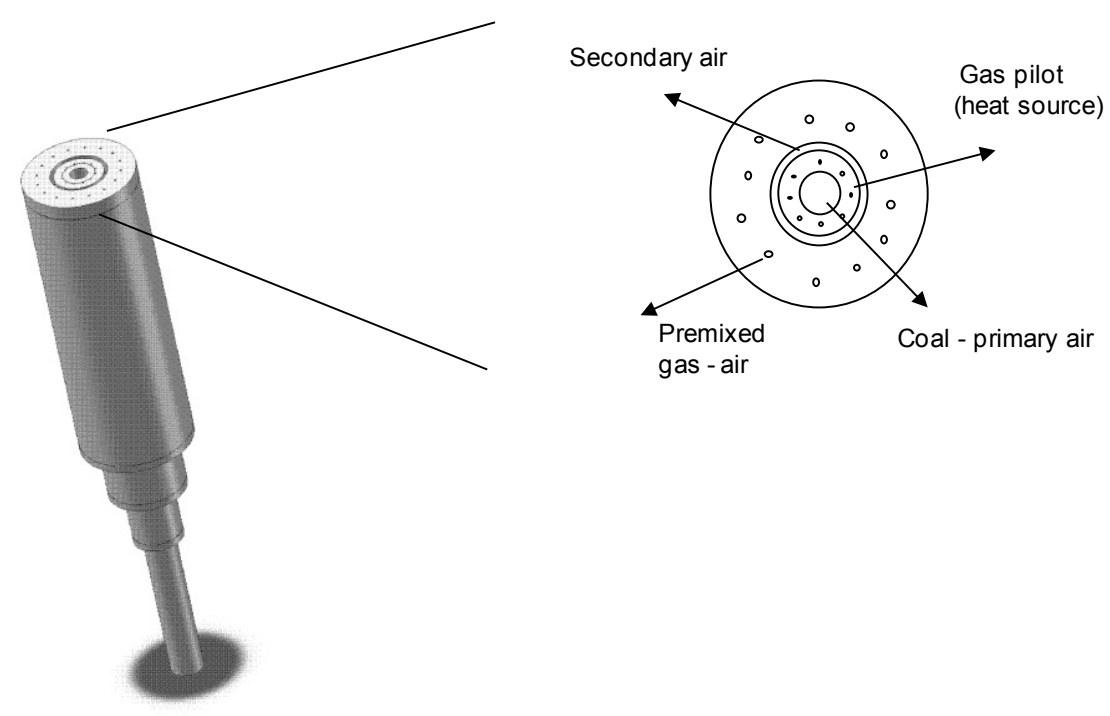

Figure 6. Diagram of the coal burner for PIV measurements. The central tube is the coal jet while the surrounding annulus is the air stream. The two pinhole rings are ethylene gas pilots.

In this design, the coal is transported from the coal feeder and fed via a gas stream (carrier gas) through the central tube of the burner. Immediately circling the central coal jet there is an ethylene pilot whose purpose is to ignite the coal. Outside of the pilot ring there is an air annulus feed that will provide air to both the pilot and coal flames and will allow for control of the stoichiometric ratio during coal combustion. The final annular ring (outside of the air stream) is a pre-mixed ethylene/air stream. The primary purpose of this stream is to heat the air stream, facilitating ignition of the coal jet, and to reduce heat loss from the flame.

Coal feeder. Figure 7 presents the first version of the coal feeder. This design utilized a combination of gravitational feed and air entrainment to loft the coal. It consists of a case that surrounds a central exit tube. The coal powder fills the case to the top of the exit tube. Air jets directed down onto the coal surface to entrain the powder, which then flows out the exit tube. The case is supported with two tracking rails and is mechanically lifted upward by a high-torque motor to constantly re-level the coal surface at the top of the exit tube, ensuring a more constant feed rate. A vibrating unit is coupled to the system to help disturb coal aggregates.

This design was hampered by unsteady upward motion of the pneumatic section, leading to very large variability in the coal flow. Some of the unsteady motion resulted from mechanical instability but there were also problems with friction caused by coal powder coating the sliding surfaces. Although a vibration system was used to disrupt the coal and air jets were used to have some sort of fluidization, there were also aggregation issues with the coal powder that also contributed to the feed rate variability. The 
variation of mass flow rate was not less than $40 \%$ at any operating condition, which was unacceptable for PIV data.

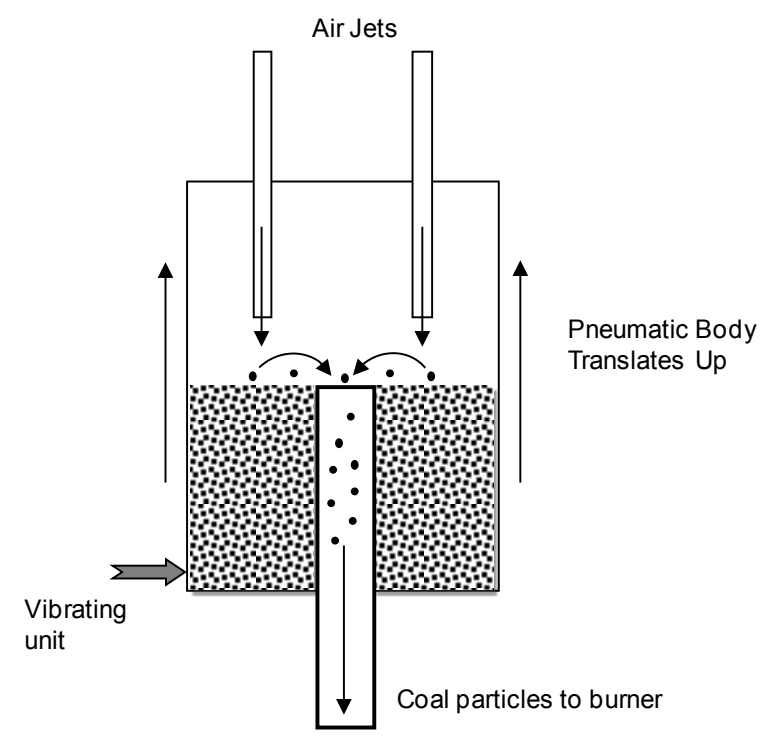

Figure 7. First version of the coal feeder.

Although this version of the coal feeder was not completely optimized, functionality was sufficient to enable preliminary PIV measurements in the laboratory coal flame.

A new coal feeder was designed and built in order to reduce variability in the PIV measurements. Figure 8 represents the new coal feeder system. The new feeder case was built of quartz $(0.95 \mathrm{~cm}$ inner diameter, $1.27 \mathrm{~cm}$ outer diameter, and $19 \mathrm{~cm}$ long). The quartz tube is supported by a metal plate and driven upwards with a motor. 


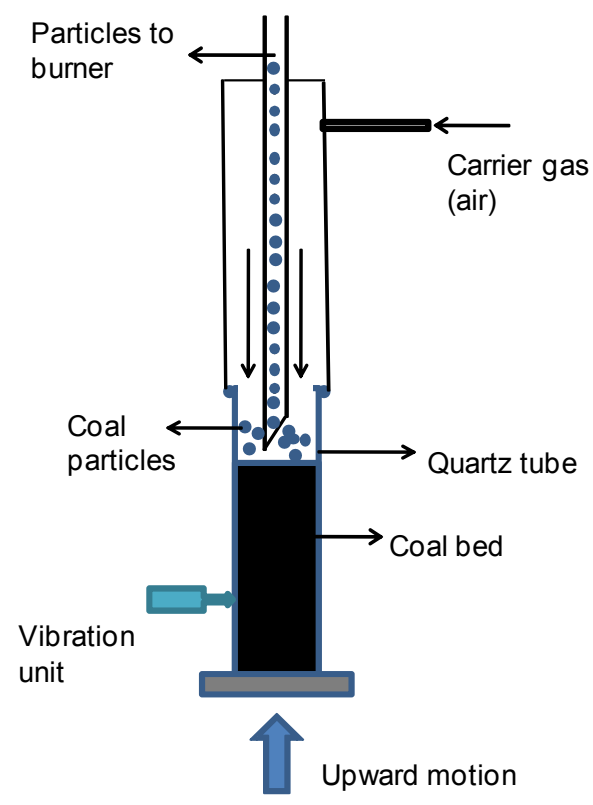

Figure 8. Second version of the coal feeder.

A stainless steel tube (2.2 $\mathrm{mm}$ inner diameter and $3.2 \mathrm{~mm}$ outer diameter) is placed at a fixed position and put inside the quartz tube, and air is used as carrier gas to transport the coal particles. A vibration unit is in contact with the quartz tube in order to facilitate particle fluidization and transport. In this new design, the coal is fluidized and transported upwards by the carrier gas through the stainless steel tube, which is connected to the burner. The motor moves the quartz tube upwards at the same speed as the coal level decreases, keeping constant the distance between the coal-bed surface and the inlet of the stainless steel tube. In this way, the mass flow rate of coal fed to the burner is uniform.

A better fluidization of the particles facilitated a more uniform coal flow and thus higher quality PIV data. For the range of mass flow rate chosen for the PIV tests (on the order of $100 \mathrm{mg} / \mathrm{min}$ ), the variation of mass flow rate with the new coal feeder was less than $13 \%$, which is much less than the $40 \%$ variation obtained with the first coal feeder.

PIV system. The initial PIV system used for evaluation of the gaseous flame and for preliminary tests with the coal-flame consisted of:

- A high speed camera, Photron (1k x $1 \mathrm{k}$ format), with a frame rate between 1500-3000 frames per second, (fps) and a shutter speed of $1 /$ frame rate $(333-166 \mu \mathrm{s})$

- A Q-switched double-headed continuum laser, with repetition rate $15 \mathrm{~Hz}$, energy per pulse $25 \mathrm{~mJ}$ and time between PIV laser pulses 666-166 $\mu \mathrm{s}$

- Spherical and cylindrical lenses for laser sheet formation

- A $532 \mathrm{~nm}$ band pass interference filter to reduce luminosity of flame (Edmund)

- A fluidized bed solid particle seeder (PB 100, Lavision)

- Seeding particles, Aerosil (through air channel up to 2 bars)

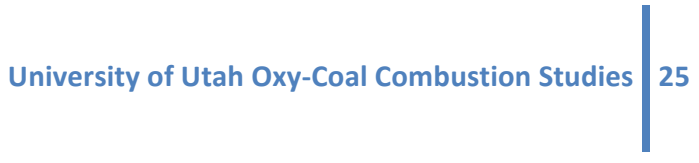


- $\quad$ PIV software, Lavision with Davis 7.2

- A cross Correlation method for analysis, IA 32 x 32 Px

The camera and the lasers are synchronized through a programmable timing unit (PTU 7, Lavision). The laser beams are transformed into a laser sheet, of thickness $\sim 1 \mathrm{~mm}$, using spherical and cylindrical lenses of focal lengths of 500 and $-200 \mathrm{~mm}$, respectively. To minimize the effect of flame luminosity an interference filter centered at the $532 \pm 5 \mathrm{~nm}$ was used and mounted in the camera lens. The time between the two laser pulses is matched to the framing rate of the camera, and using PIV software, the velocity of the seeding particles (in the gaseous flame) or coal particles (in the coal-flame) is measured.

Improvements in some components of the PIV system (camera and laser) were required to enhance the quality of the PIV data. A double frame CCD camera (Imager Pro X, 12 bits, 2048 x 2048 format, Lavision) and a double headed laser (Nd:YAG, $532 \mathrm{~nm}, 50 \mathrm{~mJ} /$ pulse, $7.26 \mathrm{~Hz}$ in double mode, Lavision) were used for this purpose. Also a camera shutter (Lavision) was mounted in the camera lens to shorten the exposure time of the $2^{\text {nd }}$ frame taken by the camera. Without this shutter it is impossible to get PIV information as the $2^{\text {nd }}$ frame is always over exposed with the luminosity of the flame due to the long exposure time of the $2^{\text {nd }}$ frame.

The images are cross-correlated using the PIV software (Davis 7, Lavision) with an initial interrogation size of 128 px x 128 px for initial pass and 64 px x 64 px for final pass. Each frame is $3.8 \mathrm{~cm} \mathrm{x} 3.8 \mathrm{~cm}$ with a resolution $18 \mu \mathrm{m} / \mathrm{px}$. The time between laser pulses, $50 \mu \mathrm{s}$, and the size of the interrogation window, $64 \mathrm{px} \times 64 \mathrm{px}(1.2 \mathrm{~mm} \times 1.2 \mathrm{~mm})$, were chosen such that the maximum displacement from frame $a$ to frame $b$ is less than $1 / 4$ of the interrogation area width (for an interrogation window of $64 x 64 \mathrm{px}$ this means a maximum allowed displacement of $16 \mathrm{px}$ ).

\section{Oxy-fuel combustor}

The $100 \mathrm{~kW}$ down-fired OFC is shown in Figure 9. The facility was designed to allow testing related to flame stability and ash characterization during oxy-coal combustion. The OFC can burn gas, liquid, and pulverized solid fuels; can be operated under air or oxy-firing conditions and has a systematic control of burner variables. The furnace has optional heated walls and optical access through quartz windows for visual observation and optical diagnostics in the main burner zone. Some specifications of the furnace include: it has a swirl-stabilized burner, heated walls with $24 \times 840$ watt ceramic heaters in the main burner zone; the overall dimensions are $1 \mathrm{~m}$ diameter $\mathrm{x} 12 \mathrm{~m} \mathrm{(} 3 \mathrm{ft} \times 39 \mathrm{ft})$; and the main burner zone is $0.6 \mathrm{~m}$ diameter $\mathrm{x} 1.2 \mathrm{~m}$ height ( 24 in $\mathrm{x} 48$ in). 


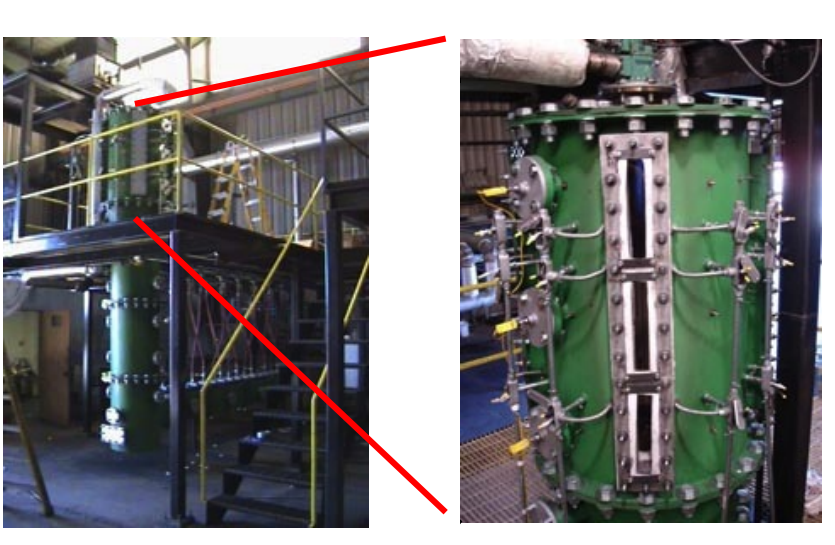

Figure 9. Oxy-fuel combustor.

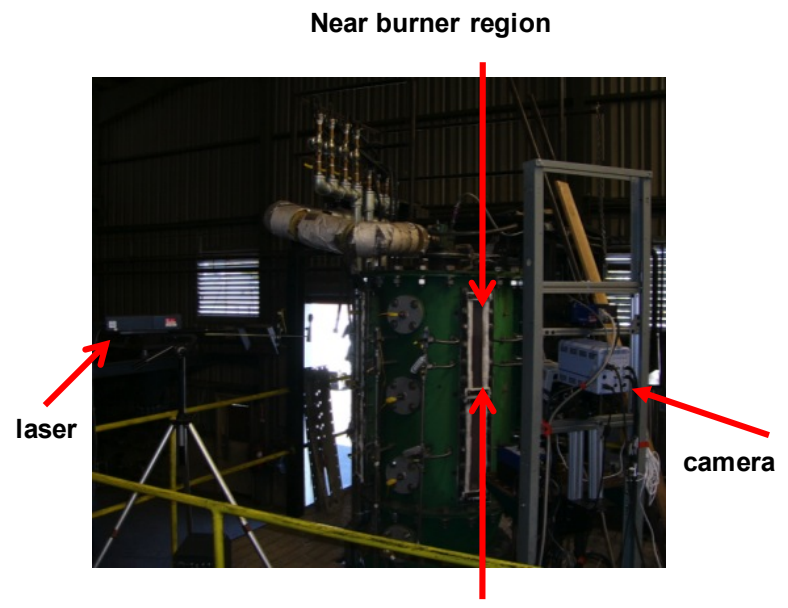

Far burner region

\section{Experimental conditions}

\section{Laboratory bench-scale diffusion flame}

Gaseous flames. Ethylene was used as the fuel, and air at varying ratios was used as the oxidizer. Aerosil ${ }^{\circledR}$ powder was the seeding material used for tracking the particles in the flow. Air was fed through the particle seeder and this was used to introduce the seeding particles in the burner through the air annulus ring.

Coal flames. In the PIV experiments for pulverized coal particles, there was no need to use the particle seeding apparatus, the coal particles themselves were used as the seeding particles.

Pulverized Utah coal with a maximum particle diameter of $75 \mu \mathrm{m}$ (due to previous screening of the coal) was used for preliminary tests. PIV measurements were carried out using the optimized PIV parameters obtained for the gaseous flame (these parameters are presented in the results and discussion section).

Variables of the coal feeder such as motor speed (determines the vertical speed at which the coal feeding system moves upwards), volumetric flow rate of carrier gas and the intensity of the vibration unit were evaluated for characterization of the coal flow rate given by the feeder.

Coal flow rates lower than $250 \mathrm{mg} / \mathrm{min}$ were preferred for PIV tests, since for these conditions the PIV images permitted the isolation of individual coal particles in the flame, facilitating the estimation of particle size and particle velocities. PIV images obtained for coal flow rates larger than $300 \mathrm{mg} / \mathrm{min}$ usually showed a cloud of particles in the flame, making it difficult to isolate individual particles. 
The mass flow rate of coal fed to the burner was on the order of $100 \mathrm{mg} / \mathrm{min}$. This coal flow rate was obtained under $50 \%$ motor speed capacity, $1.8 \mathrm{~L} / \mathrm{min}$ of carrier gas and intensity of the vibration unit equals to 1 .

The pulverized coal was sieved and separated into six different size ranges in order to investigate the effect of coal particle size on the velocity field and the dynamics of the combustion of pulverized coal. The first particle size range consisted of particles less than 38 micron in diameter, the second consisted of particles between 38 and 52 microns, the third between 53 and 74 microns, the fourth between 75 and 87 microns, the fifth between 88 and 105 microns, and the sixth between 106 and 125 microns.

Each particle size range was evaluated:

- Under three different equivalence ratios $(\phi=0.25,0.44$ and 0.92$)$.

- At different height locations in the flame. The particle velocities were evaluated in three regions of the flame, starting from the burner face to $3.5 \mathrm{~cm}$ vertically, then from $3.5 \mathrm{~cm}$ to $7 \mathrm{~cm}$ and finally from $7.5 \mathrm{~cm}$ to $10.5 \mathrm{~cm}$ in order to show the dynamic nature of the coal flame as we move vertically up in the flame

\section{Oxy-fuel combustor}

Pulverized Illinois 6 coal with a maximum particle diameter of $75 \mu \mathrm{m}$ (due to preliminary screening of the coal) was used for the tests. The velocity fields for the pulverized coal flame in the OFC were studied at two different locations in the flame in the main burner zone (see Figure 9). One location was at $7.6 \mathrm{~cm}$ from burner tip (referred in Figure 9 as near-burner region), and the other location was at $30.1 \mathrm{~cm}$ from the burner tip (referred in Figure 9 as far-burner region). PIV measurements were carried out at different primary $\mathrm{O}_{2}$ concentrations, ranging from 0 to $21 \%$ (with balance being $\mathrm{CO}_{2}$ ), to study examples of attached and detached flames in the combustor.

\section{Subtask 3.4 - Oxy-Coal Combustion in Circulating Fluidized Beds}

The initial development of CFB began in Germany (Koornneef et al. 2007) to use low-grade fuels and yet produce low emissions $\left(\mathrm{SO}_{\mathrm{x}}, \mathrm{NO}_{\mathrm{x}}\right)$. Several countries, including USA, UK, China, Germany etc., are the main drivers to spur development since they have abundant quantities of low-grade coal with high sulfur. Other countries in Northern Europe, such as Finland and Norway, are also very interested in fluidized bed technology for biomass combustion (peat, wood waste, sludge and bark). As one of the most popular fluidized bed designs, CFB provides unique advantages, wide industrial application and outstanding economic cost effectiveness (Beér 2007). It operates at a high gas velocity $(4-10 \mathrm{~m} / \mathrm{s}$ ) to fluidize a substantial body of solid matter (bed material, coal particle, limestone, or biomass). One advantage of CFBs includes relatively long residence time of the fuel particle in the CFB, which can improve fuel utilization. Another advantage is that the most efficient and favored operating temperature range for CFB is as low as 800-900 C. At this temperature, limestone has the most optimum $\mathrm{SO}_{\mathrm{x}}$ removal efficiency. The temperature is high enough to enhance $\mathrm{SO}_{\mathrm{x}}$ removal kinetic rates by limestone, but still much lower than that of $\mathrm{CaSO}_{4}$ decomposition and limestone sintering. Unlike CFB, most pulverized coal combustors have

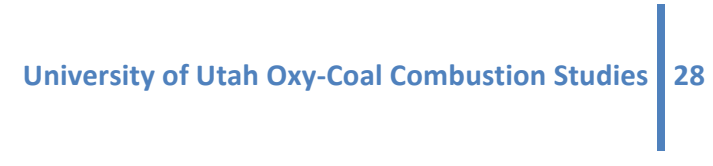


to use flue gas desulfurization (FGD) facilities to remove $\mathrm{SO}_{\mathrm{x}}$, which significantly increases the cost of sulfur control.

In the past decades, sulfur behavior in air firing has been extensively studied and reviewed (Attar 1978), and many of its mechanisms and evolution paths are well known. As expected, some sulfur mechanisms and evolution paths are expected to be very similar between air-fired and oxy-fired cases. Theoretical and experimental studies on oxy firing have focused on simulation, thermodynamics, flame characteristics, heat transfer and $\mathrm{NO}_{\mathrm{x}} / \mathrm{SO}_{\mathrm{x}}$ formation. However, there have been contradictory observations on $\mathrm{SO}_{2}$ emissions under oxy firing and air firing. Some researchers (Kiga et al. 1997, Croiset et al. 2001, Yamada 2007, D.M. Woycenko 1995, Hu et al. 2000, Wall et al. 2009) have indicated that $\mathrm{SO}_{2}$ emissions under oxy firing decreased as compared to air firing. In contrast, others (Hao Liu 2005, Klostermann 2008, Zheng et al. 2003) indicated no difference, based on experimental studies or equilibrium models. Most studies (Croiset and Thambimuthu 2001, Yamada 2007, D.M. Woycenko 1995, Hu et al. 2000), however, have shown that oxy-firing with flue gas recycling results in a higher concentration of $\mathrm{SO}_{2}$ (in ppm) but a lower $\mathrm{SO}_{2}$ emission on a mass (mg/MJ) basis. Some researchers (Buhre et al. 2005) suggest that it is caused by the higher conversion of $\mathrm{SO}_{2}$ compared to other sulfur species, such as $\mathrm{SO}_{3}$, in oxy-fuel combustion. Sarofim (2007) indicated that high concentrations of $\mathrm{SO}_{2}$ were the result of high sulfur removal by sulfation of ash under oxy-fuel combustion.

Although most of the fuel-bound sulfur is oxidized to $\mathrm{SO}_{2}$, a small percentage can be further oxidized to sulfur trioxide $\left(\mathrm{SO}_{3}\right)$, and the extent of this conversion depends on temperature, moisture, $\mathrm{O}_{2}$ concentration, $\mathrm{SO}_{2}$ concentration, and catalytic matter in fly ash. Usually, the amount of $\mathrm{SO}_{3}$ is small; however, $\mathrm{H}_{2} \mathrm{SO}_{4}$ formed from $\mathrm{SO}_{3}$ and moisture would cause severe corrosion to the flue gas recycle lines, heat recovery zones, $\mathrm{CO}_{2}$ transportation streams. Moreover, $\mathrm{SO}_{3}$ also has environmental consequences since it can be released as an acid aerosol, which creates visible plumes and also leads to acid rain. Conversely, $\mathrm{SO}_{3}$ can have positive impacts by improving electrostatic precipitator efficiency by forming an adsorbed layer on the surface of the fly ash particles.

$\mathrm{O}_{2}$ concentrations $(28 \%)$ in the oxidant streams for oxy-firing are required to be slightly higher than that $(21 \%)$ in air firing in order to provide similar flame temperatures or heat flux profiles. At the same time, an increased amount of $\mathrm{O}_{2}$ in oxy firing has the potential for affecting the degree of oxidation of $\mathrm{SO}_{2}$ to $\mathrm{SO}_{3}$. There are still several issues that need to be addressed regarding $\mathrm{SO}_{3}$ formation to support commercial development (Stanger et al. 2010). The formation of $\mathrm{SO}_{3}$ is very dependent on the type of coal and fly ash encountered during flue gas cooling. Another great challenge is how to close the sulfur balance (Toftegaard et al. 2010). The difficulty with closing the sulfur balance lies not only in measurement of $\mathrm{SO}_{3}$, but also in reducing-S containing species $\left(\mathrm{H}_{2} \mathrm{~S}, \mathrm{COS}, \mathrm{CS}_{2}\right.$, etc.), which are almost impossible to measure, especially at fuel-rich condition.

$\mathrm{SO}_{\mathrm{x}}$ removal during coal combustion is particularly important, and several approaches have been developed, including relatively expensive FGD and cheap direct injection of limestone, as used in CFBs. It is important that the impact of oxy-firing on the chemistry of limestone sulfation is understood, to facilitate the design of commercial oxy-fired systems. Generally, the sulfation mechanisms of limestone

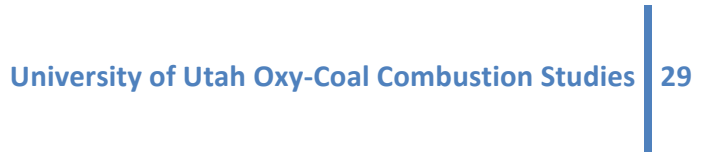


depend on whether calcination of the limestone occurs. The direct sulfation reaction takes place in an uncalcined condition while the indirect sulfation reaction occurs in a calcined state. Normally, the direct sulfation reaction occurs in oxy firing, and the indirect sulfation reaction occurs in air fired conditions at fluidized bed operating temperatures. Both mechanisms are illustrated by the following chemical reactions:

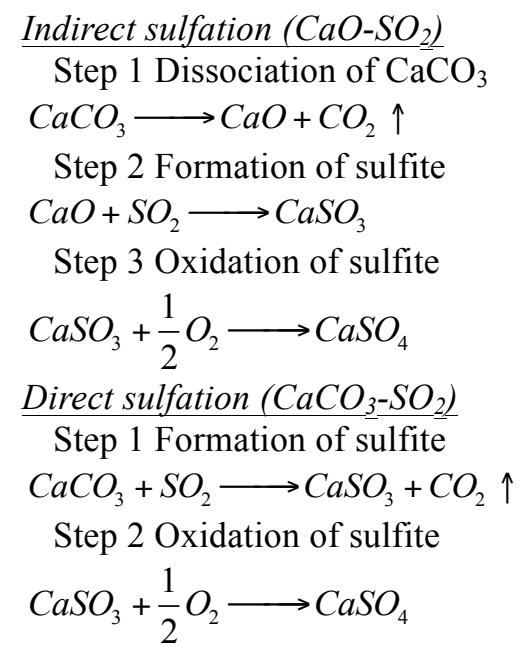

A few potential mechanisms are presented in the literature (Silcox et al. 1989, Zhong 1995, Hajaligol et al. 1988, Michael J. H. Snow 1988, Liu et al. 2000, Illerup et al. 1993). Experimental observations by Tullin et al. (1993) showed in particular the inhibiting effect of high $\mathrm{CO}_{2}$ concentration on the direct sulfation reaction. In general, the knowledge about the mechanism of the direct sulfation reaction is limited and highly speculative. Little else can be confirmed except that the final product is $\mathrm{CaSO}_{4}(\mathrm{Hu}$ et al. 2006).

\section{Pilot-scale circulating fluidized bed}

The pilot-scale CFB at the University of Utah is used for the study of combustion of standard fuels (coal, natural gas, fuel oil, etc.) and waste incineration. It was modified to accommodate direct oxy-firing with flue gas recycled. An existing $330 \mathrm{~kW}$ CFB stands approximately $8.5 \mathrm{~m}$ in height with an outer and inner shell diameter of $0.61 \mathrm{~m}$ and $0.25 \mathrm{~m}$, respectively. As Figure 10 shows, the CFB consists of five main sections: plenum/distributor; lower bed (Sections 1 \& 2); freeboard (Sections 3-6); transition/cyclone and the loop seal/standpipe. Four lines can inject oxidant into the furnace (primary, secondary, loop seal \#1 \& \#2).

Usually, the primary oxidant line was heated up to around $400 \mathrm{C}$ using an electrical insertion heater, which is one of the approaches to adjust the bed temperature. Air or flue gas (mainly $\mathrm{CO}_{2}$ ) with enriched $\mathrm{O}_{2}$ introduced by the primary oxidant line passed through the distribution plate equipped with many bubbling caps, which then fluidized the bed material (sands), limestone or coal particle. Meanwhile, coal was fed from a screw feeder with an auger that fed the fuel into the CFB at the bottom of section 3. At the same time, additional limestone was injected using the second feeder auger. An ash removal auger located 
in section 1 was supposed to remove ash and excess bed material when the bed pressure was excessive. The cyclone efficiently separated effluent gas into two streams: solid stream, i.e. tiny limestone particles, unburned coal particles, some bed materials, passed through the loop seals prior to returning to CFB, and the gas flow at loop seal maintained enough pressure to push particulate matter into CFB, and keep the mass balance for whole system. The gas stream was passed through the water-cooled heat exchanger prior to the bag house. And then the flue gas was divided into two steams in the bas house: one stream exhausted into the atmosphere, while the other was recycled into the furnace as a way to dilute pure $\mathrm{O}_{2}$ during oxy firing. All oxidant lines were capable of switching from air to recycled flue gas by closing a ball valve opened to either atmosphere or the flue gas recycling system. These oxidant lines were also manipulated with control valves and V-cones. Also, the loop seal lines can introduce $\mathrm{CO}_{2}$, instead of air, during oxy firing.

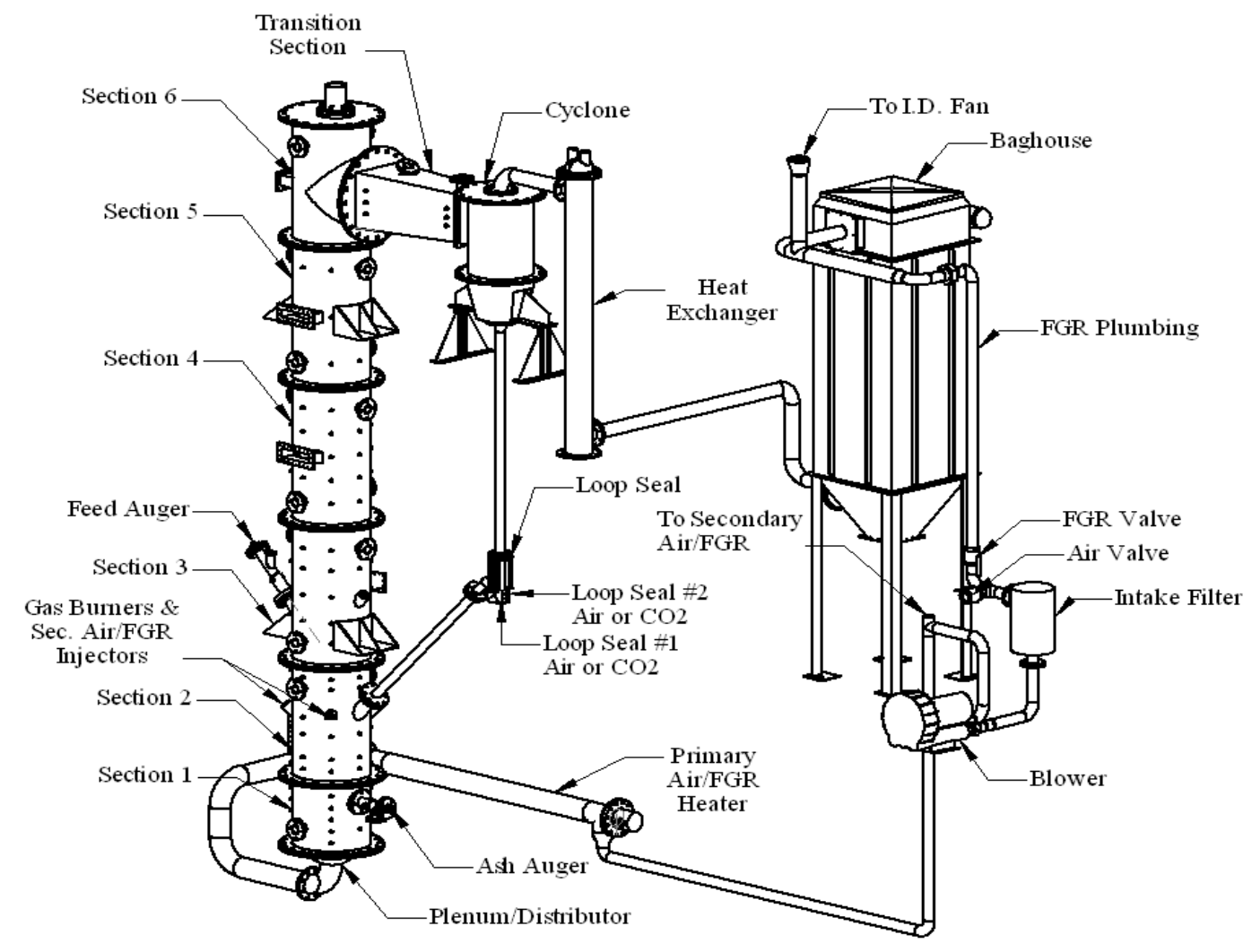

Figure 10. Schematic of pilot-scale CFB.

After initial experimental work, it was determined that additional heat removal would be required in order to maintain bed temperatures low enough to prevent agglomeration of accumulated ash material. A number of water-cooled lances were fabricated that could be inserted as needed in sections 1-6 to control bed temperature. Redesigning the standpipe and loop seal connections with water-cooled jackets 
facilitated additional heat removal. In this manner, heat could be removed from the solids return line as well, providing an additional degree of freedom. The addition of water-cooled jackets also improved operation of the loop seal, due to decreased solids temperatures and minimization of oxidation of unburned char particles in the return line.

The gas sample was taken out from the different locations (section 4-6 and transition section) of the fluidized bed. Then, the gas samples were passed through the refrigerator, where $\mathrm{H}_{2} \mathrm{O}$ vapor was removed prior to introducing to gas analyzers. An online $\mathrm{SO}_{2}$ analyzer (CAI Model 601 NDIR) was used to determine the $\mathrm{SO}_{2}$ content of the flue gas. Temperatures at the sampling location varied from 410 to 510 $\mathrm{K}$ to prevent $\mathrm{SO}_{3}$ from condensing, and the $\mathrm{SO}_{3}$ concentration in the flue gas was determined by the controlled condensation method (CCM). For the CFB tests the Utah Skyline coal was combusted at both air-firing condition and oxy-firing condition. For oxy-firing conditions, $27 \% \mathrm{O}_{2}$ concentration (wet basis) was used for all tests in the CFB facilities to simulate the air firing condition due to the higher heat capacity of $\mathrm{CO}_{2}$. The elemental analyses of the fuels utilized are described in Table 2 .

Table 2. Ultimate and proximate analysis of Utah coal.

\begin{tabular}{cccc}
\hline Properties & Value & Properties & Value \\
\hline Loss on dying (\%) & 3.18 & $\mathrm{~S}(\mathrm{wt} \%)$ & 0.53 \\
Ash (wt \%) & 8.83 & O (wt \%) & 13.21 \\
C (wt \%) & 70.60 & Volatile Matter (wt \%) & 38.6 \\
H (wt \%) & 5.41 & Fix carbon (wt \%) & 49.39 \\
N (wt \%) & 1.42 & Higher heating value (Btu/lb) & 12,606 \\
\hline
\end{tabular}

\section{$\mathrm{SO}_{3}$ sampling methodology}

As Figure 11 shows, The CCM (Jain 1997) was used to measure the emissions of $\mathrm{SO}_{2}$ and $\mathrm{SO}_{3}$. The pump can create negative pressure to draw the gas sample into the measurement system. The gas sample was drawn through the quartz glass inside of a heated tube, and the filter system can remove the particulate matter, which has significant impact on $\mathrm{SO}_{3}$ measurement. Both tubing and filter were heated by heating tapes to prevent $\mathrm{SO}_{3}$ from condensing. Then the sample gas was sucked into a condenser, where $\mathrm{SO}_{3}$ is set apart by condensation at the desired operating temperature (75-78 C). Meanwhile, other gas species, such as $\mathrm{H}_{2} \mathrm{O}, \mathrm{SO}_{2}$, would proceed further. After passing the condenser, the gas sample goes into four glass impingers in an ice bath. The first two impingers filled with $\mathrm{H}_{2} \mathrm{O}_{2}$ solution allowed oxidizing of $\mathrm{SO}_{2}$ to $\mathrm{SO}_{3}$, and then $\mathrm{SO}_{3}$ was captured. The last impinger with silica gel can prevent moisture entering the measurement system. As a result, $\mathrm{SO}_{3}$ and $\mathrm{SO}_{2}$ are retained in the condenser and $\mathrm{H}_{2} \mathrm{O}_{2}$ solutions in the first two impingers, respectively.

According to EPA method $8 \mathrm{~A}, \mathrm{SO}_{3}$ was titrated using barium perchlorate solution and thorin indicator. All samples were titrated at least three times to reduce the experimental error. In addition, the concentration of $\mathrm{SO}_{2}$ was quantified with hydrogen peroxide by titration of the solution and compared with that from an online California Analytical Model 600 Non-Dispersive Infrared (NDIR) analyzer to verify the results and accuracy of the titration procedure. In addition, a dilution system using $\mathrm{N}_{2}$ gas was

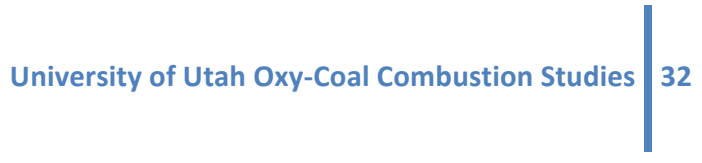


required by the analyzer measurement range for high $\mathrm{SO}_{2} \mathrm{ppm}$ condition. The dilution system contains two California Analytical Model ZRH NDIR gas analyzers to measure the $\mathrm{CO}_{2}$ concentration before and after dilution.

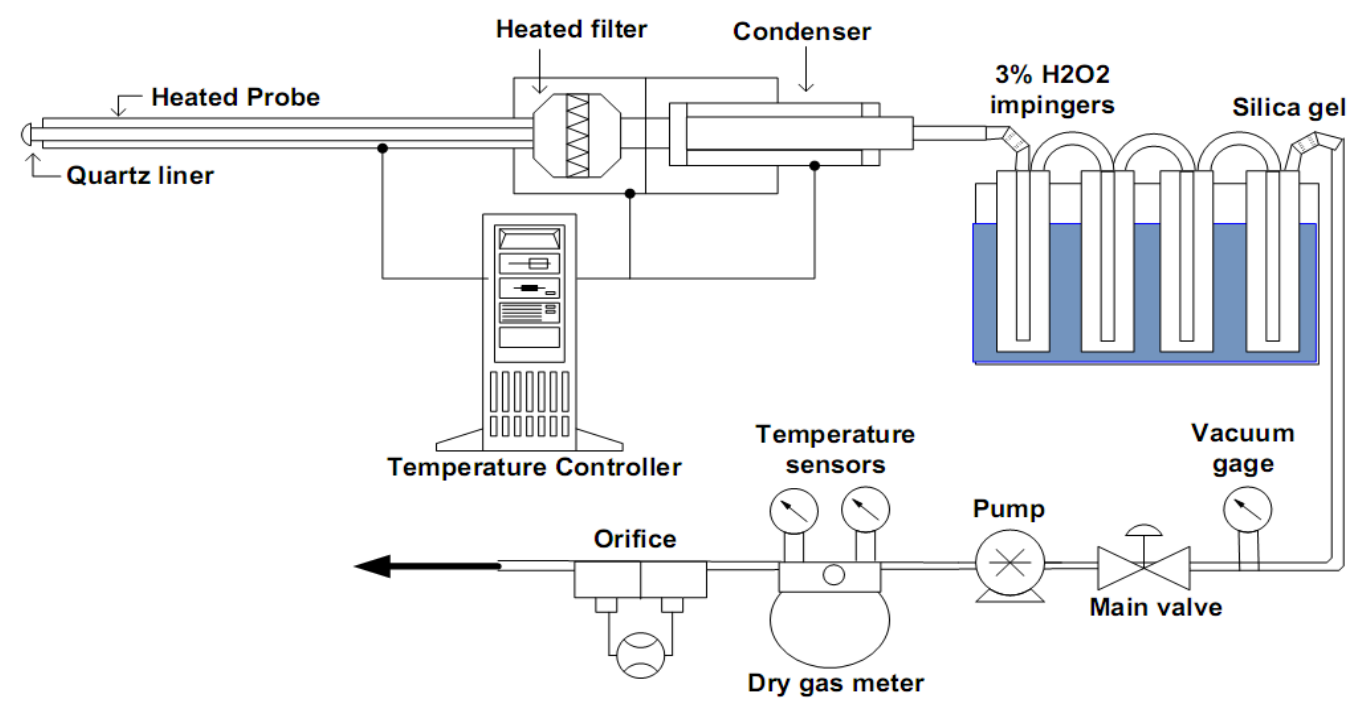

Figure 11. Schematic of controlled condensation method.

Additional insights into $\mathrm{SO}_{3}$ formation were obtained using thermo chemical equilibrium calculations. Equilibrium calculations (Ahn et al. 2011) for $\mathrm{SO}_{3}$ formation under various conditions used the NASA CEA equilibrium model along with $\mathrm{SO}_{3}$ concentration values obtained with the Illinois coal. At higher temperatures $\left(>1000 \mathrm{C}\right.$ ), equilibrium favors $\mathrm{SO}_{2}$ formation, not $\mathrm{SO}_{3}$. The equilibrium calculations showed formation of $\mathrm{SO}_{3}$ occurred at lower temperatures, but even at lower temperatures the amount of $\mathrm{SO}_{3}$ formed at equilibrium was much less than $\mathrm{SO}_{2}$. When the gas mixture was heated to a high temperature $(1700 \mathrm{C})$, the yield of $\mathrm{SO}_{3}$ fell to zero because $\mathrm{SO}_{3}$ is decomposed at such high temperatures. The equilibrium $\mathrm{SO}_{3}$ concentration achieved a maximum value at around $530 \mathrm{C}$. Therefore, if the combustion products are sampled at too high a temperature, $\mathrm{SO}_{3}$ in gas samples tend to decompose, and the results of the measurement might not be accurate. In addition, some $\mathrm{SO}_{3}$ might be condensed prior to sampling if the temperature is too low. It is important, therefore, to sample for $\mathrm{SO}_{3}$ in an optimal temperature window to account for the formation, given the thermal profile of the combustion system, but to also sample prior to any $\mathrm{SO}_{3}$ condensation. To sum up from the above discussions, the temperature in the heat probe and its location needs to be in the appropriate temperature window to get an accurate $\mathrm{SO}_{3}$ concentration during the combustion process.

\section{Subtask 3.5 - Single-Particle Oxy-CO ${ }_{2}$ Combustion}

In the past decades, great efforts have been made to understand the mechanisms of sulfur emissions. Theoretical and experimental studies on oxy-fuel combustion have focused on simulation, thermodynamics, flame characteristics, heat transfer and $\mathrm{NO}_{\mathrm{x}} / \mathrm{SO}_{\mathrm{x}}$ formation. However, as discussed in 
under Subtask 3.4, there have been contradictory observations on $\mathrm{SO}_{2}$ emissions under oxy-fuel combustion and air-combustion.

The shrinking-core model (Szekely 1976, Levenspiel 1962) is the most frequently used model for the description of the sulfation reaction (Zhong 1995, Hajaligol et al. 1988, Snow 1988, Iisa 1992, Krishnan et al. 1993, Qiu et al. 2000, Fuertes et al. 1994, Zevenhoven et al. 1998). It is a simplified model for gassolid reaction, which assumes a sharp boundary between the unreacted core and the formed product layer. It is often valid for pore-less particles but not for porous particles (Dam-Johansen et al. 1991). A few authors have tried other models, such as the "parallel-pore model" by Spartinos (1991) and the CIS model by Zevenhoven (1998). However, no general gas-solid and reaction-diffusion model was developed for most gas-solid cases, such as single coal particle, lime- $\mathrm{SO}_{2}$, industrial catalyst pellet.

In this study, a general gas-solid and reaction-diffusion model is based on fully governing equations and numerical solutions. It also covers traditional shrinking un-reacted and reacted, grain, and parallel poremodels. The mathematical model is used to describe the mechanism of sulfur release and capture as well as sulfation behavior of limestone. One of the difficulties is to couple parameters of pore diffusion, external mass and heat convection, internal heat conduction, radiation, chemical reactions, etc., using the mathematical model. Another difficulty is numerical solutions in the rapid coal combustion processes, so the stability and convergence of the numerical solutions need to be carefully considered.

\section{Experimental approach}

A single particle fluidized bed reactor is used to follow the evolution of fuel sulfur (Illinois \#6 coal) in mixtures of $\mathrm{O}_{2}$ with $\mathrm{N}_{2}$ or $\mathrm{CO}_{2}$ at the same conditions (mass flow rate, $\mathrm{O}_{2}$ concentration and fluidized-bed temperature, etc.). In this way, we can examine the effect of the presence of $\mathrm{CO}_{2}$ on $\mathrm{SO}_{2}$ emissions or other participating species. A complementary study is carried out by equilibrium modeling using NASA's Chemical Equilibrium with Applications (CEA) program. $\mathrm{SO}_{2}$ emission was simulated in oxy-fuel and air combustion conditions using CEA program.

\section{Bench-scale fluidized bed}

The single-particle, coal-combustion experiments were performed in a bench-scale fluidized bed (Can et al. 2007, Sánchez et al. 2010). The schematic is shown in Figure 12. It is a vertical, cylindrical, stainlesssteel furnace with a combustion chamber length of $771 \mathrm{~mm}$ and an inner diameter of $44 \mathrm{~mm}$. The column has a $2 \mathrm{~mm}$ thick perforated plate distributor with 60 holes. The temperatures of bed material, furnace wall and gas phase are measured by K-type thermocouples. A Magna-IRTM Spectrometer 550 FTIR measures the effluent.

Preliminary experiments suggested that it was necessary to purge the preheat furnace with $\mathrm{N}_{2} / \mathrm{O}_{2}$ or $\mathrm{CO}_{2} / \mathrm{O}_{2}$ to maintain the same conditions as the introduced gas. The gas streams were controlled by massflow controllers and were premixed before being introduced into the furnace. Electric furnaces heated the

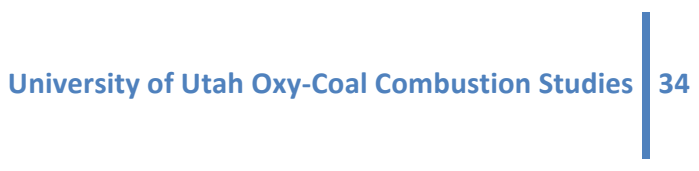


column and the preheating section of the fluidized bed to the desired temperature. Soot was removed by glass filter prior to the gas cell of FTIR.

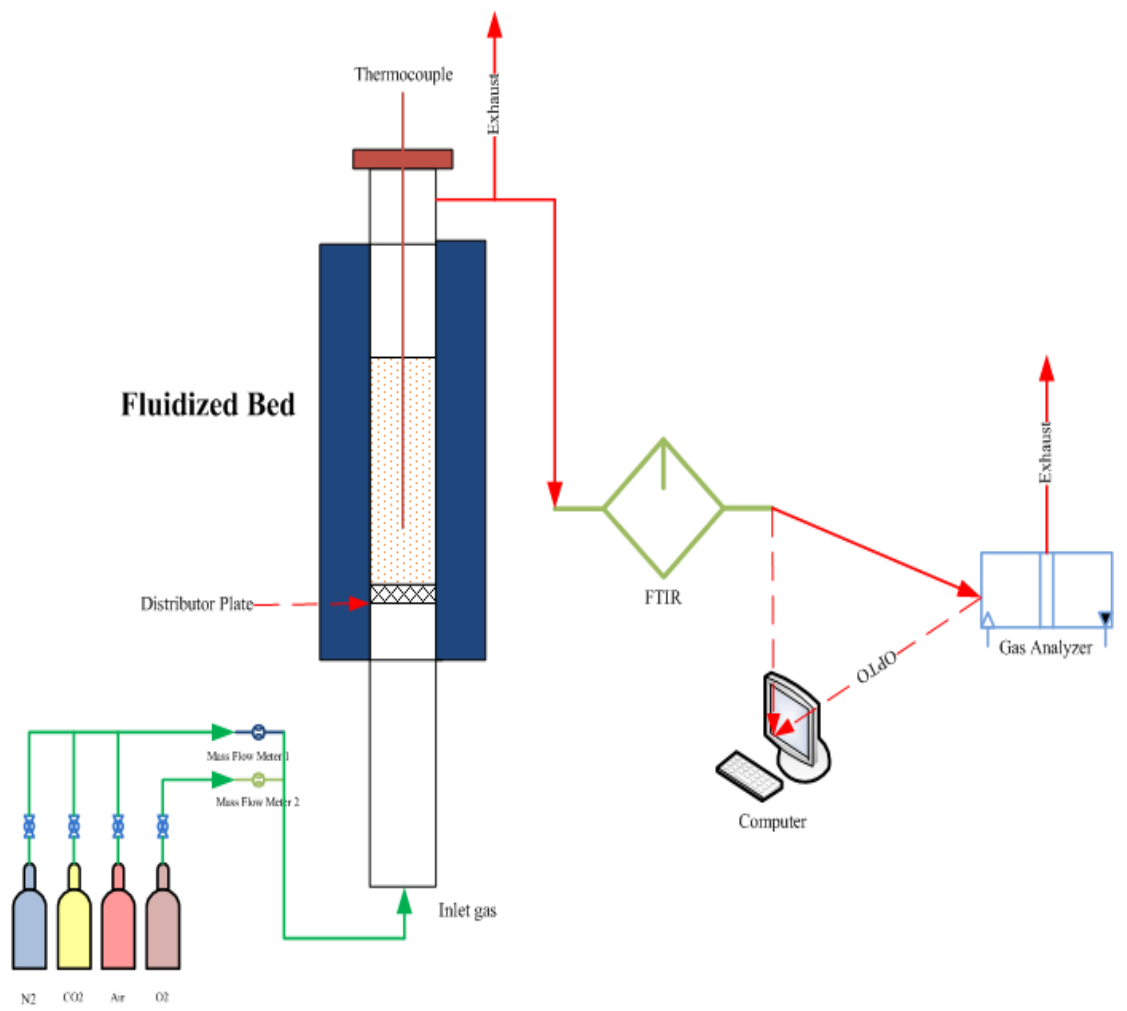

Figure 12. Schematic setup of bench-scale fluidized bed combustor.

Sulfur release in oxy-fuel combustion and air-combustion. Observations of $\mathrm{SO}_{2}$ emissions under oxy- and air-fired conditions are inconsistent (Kiga et al. 1997, Croiset and Thambimuthu 2001, Yamada 2007, D.M. Woycenko 1995, Hu et al. 2000, Wall et al. 2009). However, it is the most fundamental issue of sulfur evolution during oxy-fuel combustion process. Table 3 provides the experimental conditions, which include a wide range of fluidized-bed temperatures from $765 \mathrm{C}$ to $902 \mathrm{C}$ and $\mathrm{O}_{2}$ concentrations from $10 \%$ to $30 \%$. Each experimental condition was repeated at least 5 times, thus, there were a total of 120 experiments to ensure experimental repeatability. The bench-scale fluidized bed also lends itself to repeating many experiments for each condition due to its low cost.

Premixed gases $\left(\mathrm{N}_{2}+\mathrm{O}_{2}\right.$ or $\left.\mathrm{CO}_{2}+\mathrm{O}_{2}\right)$ were introduced into the bottom of the reactor, and passed through the distributor plate. In addition, $0.12 \mathrm{~g}$ of coal particles was introduced into the reactor, which contained approximately $300 \mathrm{~g}$ of bed materials. 
Table 3. Experimental matrix for $\mathrm{SO}_{2}$ formation in air- vs. oxy-combustion.

\begin{tabular}{ll}
\hline Experimental Parameters & \\
\hline Temperature of fluidized bed (C) & $765,835,874,902$ \\
$\mathrm{O}_{2}$ concentration (vol. \%) & $10,20,30$ \\
Combustion type & air-combustion $\left(\mathrm{N}_{2} / \mathrm{O}_{2}\right)$, oxy-combustion $\left(\mathrm{CO}_{2} / \mathrm{O}_{2}\right)$ \\
Total gas flow rate (liter/min) & 4 \\
Type of coal & Illinois $\# 6(4.0 \% \mathrm{~S})$ \\
Coal particle weight $(\mathrm{g})$ & $0.12(\mathrm{avg}$.) \\
Coal particle size $(\mathrm{mm})$ & $3.4-4.6$ \\
Bed material & $300 \mathrm{~g}$ of zirconium silicate (BSLZ-3) \\
\hline
\end{tabular}

Note: each experimental condition was repeated 5 times

Sulfur capture with limestone in oxy-combustion and air-combustion. $\mathrm{SO}_{2}$ emissions can be removed by injecting limestone directly into the fluidized bed. The calcination of limestone is usually inhibited due to high $\mathrm{CO}_{2}$ concentrations in the oxy-fuel combustion. Thus, the sulfation behavior of limestone in oxy-fuel combustion is quite different compared with air combustion. The main difficulty of this experiment lies in how to ensure enough contact between the limestone and a single coal particle. To address this, manufactured coal pellets were developed by our research group, which have specific Ca:S ratios. The sulfation behavior of limestone is very dependent on temperature. However, temperature of the manufactured coal pellets is hard to measure during the combustion process. A large $\mathrm{Ca}: \mathrm{S}$ ratio $(\mathrm{Ca}: \mathrm{S}$ is above 2000:1) is employed, so it can ensure enough contact between limestone and the single coal particle.

The experimental parameters of sulfur capture are given in Table 4. A wide range of fluidized-bed temperatures ( 765 to $902 \mathrm{C}$ ) and various $\mathrm{O}_{2}$ concentrations (10\% to $\left.30 \%\right)$ were investigated. Each condition was repeated 5 times.

Table 4. Experimental matrix for single coal particles with limestone.

\begin{tabular}{ll}
\hline Experimental Parameter & \\
\hline Temperature of fluidized bed $(\mathrm{C})$ & $765,835,902$ \\
$\mathrm{O}_{2}$ concentration (vol.\%) & $10,20,30$ \\
Combustion type & air-combustion $\left(\mathrm{N}_{2} / \mathrm{O}_{2}\right)$, oxy-fuel combustion $\left(\mathrm{CO}_{2} / \mathrm{O}_{2}\right)$ \\
Total gas flow rate (liter/min) & 4 \\
Type of coal & Illinois $\# 6(4.0 \% \mathrm{~S})$ \\
Coal particle weight $(\mathrm{g})$ & $0.12(\mathrm{avg})$. \\
Coal particle size $(\mathrm{mm})$ & $3.4-4.6$ \\
Bed material & $300 \mathrm{~g}$ of zirconium silicate $(\mathrm{BSLZ}-3)$ \\
Limestone & Obtained from the chemistry stockroom \\
Limestone weight $(\mathrm{g})$ & 10.00 \\
Limestone size $(\mathrm{mm})$ & $0.6-1.0 \mathrm{~mm}$ \\
\hline
\end{tabular}

Note: each experimental condition was repeated 5 times.

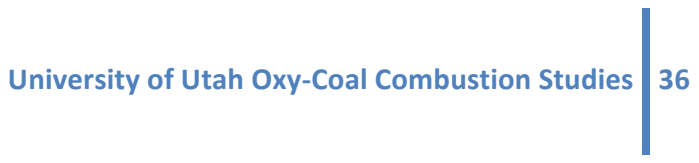




\section{Sulfur capture with limestone by $\mathrm{SO}_{2}$ calibration gas}

The sulfation behavior of limestone was studied under oxy-fuel combustion and air combustion conditions using a $\mathrm{SO}_{2}$ calibration gas. Unlike single coal-particle transient combustion, $\mathrm{SO}_{2}$ calibration gas can provide a steady-state gas concentration and makes experiments much easier to conduct. It can show the clear relationship between $\mathrm{Ca}: \mathrm{S}$ ratio and the sulfation ability of limestone, as well as the effect of the $\mathrm{CaSO}_{4}$ layer.

The experiment was performed in the bench-scale fluidized bed reactor, described in the previous section. $1.0 \mathrm{~g}$ of limestone was put into the reactor where there was already approximately $300 \mathrm{~g}$ of bed material. The limestone was given plenty of time to attain complete calcination (in the case of the $\mathrm{N}_{2}$ atmosphere). The premixed gas flow was then switched to a sulfur-containing gas stream $\left(\mathrm{N}_{2}\right.$ or $\left.\mathrm{CO}_{2} / \mathrm{O}_{2} / \mathrm{SO}_{2}\right)$, which was fed into the reactor. The total reaction time was 1 hour.

Table 5. Experimental matrix for known $\mathrm{SO}_{2}$ concentration in $\mathrm{N}_{2} / \mathrm{CO}_{2}$ with limestone.

\begin{tabular}{ll}
\hline Experimental Parameters & \\
\hline Temperature of fluidized bed (C) & $765,835,874$ \\
$\mathrm{O}_{2}$ concentration (vol. \%) & 20 \\
Calibration gas (vol. \%) & 80 \\
$\mathrm{SO}_{2}$ concentration in calibration gas (ppm) & 1000 \\
$\mathrm{SO}_{2}$ concentration in final mixture (ppm) & 800 \\
Bed material & $300 \mathrm{~g}$ of zirconium silicate (BSLZ-3) \\
Limestone & Obtained from the chemistry stockroom \\
Limestone weight (g) & 1 \\
Limestone size (mm) & $0.6-0.991 \mathrm{~mm}$ \\
Total gas flow rate (liter/min) & 3 \\
\hline
\end{tabular}

\section{Gas analysis}

Online monitoring has a great advantage in many industrial applications and lab research. Here, Fourier transform infrared (FTIR) spectroscopy is applied for online monitor of $\mathrm{CO}_{2}, \mathrm{CO}, \mathrm{SO}_{2}$. Compared with gas chromatography, FTIR can collect gas samples much faster, so it can track the rapid evolution of sulfur and intermediates in combustion processes and assist with understanding of kinetics. The Magna $550^{\mathrm{TM}}$ spectrometer (Nicolet Inc.) has four optional resolutions. As the scan number increases, higher resolution is attained. However, the penalty is to require longer collection time. Conversely, less scans can shorten sample collection time, but decrease the resolution of the spectra. The spectrometer is equipped with a mercury cadmium telluride detector cooled by liquid nitrogen, and the spectral range is $650-4000 \mathrm{~cm}^{-1}$. The number of scans employed was 4 in our experiments to optimize resolution and collection time. The software, Omnic version 5.2 is used to analyze the spectra. 


\section{Approach: General gas-solid and reaction-diffusion model}

The gas-solid model can be applied to coal particle combustion, limestone- $\mathrm{SO}_{2}$ capture, and industrial catalyst pellets. In addition, the gas-solid model can provide the details of pore gas diffusion, internal heat conduction, external heat convection, radiation and chemical reactions. The well-known shrinking-core particle model has limited application since the assumption of an internal structure of "no pore". Since the general gas-solid and reaction-diffusion model was developed without a lot of assumptions it will have much wider application. The model as coded by Matlab, also adopted special numerical solution techniques to solve the stiff problem such as the implicit method, dynamical time step, and the modified Rosenbrock formula of order 2.

The mathematical framework of the general model is based on governing equations, including one energy equation and several mass equations. The energy equation can give the profile of temperature in time and space. The numbers of mass equations are determined by how many species (gas and solid) are in the system. Also, these mass equations can provide species concentration in time and space. The chemical reactions and diffusion can be simulated simultaneously. Mass equations are coupled with the energy equation by the Arrhenius equation, which gives the connection between reaction rate constant and temperature. Also, the temperature profile is relative to external heat convection and internal heat conduction, radiation, and chemical heat generation. Moreover, the chemical heat generation is relative to mass species, which couples the energy and mass equations. At the same time, the profiles of mass species are also dependent on the temperature due to the kinetics constant rate. During the computing process, all of the parameters are coupled.

The solid phase is a key to determinate the reaction process. For instance, in single coal particle combustion, fixed carbon is the solid phase. When it is burned out, combustion stops immediately. Using this model, the combustion process will go on forever unless the mass equation contains a solid phase. Additionally, the mass "information" between particle and external environment is transported by the gaseous phase, as well as by particle interaction. In the single coal particle combustion model, first gas phase $\mathrm{O}_{2}$ diffuses into the coal particle from the surrounding gas, and then reacts with fixed carbon (solid phase) to produce $\mathrm{CO}$ and $\mathrm{CO}_{2}$ (gaseous phase). Later, product gases $\left(\mathrm{CO}\right.$ and $\left.\mathrm{CO}_{2}\right)$ diffuse out of the particle. Through the above processes, fixed carbon (solid phase) is "brought out" from the coal particle to the external environment by the different "gases".

Finally, solid and gas phases are distinguished by the definition that gases rather than solids are movable by diffusion. Accordingly, gas-phase mass equations have two boundary conditions (1-D dimension) and one initial condition (relative to time). Whereas, the solid-phase mass equation has only one initial condition and no boundary condition due to its immobility. The finite differential method has been applied to solve the coupled governing equations. Special techniques of numerical solutions (adoptable time step, implicit method to keep the solution stable) were adapted.

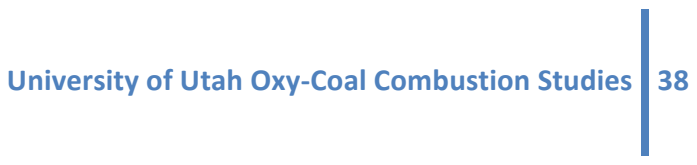




\section{Single coal particle combustion model}

The general gas-solid model is applied to the single coal particle combustion model. Here, the single coal particle combustion model shows the profiles of temperature and each species concentration with time and space as well as the details between coal particle and external environment (such as energy exchange (external heat convective, radiation), and mass exchange (external mass convective).Moreover, the details inside the coal particle are given, such as, internal heat conduction, internal mass diffusion, chemical heat generation, as well as chemical reactions. The single coal particle model can predict carbon consumption, species' evolution, ignition time, burn out time, as well as temperature distribution inside the coal particle. If ash is considered in the solid mass equations, then the ash deposition model can be set up. Then, the effect of the ash layer on the combustion process is more predictable.

The finite differential method is applied to solve coupled partial differential equations for obtaining the profiles of temperature and species concentrations along the particle radius and changes in time. According to the numerical method, the coal particle is subdivided into 60 equal segments. All of the parameters, such as gas diffusion coefficients, heat conductivity, coal particle porosity, the specific surface area, will update by iteration of the time step.

Energy equation. The right side of the transient energy equation is energy accumulation, which shows the relationship between temperature and time.

$$
\begin{gathered}
c_{p} \frac{\partial\left(\rho_{\text {char }} T\right)}{\partial t}=\frac{1}{r^{2}} \frac{\partial}{\partial r}\left(r^{2} \lambda_{\text {eff,char }} \frac{\partial T}{\partial r}\right)+\sum \Delta H_{i} \hat{r}_{i} \\
\left.\frac{\partial T}{\partial r}\right|_{r=0}=0,\left.\lambda_{\text {eff }} \frac{\partial T}{\partial r}\right|_{r=R}=\alpha \varepsilon_{r}\left(T_{s}-T_{b}\right)+\delta\left(T_{s}^{4}-T_{w}^{4}\right)
\end{gathered}
$$

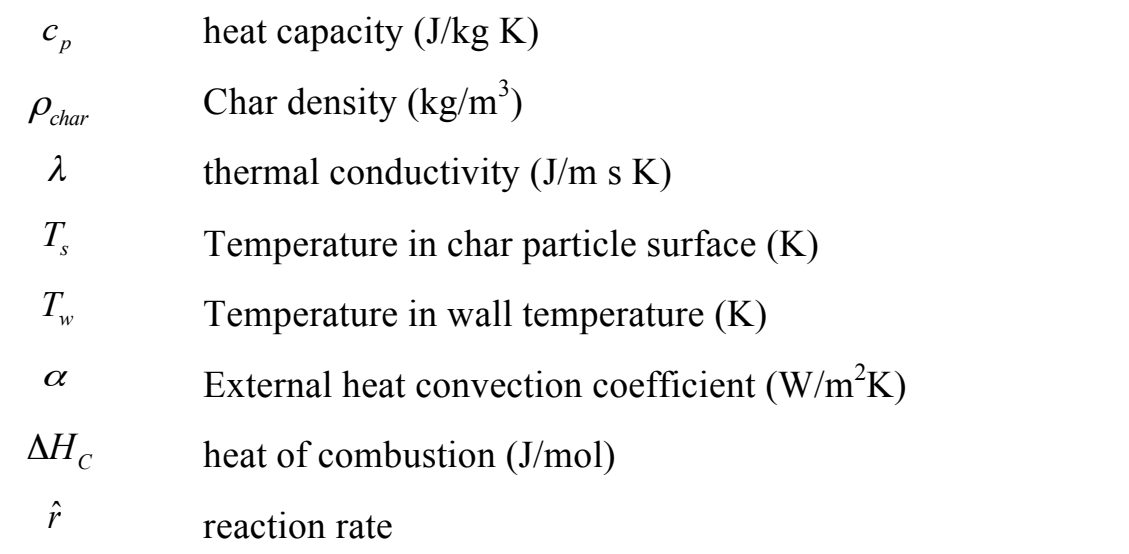

Two boundary conditions are located in the particle center and at the particle surface. In the center of the particle heat flux is zero. Also, another boundary condition in the coal particle surface is dependent on radiation and heat convection, which is a "gate" for energy exchange between the coal particle and the 
environment. If the surface temperature is lower than the surrounding gas phase temperature, then heat flux is into the coal particle. If the temperature of the coal particle is higher than the gas-phase temperature, the surrounding gas cools the coal particle. In addition, internal heat conduct and chemical heat generation re-distribute energy inside the coal particle.

Mass equations. In the coal particle combustion model, the number of species determines the number of mass equations. If $\mathrm{CO}, \mathrm{CO}_{2}$, and $\mathrm{O}_{2}$ as gas species are studied, as well as fixed carbon as the only solid phase species, then three gas-phase mass equations and one solid-phase mass equation are needed.

$$
\varepsilon_{s} \frac{\partial C_{C O}}{\partial t}=\frac{1}{r^{2}} \frac{\partial}{\partial r}\left(r^{2} D_{e f f, C O} \frac{\partial C_{C O}}{\partial r}\right)+\sum v_{i, C O} \hat{r}_{C O}
$$

The boundary condition for $\mathrm{CO}$ mass equation will be,

$$
\left.\frac{\partial c_{C O}}{\partial r}\right|_{r=0}=0,\left.D_{C O, e f f} \frac{\partial c_{C O}}{\partial r}\right|_{r=R}=k_{m}\left(c_{C O, s}-c_{C O, b}\right)
$$

The mass equation for $\mathrm{CO}_{2}$,

$$
\varepsilon_{s} \frac{\partial C_{\mathrm{CO}_{2}}}{\partial t}=\frac{1}{r^{2}} \frac{\partial}{\partial r}\left(r^{2} D_{e f f, C O_{2}} \frac{\partial C_{\mathrm{CO}_{2}}}{\partial r}\right)+\sum v_{i, \mathrm{CO}_{2}} \hat{r}_{\mathrm{CO}_{2}}
$$

The boundary condition

$$
\left.\frac{\partial c_{\mathrm{CO}_{2}}}{\partial r}\right|_{r=0}=0,\left.D_{\mathrm{CO}_{2}, \text { eff }} \frac{\partial c_{\mathrm{CO}_{2}}}{\partial r}\right|_{r=R}=k_{m}\left(c_{\mathrm{CO}_{2}, s}-c_{\mathrm{CO}_{2}, b}\right)
$$

The mass equation for $\mathrm{O}_{2}$,

$$
\varepsilon_{s} \frac{\partial C_{O_{2}}}{\partial t}=\frac{1}{r^{2}} \frac{\partial}{\partial r}\left(r^{2} D_{e f f, O_{2}} \frac{\partial C_{O_{2}}}{\partial r}\right)+\sum v_{i, O_{2}} \hat{r}_{O_{2}}
$$

The boundary condition:

$$
\left.\frac{\partial c_{O_{2}}}{\partial r}\right|_{r=0}=0,\left.D_{O_{2}, e f f} \frac{\partial c_{O_{2}}}{\partial r}\right|_{r=R}=k_{m}\left(c_{O_{2}, s}-c_{O_{2}, b}\right)
$$

Due to the solid phase' immobility, there is no boundary condition for the solid mass equation.

$$
\varepsilon_{s} \rho \frac{\partial \omega_{C}}{\partial t}=\sum v_{i, C} \hat{r}_{C} M_{C}
$$

$D_{e f f, j} \quad$ Effective diffusivity of component $\mathrm{j}$ through the solid pore $\omega_{C} \quad$ Mass fraction 
$M_{C} \quad$ Molecule weight of fixed carbon

Chemical reaction. Reactions are one of the most important factors in general gas-solid models. Here, two basic chemical reactions are considered in the combustion process. $\mathrm{O}_{2}$ reacts with fixed carbon, which is a heterogeneous reaction. It is a function of fixed carbon (the specific surface).

$$
\left[\frac{2\left(\frac{x}{y}+1\right)}{\frac{x}{y}+2}\right] C+O_{2} \stackrel{\hat{t}_{1}}{\longrightarrow}\left[\frac{2 \frac{x}{y}}{\frac{x}{y}+2}\right] C O+\left[\frac{2}{\frac{x}{y}+2}\right] C O_{2}
$$

If we consider $\frac{x}{y}=\eta$, then equation will be

$$
\begin{gathered}
{\left[\frac{2(\eta+1)}{\eta+2}\right] C+O_{2} \stackrel{\hat{r}_{1}}{\longrightarrow}\left[\frac{2 \eta}{\eta+2}\right] \mathrm{CO}+\left[\frac{2}{\eta+2}\right] \mathrm{CO}_{2}} \\
\eta=A_{\mathrm{CO} / \mathrm{CO}_{2}} \exp \left(\frac{-E_{\mathrm{CO} / \mathrm{CO}_{2}}}{R_{g} \cdot T}\right) \\
\hat{r}_{1}=k_{1} \bullet c_{\mathrm{O}_{2}} \bullet S
\end{gathered}
$$

Here, $S$ is the specific pore surface area, which is a function of the degree of carbon conversion $\left(X_{C}\right)$. $s=s_{0} \bullet\left(1-X_{C}\right) \cdot \sqrt{1-\psi \cdot \ln \left(1-X_{C}\right)}$

$s_{0} \quad$ Initial solid particle phase area

$\psi \quad$ Pore parameter

$X_{C} \quad$ Conversion of fix carbon

The reaction between $\mathrm{CO}$ and $\mathrm{O}_{2}$ is supposed to happen in coal particle pores, which is a homogenous reaction. Accordingly, this reaction is not dependent on the specific coal particle surface.

$$
\begin{gathered}
2 \mathrm{CO}+\mathrm{O}_{2} \stackrel{\hat{r}_{2}}{\longrightarrow} 2 \mathrm{CO}_{2} \\
\hat{r}_{2}=k_{2} \cdot c_{C O}^{2} \cdot c_{O_{2}}
\end{gathered}
$$

The reaction rate constant is a function of temperature by the Arrhenius equations.

$$
k_{i}=A_{i} \exp \left(\frac{-E_{i}}{R_{g} \cdot T}\right)
$$


Diffusion coefficient and heat conduction coefficient (inside char particle). The diffusivity (molecular diffusion coefficient) of $\mathrm{O}_{2}, \mathrm{CO}, \mathrm{CO}_{2}$ in gas surrounding the particle was calculated by the ChapmanEnskog equation.

$$
\begin{aligned}
\bigoplus_{A B} & =C T^{3 / 2} \frac{\sqrt{\left\{\left(M_{A}+M_{B}\right) /\left(M_{A} M_{B}\right)\right\}}}{P \sigma_{A B}^{2} \Omega_{D}} \\
\Omega_{D} & =\frac{A}{\left(T^{*}\right)^{B}}+\frac{C}{\exp \left(D T^{*}\right)}+\frac{E}{\exp \left(F T^{*}\right)}+\frac{G}{\exp \left(H T^{*}\right)} \\
T^{*} & =\frac{k_{b} T}{\varepsilon_{A B}}, \quad \sigma_{A B}=\frac{\sigma_{A}+\sigma_{B}}{2}, \varepsilon_{A B}=\sqrt{\varepsilon_{A} \varepsilon_{B}}
\end{aligned}
$$

Gas diffusivity's mixing rule comes from the Stefan-Maxwell diffusion equation. A simple formula was proposed by Wilke to evaluate the diffusion coefficient in multi-component gas mixtures. The equation was derived from the Stefan-Maxwell diffusion equation. The diffusion coefficient of species A to the remaining mixture, containing $\mathrm{B}, \mathrm{C}, \mathrm{D}$ and other species equation has the following formulation

$$
D_{A, m}=\frac{1-X_{A}}{\frac{X_{B}}{\bigoplus_{A B}}+\frac{X_{C}}{\bigoplus_{A C}}+\frac{X_{D}}{\bigoplus_{A D}}+\mathrm{L}}
$$

The effective diffusion coefficient of gaseous components within the particle pores were calculated considering both molecular diffusion and Knudsen diffusion, which should consider particle porosity and tortuosity factor.

$$
\begin{gathered}
D_{A, M}^{K}=D_{A, M} \frac{\varepsilon}{\varepsilon_{0}} \frac{\tau_{0}}{\tau} \\
\frac{\varepsilon}{\varepsilon_{0}}=1-\frac{(Z-1)\left(1-\varepsilon_{0}\right) X}{\varepsilon_{0}}
\end{gathered}
$$

$\varepsilon \quad$ porosity of coal particle

$\tau \quad$ Tortuosity

$D_{A, M}^{K} \quad$ Knudsen diffusion of species A

$Z \quad$ Ratio of molar volume of solid phase after reaction to that before reaction 
Subtask 3.6 - Ash Partitioning Mechanisms for Oxy-Coal Combustion with Varied Amounts of Flue Gas Recycle

\section{Drop-tube studies}

The formation of fine ash particles in the coal combustion system affects the emissions of toxic metals and the formation of furnace deposits. The formation of micron size aerosols during coal combustion is caused by mineral vaporization under local combustion conditions and subsequent particle formation. Quann and Sarofim (1982) and Senior and Flagan (1982) found that refractory metals vaporize during pulverized coal combustion, oxidize in the $\mathrm{O}_{2} / \mathrm{N}_{2}$ atmosphere and then diffuse away from the char particle. Diffused metallic oxide vapors encounter an $\mathrm{O}_{2}$ rich environment and reoxidize to become saturated vapors. The saturation ratios could be so high that the amount of ultrafine ash particles are formed by homogeneous nucleation. Then, these newly formed ultrafine particles grow in size by coagulation and heterogeneous condensation to become fine particles. The coarse size particles are mainly formed by char fragmentation and mineral coalescence. These large particles form directly from coal chars burnout. Padia et al. (1977) found that the coalescence of molten minerals is considered as the primary formation mechanism of the coarse mode. Examinations of partially oxidized coal particles revealed that the condensation and abundance of molten minerals on the existing char or ash particle surfaces dominated the formation of the larger size particles (Ramsden 1969, Kang et al. 1989). However, the mineral distribution inside char particles, strongly affected the coalescence process. At the experimental $\mathrm{O}_{2}$ concentration conditions considered in this study, char particles are probably oxidized mainly on the external surface first, and then the particle is formed by mineral condensation. A schematic presenting the current understanding of the ash particulate transformation is shown in Figure 13.

Introducing $\mathrm{CO}_{2}$ into the combustion environment and changing the combustion temperature would cause variations in vaporization, diffusion, oxidation, condensation and nucleation, all of which affect ash formation. Based on the hypothesis that was originally developed by Quann (1982) (Haynes et al. 1982), (Neville et al. 1981), (Kauppinen \& Pakkanen 1990), vaporization of the refractory oxides is governed by the following reaction: $\mathrm{MO}_{\mathrm{n}}(\mathrm{s})+\mathrm{CO}(\mathrm{g}) \leftrightarrow \mathrm{CO}_{2}(\mathrm{~g})+\mathrm{MO}_{\mathrm{n}-1}(\mathrm{~g})$. The vapor pressure of the vaporizing suboxides or metal $\left(\mathrm{MO}_{\mathrm{n}-1}\right)$ is determined by the equilibrium of the reaction between the refractory metal oxides $\mathrm{MO}_{\mathrm{n}}$ and $\mathrm{CO}$ inside the particle at high temperatures. Therefore, increasing $\mathrm{CO}_{2}$ concentrations could effectively reduce the formation of refractory metal oxides and reduce the yield of ash particulate.

The focus of this study was to investigate the effects of furnace temperature, coal type, and gas-phase conditions $\left(\mathrm{CO}_{2}\right.$ versus $\left.\mathrm{N}_{2}\right)$ on ash formation. Understanding the impact of oxy-fuel combustion on ash formation behavior is important for emission prediction, regulation and control. 


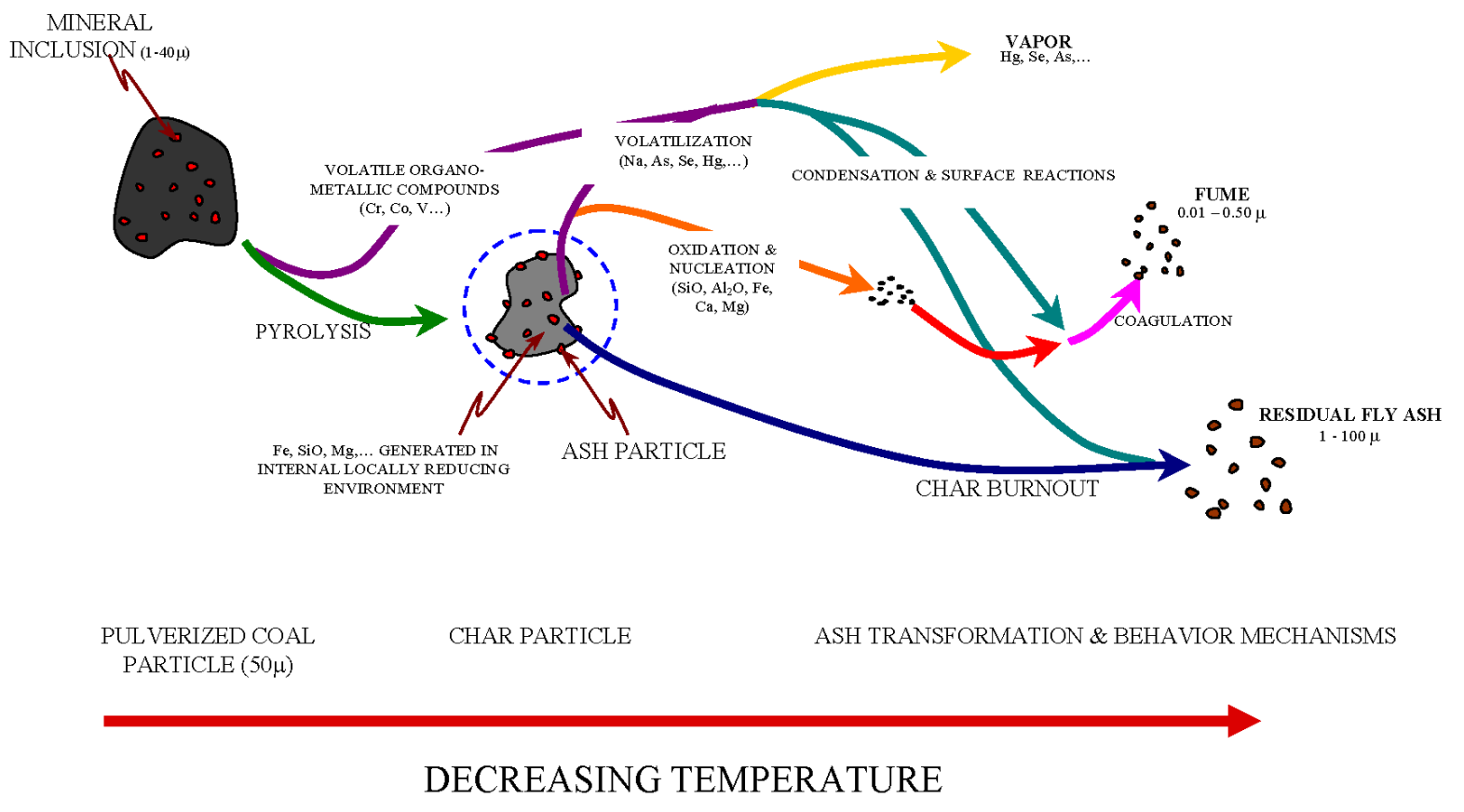

Figure 13. Transformation mechanisms in coal combustion.

\section{Modifications to experimental facilities}

The high-temperature drop tube (HTDT) furnace, built in 1974, was used for the ash formation studies. The furnace is capable of high-temperature, isothermal operation and well-controlled coal combustion and ash generation. It can operate at temperatures up to $1600 \mathrm{~K}$, with an independently variable residence time, particle-feeding rate, and gas composition.

The heat was provided by an Astro model 1000A-3560 graphite element furnace. The heated section was $430 \mathrm{~mm}$ long. The first $170 \mathrm{~mm}$ served as a preheat section. An alumina honeycomb was set centrally at the last $50 \mathrm{~mm}$ of the preheat section to ensure laminar flow. The pulverized coal was fed into the furnace at an approximate rate of $1-2 \mathrm{~g} / \mathrm{hr}$. The furnace pressure was maintained at ambient pressure during all tests.

Some minor repairs were completed before experiments began, namely, collection probe remanufacturing, furnace modifications, and collection system alignment maintenance. The collection probe was more than 30 years old and had warped over the years. Its axis was no longer straight and did not align with the injection probe, making it unable to provide high collection efficiency. To obtain $85+\%$ collection efficiency, a new collection probe was designed and built (Figure 14). As compared to the old collection probe, the diameter of the new probe was increased from 1.25 " to 1.75 ", to increase the collecting area. As the products passed through the probe, they were quenched and diluted with $\mathrm{N}_{2}$.

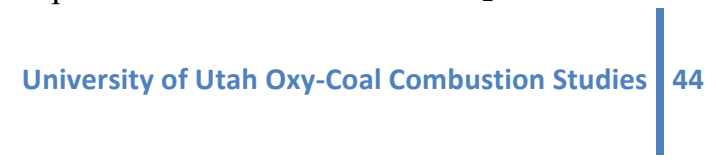




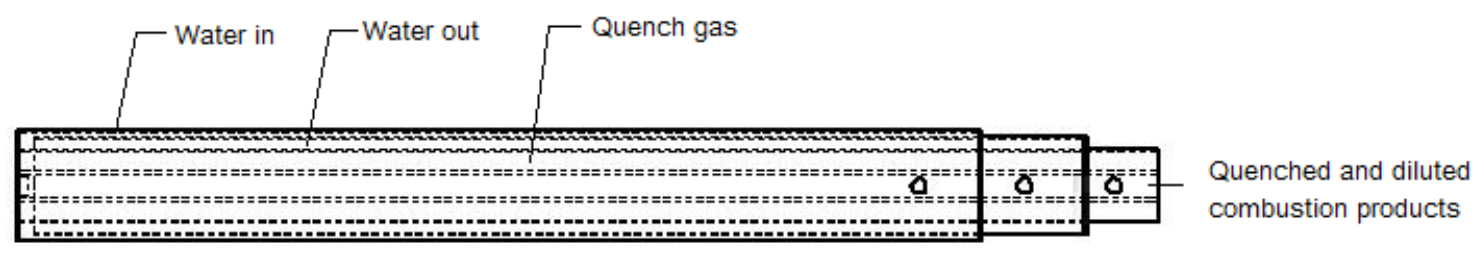

Figure 14. The side view of the collection probe.

The top and bottom connecting flanges, which had recirculation water for cooling, were re-fabricated to meet the larger O.D. alumina muffle tube, which was 3.25". The flanges were milled to have an I.D. of 3.27", allowing the outer alumina tube to move smoothly with the flanges. Unfortunately, the bottom flange had a water leak under high water pressure conditions after its four constructions. So, a new same flange was built to replace this broken one.

The old collection probe had just one supporting flange making the central line difficult to maintain. One stub flange was welded to the supporting flange and then connected to the other stub flange by O-ring and clamps. The new flange was constructed from aluminum and not water cooled to maintain a low weight. A more precise positioning of the collection probe can be obtained by these two flanges. The final collection efficiency reached over $90 \%$ after HTDT modifications.

Finally, the cooling water circulation system had been running for years without a thorough cleanup. Crystallization of solid salts, oxides and hydroxides from the minerals in water, such as calcium and magnesium caused fouling. The fouling reduced the water flow and thermal conductivity efficiency, increased pressure drop and energy expenditure, and introduced additional heat to the system. Chemical and mechanical cleaning processes were performed to remove deposits from the cooling water circulation system. In addition, the pipes and filters that had serious deposition were replaced. After the cleanup, the cooling water circulation system efficiency improved significantly. A high temperature test confirmed that the cooling water circulation system can protect HTDT running up to $1600 \mathrm{~K}$.

Figure 15 shows the overview of HTDT furnace with sampling system after modifications. 


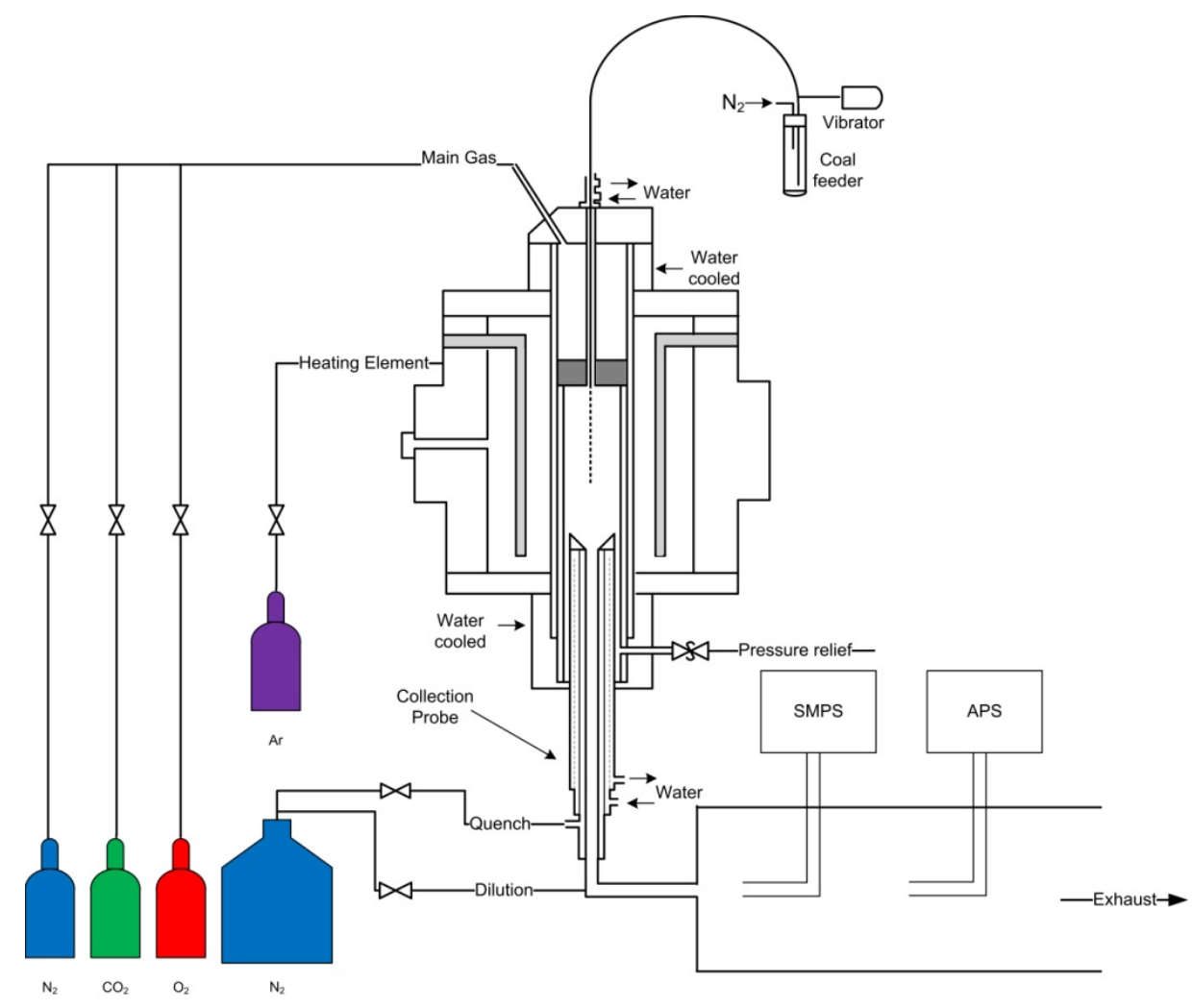

Figure 15. The overview of drop tube furnace.

\section{Construction of new drop-tube reactor}

Because of the age of the current reactor, about 40 years old, and other limitations, the investigators have built a new drop-tube furnace. The reactor's age makes it difficult to find repair parts and material. This new reactor allows operation at higher temperatures and with longer reaction times to ensure complete burnout of the coal, which has been a problem in the data gathered in the old system. The new system is a hybrid of the drop tube at EPA, Research Triangle Park and an existing drop tube at the University of Utah, which is being used in another laboratory.

The new furnace has three separate zones each with a maximum temperature of $1500 \mathrm{C}$. Each zone is 12 " long plus 6" of insulation on top and bottom for a total length of 48" (Figure 16 and Figure 17). The clam-shell configuration allows for easy access and removal of the inner reaction tube. The three furnace zones allow for greater flexibility as well as minimization of heat loss at the entrance and exit of the system. This size and capacity was chosen to allow for a residence time of approximately 2 sec and Reynolds number of 340. Using mass flow controllers (MFCs) with a wider range (up to 12 slpm each) and more flexible coal feed rates $(0-2 \mathrm{~g} / \mathrm{hr})$ should allow much greater range of these parameters. Four MFCs will meter the purge and reaction gases. An outer ceramic liner is 3.125 " id x 60" long, and the 
inner reaction tube is 2.0 " id $\mathrm{x} 48$ " long. This allows for the introduction of reaction gases to the bottom so they can flow between these two for preheating.

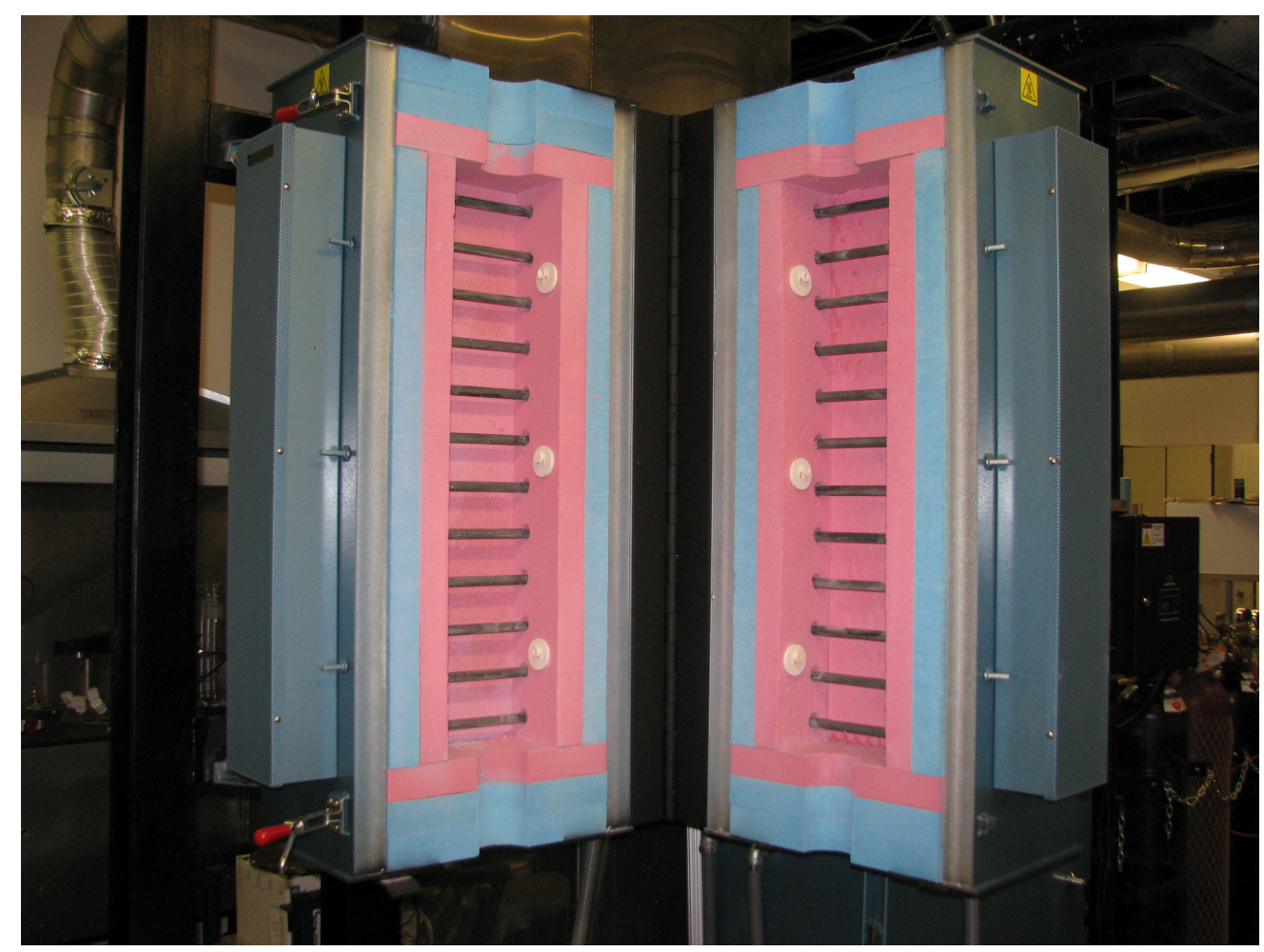

Figure 16. Clam shell furnace open to show insulation and heating elements.

We designed the downstream flanges to accept a variety of probes, filters, and cyclones. These have quick mating flanges that use wing nut clamps to reduce the work involved in preparation or maintenance of the accessories. Elimination of many o-rings and a cooling system helped reduce overall complexity.

The furnace has been installed on its frame, heating elements installed and all power connections are finished. The furnace has been turned on and warmed up. In addition, the gas cylinder rack is finished. 


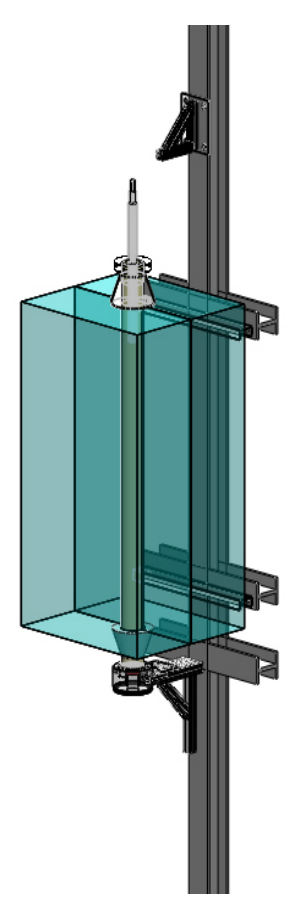

Figure 17. Overall view of the new drop-tube furnace.

Experiments with simulated flue gases for Utah Skyline, PRB and Illinois \#6 coals

Two bituminous coals and one sub-bituminous coal were studied: Utah Skyline, Illinois \#6 and PRB, respectively. The coals were pulverized and sieved to $52-72 \mu \mathrm{m}$ in the laboratory. The properties of the coals are summarized in Table 6, provided by Huffman Laboratories, Inc. The coals were dried at $105{ }^{\circ} \mathrm{C}$ before testing to ensure continuous and stable feeding. Dried coal was introduced from the top of the furnace by a vibrating feeder at approximately $1-2 \mathrm{~g} / \mathrm{hr}$. Pulverized coals were burned in the HTDT furnace. The ash particulates generated from coal combustion were isokinetically collected and quenched by collection probe.

The incomplete combustion of Utah Skyline coal was observed in previous experiments, resulting in soot with ash product. The residence time was increased by decreasing the coal feed rate, gas flow rate (still keeping high excess $\mathrm{O}_{2}$ ) and increasing the reaction zone (adjusting the position of the collection probe) to ensure that the coal combusted completely. Analysis with a photo-acoustic analyzer confirmed that there was no soot in the particulate collected in the long residence time experiments. The residence time was approximately $0.91 \mathrm{~s}$ to achieve complete the combustion. 
Table 6. Coal analysis data for Utah Skyline, PRB and Illinois \#6 coals.

\begin{tabular}{|c|c|c|c|c|c|c|c|c|c|c|c|}
\hline & $\begin{array}{c}\text { LOD } \\
105^{\circ} \mathrm{C} \\
\end{array}$ & $\begin{array}{c}\text { Ash } \\
750{ }^{\circ} \mathrm{C}\end{array}$ & $\mathrm{C}$ & $\mathrm{H}$ & $\mathrm{N}$ & $\mathrm{S}$ & $\begin{array}{l}\text { O by } \\
\text { diff. }\end{array}$ & $\begin{array}{l}\text { Volatile } \\
\text { Matter }\end{array}$ & $\begin{array}{l}\text { Fixed } \\
\text { Carbon }\end{array}$ & HHV & \\
\hline & $\%$ & $\%$ & $\%$ & $\%$ & $\%$ & $\%$ & $\%$ & $\%$ & $\%$ & BTU/lb & \\
\hline $\begin{array}{c}\text { Utah } \\
\text { Skyline }\end{array}$ & 3.18 & 8.83 & 70.6 & 5.41 & 1.42 & 0.53 & 13.21 & 38.6 & 49.39 & 12606 & \\
\hline PRB & 23.69 & 4.94 & 53.72 & 6.22 & 0.78 & 0.23 & 34.11 & 33.36 & 38.01 & 9078 & \\
\hline $\begin{array}{c}\text { Illinois } \\
\# 6 \\
\end{array}$ & 9.65 & 7.99 & 64.67 & 5.59 & 1.12 & 3.98 & 16.65 & 36.78 & 45.58 & 11598 & \\
\hline \multicolumn{12}{|c|}{ Ash Analysis } \\
\hline & $\mathrm{Al}$ & $\mathrm{Ca}$ & $\mathrm{Fe}$ & $\mathrm{Mg}$ & $\mathrm{Mn}$ & $\mathrm{P}$ & $\mathrm{K}$ & $\mathrm{Si}$ & $\mathrm{Na}$ & $\mathrm{S}$ & $\mathrm{Ti}$ \\
\hline & $\begin{array}{c}\text { as } \\
\mathrm{Al}_{2} \mathrm{O}_{3}\end{array}$ & as $\mathrm{CaO}$ & $\begin{array}{c}\text { as } \\
\mathrm{Fe}_{2} \mathrm{O}_{3}\end{array}$ & $\begin{array}{c}\text { as } \\
\mathrm{MgO}\end{array}$ & $\begin{array}{c}\text { as } \\
\mathrm{MnO}\end{array}$ & $\begin{array}{c}\text { as } \\
\mathrm{P}_{2} \mathrm{O}_{5} \\
\end{array}$ & $\begin{array}{c}\text { as } \\
\mathrm{K}_{2} \mathrm{O}\end{array}$ & as $\mathrm{SiO}_{2}$ & $\begin{array}{c}\text { as } \\
\mathrm{Na}_{2} \mathrm{O}\end{array}$ & as $\mathrm{SO}_{3}$ & $\begin{array}{c}\text { as } \\
\mathrm{TiO}_{2} \\
\end{array}$ \\
\hline $\begin{array}{c}\text { Utah } \\
\text { Skyline }\end{array}$ & 14.52 & 6.11 & 5.09 & 1.39 & 0.02 & 0.59 & 0.57 & 60.89 & 1.41 & 2.33 & 0.88 \\
\hline PRB & 14.78 & 22.19 & 5.2 & 5.17 & 0.01 & 1.07 & 0.35 & 30.46 & 1.94 & 8.83 & 1.3 \\
\hline $\begin{array}{c}\text { Illinois } \\
\# 6\end{array}$ & 17.66 & 1.87 & 14.57 & 0.98 & 0.02 & 0.11 & 2.26 & 49.28 & 1.51 & 2.22 & 0.85 \\
\hline
\end{tabular}

LOD: Loss on drying determined in air at $105^{\circ} \mathrm{C}$ for one hour and is reported on an as received sample weight basis. HHV: higher heating value.

Ash analysis results are reported on an ashed sample weight basis after stage ashing in air overnight at $750^{\circ} \mathrm{C}$.

An $\mathrm{O}_{2} / \mathrm{CO}_{2}$ mixture was used as the oxidant in the HTDT experiments to simulate $\mathrm{O}_{2} /$ recycled flue gas combustion, and these results were compared with the $\mathrm{O}_{2} / \mathrm{N}_{2}$ combustion conditions. During the experiments, the furnace temperature was set at $1373 \mathrm{~K}$ and $1500 \mathrm{~K}$ to study the effect of the combustion temperature on PSDs. Two $\mathrm{O}_{2}$ concentrations, $21 \%$ and $31.5 \%$, were used to investigate the gas composition effects. The experimental conditions are shown in Table 7.

Table 7. Combustion conditions.

\begin{tabular}{|c|c|c|}
\hline Furnace Temperature & Gas Composition & Oxygen Ratio \\
\hline \multirow{3}{*}{$1373 \mathrm{~K}$} & $\mathrm{O}_{2} / \mathrm{N}_{2}$ & $21 \%$ \\
\cline { 2 - 3 } & \multirow{2}{*}{$\mathrm{O}_{2} / \mathrm{CO}_{2}$} & $31.5 \%$ \\
\cline { 2 - 3 } & $\mathrm{O}_{2} / \mathrm{N}_{2}$ & $21 \%$ \\
\hline \multirow{3}{*}{$1500 \mathrm{~K}$} & $\mathrm{O}_{2} / \mathrm{CO}_{2}$ & $21.5 \%$ \\
\cline { 2 - 3 } & & $31.5 \%$ \\
\cline { 2 - 3 } & & $21 \%$ \\
\hline
\end{tabular}

\section{Analytical techniques}

A TSI SMPS model 3080 and a TSI Aerosol Particle Sizer (APS) model 3321 were used for PSDs investigation. The SMPS has a theoretical measurement range of 14.3 to $673.2 \mathrm{~nm}$. The APS was also 
applied to measure particle sizes ranging from $532 \mathrm{~nm}$ to $20 \mu \mathrm{m}$. Combining the SMPS and APS results yielded a measurement range of particles size from $14.3 \mathrm{~nm}$ to $20 \mu \mathrm{m}$. The measuring methods of these two instruments are different. For the SMPS, the sample passes through a charger, which imparts a bipolar equilibrium charge to the particles. The charged aerosol enters the differential mobility analyzer where a fraction of the particles is selected according to its electrical mobility, which correlates with aerodynamic particle size. The selected fraction of the particles is counted in the condensation particle counter.

The APS counts particles by measuring the acceleration of aerosol particles in response to the accelerating flow field created by the inlet nozzle. The particle response to the accelerating flow field is dependent on its inertia and aerodynamic size. As the particle leaves the nozzle, its time-of-flight over a given distance depends on its aerodynamic size. The time-of-flight of the particle is found from the scattered light, which appears when the particle crosses the laser beams.

A quarter inch sampling probe was placed down to the collection probe outlet to obtain quenched sample. All samples drawn through the sampling probe were drawn and diluted with clean air in a dilution tunnel, in which the sample flow rate was held constant while the clean air flow rate varied, resulting in varied dilution ratios. In these experiments, two dilution ratios were tested, 1:17.8 and 1:22.2. The dilution tunnel contained sample ports for the particle sizing instruments (SMPS and APS).

Gravimetric measurements were collected to confirm the PSDs. Samples extracted by the collection probe from the furnace were routed through a Berner Low Pressure Impactor (BLPI) (Hillamo and Kauppinen 1991) using a $\mathrm{N}_{2}$ dilution gas and vacuum pump. The bottom stage of the BLPI worked as a sonic orifice to control the total flow rate flowing through the BLPI. During the experiments, the total gas flow rate for BLPI was maintained at a constant value of $25.4 \mathrm{slpm}$ (standard liters per minute). The combustion gas was diluted at 1:12.7 in BLPI. The BLPI uses low pressure and high jet velocities for particles size segregation, which collects particles on 11 stages with particle sizes as follows (50\% aerodynamic cutoff diameter - in microns): 15.7 (stage 11), 7.33, 3.77, 1.98, 0.973, 0.535, 0.337, 0.168, 0.0926, 0.0636 and 0.0324 (stage 1, bottom).

Particulate samples were collected on greased alumina foils in the BPLI for gravimetric measurements. To collect sufficient mass of ultrafine particles for measurements, the BLPI was operated in two steps. First, a cyclone was attached to the outlet of collection probe to remove particles larger than $1 \mu \mathrm{m}$, which were collected from stage 7 to stage 11 . Operation with cyclone lasted about 180 min to ensure sufficient ultrafine particles were collected on the bottom stages, without overloading the larger particle stages. Then, the cyclone was removed to allow the BLPI collected larger particles on the upper stages. The whole PSD was obtained by combining results from both BLPI operating modes.

Particulates were also collected on polycarbonate membranes in the BLPI for morphology and elemental analysis. The BLPI was applied for 15 - 20 min to allow a few particles to deposit on each impactor stage. Samples were examined by a FEI Nova Nano SEM and an Energy Dispersive X-ray detector (EDAX). The SEM ran at 0.3 torr water vapor low vacuum with vCD detector for morphology observation. The University of Utah Oxy-Coal Combustion Studies 50 
accelerating voltage used for morphology was $7 \mathrm{kV}$, the beam current was set to $22 \mathrm{pA}$, and the working distance was $6 \mathrm{~mm}$. This small beam current and short working distance would improve imaging resolution at high magnifications. LVD detector was replaced by $\mathrm{vCD}$ detector for elemental analysis.

The accelerating voltage increased to $15 \mathrm{kV}$ for identification of high atomic number element, such as $\mathrm{Fe}$. Seven main elemental oxides were analyzed for the eleven ash samples, including major elements, Na, $\mathrm{Mg}, \mathrm{Al}, \mathrm{Si}, \mathrm{S}, \mathrm{Ca}$ and $\mathrm{Fe}$ (reported as oxides). An elemental size distribution of PM generated by burning Utah Skyline, PRB and Illinois $\# 6$ coals at $1500 \mathrm{~K}$ in $\mathrm{O}_{2} / \mathrm{N}_{2}$ and $\mathrm{O}_{2} / \mathrm{CO}_{2}$ atmospheres were studied.

Elemental distribution is presented as the weight percentage of the major elemental oxides as a function of particle size, and the mass distributions of particulates on stage 1 to 10 are also presented.

\section{Coal char particle combustion simulation}

The particle temperature changes at different oxygen concentrations (Suriyawong et al. 2006). Thus, a model was developed to determine relative coal char temperature differences. Since the intent of the model was not to fully describe the conditions but to show differences between conditions, a spherical, homogeneous particle was considered, reactions in the boundary layer were ignored, and no temperature gradient within the particle was used (Badzioch et al. 1964, Carslaw and Jaeger 1959). In this calculation the only reaction considered at the char particle surface was the direct oxidation of carbon to form carbon monoxide, $\mathrm{C}+\frac{1}{2} \mathrm{O}_{2} \rightarrow \mathrm{CO}$, following the approach of Field (1969) and Gavalas (1981), and supported by the findings of Tognotti et al. (1991). Gas-phase oxidation of $\mathrm{CO}$ to $\mathrm{CO}_{2}$ was assumed to occur in the free stream and therefore did not enter into the energy and material balance equations.

The reaction considered in the simulation was:

$\mathrm{C}(\mathrm{s})+\frac{1}{2} \mathrm{O}_{2}(\mathrm{~g}) \rightarrow \mathrm{CO}(\mathrm{g})($ Geier et al. 2010).

Based on the work of Haynes et al., recent computational results suggest that the endothermic char gasification reaction, $\mathrm{C}+\mathrm{O} \rightarrow \mathrm{CO}$, in oxy-fuel combustion is reasonable for the particle combustion temperature prediction.

The following heat balance expression was used, which gives the rate of change of particle temperature with time:

$\mathrm{m}_{\mathrm{p}} \mathrm{C}_{\mathrm{p}} \frac{\mathrm{dT} \mathrm{p}}{\mathrm{dt}}=-\varepsilon \sigma \mathrm{A}_{\mathrm{p}}\left(\mathrm{T}_{\mathrm{p}}^{4}-\mathrm{T}_{\mathrm{w}}^{4}\right)-\mathrm{hA} \mathrm{A}_{\mathrm{p}}\left(\mathrm{T}_{\mathrm{p}}-\mathrm{T}_{\mathrm{g}}\right)+\Delta \mathrm{H} \gamma$

(1) (3) (4)

The term (1) represents the change of particle temperature with time.

$$
M_{p}=\rho \frac{4}{3} \pi d_{p}^{3}
$$


where

$\mathrm{m}_{\mathrm{p}}$ : particle mass $(\mathrm{kg})$,

$\mathrm{d}_{\mathrm{p}}$ : particle diameter $(\mathrm{m})$,

$\rho$ : particle density $\left(\mathrm{kg} / \mathrm{m}^{3}\right)$,

$\mathrm{C}_{\mathrm{p}}$ : specific heat of the particle $(\mathrm{J} / \mathrm{kg} \cdot \mathrm{K})$,

$\mathrm{T}_{\mathrm{p}}$ : particle surface temperature $(\mathrm{K})$,

t: time (s).

The term (2) gives heat loss by radiation, where

$\varepsilon$ : particle emissivity, usually uses 0.8 for coal particle,

$\sigma$ : the Stefan-Boltzmann constant; its value is $5.67051 \times 10^{-8} \mathrm{~W} / \mathrm{m}^{2} \cdot \mathrm{K}^{4}$,

$A_{p}$ : the surface area of the particle $\left(\mathrm{m}^{2}\right), A_{p}=4 \pi d_{p}^{2}$,

$\mathrm{T}_{\mathrm{w}}$ : wall temperature $(\mathrm{K})$.

The term (3) is convective heat loss of the particle, where

$h$ : the convective heat transfer coefficient of the process, $\left(\mathrm{W} / \mathrm{m}^{2} \cdot \mathrm{K}\right)$.

The term (4) is heat generated from chemical reaction, where

$\Delta \mathrm{H}$ : heat release at partcle surface per unit mass of char combustion

$\mathrm{C}(\mathrm{s})+\frac{1}{2} \mathrm{O}_{2}(\mathrm{~g}) \rightarrow \mathrm{CO}(\mathrm{g}), \mathrm{kJ} / \mathrm{kg}$.

$\gamma$ : overall reaction rate, $\mathrm{kg} / \mathrm{s}$.

Both the diffusion coefficient and reaction coefficient were considered for the burning rate computation.

The thermodynamic properties of the char particle and bulk gas mixture were calculated at each change in temperature. The reaction rates of these three coals were assumed to be the same; the differences among these three coals were mainly due to the physical properties and heating values.

\section{Studies in the OFC}

Recycled flue gas is necessary in retrofit situations to maintain similar heat transfer performance to air firing under oxy-fired conditions. The recycle allows the flame temperature to be modulated from the very high temperatures that would occur when coal is burned using oxygen rather than air, by introducing a mixture containing diluent $\mathrm{CO}_{2}$ from the flue gas. An inlet oxidant mixture containing $68 \%$ recirculated flue gas and $32 \% \mathrm{O}_{2}$ achieves similar theoretical adiabatic flame temperatures to those produced when the fuel is burned with air. Therefore $32 \% \mathrm{O}_{2}$ in the oxidant is used as a base condition when exploring the effect of variations of recycled flue gas amounts on ash partitioning mechanisms. In this work the focus is on comparing the ash aerosol partitioning mechanisms under conditions of purified flue gas recycle containing no impurities (simulated by once-through $\mathrm{CO}_{2}$ ) to those when the recycled flue gas is dirty and contains impurities.

Recycled flue gas composition can vary, based on numerous "contaminants" present in the $\mathrm{CO}_{2}$, namely: water vapor, $\mathrm{SO}_{\mathrm{x}}$, particulate matter. These impurities depend also on coal composition. One can ask

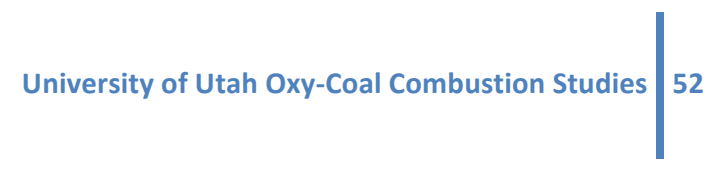


whether these recycled contaminants significantly affect ultrafine (15-640nm) PSDs and/or ash aerosol size-segregated compositions. To address this question, a modified laboratory combustor with a complex FGR system had first to be designed and built to allow for systematic variation of FGR conditions

\section{Experimental facilities}

Figure 18 depicts the oxy-fuel furnace prior to modifications required to introduce recycled flue gas into the burner. This is the configuration used for all the tests with "once-through $\mathrm{CO}_{2}$ ", simulating purified flue gas. In this case, fresh $\mathrm{CO}_{2}$ was mixed with $\mathrm{O}_{2}$ and introduced into the burner. The furnace is rated for a maximum firing rate of $100 \mathrm{~kW}$ and is designed to be representative of full-scale units insofar that it employs self sustaining combustion of coal with similar residence times, temperature histories, and particle and gas species concentrations as in full scale systems. This is thought to be especially important in ash partitioning mechanisms. Although large enough to simulate a practical system, the combustor is small enough to allow systematic variation of parameters, allowing the experimentation described below. Figure 18 also shows the location of the sample point at which ash aerosol samples were withdrawn.

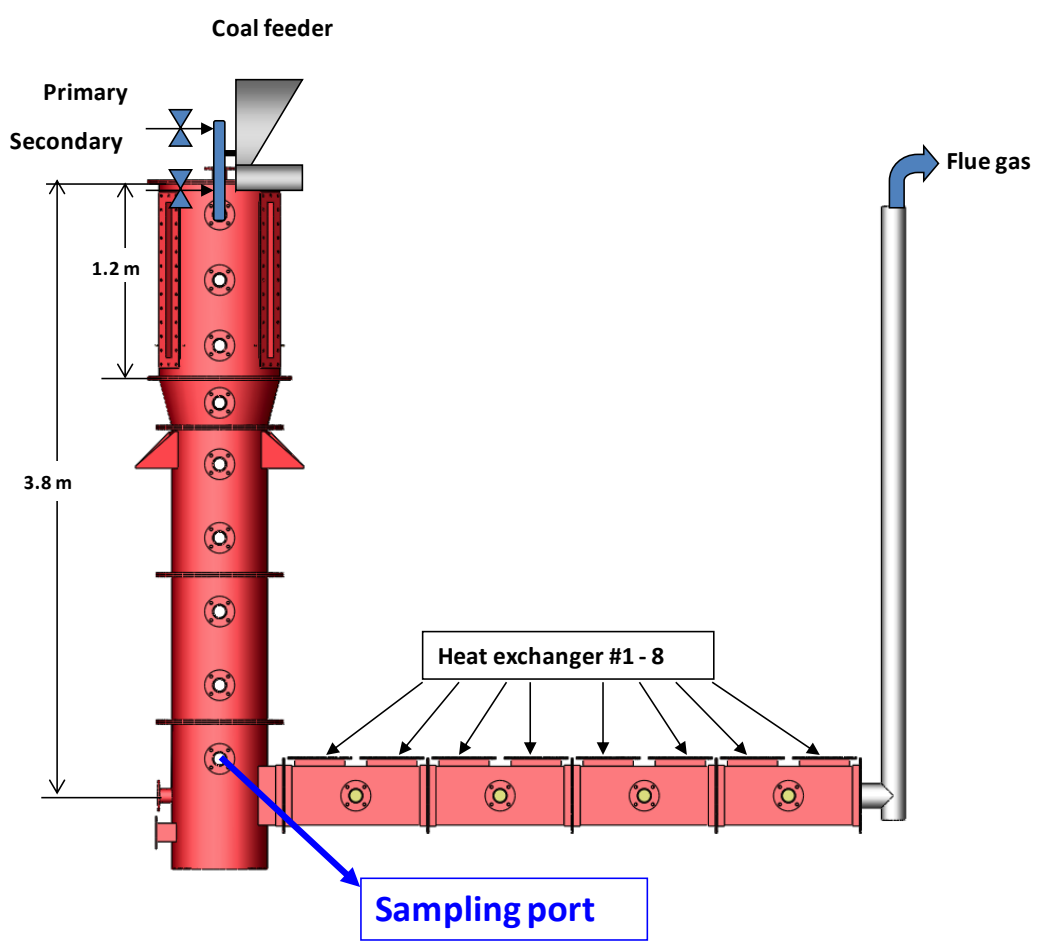

Figure 18. OFC prior to modifications for flue gas recycle.

Figure 19 shows a schematic of the OFC with the new flue gas recycle system in place. The new system contains two blowers: 
1. a high temperature vastly oversized blower with a $95 \%$ recycle loop from which approximately $5 \%$ of the compressed gas is withdrawn to the furnace

2. a properly sized blower that handles cleaned gas that has passed through a baghouse to remove essentially all the super micron large particles.

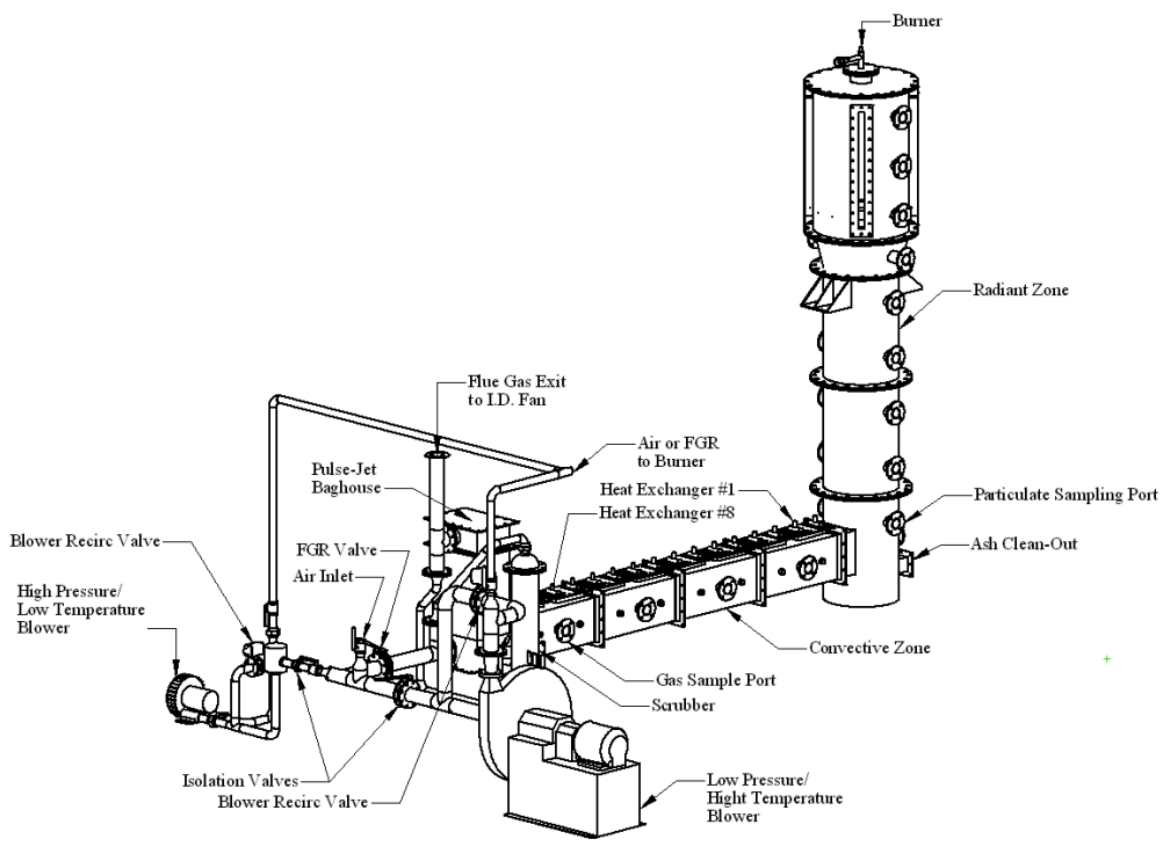

Figure 19. OFC with new FGR system installed.

A schematic of the overall process is shown in Figure 19. Recycle loops around each blower were utilized in order to help balance pressures throughout the system. While this does add complexity, it was critical for stable operation of the system with minimal air in-leakage. The valve on the recycle loop for the high-pressure blower was automated to provide control of the pressure of the blower, while the valve on the low temperature blower recycle loop was a manual valve kept fully open. The isolation valve on the inlet of the large blower was automated and used to provide the necessary pressure drop to meter the flow of the flue gas drawn out of the furnace. Initially, the valve on the recycle loop of the large lowpressure valve had been automated, but testing proved that the controller should be moved to the blower inlet for better control.

The condenser and scrubber unit could be filled with a slurry of lime and water to provide sulfur removal, or just a water bath, to provide the necessary cooling to condense much of the water vapor in the flue gas. This system could also be bypassed, and the bags removed from the bag house to provide an untreated gas stream for flue gas recycle. In these instances, a hydrometer was used to record the percent moisture content of the wet recycled flue gas. 
Due to space and temperature constraints, the blowers and the accompanying valves were located outside of the research building as shown in Figure 20, which shows both blowers installed, as a basis for comparison.

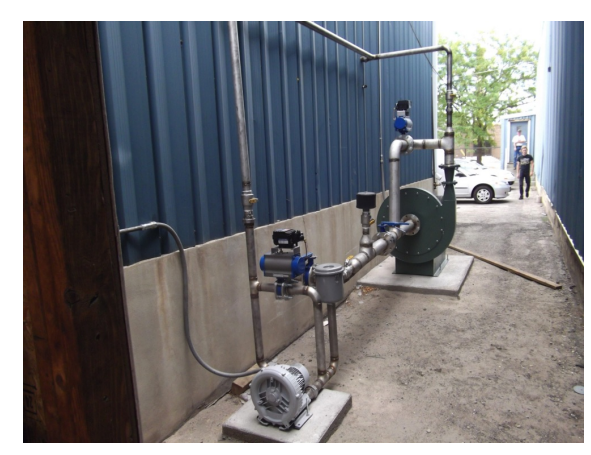

Figure 20. Blower configuration.

The same three coals, i.e. Utah Skyline bituminous coal, Illinois bituminous coal, and PRB subbituminous coal, were tested with once-through $\mathrm{CO}_{2}$ as well as with FGR, with an inlet oxidant mixture of $68 \%$ flue gas or pure $\mathrm{CO}_{2}$, and $32 \% \mathrm{O}_{2}$. Rather than vary the oxygen content, as was originally planned, but was not possible because of temporary operational concerns, it was decided to extend the study to three coals and apply different FGR configurations to each so that the impacts of varying flue gas composition on ash partitioning could also be well investigated. Coal composition effects turn out to be important. The effect of varying $\mathrm{O}_{2}$ concentration was reserved for a later report. Here each coal was tested under two different FGR configurations. One was the configuration that used FGR without any flue gas cleaning devices (denoted as "Dirty FGR"). The other configuration was different for different coals.

For the Utah coal, only a baghouse was used to remove particulates in the flue gas, as shown in Figure 21. For the Illinois coal, both the baghouse and a scrubber were used to remove particulates, moisture and sulfur oxides (Figure 22). As for the PRB coal, both the baghouse and a condenser were used to remove particulates and moisture in the flue gas (Figure 23). This configuration was denoted as "Cleaned FGR". For each coal, the same firing rate was used for different FGR configurations, so that the impacts of different FGR on ash chemistry can be compared.

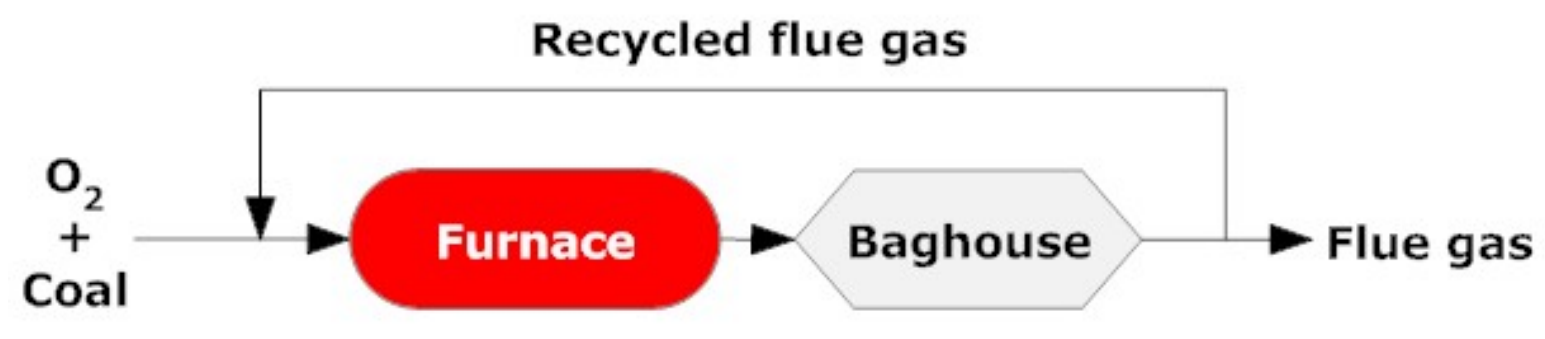

Figure 21. Cleaned FGR for the Utah coal.

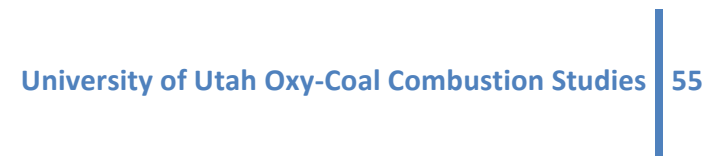




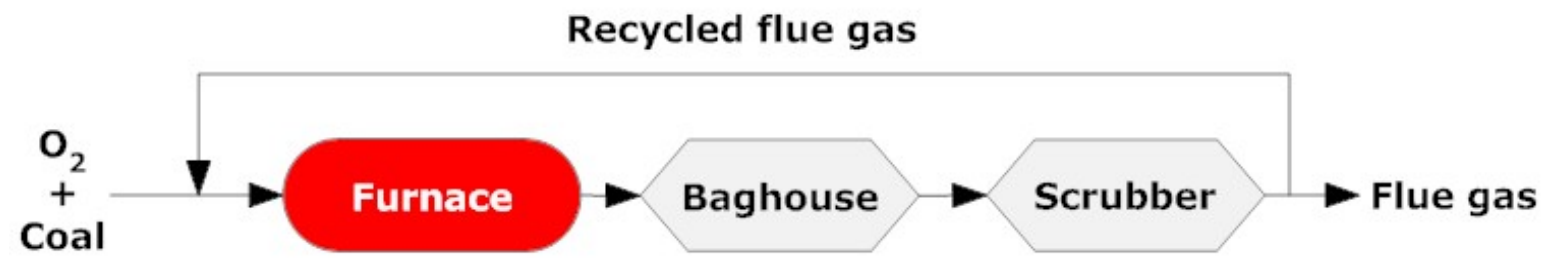

Figure 22. Cleaned FGR for the Illinois coal.

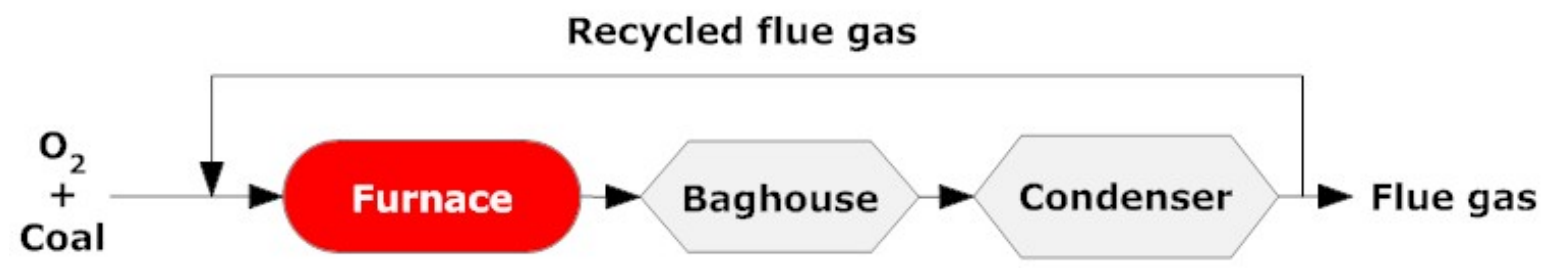

Figure 23. Cleaned FGR for the PRB coal.

Coal compositions

Coal compositions are shown below on Table 8. Important variables that influence the results are the Moisture Content (LOD) and the calcium content of the PRB coals and the sulfur content of the Illinois coal.

Table 8. Coal Analysis (on an as received basis) in percentages unless otherwise noted.

\begin{tabular}{|c|c|c|c|c|c|c|c|c|c|c|c|}
\hline Sample & LOD & Ash & C & $\mathbf{H}$ & $\mathbf{N}$ & $\mathbf{S}$ & $\begin{array}{l}O \\
\text { (diff) }\end{array}$ & $\begin{array}{l}\text { Volatile } \\
\text { Matter }\end{array}$ & $\begin{array}{l}\text { Fixed } \\
\text { Carbon }\end{array}$ & $\begin{array}{l}\text { HHV } \\
\text { BTU/lb }\end{array}$ & \\
\hline Utah & 3.18 & 8.83 & 70.60 & 5.41 & 1.42 & 0.53 & 13.21 & 38.60 & 49.39 & 12606 & \\
\hline PRB & 23.69 & 4.94 & 53.72 & 6.22 & 0.78 & 0.23 & 34.11 & 33.36 & 38.01 & 9078 & \\
\hline Illinois & 9.65 & 7.99 & 64.67 & 5.59 & 1.12 & 3.98 & 16.65 & 36.78 & 45.58 & 11598 & \\
\hline \multicolumn{12}{|c|}{ Ash Analysis } \\
\hline & $\begin{array}{l}\mathbf{A l} \\
\text { as } \\
\mathrm{Al}_{2} \mathrm{O}_{3}\end{array}$ & $\begin{array}{l}\mathbf{C a} \\
\text { as } \\
\mathrm{CaO}\end{array}$ & $\begin{array}{l}\mathbf{F e} \\
\text { as } \\
\mathrm{Fe}_{2} \mathrm{O}_{3}\end{array}$ & $\begin{array}{l}\mathbf{M g} \\
\text { as } \\
\mathrm{MgO}\end{array}$ & $\begin{array}{l}\text { Mn } \\
\text { as } \\
\mathrm{MnO}\end{array}$ & $\begin{array}{l}\mathbf{P} \\
\text { as } \\
\mathrm{P}_{2} \mathrm{O}_{5}\end{array}$ & $\begin{array}{l}\mathbf{K} \\
\text { as } \mathrm{K}_{2} \mathrm{O}\end{array}$ & $\begin{array}{l}\mathbf{S i} \\
\text { as } \mathrm{SiO}_{2}\end{array}$ & $\begin{array}{l}\mathbf{N a} \\
\text { as } \mathrm{Na}_{2} \mathrm{O}\end{array}$ & $\begin{array}{l}\mathbf{S} \\
\text { as } \mathrm{SO}_{3}\end{array}$ & $\begin{array}{l}\mathbf{T i} \\
\text { as } \\
\mathrm{TiO}_{2}\end{array}$ \\
\hline Utah & 14.52 & 6.11 & 5.09 & 1.39 & 0.02 & 0.59 & 0.57 & 60.89 & 1.41 & 2.33 & 0.88 \\
\hline PRB & 14.78 & 22.19 & 5.2 & 5.17 & 0.01 & 1.07 & 0.35 & 30.46 & 1.94 & 8.83 & 1.3 \\
\hline Illinois & 17.66 & 1.87 & 14.57 & 0.98 & 0.02 & 0.11 & 2.26 & 49.28 & 1.51 & 2.22 & 0.85 \\
\hline
\end{tabular}


Particulate samples were withdrawn isokinetically through a dilution probe and then further diluted by clean air to allow PSD measurement by a scanning mobility particle sizer (SMPS) (Figure 24) and also soot concentrations by photo acoustic analyzer (PA).

For size-segregated ash aerosol compositions, the particles were size segregated in a BLPI prior to the second dilution, allowing segregation into 11 size classes. In this report composition data by Electron Dispersive Spectroscopy (EDS) are available.

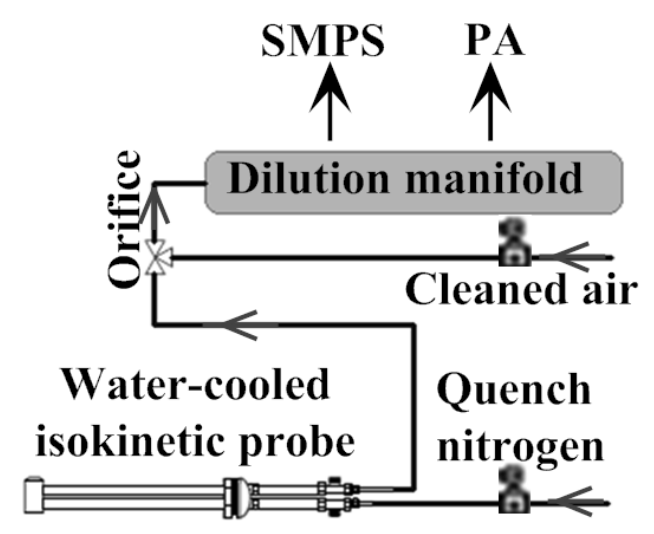

Figure 24. Water cooled, water quenched isokinetic sampling probe with additional dilution for SMPS measurements. 


\section{RESULTS AND DISCUSSION}

\section{Subtask 3.1 - Oxy-Coal Combustion Large Eddy Simulations}

\section{Non-reacting particle laden flows}

The following section presents a verification and validation study, which aims to show that the LES and DQMOM approach is able to model gas and particles behavior correctly in the near-burner region of a coal flame. It presents LES simulations with DQMOM of coaxial particle-laden jets and compares the results to experimental data. Special attention is given to the following important characteristics of particle-laden jets: gas and particle velocity, particle size segregation and particle clustering.

\section{Model formulation}

In a gas-solid flow, the particle motion is affected by the drag force, which can be described by the Stokes drag law. For a meso-scale size particle, when the other additional mass forces are omitted, the momentum equation for the particle can be expressed by an ordinary differential equation.

$$
\frac{d u_{i, p}}{d t}=\sum_{i}\left(\frac{f_{d r a g}}{\tau_{p}}\left(u_{i, g}-u_{i, p}\right)+\frac{g_{i}\left(\rho_{p}-\rho_{g}\right)}{\rho_{p}}+\frac{F_{i, v}}{m_{p}}\right)
$$

where $\mathrm{i}$ denotes the $\mathrm{i}^{\text {th }}$ direction, $\mathrm{g}$ is the gravity force acting on the particle, $\mathrm{F}_{\mathrm{v}}$ are the other body forces acting on the particle, $u_{p}$ is the particle velocity, $\rho_{p}$ is the particle density, $\rho_{g}$ is the gas density, $m_{p}$ is the particle mass and $f_{\text {drag }}$ is the coefficient of the drag force, which has a close relationship with particle Reynolds number (Re).

In this model, each component of the particle velocity is set as an internal coordinate. The drag force is then a source term in the transport equations for the particle velocity components.

$$
\begin{gathered}
f_{\text {drag }}= \begin{cases}1 & R e_{p}<1 \\
1+0.15 R e_{p}^{0.687} & 1<R e_{p}<1000 \\
0.0183 R e_{p} & R e_{p}>1000\end{cases} \\
R e_{p}=\frac{\rho_{p} d_{p}\left|u_{p}-u_{g}\right|}{\mu_{g}} . \\
\tau_{p}=\frac{\rho_{p} d_{p}^{2}}{18 \mu_{g}} .
\end{gathered}
$$


where $d_{p}$ is the particle diameter abd $\mu \mathrm{g}$ is the gas viscosity.

The particle phase has been coupled to the gas phase to account for momentum exchange.

\section{Verification}

A periodic box with an initial gas velocity $U=[10,5,1] \mathrm{m} / \mathrm{s}$ was set up. Particles have no initial velocity. The particle size is 50 micron and the particle density is $1000 \mathrm{~kg} / \mathrm{m}^{3}$. This case has one quadrature node and 4 internal coordinates (particle size and the three particle velocity components). Results from Arches were compared to the results from a Matlab script. In the case without coupling with the gas phase, the weight is $1 \mathrm{e} 10$ particles $/ \mathrm{m}^{3}$ and with coupling it is 1e8. As shown in Figure 25, all the curves match.

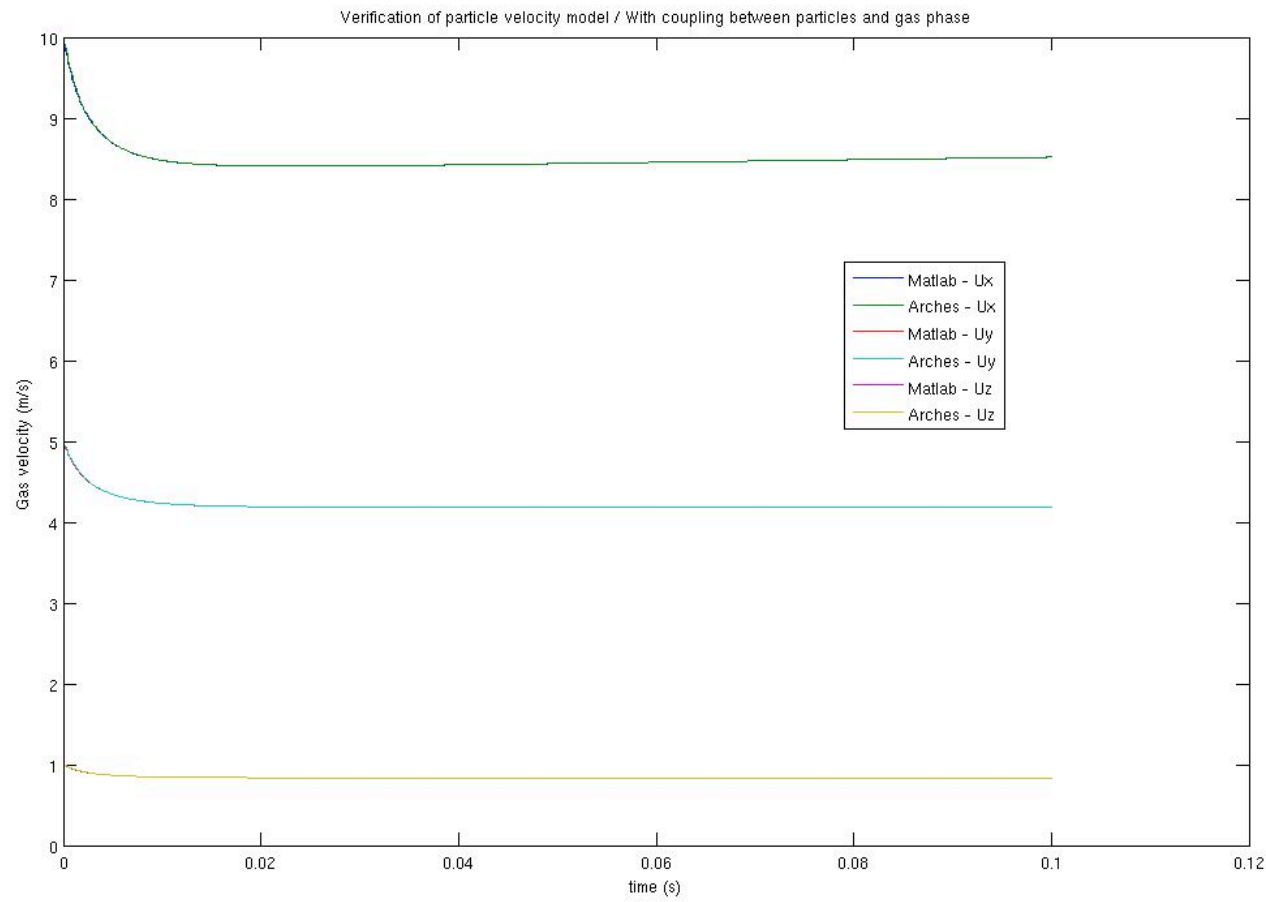




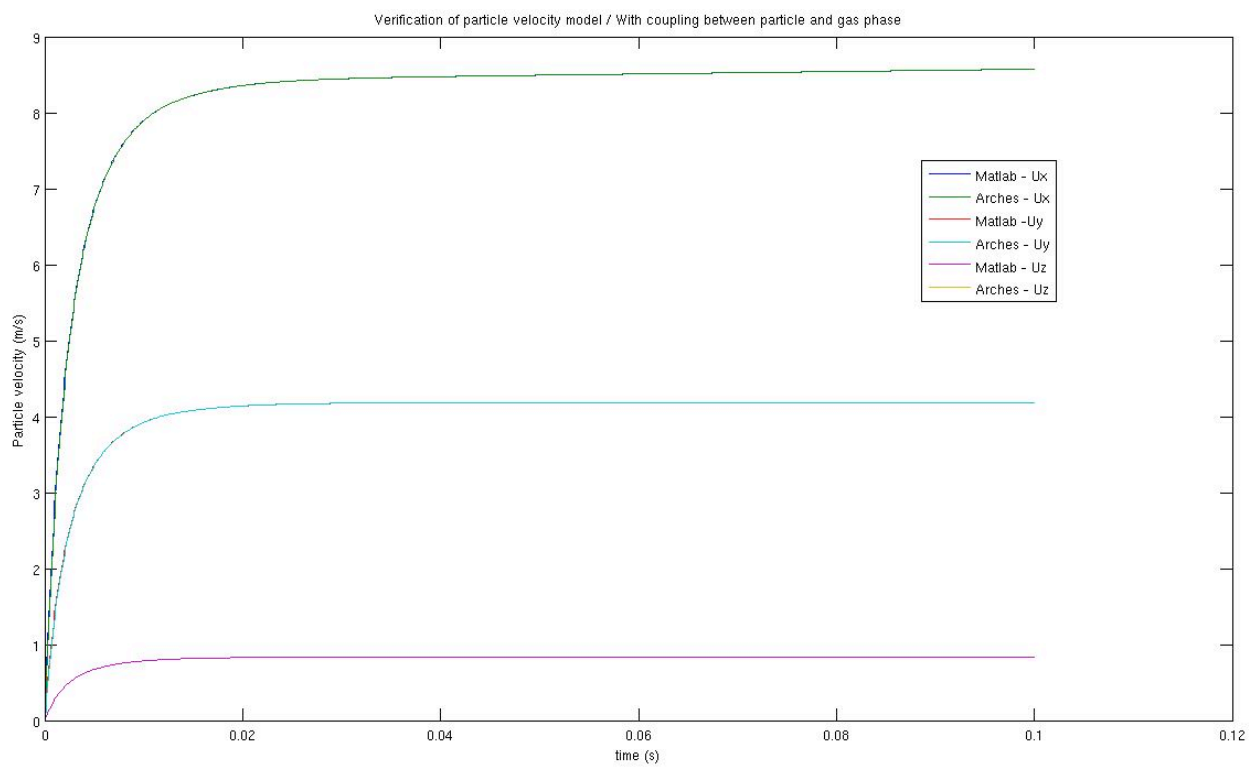

Figure 25. Verification for gas velocity and particle velocity.

\section{Validation}

The following part presents LES simulations with DQMOM of coaxial particle-laden jets and compares the results to experimental data. Since few data on particles in coal flames are available, experimental data for non-reacting turbulent flows with particles were chosen. Simulation of a coaxial particle-laden jets are performed with three different velocity ratios between the primary and secondary stream and two PSDs. Simulations results show predictions of both the gaseous and solid phase average velocity and are compared to experimental data.

\section{Experimental setup}

LES is applied to the particle-laden coaxial jet that was used by Budilarto (2003) for his experiments. Particles are conveyed with air in the primary nozzle whereas the secondary nozzle is fed only with air. Air and particles are injected at room temperature in a 18x18 inches chamber. The experiments focus on the effects of velocity ratio on the flow-field at the near-field region of a coaxial jet. The velocity ratio, which is defined as the ratio of the annular to central inlet velocity, was varied at three different values: 0 , $1.0,1.5$ by varying the volumetric flow rate of the annular jet. The Reynolds number based on the average central inlet velocity is 8,400 . Table 9 lists the flow conditions for the experiments. The investigation also studied the effect of velocity ratio and particle size on the motion of particles in the near field region. Two PSDs were used for this purpose, one with a mean diameter of 25 micron and one with a mean diameter of 70 micron. Particles are glass beads with a density of $2500 \mathrm{~kg} / \mathrm{m}^{3}$. The particle mass loading 
is maintained at 0.5 for all velocity ratios. Laser Doppler velocimetry and phase Doppler anemometry were used to measure time-averaged velocities.

Table 9. Experimental setup for the different velocity ratios.

\begin{tabular}{|c|c|c|c|c|c|}
\hline Case & $\mathrm{d}$ (inch) & $\mathrm{D}$ (inch) & $\begin{array}{c}\text { Central jet maximum } \\
\text { inlet velocity } U_{0}(\mathrm{~m} / \mathrm{s})\end{array}$ & $\begin{array}{c}\text { Annular jet maximum } \\
\text { inlet velocity } U_{a}(\mathrm{~m} / \mathrm{s})\end{array}$ & $\begin{array}{c}\text { Velocity } \\
\text { ratio (VR) }\end{array}$ \\
\hline \hline 1 & 0.56 & 1.254 & 11.7 & 0 & 0 \\
\hline 2 & 0.56 & 1.254 & 11.7 & 11.6 & 1.0 \\
\hline 3 & 0.56 & 1.254 & 11.7 & 18.0 & 1.5 \\
\hline
\end{tabular}

\section{Computational details}

The computational domain is a cube of dimensions $0.28 \times 0.28 \times 0.28 \mathrm{~m}$. A Cartesian mesh was used with a cell size of $1.42 \mathrm{~mm}$ so that the central inlet has 10 cells across. The computational domain is thus divided into 8 million cells. Measurements have shown that the common power law velocity profile of fully developed turbulent flow can be applied at the inlet. The dynamic Smagorinsky model was used to model the subgrid-scale turbulence for the gas phase. Six simulations were performed; for each velocity ratios, simulations without particles, with 25-micron particles and with 70-micron particles were run on 512 CPUs for about 24 hours.

For the 25-micron size distribution, particles diameter ranges from a few micron up to 45 micron, whereas the 70-micron size distribution ranges from 50 to 90 micron. In the first case, the mass of the smallest particles is several orders of magnitude less than the mass of the largest particles. Since a 10 micron particle would behave significantly differently from a 40 micron particle, the size distribution was represented by three quadrature nodes in the DQMOM approach, each node corresponding to a particle size. Table 10 shows the particle diameter associated with each quadrature node as well as their weight at the inlet.

Table 10. Quadrature approximation for 25-micron particles (inlet values).

\begin{tabular}{|c|c|c|}
\hline Quadrature node & Particle diameter $(\mu m)$ & Weight $\left(\#\right.$ particles $\left./ m^{3}\right)$ \\
\hline \hline 0 & 14 & $4.11 \mathrm{e} 10$ \\
\hline 1 & 25 & $1.44 \mathrm{e} 10$ \\
\hline 2 & 34 & $2.90 \mathrm{e} 9$ \\
\hline
\end{tabular}

For the 70-micron particles, the mass of all the particles is of the same order of magnitude, so the size distribution can be represented by a single value of 70 micron. However, these particles have more inertia than the small ones and there initial velocity at the exit of the burner should be taken into account. For the 25-micron particles, measured velocity fluctuations at the inlet were smaller and they have less inertia, so assuming that all the particles have the same inlet velocity is a good approximation. On the contrary, for the 70-micron particles it is necessary to represent their velocity distribution at the inlet. Based on the measured root mean square (rms) of velocity fluctuations at the inlet, a 2-D normal distribution in particle 
velocity components Upy and Upz was assumed. Fluctuations in Upx were neglected since there are small compared to the mean velocity in this direction. The normal distribution was approximated by 5 quadrature nodes on the DQMOM approach, as shown in Table 11.

Table 11. Quadrature approximation for 70-micron particles (inlet values).

\begin{tabular}{|c|c|c|c|c|c|}
\hline Quadrature node & Particle diameter $(\mu m)$ & $\mathrm{Upx}(\mathrm{m} / \mathrm{s})$ & $\mathrm{Upy}(\mathrm{m} / \mathrm{s})$ & $\mathrm{Upz}(\mathrm{m} / \mathrm{s})$ & Weight $\left(\#\right.$ particles $\left./ \mathrm{m}^{3}\right)$ \\
\hline \hline 0 & 70 & 9.6 & 0 & 0 & $3.8 \mathrm{e} 8$ \\
\hline 1 & 70 & 9.6 & -0.55 & 0 & $2.3 \mathrm{e} 8$ \\
\hline 2 & 70 & 9.6 & 0.55 & 0 & $2.3 \mathrm{e} 8$ \\
\hline 3 & 70 & 9.6 & 0 & -0.55 & $2.3 \mathrm{e} 8$ \\
\hline 4 & 70 & 9.6 & 0 & 0.55 & $2.3 \mathrm{e} 8$ \\
\hline
\end{tabular}

Results for the two-phase coaxial jet

Simulation results of the coaxial jet for the three velocity ratios (VR) and the two PSDs are presented in this section. Results for the six simulations are analyzed both qualitatively and quantitatively.

Figure 26 shows instantaneous snapshots of particle concentration for a given quadrature node in the XZ plane for the simple jet case $(\mathrm{VR}=0)$. Images for the 25 -micron particles case are presented on the left side [(a), (c), (e)], whereas images for the 70-micron particles case are on the right side [(b), (d), (f)]. Figure 1-a shows the concentration of particles of 14 micron diameter (quadrature node 0), whereas figure 1-e shows concentration of 34 micron particles (quadrature node 2). It can be observed that the smaller particles disperse faster than the larger ones and form a wider jet. Figures $1 \mathrm{~b}, \mathrm{~d}$, f show particle concentration for quadrature nodes 1, 3 and 4, respectively, in the 70-micron particles case. The 70micron particles tend to keep their initial velocity and are less affected by the gas phase than the 25micron particles. 


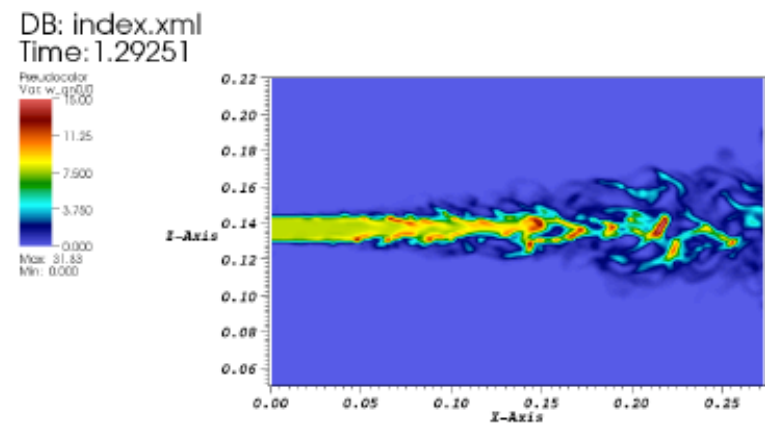

(a) Weight for quadrature node 0,25 -microns particles

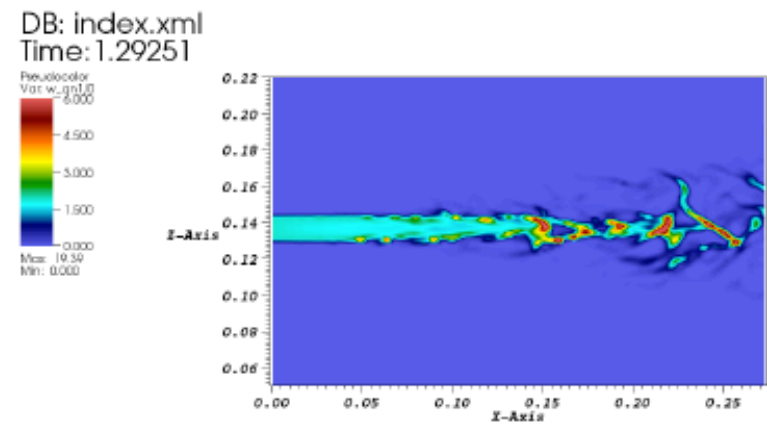

(c) Weight for quadrature node 1, 25-microns particles

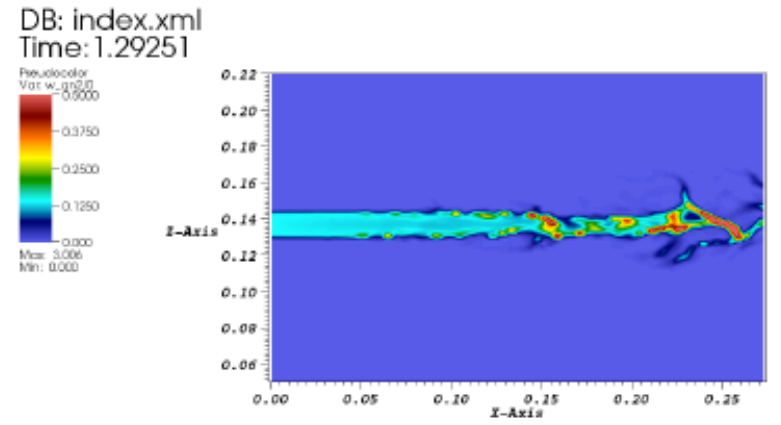

(e) Weight for quadrature node 2, 25-microns particleser density

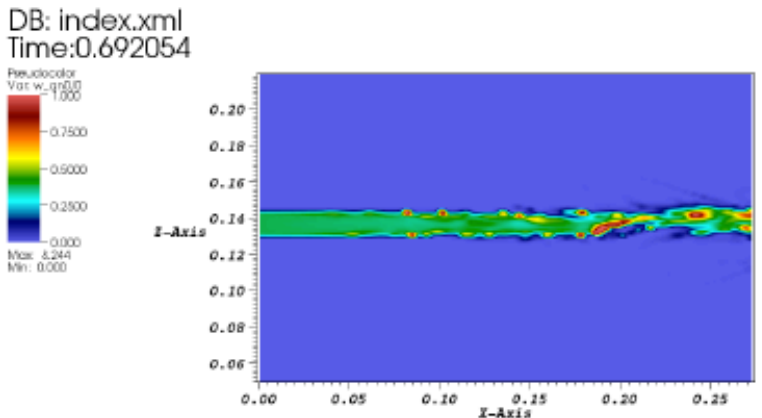

(b) Weight for quadrature node 0,70 -microns particles

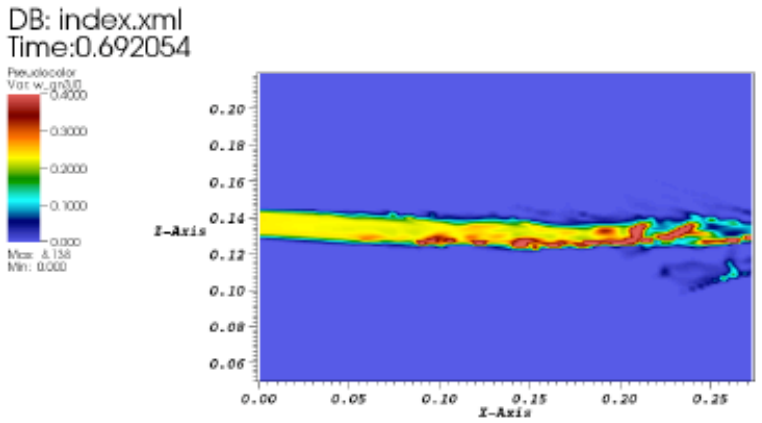

(d) Weight for quadrature node 3, 70-microns particles

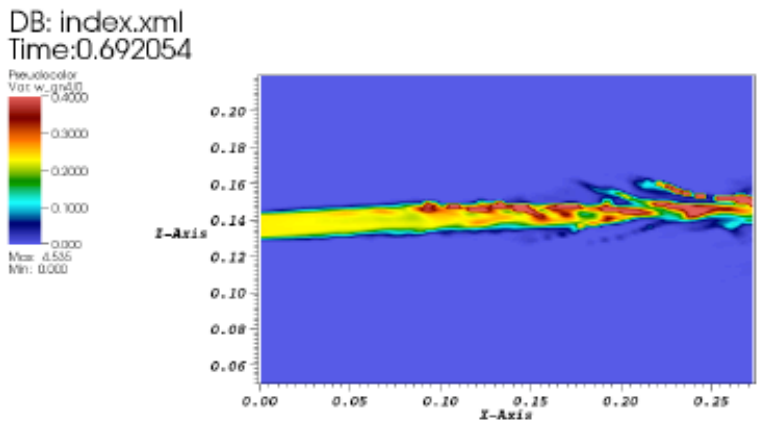

(f) Weight for quadrature node 4, 70-microns particles

Figure 26. Instantaneous profiles of weights ( $\#$ particle $\left./ \mathrm{m}^{3}\right), \mathrm{VR}=0$.

Figure 27 includes instantaneous profiles of the total particle concentrations, $\mathrm{W}_{\text {sum }}$, for each case. For VR $=0$ and 25-micron particles, the jet does not break but widens quickly. Interactions between the gas-phase eddies and the particle phase can clearly be seen. Eddies entrain the particles towards the edges of the jet in "pine tree-like" formations, which was also observed experimentally. For VR $=1.0$ and 25-micron particles, the jet is straight until about 10 diameters and then starts to wave. For VR $=1.5$ and 25 -micron particles, the kinetic energy of the gas phase is larger and is able to break the jet. The particle jet forms 
high amplitude waves around $x=6 \mathrm{~d}$ and then breaks around $\mathrm{x}=9 \mathrm{~d}$. For $\mathrm{VR}=0$ and $\mathrm{VR}=1.0$ and the 70micron particles, the jet is barely affected by the gas phase and remains straight and compact. For $\mathrm{VR}=$ 1.5, 70-micron particles, the gas phase has enough energy to create waves in the particle jet after $\mathrm{x}=8 \mathrm{~d}$, but not enough to break it. All of these phenomena were observed during experiments. Also, in every case, high particle concentration regions (red spots) can be observed and confirm the importance of clustering effects.

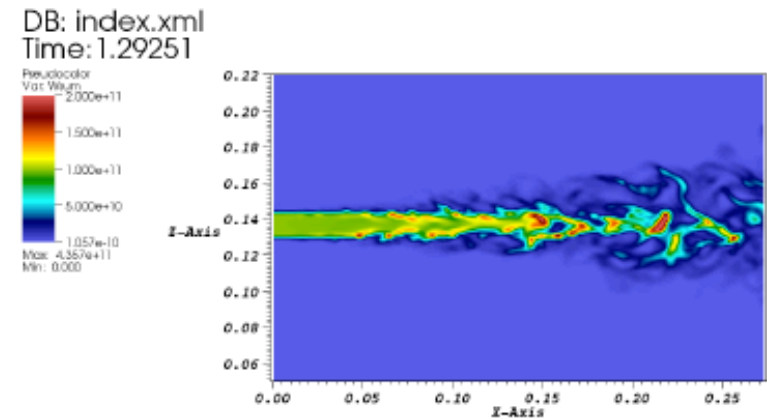

(a) $\mathrm{VR}=0,25$-microns

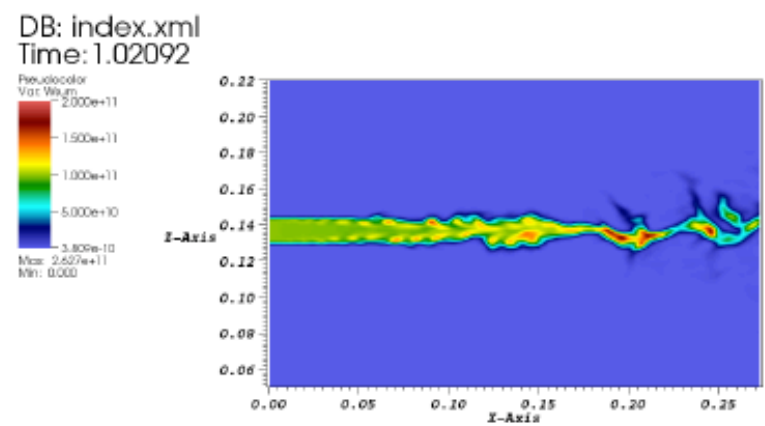

(c) $\mathrm{VR}=1.0,25$-microns

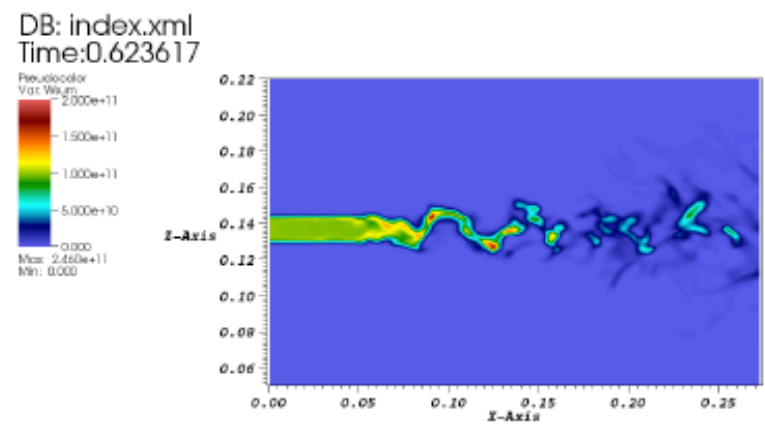

(e) $\mathrm{VR}=1.5,25$-microns

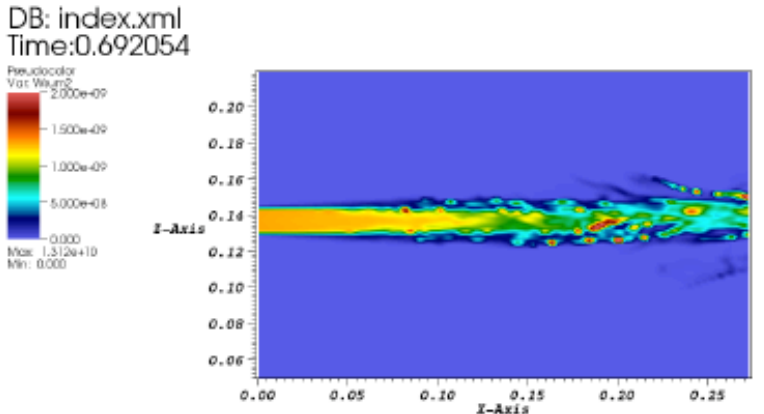

(b) $\mathrm{VR}=0,70$-microns

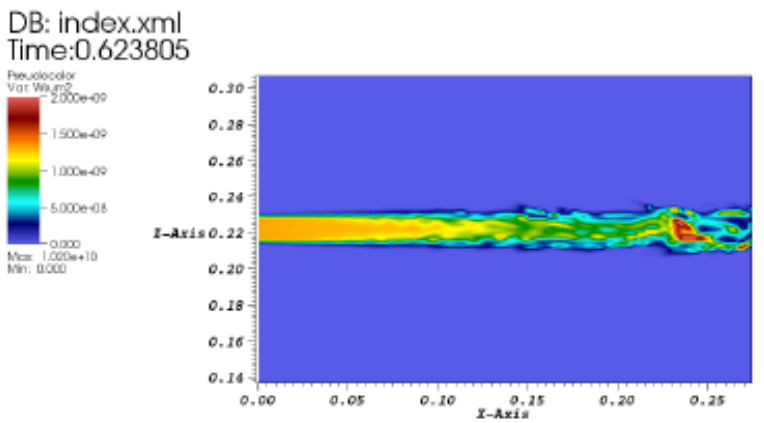

(d) $\mathrm{VR}=1.0,70$-microns

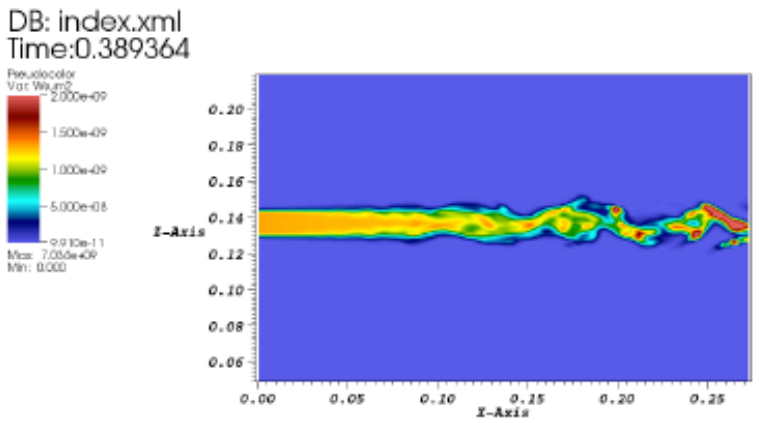

(f) $\mathrm{VR}=1.5,70$-microns

Figure 27. Instantaneous profiles of total particle concentration $\mathrm{W}_{\text {sum }}\left(\#\right.$ particle $\left./ \mathrm{m}^{3}\right)$. 
Figure 28 presents comparisons of the mean gas and particle velocity along the centerline between the simulation predictions and experimental data. For VR $=0[(a),(b)]$, small particles velocity is almost the same as the gas velocity. Initially, their velocity is slightly slower than the gas velocity, but around $\mathrm{x} / \mathrm{d}=5$, the two lines cross and because of inertia the particle velocity becomes larger than the gas velocity. Large particles have a velocity profile very different from the gas velocity. Initially, their speed is lower and when $\mathrm{x} / \mathrm{d}<6$ they slow down the gas phase while their own speed increases. Then the gas velocity drops below the particle velocity, and particles are now a positive source of momentum to the gas phase. For $\mathrm{VR}=1.0[(\mathrm{c}),(\mathrm{d})]$, it can be noticed that simulations predict slightly higher velocities than experiments, which was expected given that the gas velocity was also over predicted in the case with no particles. Results for $\mathrm{VR}=1.5[(\mathrm{e}),(\mathrm{f})]$ are in good agreement with experimental data.

Figure 29 provides plots of the $\mathbf{W}$ sum along the radial direction at $\mathrm{x}=15 \mathrm{~d}$. Values are normalized by the centerline value. For every velocity ratio, it can be observed that the fine particles have a wider distribution, whereas the coarse particle jet remains more compact. Overall, simulations give good predictions and show that the modeling approach is able to capture particle segregation, even though the spreading rate is over-predicted for $\mathrm{VR}=0$ and under-predicted for $\mathrm{VR}=1.0$ and $\mathrm{VR}=1.5$. Simulations predict a higher spreading for $\mathrm{VR}=1.5$ than for $\mathrm{VR}=1.0$, which is observed experimentally. A lower spreading rate for $\mathrm{VR}=1.0$ than for $\mathrm{VR}=0$ is predicted, which is probably a consequence of the lower shear stress; this behavior is, however, not confirmed by the experimental data. Possible reasons for the discrepancy are inaccurate inlet conditions or measurement uncertainty. 


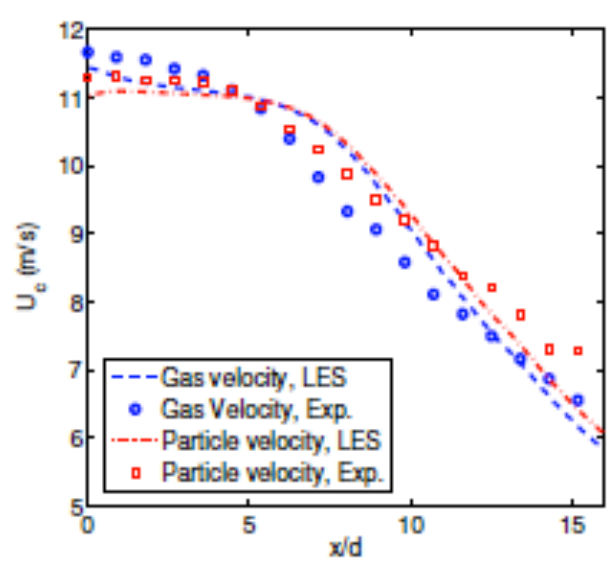

(a) $\mathrm{VR}-0$

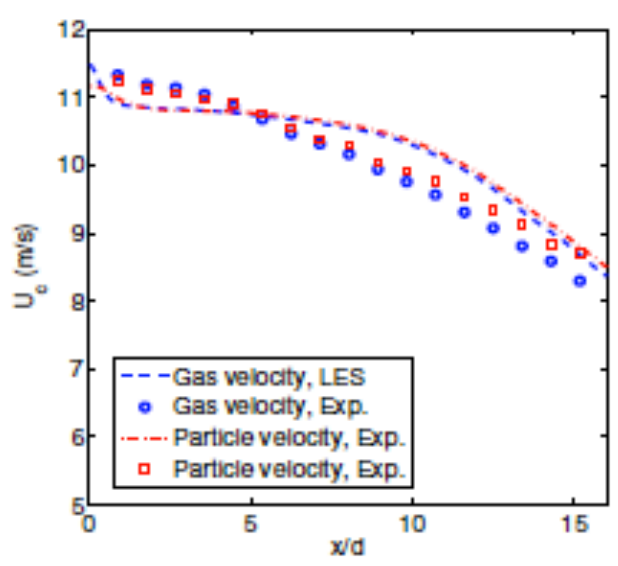

(c) $\mathrm{VR}-1.0$

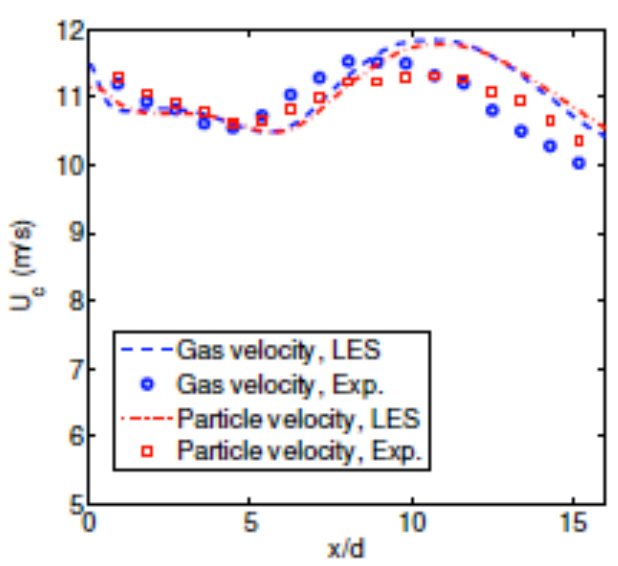

(c) $\mathrm{VR}-1.5$

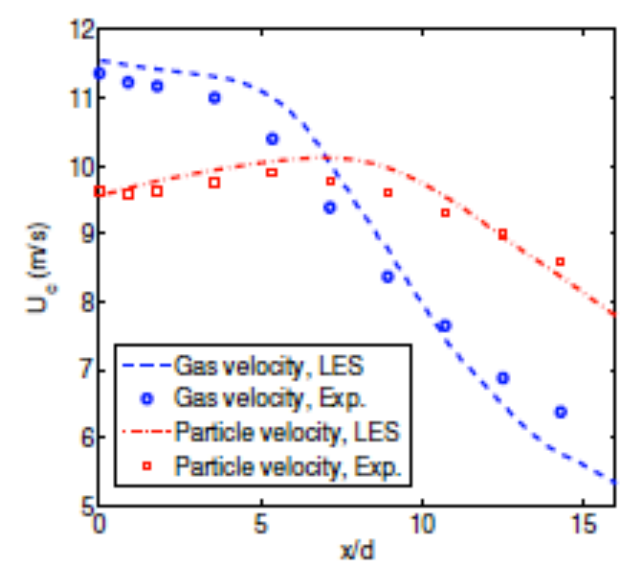

(b) $\mathrm{VR}-0$

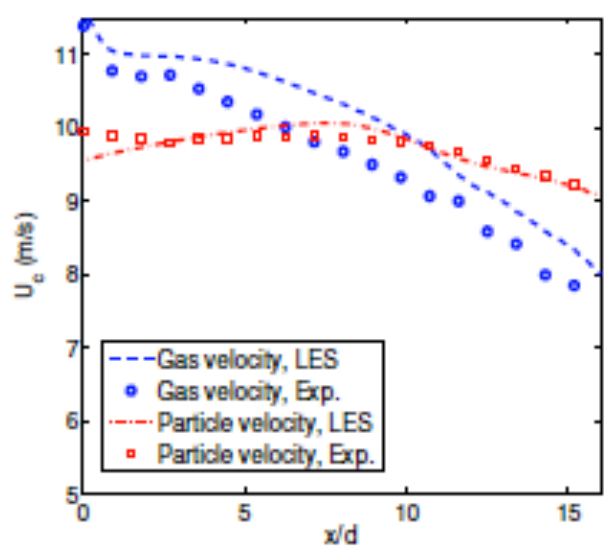

(d) $\mathrm{VR}-1.0$

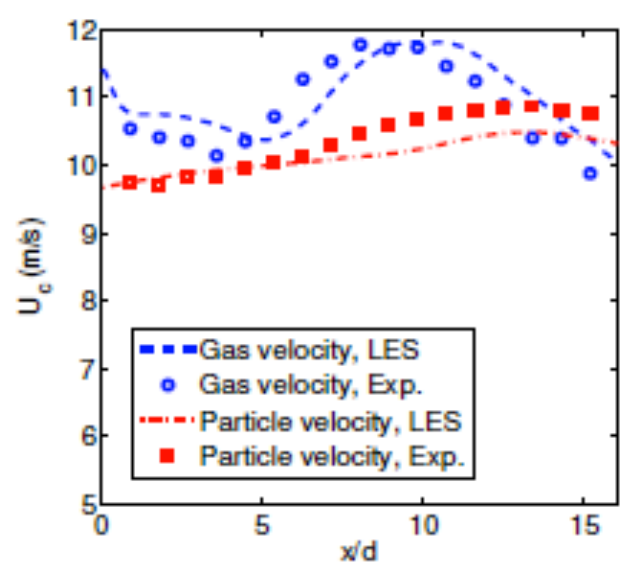

(f) $\mathrm{VR}-1.5$

Figure 28. Comparison between simulations and experimental data of time-averaged gas and particles velocities along the centerline for 25 um particles [(a) (c) (e)] and 70 um particles [(b) (d) (f)]. 


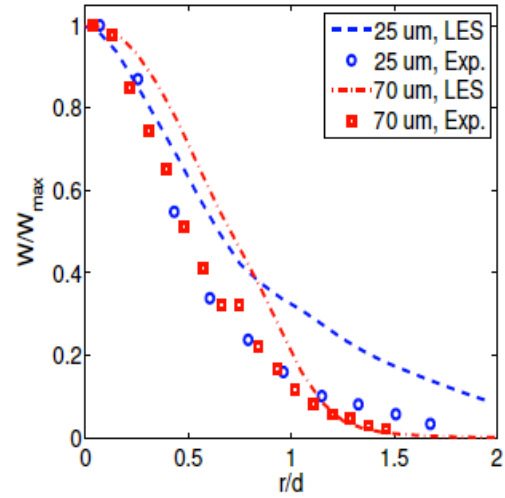

(a) $\mathrm{VR}=0$

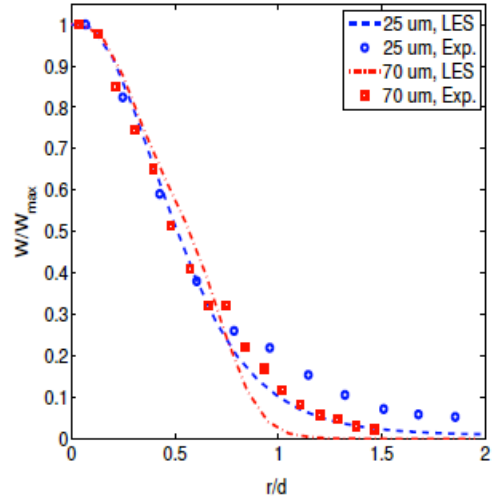

(b) $\mathrm{VR}=1.0$

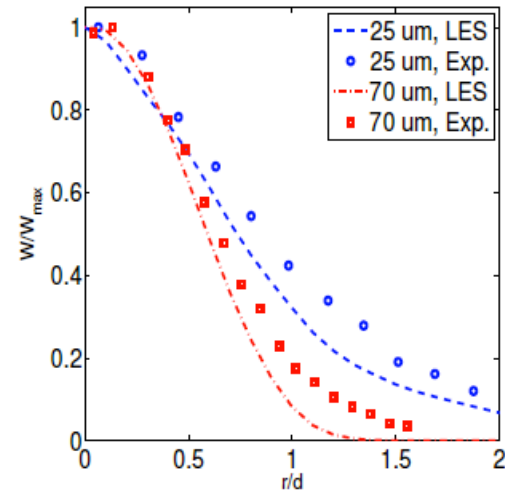

(c) $\mathrm{VR}=1.5$

Figure 29. Radial profiles of particles number density taken at $x=15 \mathrm{~d}$.

\section{Summary}

LES of particle-laden coaxial jets were performed using the DQMOM approach with 25-micron and 70micron particles. Results show that the models were able to predict the average velocities along the centerline for both gas phase and particle phase with a maximum error of $12 \%$. Simulations were able to capture clustering and segregation effects. Fine particles were strongly affected by the gas phase eddies and moved faster towards the edges of the jet whereas coarse particles remain more compact along the centerline and were less affected by the eddies.

\section{LES oxy-coal simulations}

\section{First parametric sensitivity study}

In the second part of 2010, a first sensitivity study was performed with respect to the chosen parameters: wall temperature and primary $\mathrm{P}_{\mathbf{O} 2}$. The goal was to determine the effect of those two parameters on the flame stand-off distance in the experimental conditions of the University of Utah OFC.

In order to perform simulations of oxy-coal flames, the code needed to be able to handle multiple mixture fractions and oxy-coal combustion thermodynamic tables. Previously, the code could only handle one mixture fraction. However, to perform simulations of the OFC, at least two mixture fractions were needed. Thus, this capability has been implemented into Arches, and it can now handle multiple mixture fractions. The next issue came from the thermodynamic tables. So far, only air-fired gaseous combustion tables had been used. It was thus necessary to have "oxy-coal" tables, i.e. tables with multiples mixture fractions, larger heat loss limits and a lower temperature reference state. It was indeed observed that the high concentrations of $\mathrm{CO}_{2}$ in oxy-coal flames result in heat-loss values that can be much lower than -1.

To model the OFC, the following approach was followed: 
- Two-step devolatilization model

- No char oxidation model

- Discrete Ordinates radiation model

- Constant wall temperature

- Six internal coordinates:
○ Particle size
- Particle temperature
- Raw coal mass
○ Particle velocity (3 components)

- Three quadrature nodes (Table 12).

Table 12. Initial number density function at inlet.

\begin{tabular}{llll}
\hline $\begin{array}{l}\text { Quadrature } \\
\text { Node }\end{array}$ & Particle size (um) & Weight $\%$ & Feed rate (g/s) \\
\hline 1 & 40 & 11.2 & 0.15 \\
2 & 63 & 58.6 & 0.82 \\
3 & 100 & 30.2 & 0.42 \\
\hline
\end{tabular}

To perform the sensitivity analysis, a set of three simulations was run with the conditions described in Table 13.

Table 13. Parameter values for the sensitivity analysis.

\begin{tabular}{lll}
\hline Simulation \# & Wall temperature & Primary $\mathrm{P}_{\mathbf{O} 2}$ \\
\hline 1 & $1283 \mathrm{~K}$ & $0 \%$ \\
2 & $1800 \mathrm{~K}$ & $0 \%$ \\
3 & $1283 \mathrm{~K}$ & $21 \%$ \\
\hline
\end{tabular}

Figure 30 through Figure 33 show snapshots of different variables in the center plane for the first simulation. The ignition and the flame stand-off distance is visible in Figure 32, the flame ignites at about $25 \mathrm{~cm}$ from the burner. The simulation shows that the Arches LES code is capable of capturing the delay ignition effect since the stand-off distance was measured at $30 \mathrm{~cm}$ for this case. Figure 33 presents the particle temperature for the three different particles sizes. It can be observed that the small particles ignite first, the medium size particle ignite shortly after and the largest particle need a significant additional time to ignite. 


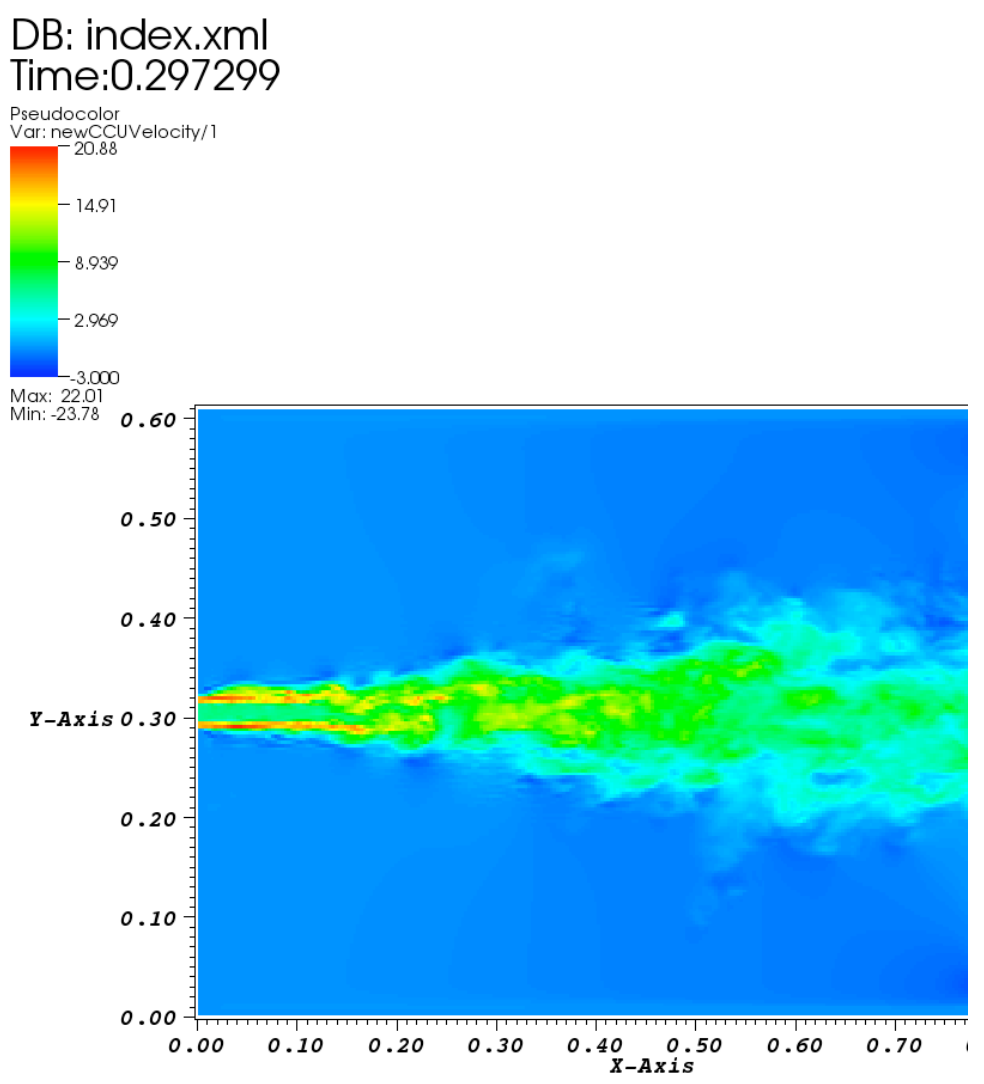

Figure 30. Gas X-velocity $(\mathrm{m} / \mathrm{s})$. 


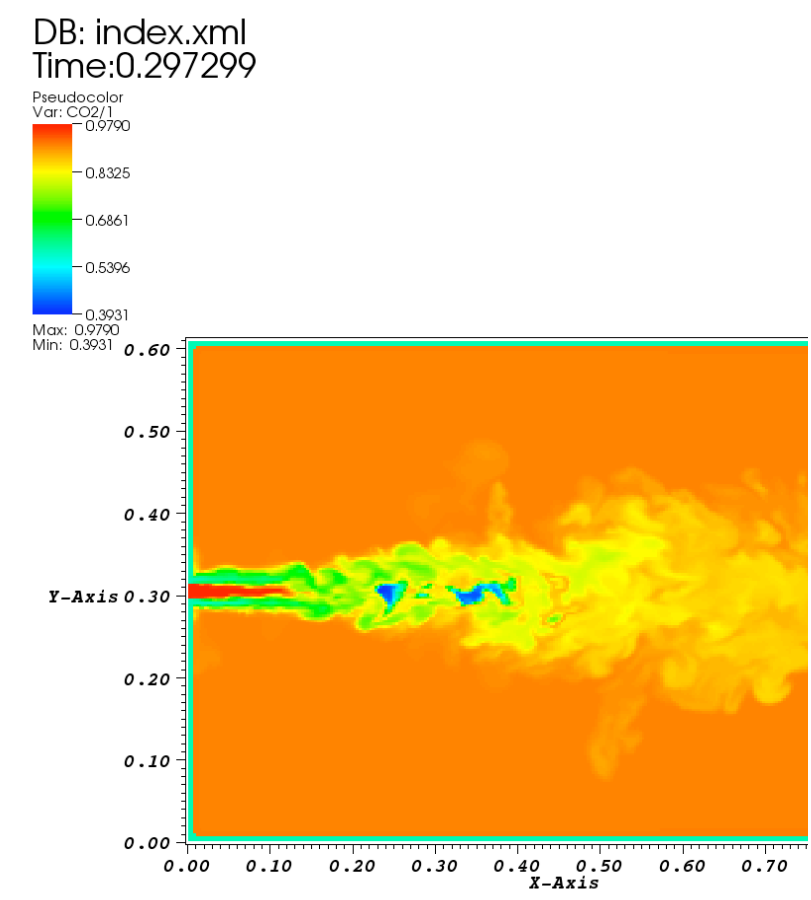

Figure $31 . \mathrm{CO}_{2}$ mass fraction.

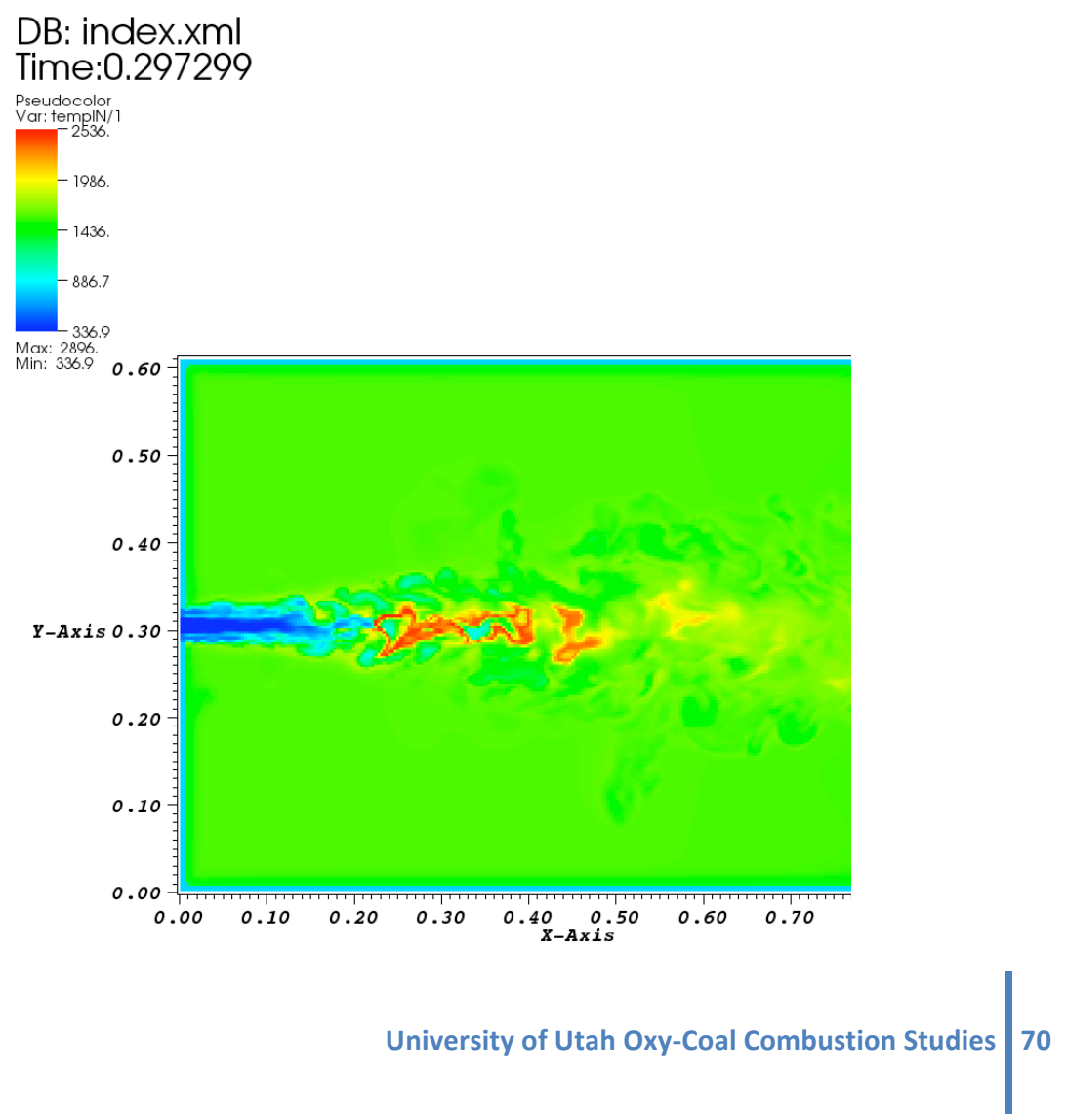


Figure 32. Gas temperature (K).
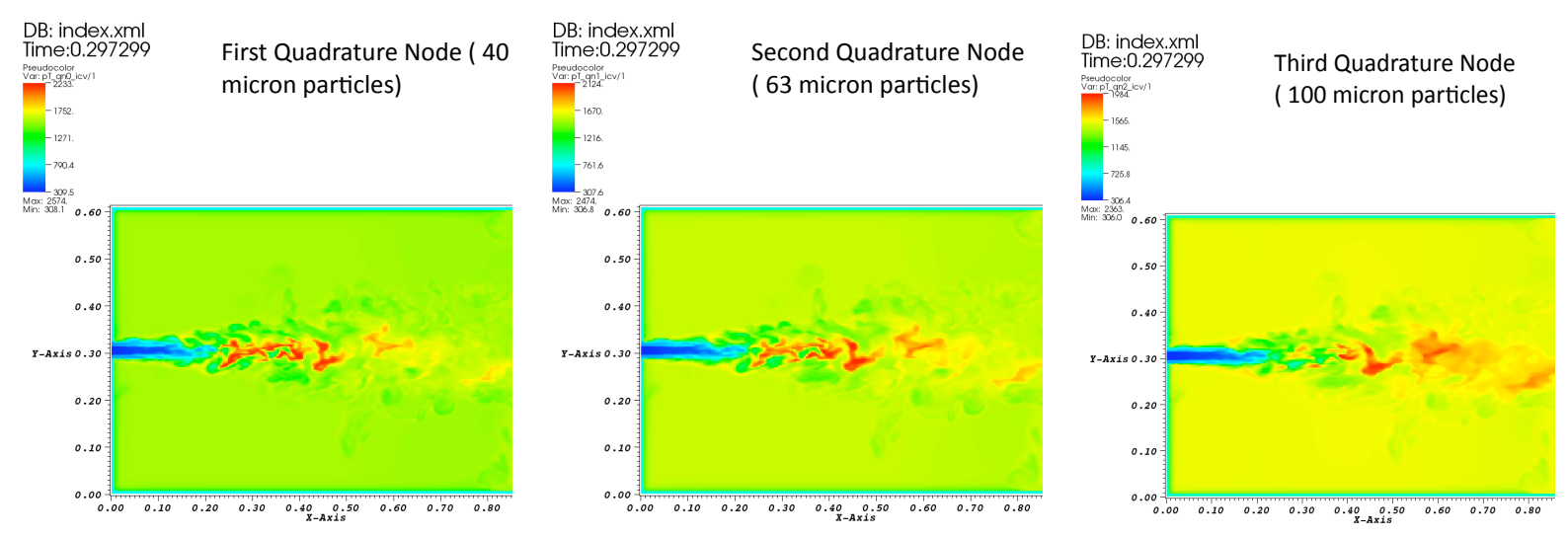

Figure 33. Particle temperature (K).

Results for the averaged flame stand-off distance are reported in Table 14.

Table 14. Average stand-off distance.

\begin{tabular}{lll}
\hline Simulation \# & Predicted stand-off distance & Measured stand-off distance \\
\hline 1 & $25 \mathrm{~cm}$ & $30 \mathrm{~cm}$ \\
2 & $<10 \mathrm{~cm}$ & N/A \\
3 & $25 \mathrm{~cm}$ & $12 \mathrm{~cm}$ \\
\hline
\end{tabular}

Results are in good agreement for the first simulation since the predicted distance is $25 \mathrm{~cm}$ and the measured one is $30 \mathrm{~cm}$. Simulation 2 shows that wall temperature strongly affects the stand-off distance since it is reduced to less than $10 \mathrm{~cm}$. However, simulation 3 predicted the same stand-off distance as simulation 1, and no sensitivity to the oxygen concentration was observed. This result was expected since the devolatilization model doesn't depend on the oxygen concentration.

In summary, the observed change in flame stand-off distance can be explained by the uncertainty in wall temperature but not by the devolatilization process alone. A possible hypothesis is that heterogeneous reactions occur in the presence of oxygen around the particles, in which case we could have heterogeneous ignition when the primary $\mathrm{P}_{\mathbf{O} 2}$ is significant.

\section{Preliminary validation data for the oxy-coal combustor}

The previous section presented the preliminary validation results. Even though it shows interesting results, the code was lacking some physics and had a few issues that needed to be solved to preformed accurate simulations. Problems with the Arches code regarding thermodynamic tables and heat loss have been resolved and energy coupling between the gas phase and the solid phase was added. Also, a char

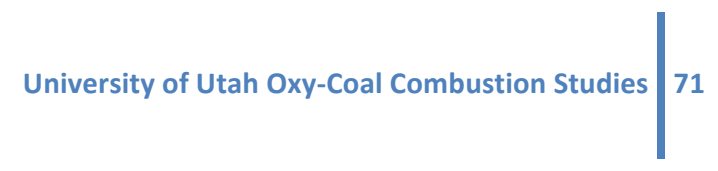


reaction model has been implemented in order to model the major reactions occurring in coal particles. Mass coupling between the two phases remains to be done.

Figure 34 summarizes the experimental measurements of flame stand-off distance from Zhang (2010). For the validation of the code, it was decided to study the trend observed on the red curve when wall temperature is fixed at $1283 \mathrm{~K}$ and primary $\mathrm{P}_{\mathbf{O} 2}$ varies from $0 \%$ to $21 \%$. To do so, simulations were performed for the two extremes cases: case 1 when primary $\mathrm{P}_{\mathbf{O} 2}=0 \%$ and case 5 when primary $\mathrm{P}_{\mathbf{O} 2}=$ $21 \%$.

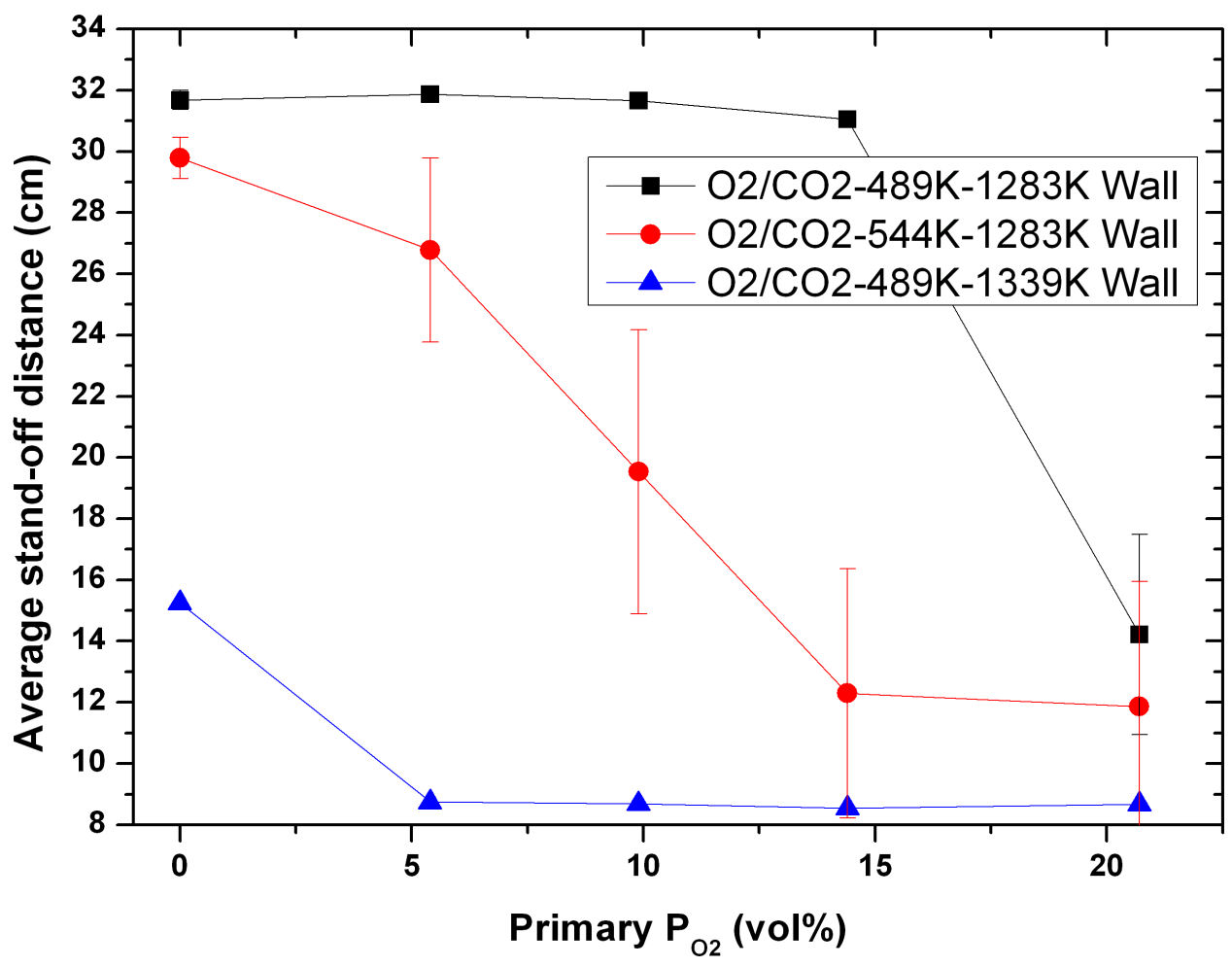

Figure 34. Experimental results from Zhang. et al. (2010).

In the previous section, we determined that prediction of flame ignition and standoff distance was not sensitive to the concentration of oxygen in the primary stream, which contradicts the experiments. In Case 1 , the predicted standoff distance was close to the measured one, but in case 5 the predicted standoff distance was much larger than the measured one. Two hypotheses were then considered to explain this behavior:

- Ignition may be controlled by heterogeneous ignition in case 5,

- Uncertainty in wall temperature may be responsible for this behavior.

The first hypothesis was considered and a heterogeneous reaction model was implemented in Arches to evaluate the likelihood of heterogeneous ignition in those cases. The model formulation and its 
parameters values were obtained from the experimental work of Shaddix (2006) on the combustion kinetics of char in oxygen-enriched environments.

Figure 35 through Figure 37 show snapshots of different variables for case $5\left(\mathrm{P}_{\mathbf{O} 2}=21 \%\right)$. In Figure 36, we can observe that flame ignition occurs at about $33 \mathrm{~cm}$ from the burner. Figure 37 shows the particle concentration for the small particles and for the large particles. They present a very different behavior; the small particles being more affected by eddies disperse faster whereas the large one remains along the centerline.

Results for Case 1 and Case 5 are presented in Table 15. The experimental flame stand-off distance is based on luminosity. However, this information is not available in the simulations, so the stand-off distance was defined as the first point on the centerline where the gas temperature is higher than $1500 \mathrm{~K}$. For Case 5, the predicted value of $31 \mathrm{~cm}$ matches the experimental value closely, but for Case 1, the predicted stand-off distance is the same and no sensitivity on oxygen concentration is observed. So, the better models helped to get a more accurate stand-off distance prediction on Case 1, but are still unable to predict the sensitivity to primary $\mathrm{P}_{\mathrm{O} 2}$.

Zhang (2010) not only reported the averaged stand-off distance but also its statistics, so it is interesting to compare with simulation results, since LES can provide temporal data. As shown on Figure 38, for Case 1 where the average stand-off distance is predicted correctly, the statistics of the flame also match extremely well.

Both simulations also showed that heterogeneous reactions only occur after devolatilization and don't fasten ignition, therefore heterogeneous ignition should be rejected as a hypothesis to explain the short flame stand-off distance in case 5. It was interesting to see what would happen if the wall temperature was slightly raised to test the sensitivity to this parameter. A third simulation was therefore performed with the operating conditions of Case 1 but with walls at 1433K. As shown in Table 15, the stand-off distance then becomes $10 \mathrm{~cm}$. So, the simulations cannot replicate the sensitivity on primary $\mathrm{P}_{\mathrm{O} 2}$, but the uncertainty on wall temperature is large enough to validate the hypothesis that a small change on wall temperature might explain the observed trend. 


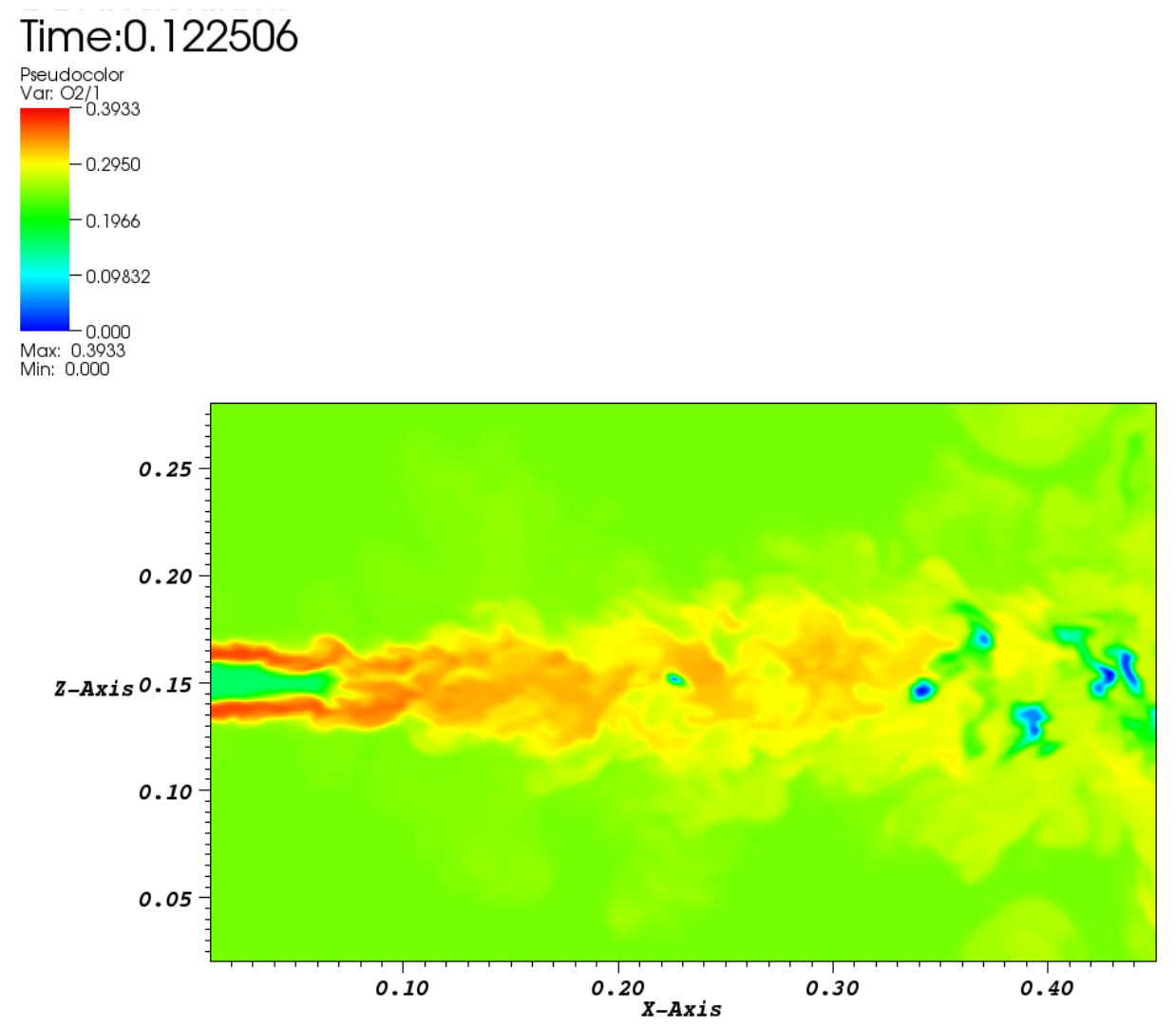

Figure $35 . \mathrm{O}_{2}$ mass fraction. 


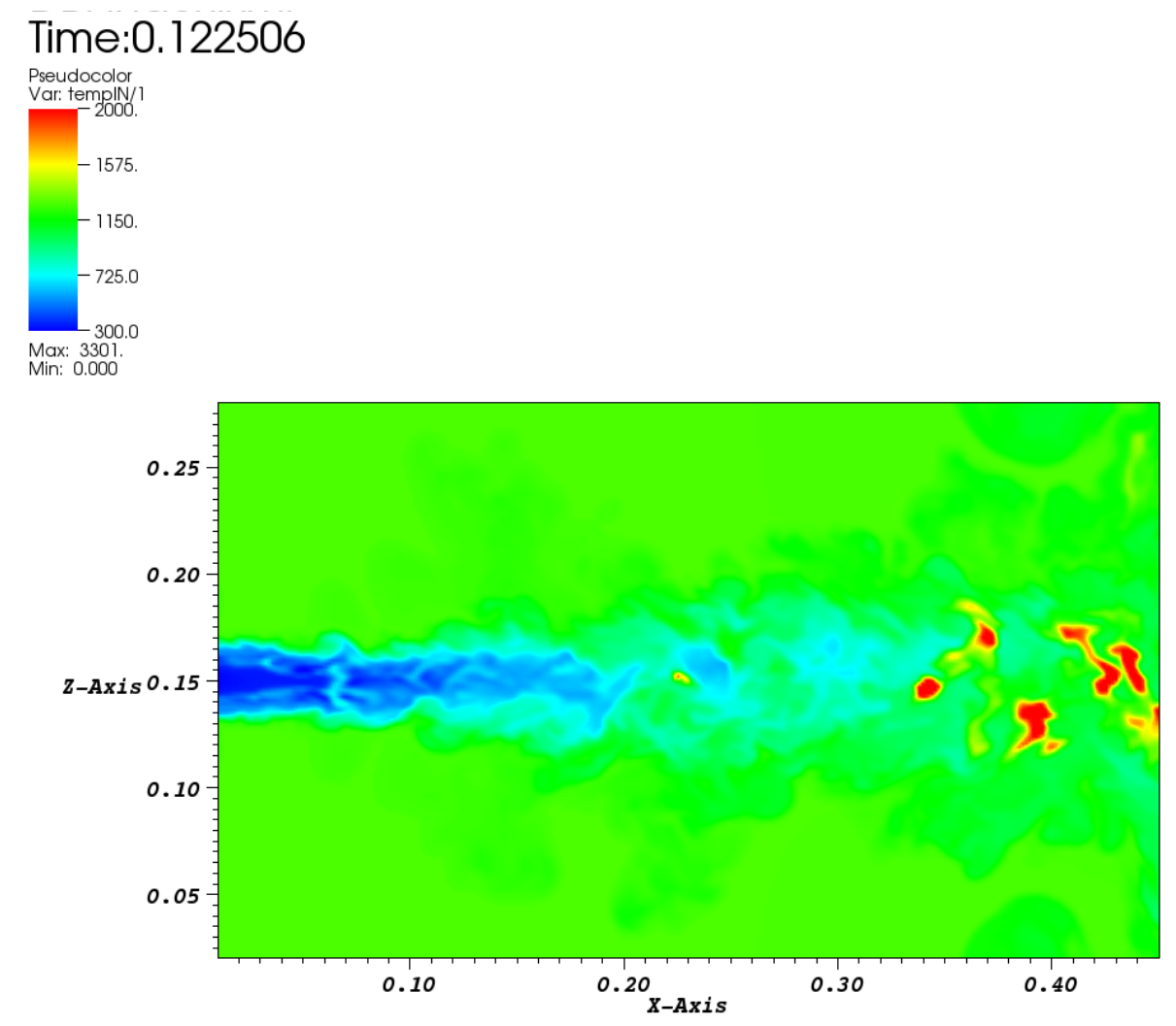

Figure 36. Gas temperature (K).
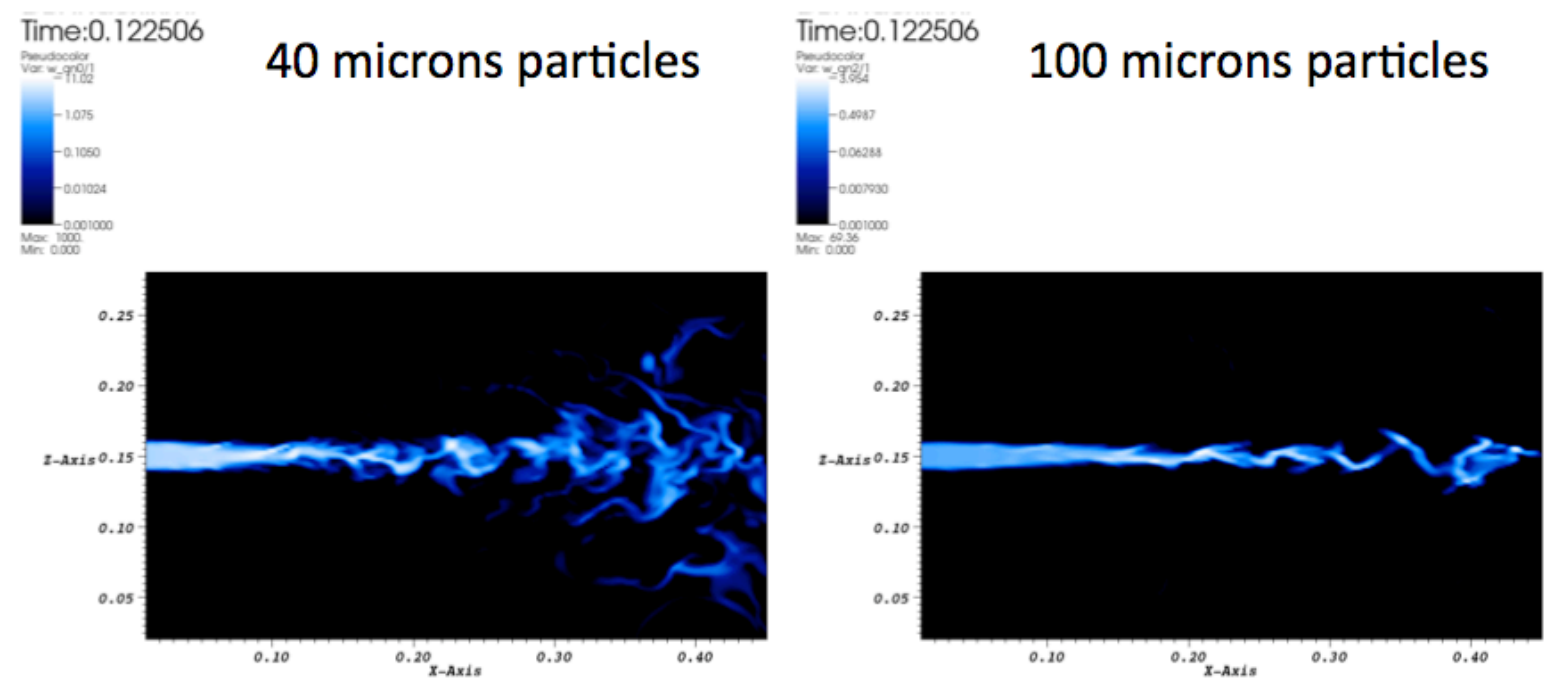

Figure 37. Particle number density $\left(\# / \mathrm{m}^{3}\right)$.

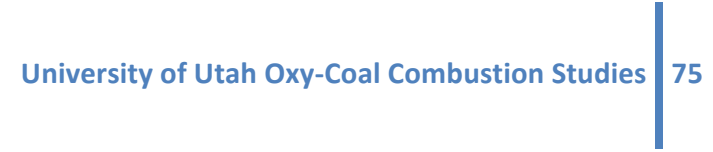


Table 15. Results for Case 1 and Case 5.

\begin{tabular}{cccc}
\hline $\mathrm{P}_{\mathrm{O} 2}$ primary & Wall temperature $(\mathrm{K})$ & $\begin{array}{c}\text { Measured average stand- } \\
\text { off distance }\end{array}$ & $\begin{array}{c}\text { Predicted average stand- } \\
\text { off distance }\end{array}$ \\
\hline $0 \%$ & $1283 \mathrm{~K}$ & $30 \mathrm{~cm}$ & $31 \mathrm{~cm}$ \\
$20.9 \%$ & $1283 \mathrm{~K}$ & $12 \mathrm{~cm}$ & $31 \mathrm{~cm}$ \\
$20.9 \%$ & $1433 \mathrm{~K}$ & $\mathrm{NA}$ & $10 \mathrm{~cm}$ \\
\hline
\end{tabular}

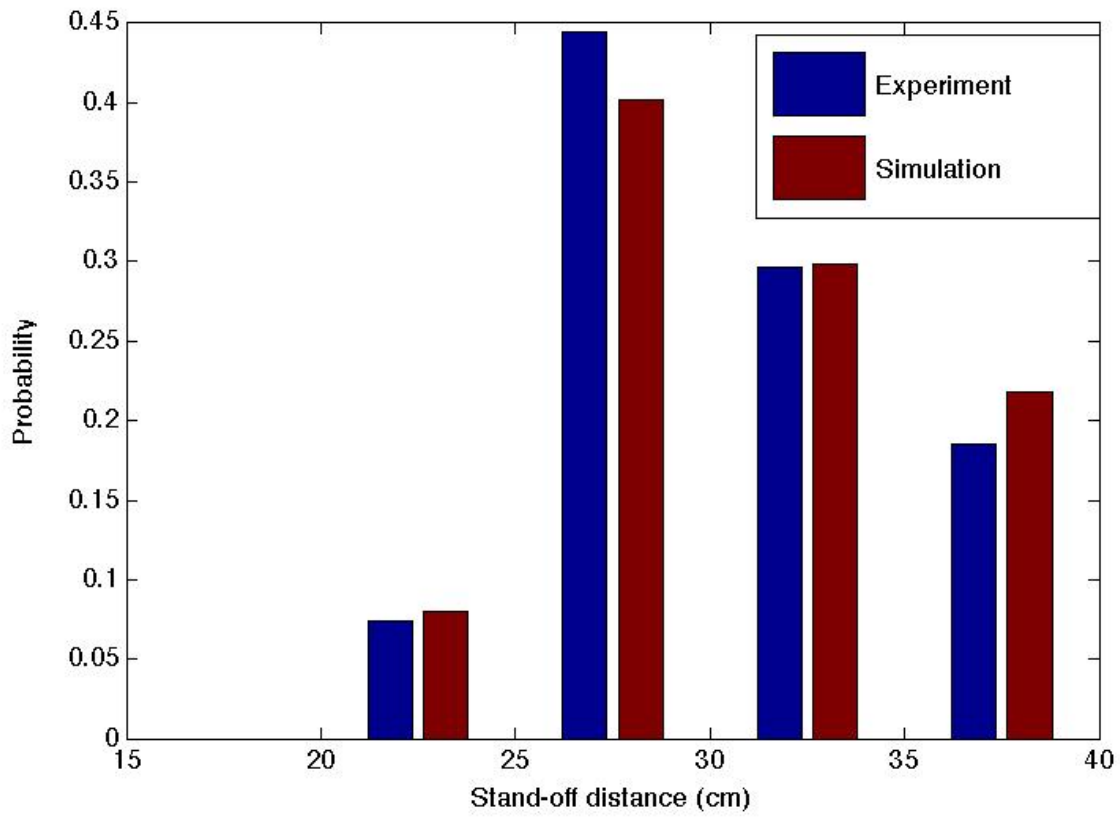

Figure 38. Comparison of flame stand-off distance statistics between simulations and experiments for Case 1.

Subtask 3.2 - Near-Field Aerodynamics of Oxy-Coal Flames with Directed Oxygen and Minimum Flue Gas Recycle

Results are presented in two sub-sections. First, the role of the composition of coal transporting fluid is investigated. The burner configuration for this was a dual concentric co-axial burner described in the previous topical report, rather than the new triple coaxial burner described in the Method Section for the oxygen directed tests. These tests provided insight into mechanisms of flame stabilization. Second, data on flame stabilization during the directed oxygen tests is presented. The preliminary data on laser diagnostic PIV tests on the OFC are presented under Subtask 3.3.

\section{Effect of variations in carrier gas composition}

In this test with the dual concentric co-axial burner, only the oxy-coal $\mathrm{O}_{2} / \mathrm{CO}_{2}$ transport stream is replaced by an $\mathrm{O}_{2} / \mathrm{N}_{2}$ mixture. The secondary stream remains $\mathrm{O}_{2} / \mathrm{CO}_{2}$. When the transporting medium is replaced, so is the momentum of that jet, for the same velocity. Therefore, two sets of tests were run - one in 
which $\mathrm{N}_{2}$ primary jet momentum was matched to that for the $\mathrm{CO}_{2}$ case, by changing the velocity - the other in which velocities were matched, yielding differences in momenta.

The effect of primary $\mathrm{P}_{\mathrm{O} 2}$ is shown in Figure 39 for the flame images taken by a Nikon D5000. These differ from the flames with $\mathrm{CO}_{2}$ as the transportation gas and show greatly increased flame stability for both matched momenta (upper row) and matched velocity (lower row) cases. In fact, for the matched velocity case, replacement of $\mathrm{CO}_{2}$ in the primary jet by $\mathrm{N}_{2}$ are always attached, even at $\mathrm{P}_{\mathrm{O} 2}=0 \%$. Additional detail is presented in the concomitant PDFs of the flame standoff distance that are shown in the two columns on Figure 40. Examination of these two figures demonstrates again the relationship between the flame shape, as seen by the human eye and the statistical basis used to quantify the effect being examined.

The implications of these results on axial coal jet ignition mechanisms are discussed below. 


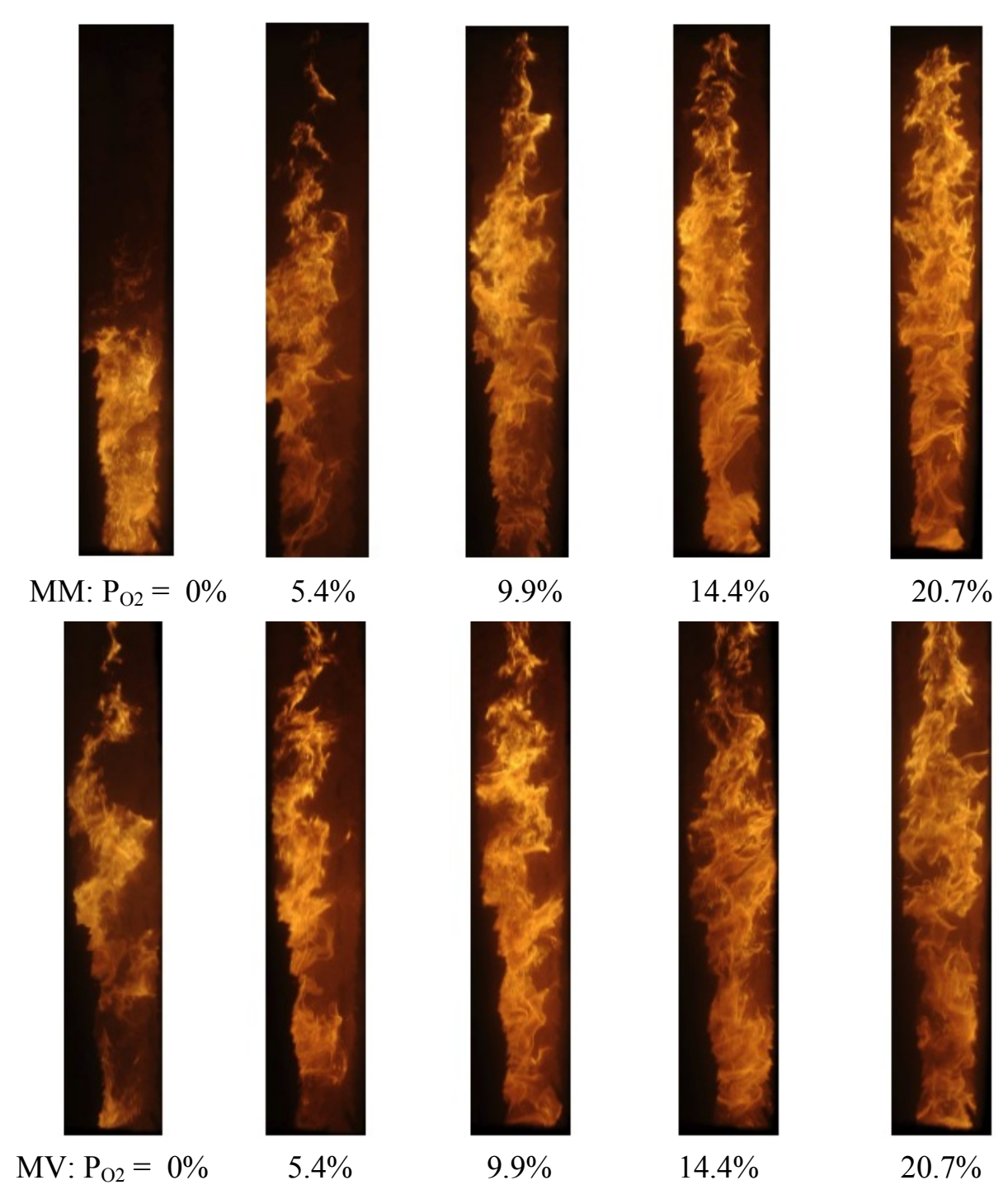

Figure 39. Flames with $\mathrm{N}_{2}$ as the coal transport fluid. Replacement of transport fluid $\mathrm{CO}_{2}$ by $\mathrm{N}_{2}$ greatly increases flame stability. $\mathrm{MM}=$ matched momentum. $\mathrm{MV}=$ matched velocity. Previous data with $\mathrm{CO}_{2}$ as transport fluid showed attached flame only for $\mathrm{P}_{\mathrm{O} 2}>14.4 \%$. 


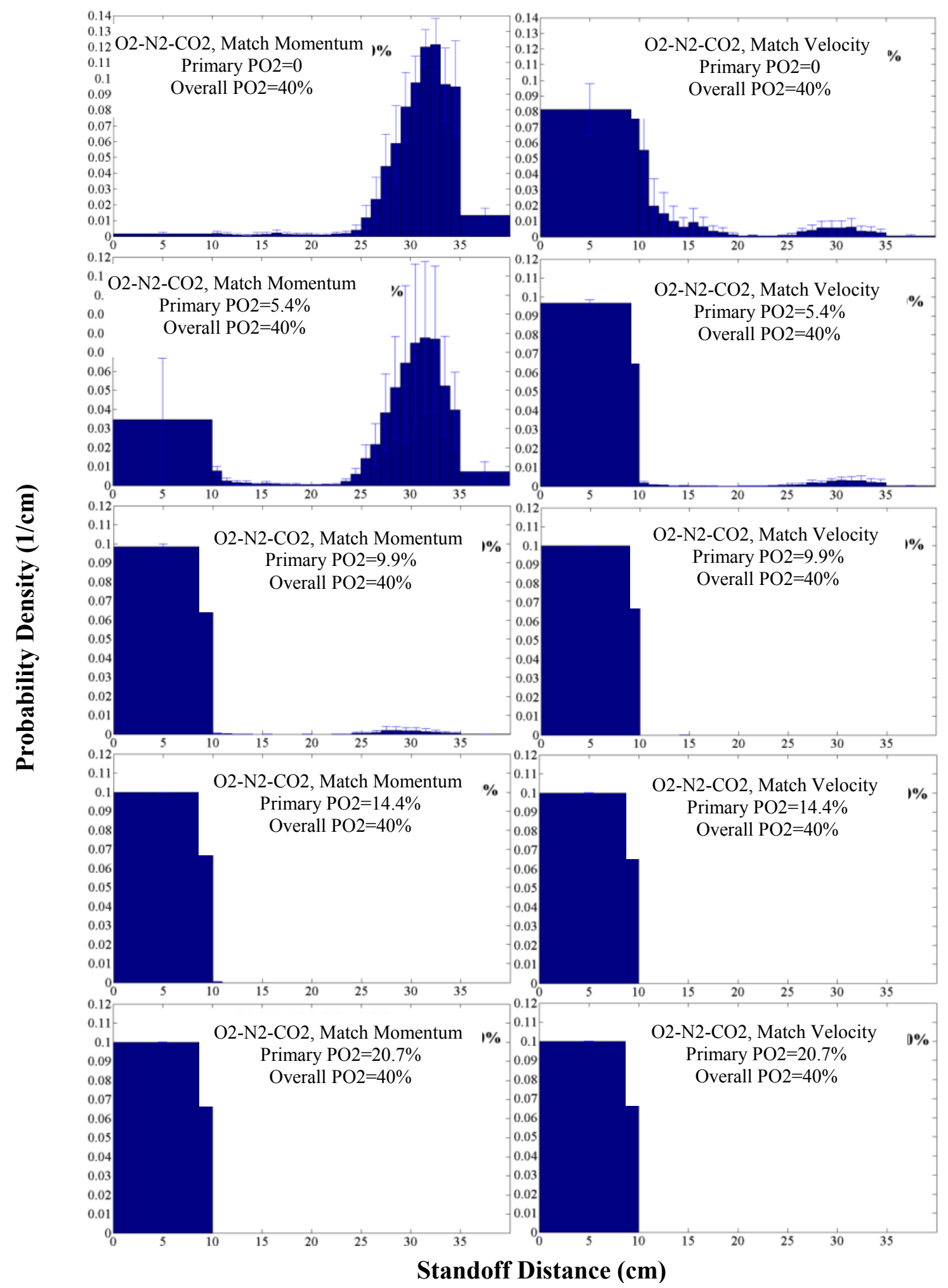

Figure 40. Flame stand-off PDFs for tests with $\mathrm{N}_{2}$ as transport fluid. University of Utah Oxy-Coal Combustion Studies 79 
The data presented hitherto suggest that both the composition of the primary jet and the effective temperature of a mixture of secondary jet and (secondary) recirculation fluid controls particle heat up. This suggests that a simple model might be able to correlate the data, particularly those in which the transport gas was changed from $\mathrm{CO}_{2}$ and $\mathrm{O}_{2}$ to $\mathrm{N}_{2}$ and $\mathrm{O}_{2}$.

The simple model is based on the following physical picture. Primary oxygen concentration determines the initial concentration of $\mathrm{O}_{2}$ seen by a particle, and it must be increased to some required ignition level at the particle surface by molecular diffusion through a stagnant film consisting of the transport fluid. The "particle" may not be a single coal particle, but might consist of a clump of particles, or even a "blob" of early volatiles. Large turbulent eddies throw these "particles" or ignitable "blobs" out into a mix of secondary oxidant and secondary (internal) recirculation. Oxygen (and probably also heat) diffuses from the mix, through a stagnant film consisting of primary transport gas, as shown on the rough schematic of Figure 41.

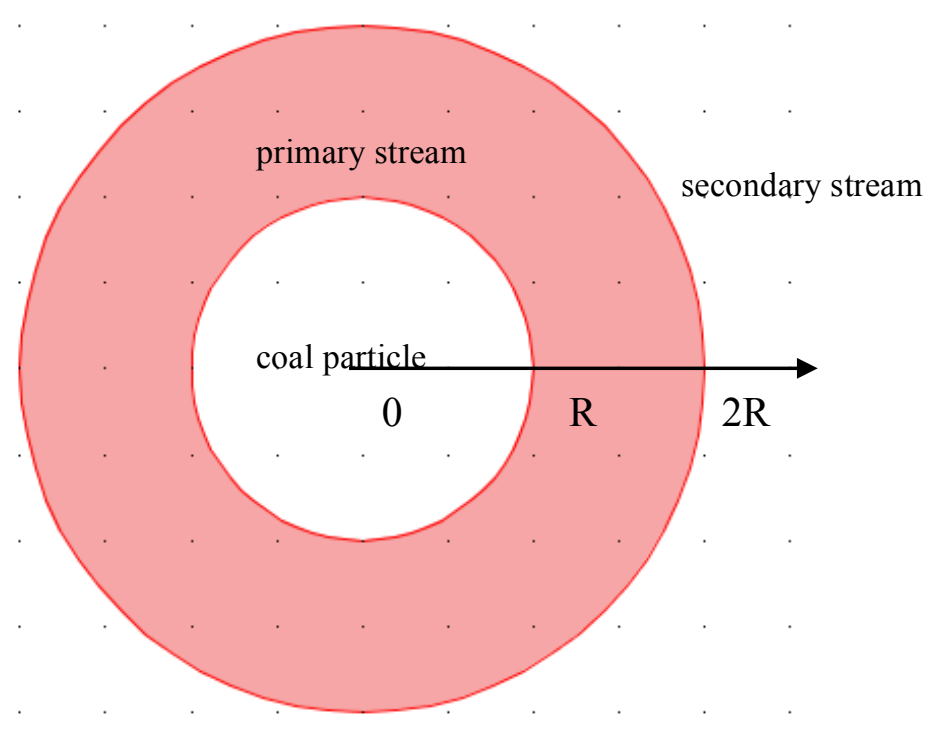

Figure 41. Simple model to correlate data on effect of transporting fluid. Model assumes that time to ignition is controlled by molecular diffusion of $\mathrm{O}_{2}$ from secondary fluid through stagnant film of transport fluid.

If we assume that ignition occurs when the $\mathrm{P}_{\mathrm{O} 2}$ vol\% at the coal particle surface reaches, say, $14.4 \%$ by molecular diffusion. For illustration purposes, a spherical coal particle was assumed, with a radius of 100 $\mu \mathrm{m}$, and was surrounded by a primary stream film (thickness: $100 \mu \mathrm{m}$ ) and then introduced into the secondary stream/recirculation mix. There are two boundary conditions:

1. $\mathrm{P}_{\mathrm{O} 2}$ in secondary stream is constant. Here it is set and equal to the values of the secondary stream, University of Utah Oxy-Coal Combustion Studies 
which is higher than that of the mix. However for the case where primary fluid is changed from $\mathrm{CO}_{2}$ to $\mathrm{N}_{2}$, it is constant, and a lower value would merely change the (constant) assumed value of $\mathrm{O}_{2}$ at the particle surface necessary to initiate ignition.

2. There is a zero flux at the surface of coal particle.

Figure 42 shows the results of the correlation between calculated ignition time and measured mean standoff distance for the data presented above (with all the crude assumptions delineated above) and suggests that molecular transport through the primary fluid is the controlling mechanism, and that is why replacement of $\mathrm{N}_{2}$ by $\mathrm{CO}_{2}$ for oxy-coal combustion will increase the standoff distance for a given $\mathrm{Po}_{2}$ and given burner momenta.

When this argument is pursued further to determine if the same correlation holds for data showing effects of increases of secondary stream $\mathrm{P}_{\mathrm{O} 2}$ we find that it does not (triangles on Figure 42). This is most likely because, in part, we should have considered $\mathrm{P}_{\mathrm{O} 2}$ of the secondary stream plus the internal recirculation mix, rather than the $\mathrm{P}_{\mathrm{O} 2}$ of the secondary stream alone.

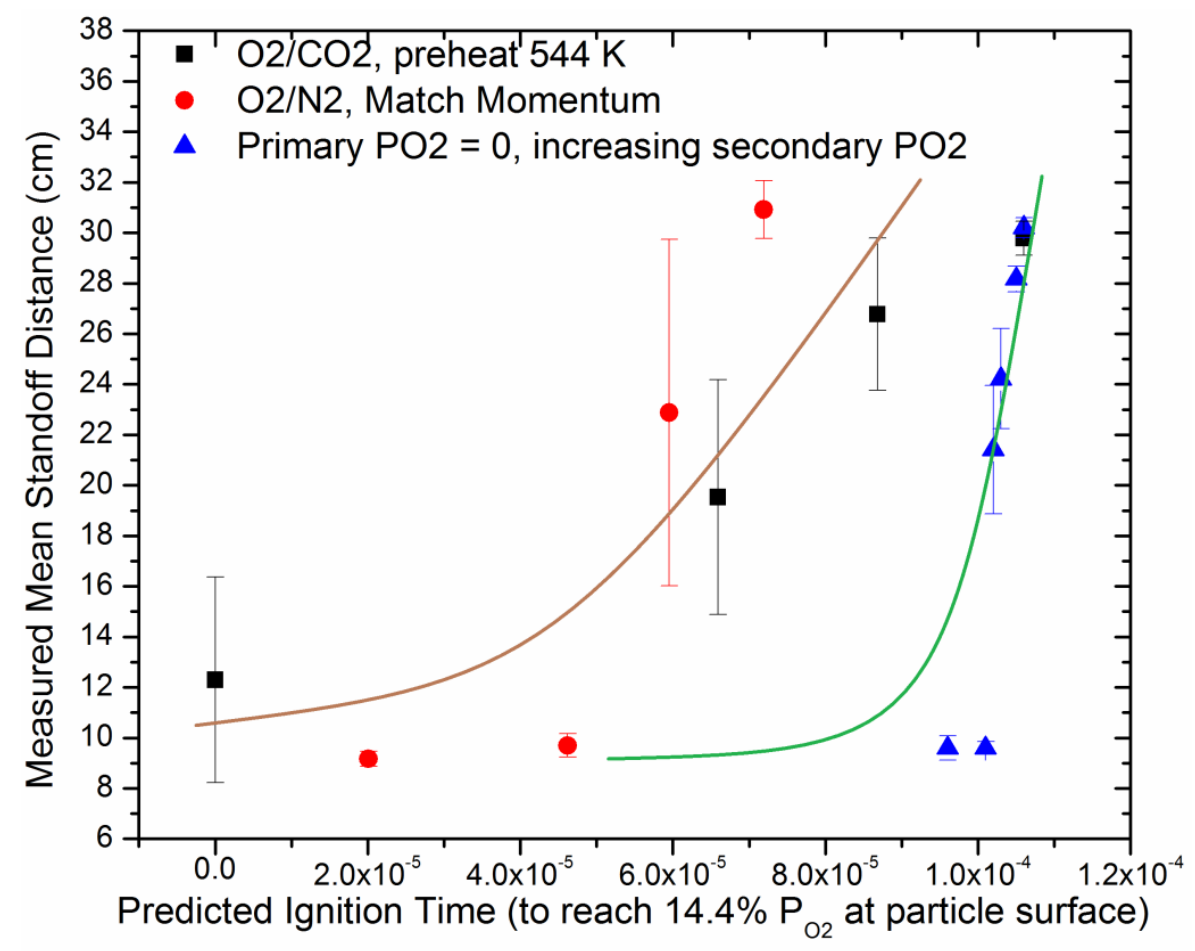

unit: $\mathrm{s}$

Figure 42. Correlation of data on effect of transport medium, using simple molecular diffusion film model.

\section{Flame stand-off distance for directed oxygen strategy}

Figure 9 shows flame stability results for the ten directed oxygen cases outlined in Table 1. Five replicates for the case number one and nine and two replicates for the other cases were performed. The results of the 
image analysis are reported in PDFs of stand-off distance. PDFs of the cases are presented in Figure 43. As seen in the figures, attachment of the flame is an unstable phenomenon until the case number 7, which is the transient point for a stable flame. The burner number seven has $75 \%$ of the total oxygen in the oxygen lance. After this point the flame was fully attached for the cases number 8 and 9 . The trend shows that attached flame occurs when the concentration of oxygen is above $75 \%$ of total oxygen.
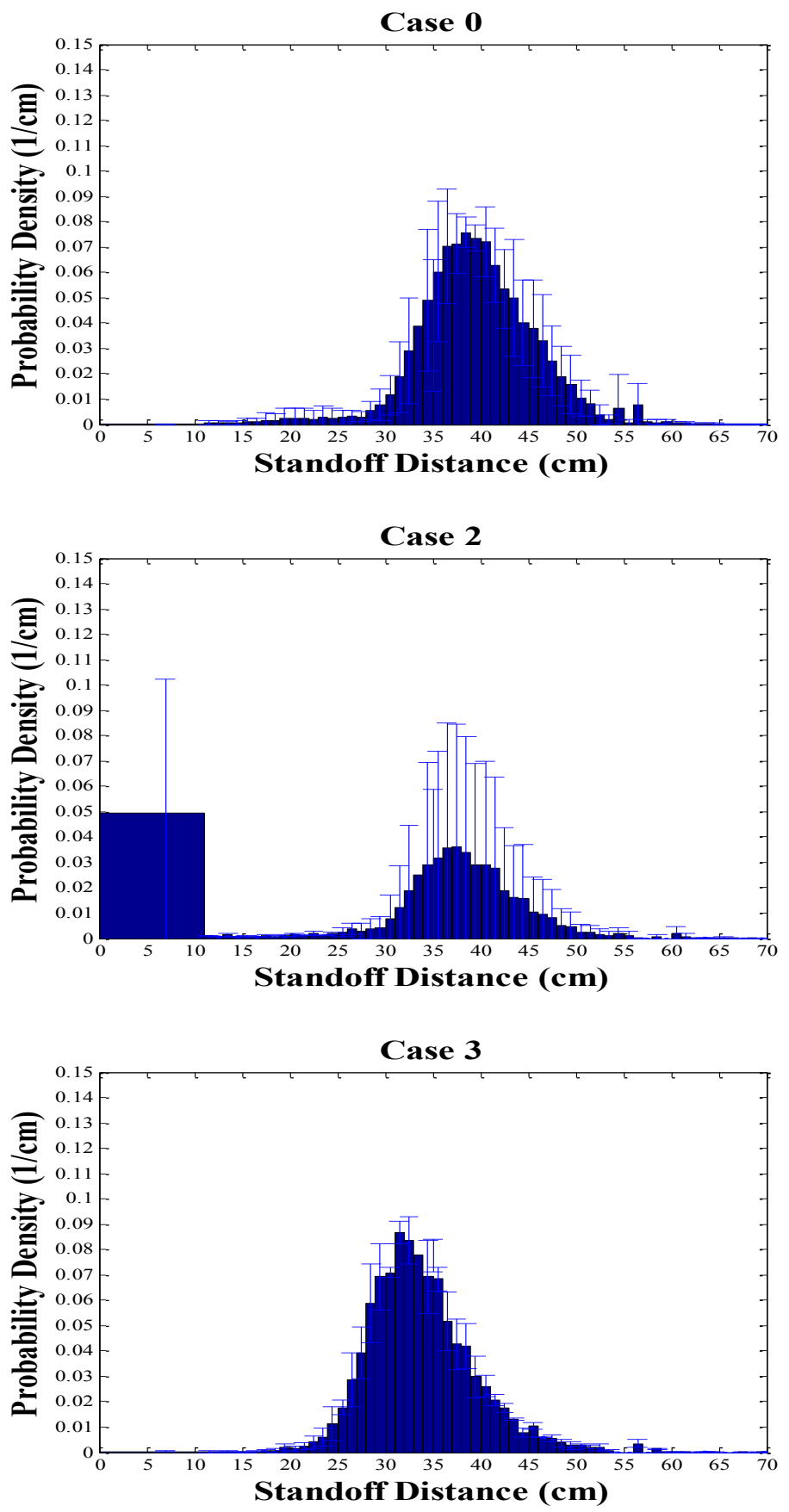

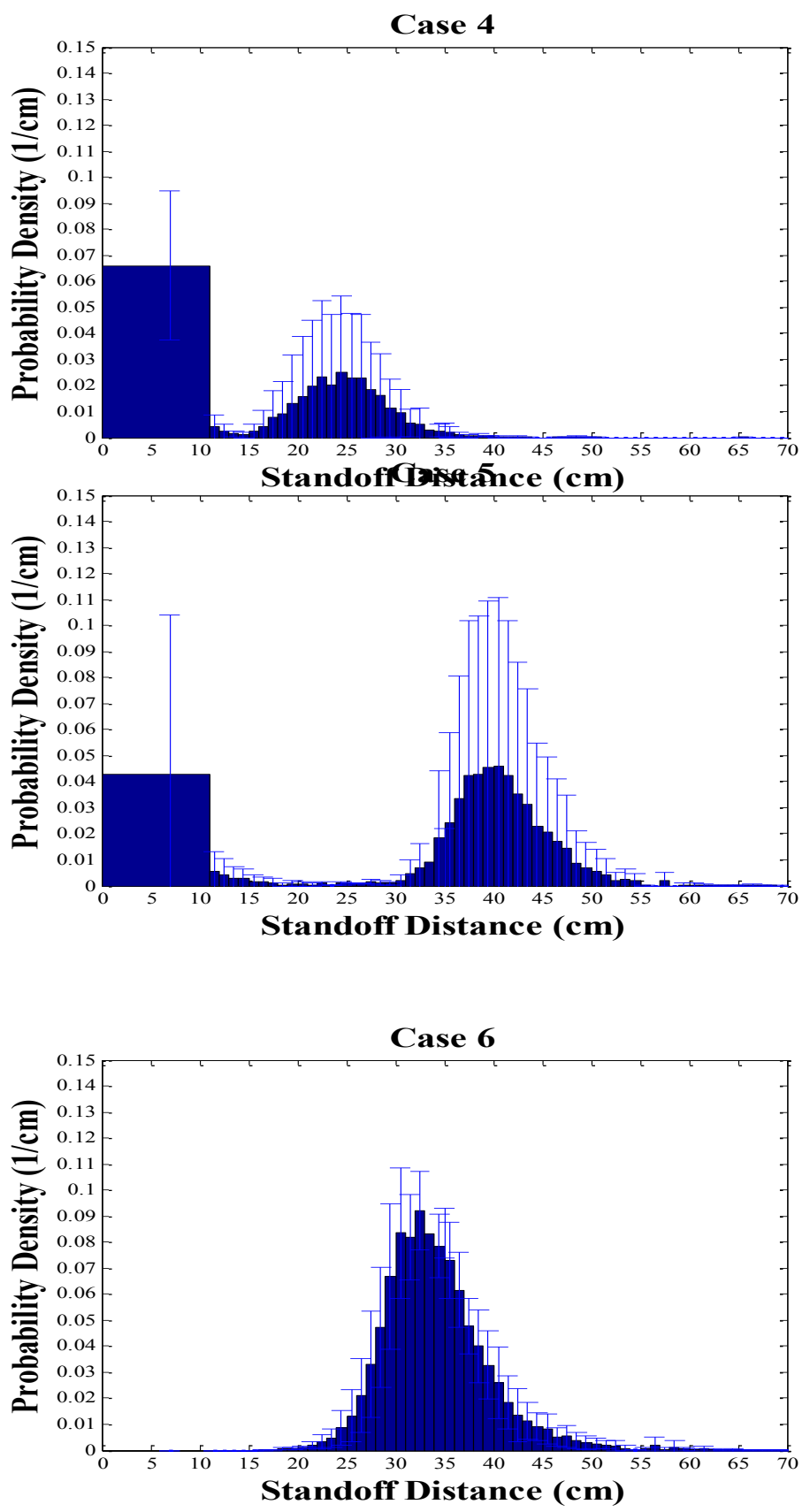

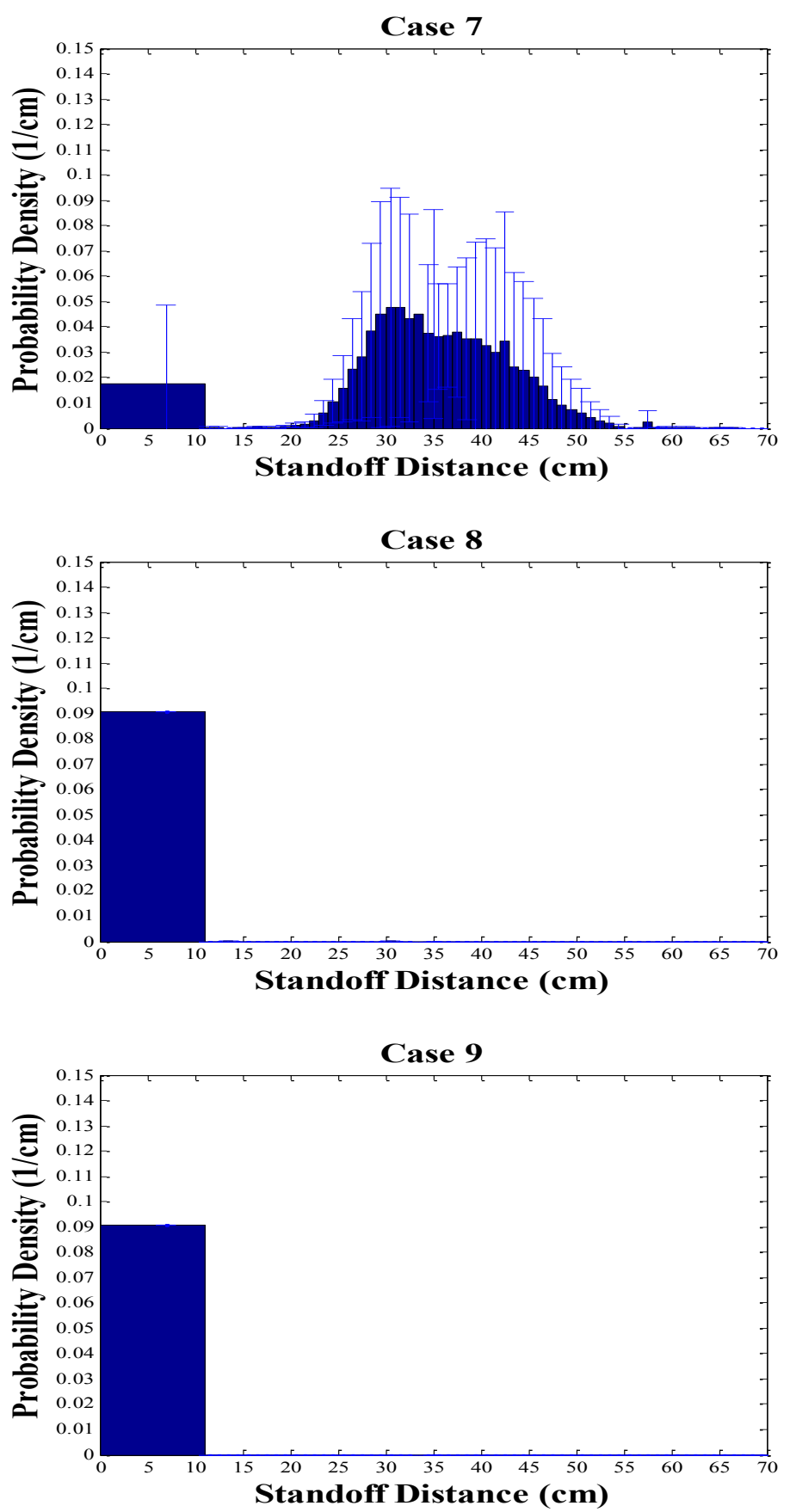

Figure 43. PDFs of stand-off distance for directed oxygen tests (Burners 0-9)

It is important to notice, in the burner number 9 all of the oxygen is being introduced by the oxygen lance. This test proved the safety and the feasibility of injection of all pure oxygen in oxygen lance. This experiment is another step forward to the goal, which is minimizing amount of $\mathrm{CO}_{2}$ in oxy-fuel combustion. 
In addition, $\mathrm{NO}_{\mathrm{x}}$ formation was measured in these experiments. NOx measurement is usually a complicated measurement; however, after having two replicates for each case, it was found that increasing oxygen in the oxygen lance will decrease the NOx formation. The results are shown in Figure 44. It is important to note that burner numbers 8 and 9 created a fully attached flame. It is significant that the lowest $\mathrm{NO}_{\mathrm{x}}$ concentrations were obtained when $100 \%$ of the oxygen was introduced via the lance (middle annulus). Calculated adiabatic flame temperatures had not changed, only the mixing of oxygen and the fuel, the secondary $\mathrm{CO}_{2}$ and the other flows.

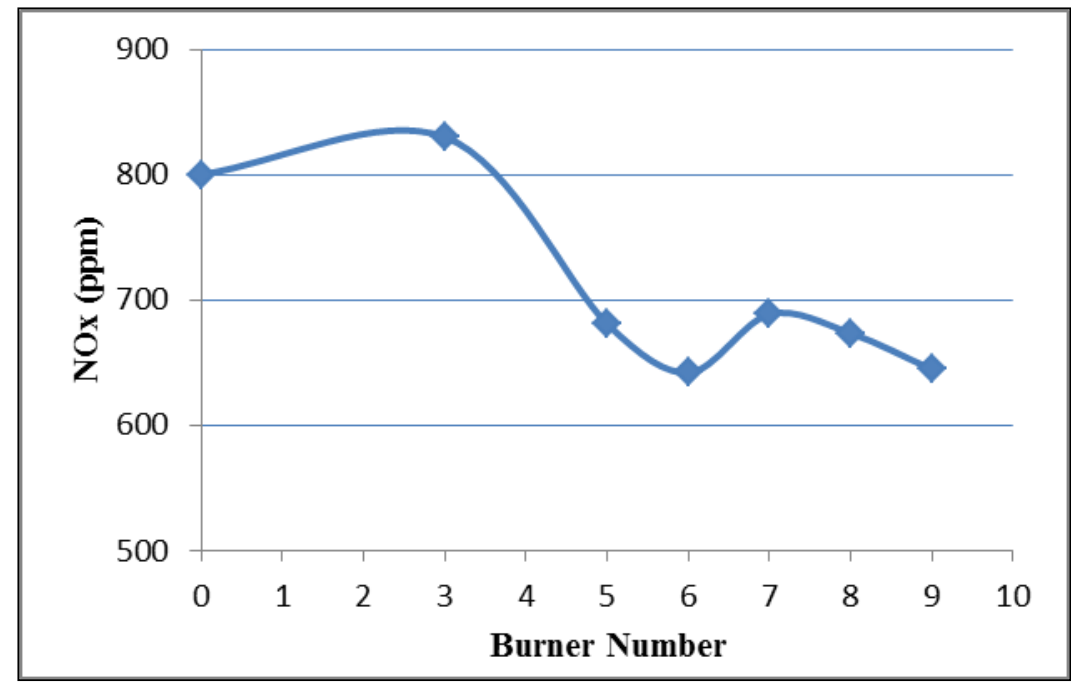

Figure 44. $\mathrm{NO}_{\mathrm{x}}$ formation versus burner number.

\section{Laser diagnostic PIV results}

Experiments were conducted in order to apply the PIV and infrared technology to the OFC burning pulverized coal, under oxy-fired conditions. The purpose was to demonstrate the applicability of the technology for subsequent validation of the simulations. The PIV results are shown in the following section.

\section{Subtask 3.3 - Advanced Diagnostics for Oxy-Coal Combustion}

The results are presented in two sections, the first one includes the results obtained in the laboratory diffusion flame for gaseous flames, and the second section includes the results obtained for the pulverized coal flames in the lab-scale burner and in the OFC.

\section{PIV results for lab-scale gaseous flames}

Before the first version of the coal feeder was in operation, initial calibration and evaluation of the PIV system were completed. The preliminary PIV data on gaseous flames was used to explore the range of capabilities of the PIV set-up, as well as to characterize the coal burner. Parameters such as the time delay 
$\left(T_{d}\right.$ ) between laser pulses (same as 1/frame rate of the camera in this experimental set-up) and the size of the interrogation area (IA) were evaluated and optimized.

\section{Effect of varying $T_{d}$}

Figure 45 shows the image maps and corresponding vector maps for the gaseous flame with the camera framing rates of 1500 and $3000 \mathrm{fps}$. These correspond to $T_{d}$ of 666 and $333 \mu$ s, respectively. The seeding particles are shown following the flame flickering. As can be seen, using the $1500 \mathrm{fps}$ results in underestimated results with the vector maps not representing the flow motion properly. However, using the 3000 fps represents the flame well, as expected.

\section{Effect of varying $I_{A}$}

Figure 46 represents the vector maps at two different IAs, namely 16 pix x 16 pix and 32 pix x 32 pix. In both cases the camera frame rate is kept at $3000 \mathrm{fps}$. The choice of the IA size depends on the resolution of the camera and the range of measured velocities. The IA size needs to be larger if the velocity is high enough to accommodate for the seeding particles in image pairs. Using the smaller IA produces overestimated velocity values.

An interrogation area of 32 pix X 32 pix and setting the camera frame rate at 3000 fps permitted the best PIV results in terms of representing the motion flow.

1500 fps

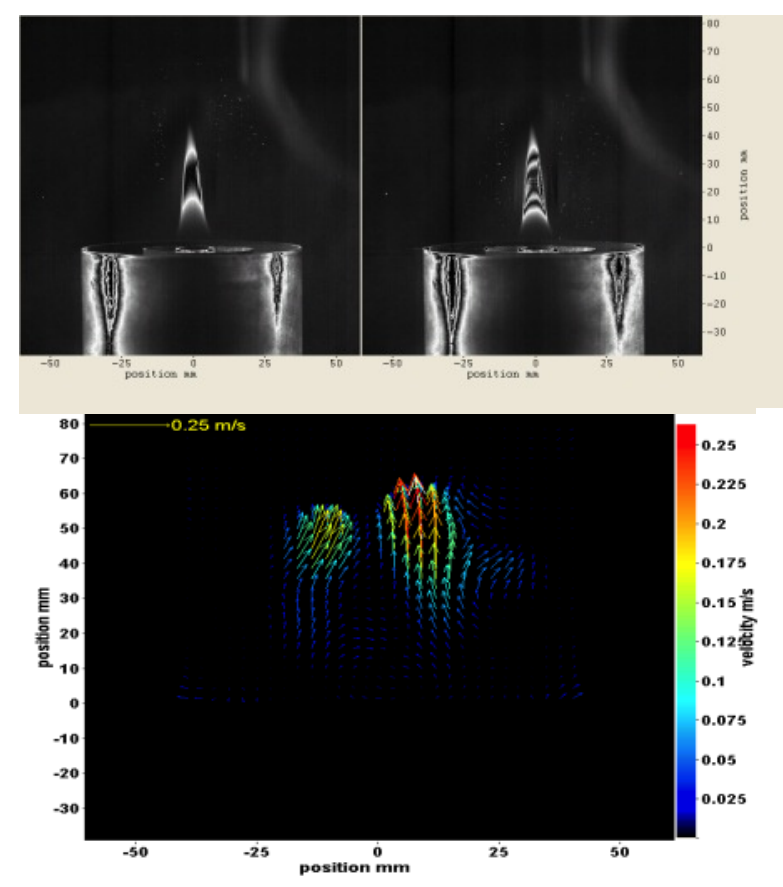

3000 fps
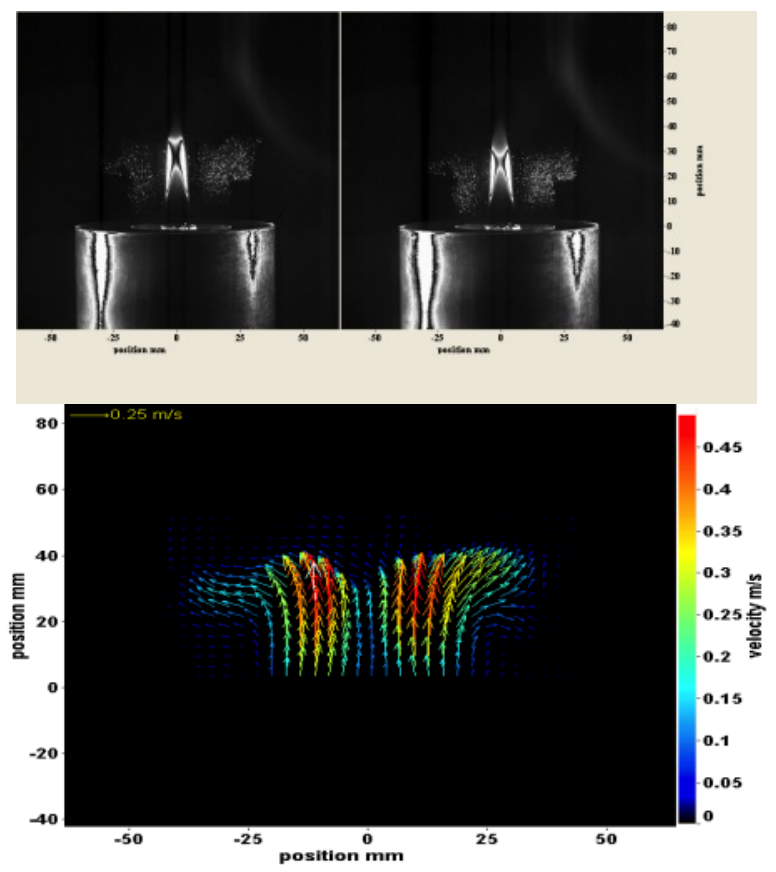

Figure 45. Image map (top) and vector maps (bottom) of the gaseous University of Utah Oxy-Coal Combustion Studies 86 
flame at 1500 and 3000 frames per second (fps).
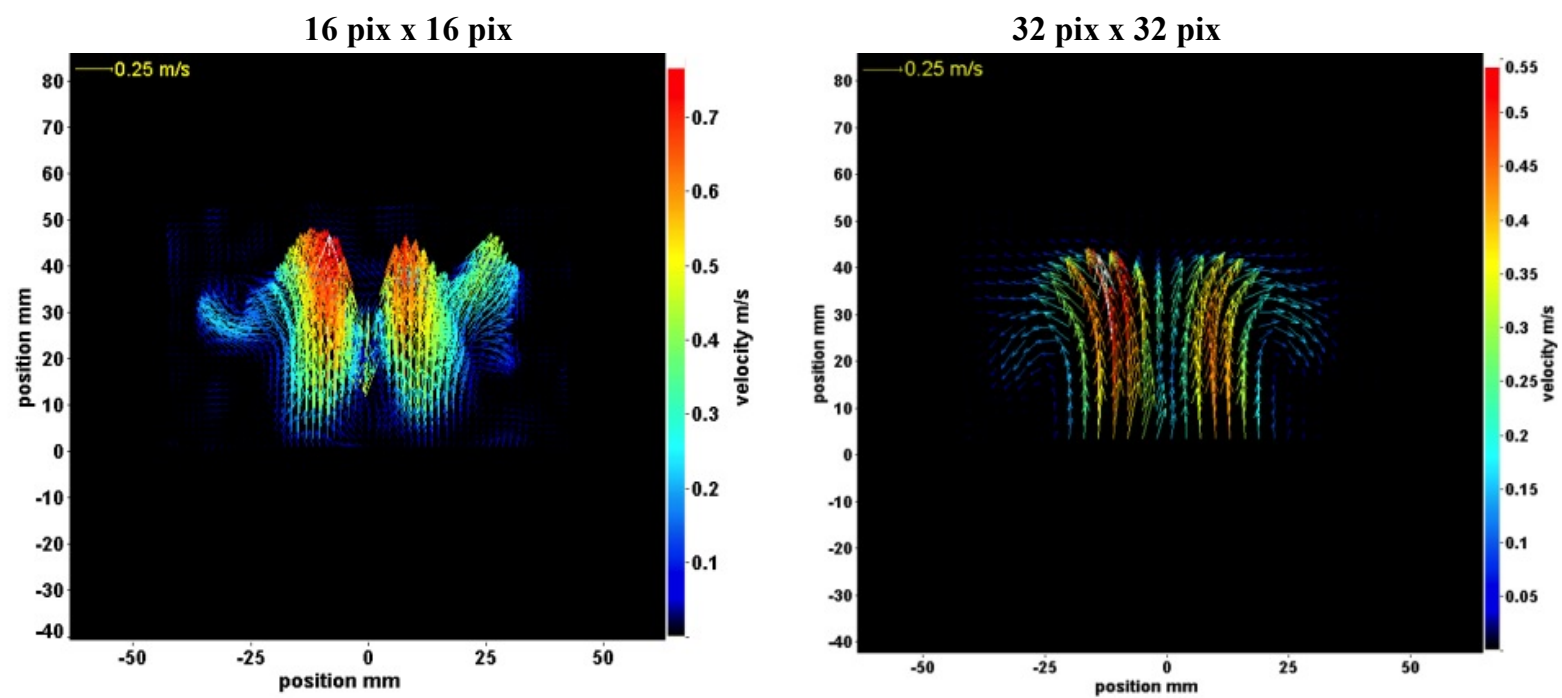

Figure 46. PIV vector maps of the gaseous flame using two different IAs. Camera frame rate was 3000 fps.

Vertical velocity as a function of height above the burner

The vertical velocity (the y-component of the velocity) was investigated at five different heights above the burner for the gaseous flame. Figure 47 shows the symmetry around the burner center and the variation in the vertical velocity, at different heights. Peak velocities continue to decrease with increasing height until a height of $50 \mathrm{~mm}$, where the velocity profile is nearly flat.

Based upon initial experimental results, some adjustments were made to the burner in order to correct some symmetry issues that became noticeable once the detailed velocity information was obtained. 


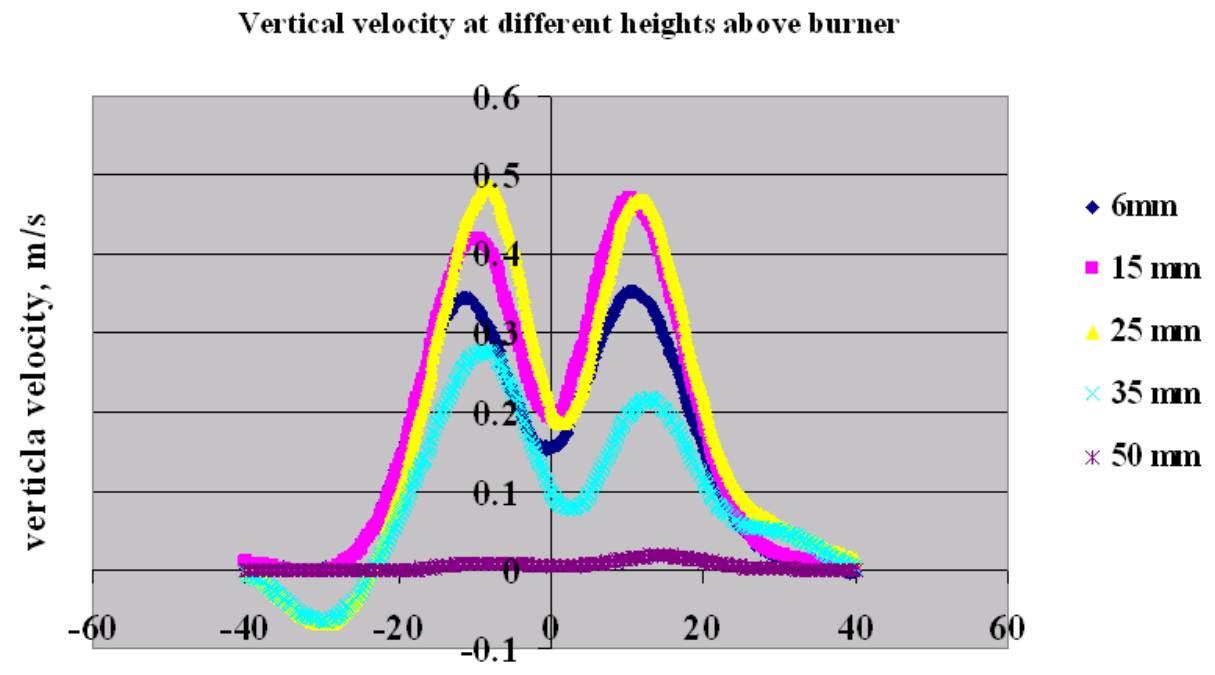

Horizontal location from burner's center, mm

Figure 47. Vertical velocity, as measured by PIV, at five different heights above the burner. Camera frame rate was 3000 fps, with an IA of 32 pix x 32 pix.

\section{Preliminary PIV results of pulverized coal flames}

Initial PIV measurements were made on a pulverized coal flame using the laboratory coal burner and the first version of the coal feeding system. PIV measurements were conducted using the Photron camera, the continuum laser and the PIV software (Davis 7.2, Lavision). The main objectives for the preliminary tests were to analyze the velocity field of the coal particles in the flame and try to isolate different particle sizes using image processing techniques.

The optimized PIV parameters found in the gaseous flames were used in the PIV analysis for pulverized coal flames. In addition, image analysis software (JM Canty, Inc) was used in conjunction with the PIV system to provide detailed image maps and velocity information, as well as for the overall particle-size distribution.

The left side of Figure 48 shows an example of image maps of the pulverized coal flame. The velocity field of the flow, produced using two consecutive image maps, is shown in the right side of Figure 48.

As can be seen from Figure 49, different sizes of particles are present in the flame. The coal PSD in the flame is obtained in each frame by image analysis using the Canty software. Figure 49 shows that both frames have very similar size distribution, with particle size 20-30 $\mu \mathrm{m}$ being the most abundant, in addition to a smaller number of larger sizes. In all images, both frames show only slightly different populations for the same size bin. 


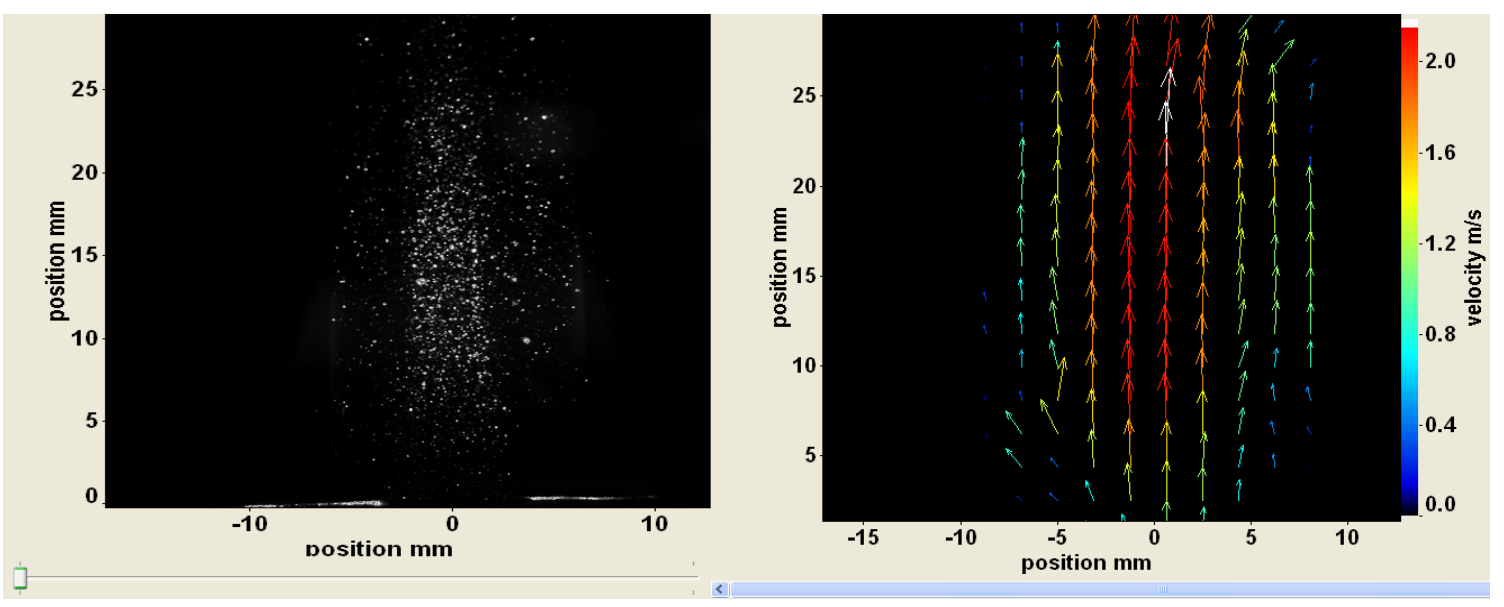

Figure 48. Example of an image map of the laboratory pulverized coal flame and the corresponding velocity field from two consecutive image maps using PIV (coal flow rate $150 \mathrm{mg} / \mathrm{min}, \phi=0.92$ ).

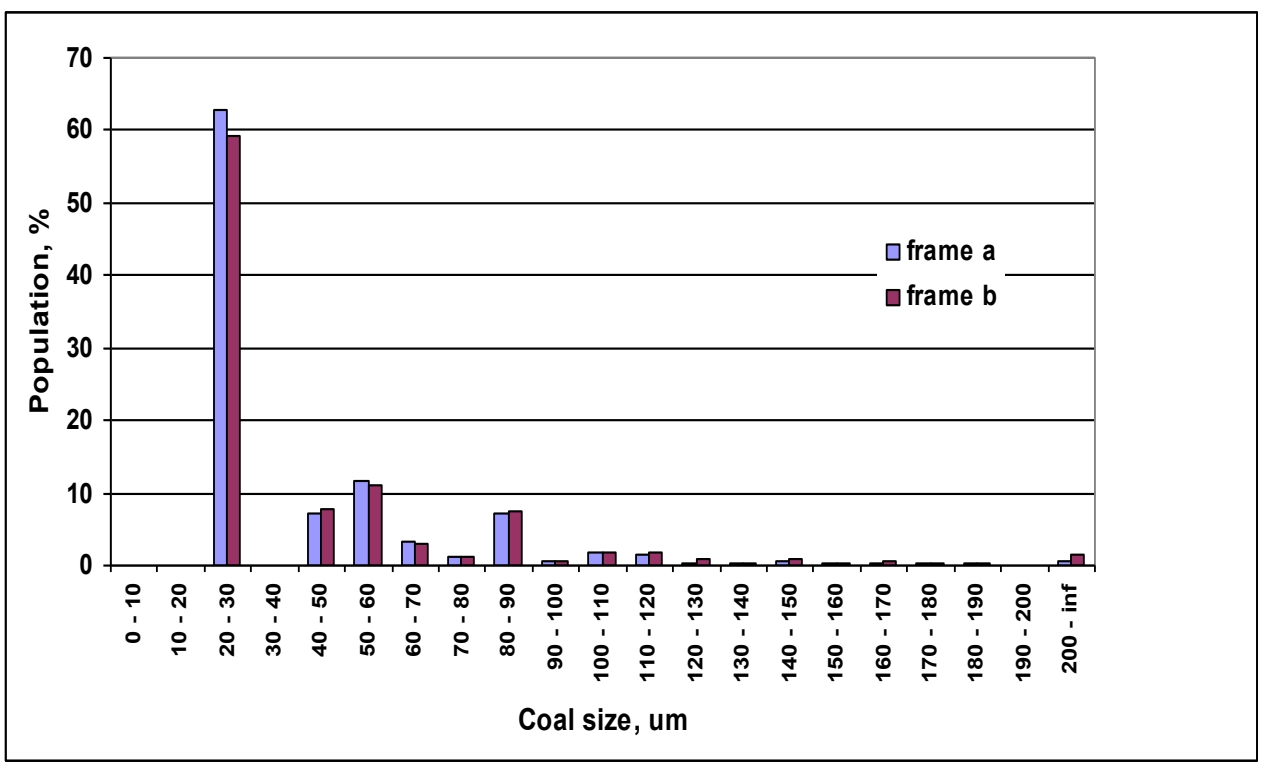

Figure 49. Particle size distribution in a pulverized coal flame, $\phi=0.92$.

These results have confirmed the ability to obtain velocity field information via PIV in a laboratory pulverized-coal flame, and have also demonstrated that it is possible to extract particle size-specific information using image analysis techniques.

Effects of coal particle size and global equivalence ratio on PIV results of pulverized coal flames

PIV data was obtained in the lab-scale burner with the new version of the coal feeder and improved components of the PIV system in order to reduce variability in the PIV measurements. Coal particle velocities were measured at different flame locations, under different global equivalence ratios $(\phi)$ and for experiments using different coal particle size fractions. 
Figure 50 shows examples of instantaneous Mie scattered images of pulverized coal flames and the corresponding velocity fields at three different heights of the flame with $\phi=0.92$ and using coal particles of sizes $<38 \mu \mathrm{m}$. It is to be noted that each image is one of twin frames taken at two different times, $t$ and $\mathrm{t}+\mathrm{dt}(\mathrm{dt}=50 \mu \mathrm{s})$. From these twin frames one velocity map is created. The inner cone in the flame is formed due to the premixed coal-air stream fed through the central tube of the burner. As can be seen in Figure 50, the velocity field of the pulverized coal flames shows that the shape of the lower regions of the flame looks more uniform than in the upper parts and have lower axial velocities than in the upper sections.

To show the dynamic nature of the coal flame as we move vertically up in the flame, the average instantaneous velocity inside a small area in the velocity field on the flame axis is compared at three different heights (left plot of

Figure 51). It is apparent that the time-average mean velocity and the fluctuation in the instantaneous velocity during the 1 minute run increase vertically. Another important consequence of this increased fluctuation in the upper parts of the flame is that the flame may move perpendicular to the laser sheet during the run and therefore no coal particles are present to scatter the laser and the image becomes blank.

This results in some zero velocities in the middle and upper flame parts- heights 5 and $8.5 \mathrm{~cm}$. The increase in velocity with height is a result of the acceleration of the flow vertically due to air entrainment. This fluctuation looks random as no specific periodicity was observed in the power spectrum as shown in the right plot of

Figure 51. Also the standard deviation was found to increase slightly with height in the flame.

Figure 52 presents an example of the image maps for different $\phi$. In these experiments increasing the equivalence ratio is done by decreasing the mass flow rate of the secondary air (air fed through the annular ring). Figure 52 shows that as the equivalence ratio of the pulverized coal flame increases, the height of the inner cone in the pulverized coal flames decreases. This reduction in the air flow rates results in less air entrainment and hence a reduction in the cone height. Furthermore, inspecting the instantaneous images in Figure 52, it is clear that with high excess air (very fuel lean condition, $\phi=0.25$ ) burning coal particles can be identified more easily than with higher $\phi$. This trend holds true inside and outside the inner cone.

Figure 53 shows the time-mean axial velocities as a function of particle size at a height of $3 \mathrm{~cm}$. It is evident from Figure 53 that flames with coarser coal particles have, in general, less axial velocity than those with smaller coal particle sizes. Also the rate of the reduction in the axial velocity increases as the equivalence ratio decreases, although the trend varies somewhat as stoichiometric conditions are approached. Although there is some scatter observed in the data, there may be trade-offs between hydrodynamic effects at low vs. higher equivalence ratios, and temperature effects due to particle ignition, which may be impacted by both local oxygen concentration and particle size. Larger coal particles will have increased drag and greater terminal velocities in this upwardly fired flame, and thus would tend to have greater slippage with the surrounding gas velocity. Smaller particles will more likely track the gas velocity and exhibit much less difference between gas and particle velocities.

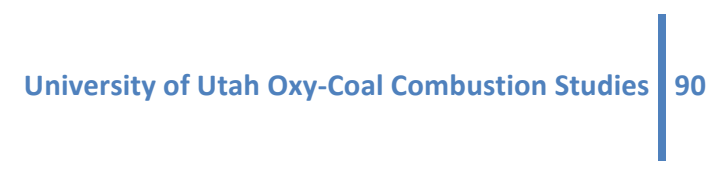



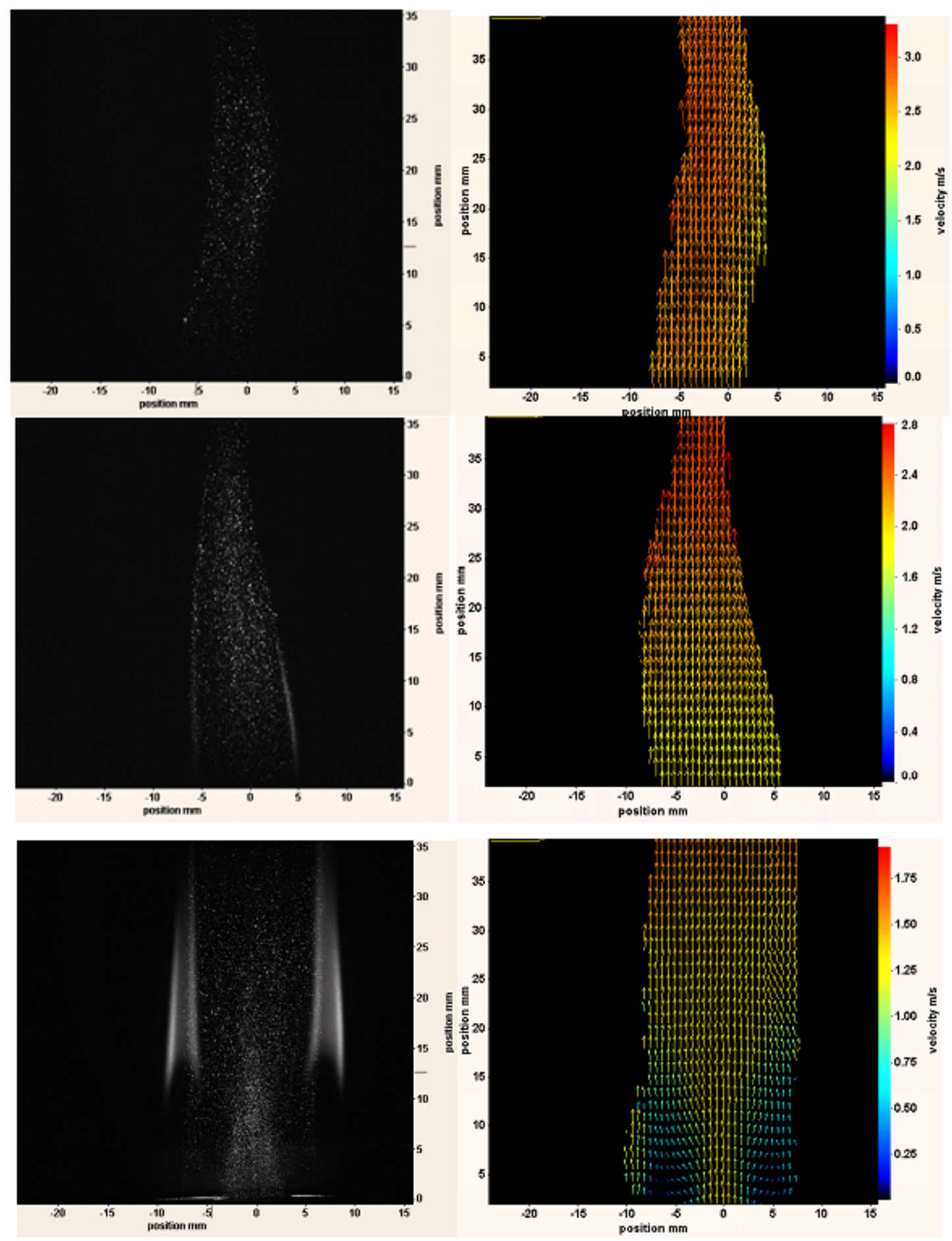

Figure 50. Image maps (left), and the corresponding velocity fields (right) of a pulverized coal flame. Viewing the flame from burner head to a height $3.5 \mathrm{~cm}$ (bottom,), $3.5-7 \mathrm{~cm}$ (middle), and $7-10.5 \mathrm{~cm}$ (top). $\phi=0.92$ and coal particle sizes $<38 \mu \mathrm{m}$. 

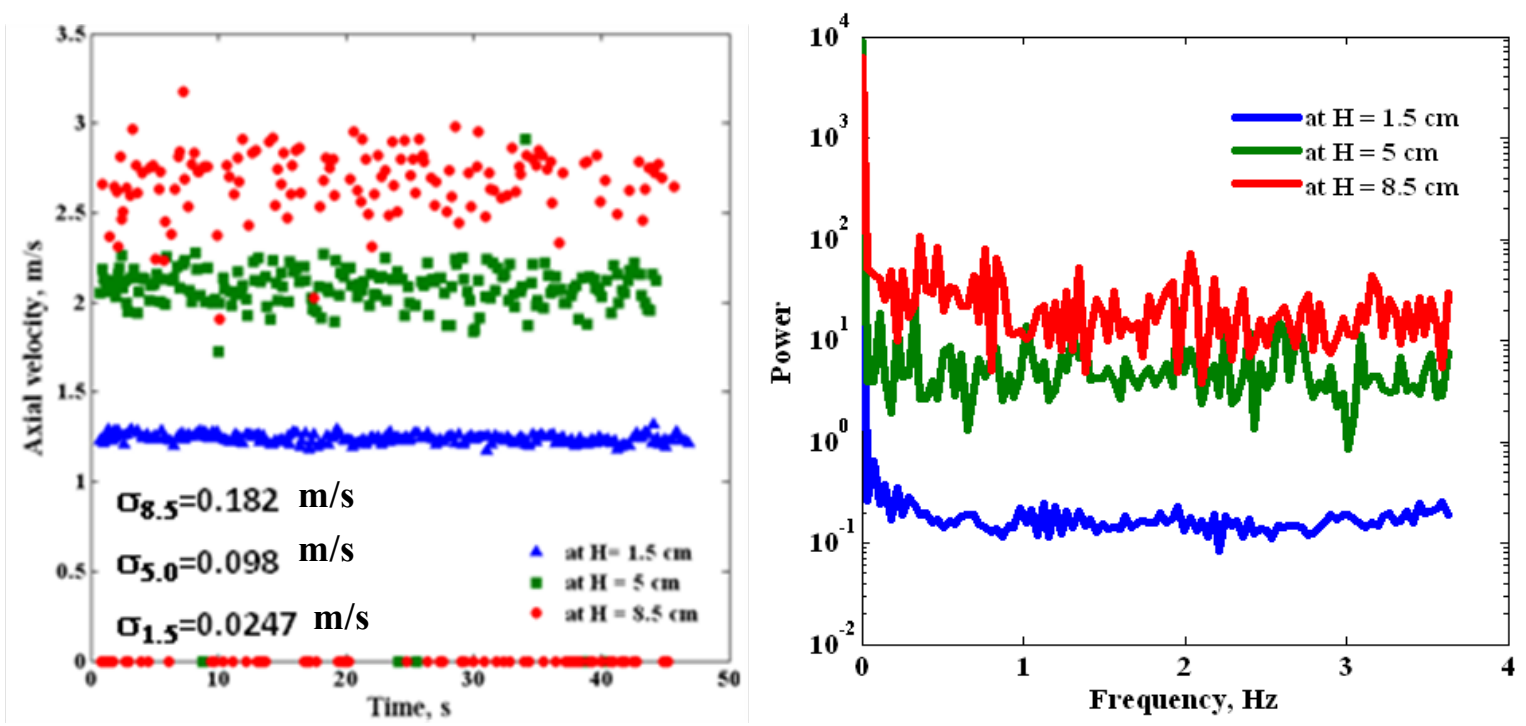

Figure 51. Fluctuation in axial velocity at 3 different heights (left plot) and corresponding power spectrum (right plot). Coal particle size $<38 \mu \mathrm{m}$ and $\phi=0.25 . \sigma$ is the standard deviation.

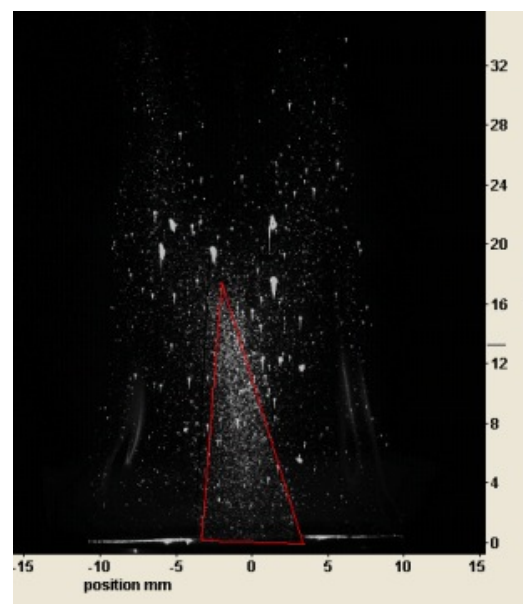

$$
\Phi=0.25
$$

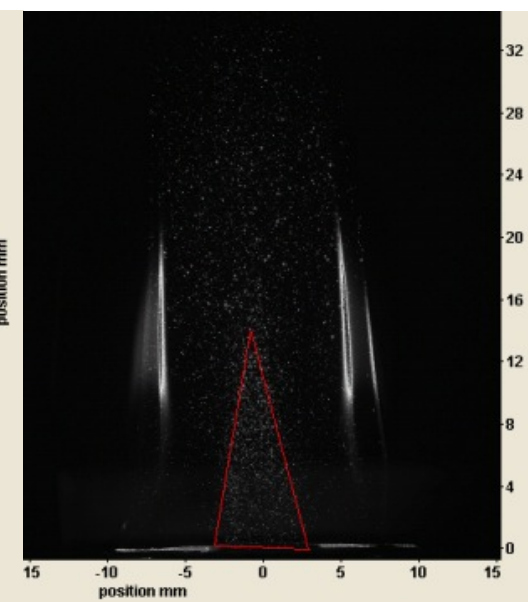

$\Phi=0.44$

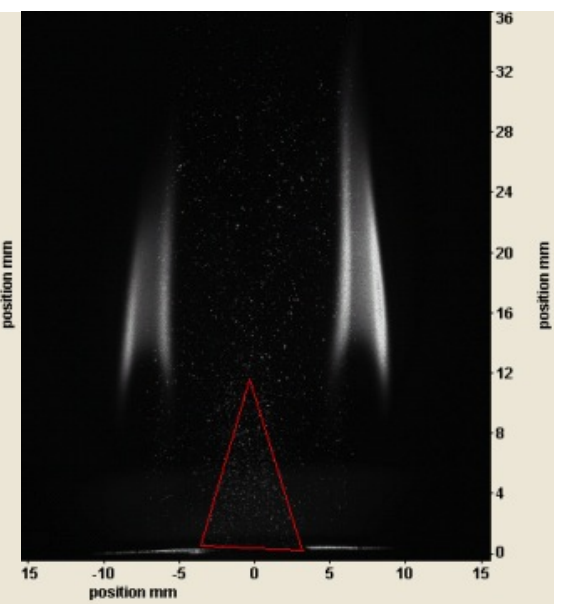

$\Phi=0.92$

Figure 52. Image maps of pulverized coal flames at different $\phi$. Coal particle size $<38 \mu \mathrm{m}$. 


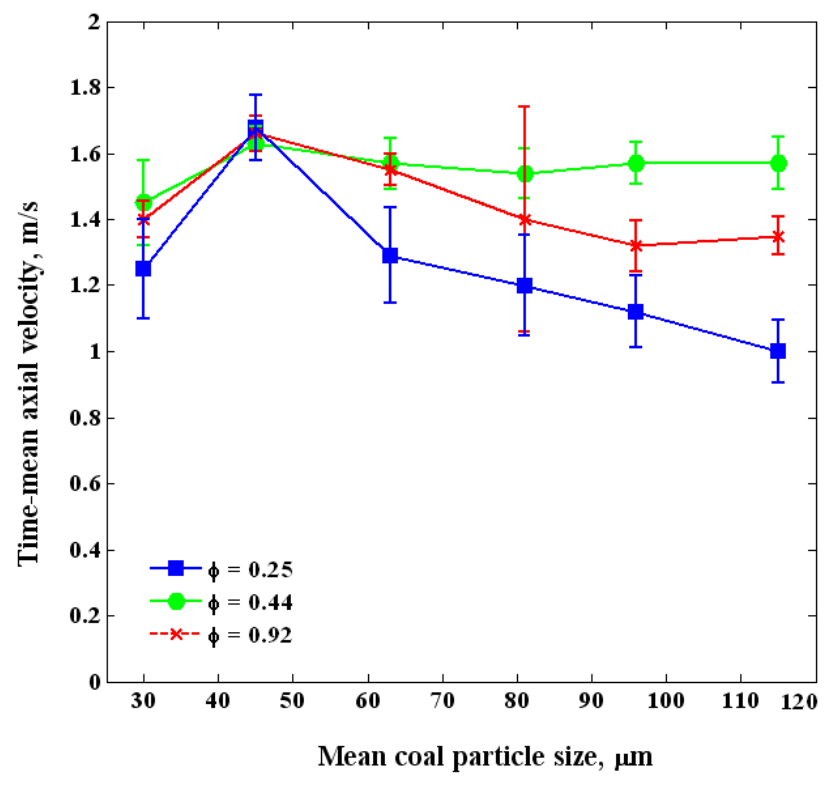

Figure 53. Mean axial velocities taken at a height of $3 \mathrm{~cm}$ vs. mean particle size of pulverized coal.

\section{PIV results of pulverized coal flame in the OFC}

After demonstrating the applicability of the PIV system in the small lab-scale burner, the investigators applied the methodology to the large-scale turbulent OFC (100 kW OFC).

Examples of PIV image maps and the corresponding velocity fields are presented at two locations in the flame, near-burner region (Figure 54a) and far-burner region (Figure 54b). Additionally, the measurements are taken at different primary $\mathrm{O}_{2}$ concentration, $\mathrm{PO}_{2}$, to show both, attached (left side of Figure 54) and detached flames (right side of Figure 54). Compared to the lab-scale measurements, the velocity field in the OFC has higher velocities, which confirms the turbulent nature of such combustors.

Each PIV run was repeated three times to investigate the reproducibility and fluctuations of the measured parameters of the flame for uncertainty quantification purposes. An example of instantaneous image maps for three runs evaluated under the same experimental conditions (flame location $7.6 \mathrm{~cm}$ from burner tip and primary $\mathrm{O} 2$ concentration $21 \%$ ) is shown in Figure 55. Figure 56 presents the time-mean velocity fields using the image maps. The images show that there is a high degree of fluctuation in the time-mean velocity fields for different runs evaluated under the same conditions.

Figure 57 and Figure 58 show the instantaneous axial velocity at a location on the axis at different primary $\mathrm{O}_{2}$ concentrations for the near-burner region ( $7.6 \mathrm{~cm}$ from burner tip) and far-burner region (30.1 $\mathrm{cm}$ from burner tip), respectively. A high degree of fluctuation in the axial velocity is observed from both figures, especially with higher concentration of $\mathrm{O}_{2}$, and the far-burner region shows much higher fluctuations in the axial velocities than those in the near-burner region. The increase in velocity 
fluctuations far from the burner tip could be due to an increase in turbulent eddies. In addition, the instantaneous axial velocity, in general, is larger in the near-burner zone than in the far burner zone, which could be explained by the decay of the turbulent jet.

Figure 59 shows the standard deviations in the instantaneous velocities as a function of the concentration of the primary $\mathrm{O}_{2}$, for both the near- and far-burner regions. The standard deviation data was obtained based on data presented in Figure 57 and Figure 58. It is clear that the standard deviation increases, generally, with increasing concentration of the primary $\mathrm{O}_{2}$, and these deviations are larger in the nearburner region.
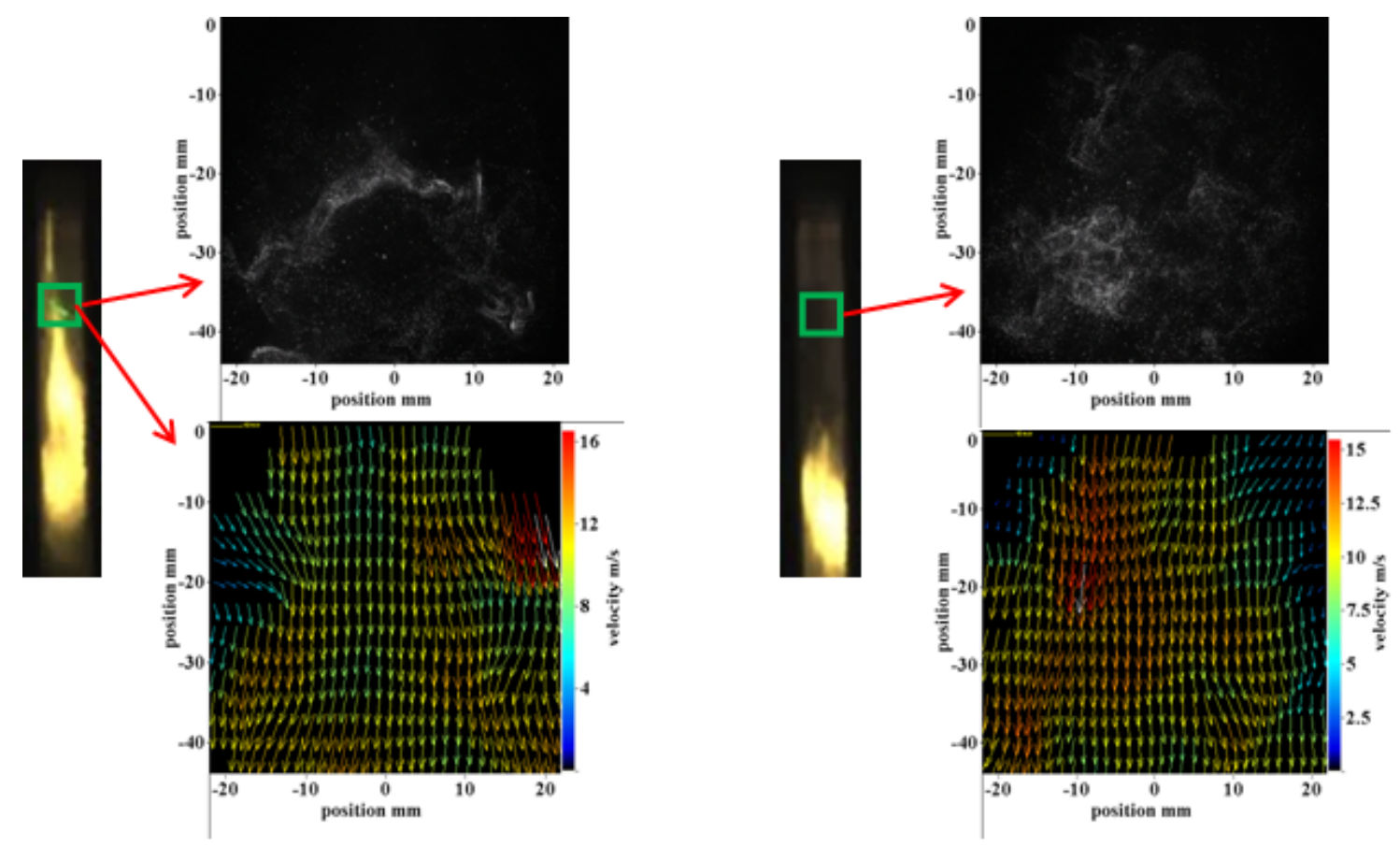

(a)

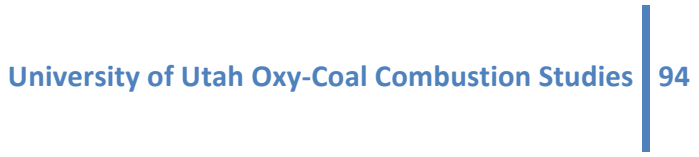



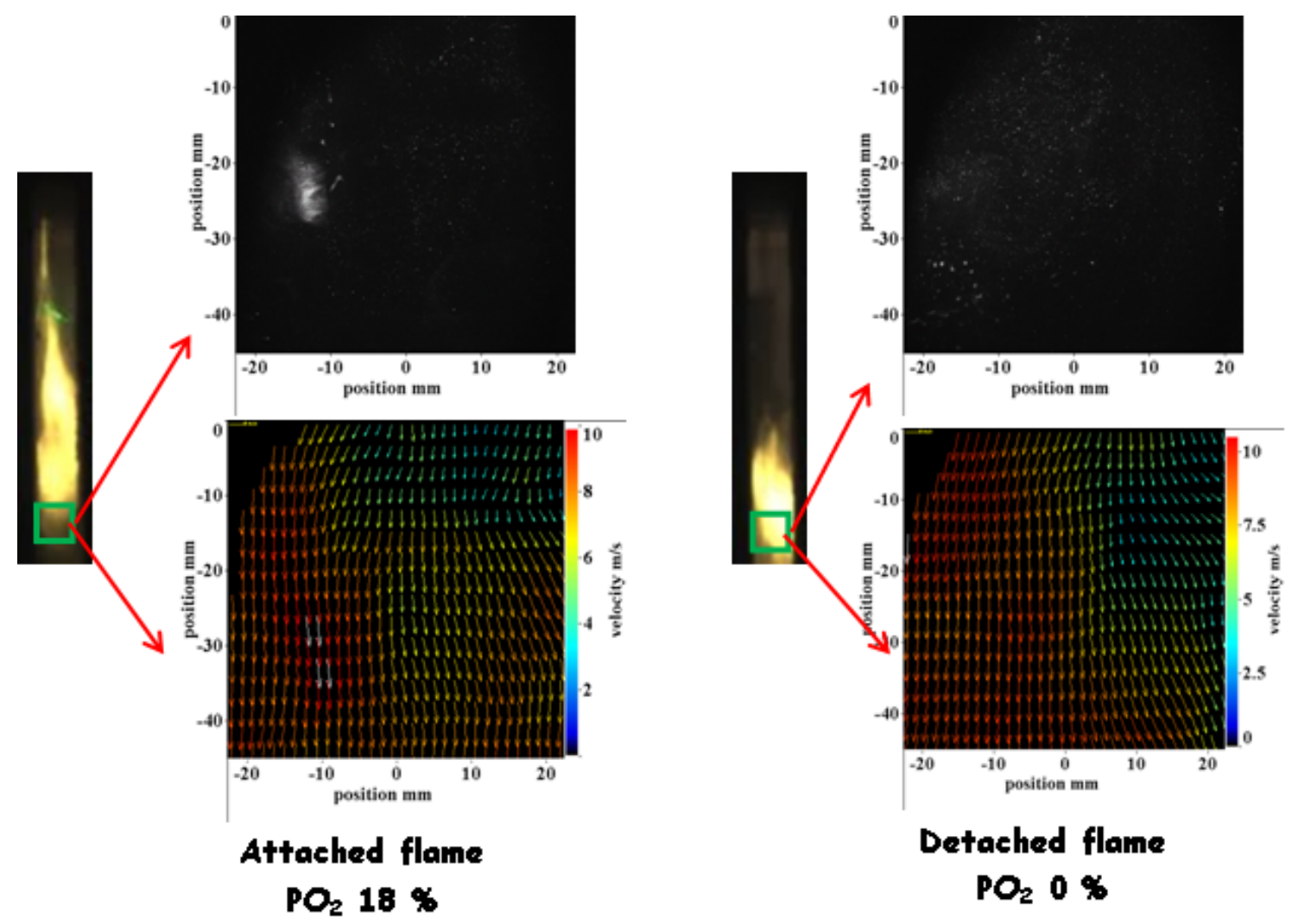

(b)

Figure 54. Two examples of PIV taken at two locations in the $100 \mathrm{KW}$ OFC, (a) near burner region, and (b) far-burner region, as shown in Figure 5. Primary $\mathrm{O}_{2}$ percentages, $18 \%$ for detached flame and $0 \%$ for attached flame.

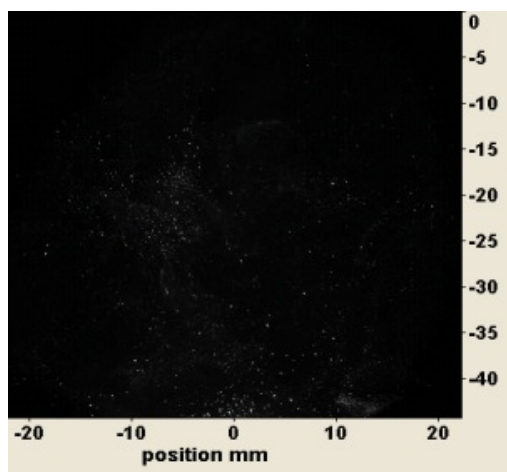

Run \#1

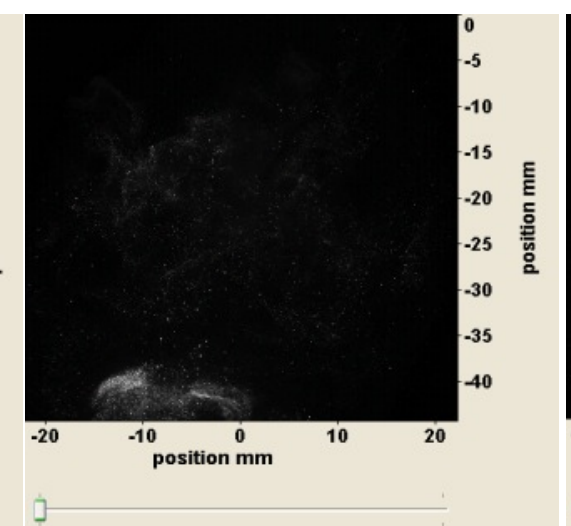

Run \#2

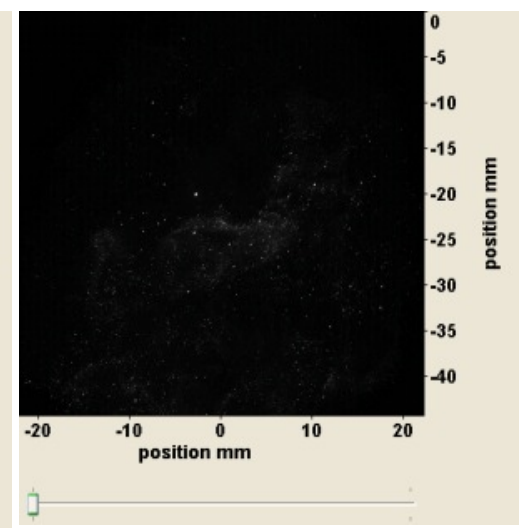

Run \#3

Figure 55. Instantaneous image maps at three runs in the near-burner region ( $7.6 \mathrm{~cm}$ from burner tip) and primary $\mathrm{O}_{2}$ concentration $21 \%$. 

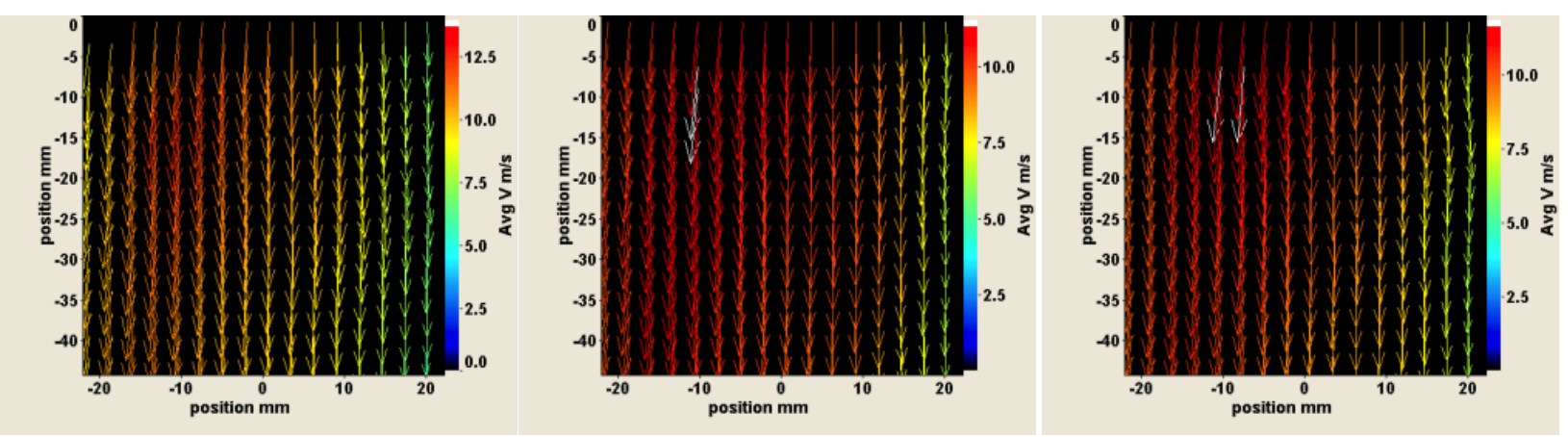

Run \#1

Run \#2

Run \#3

Figure 56. Mean-time velocity fields using image maps in Figure 16. Averaged over 75 images.
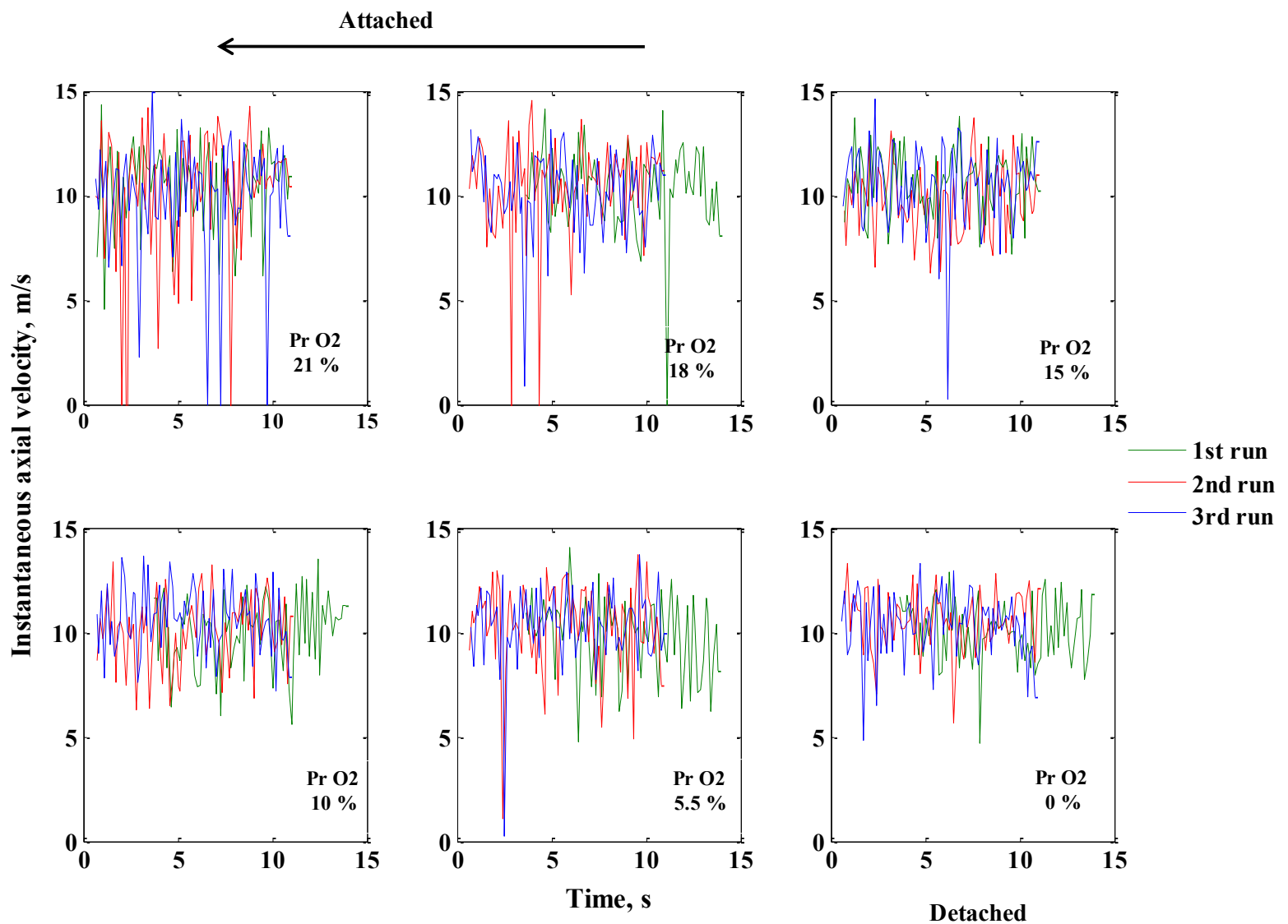

Figure 57. Instantaneous axial velocity at a point on the axis $7.6 \mathrm{~cm}$ from the burner tip (near-burner region) at different primary percentages of $\mathrm{O}_{2}$ for three different runs.

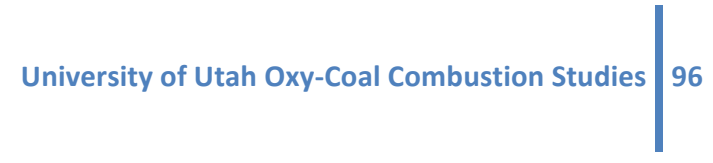



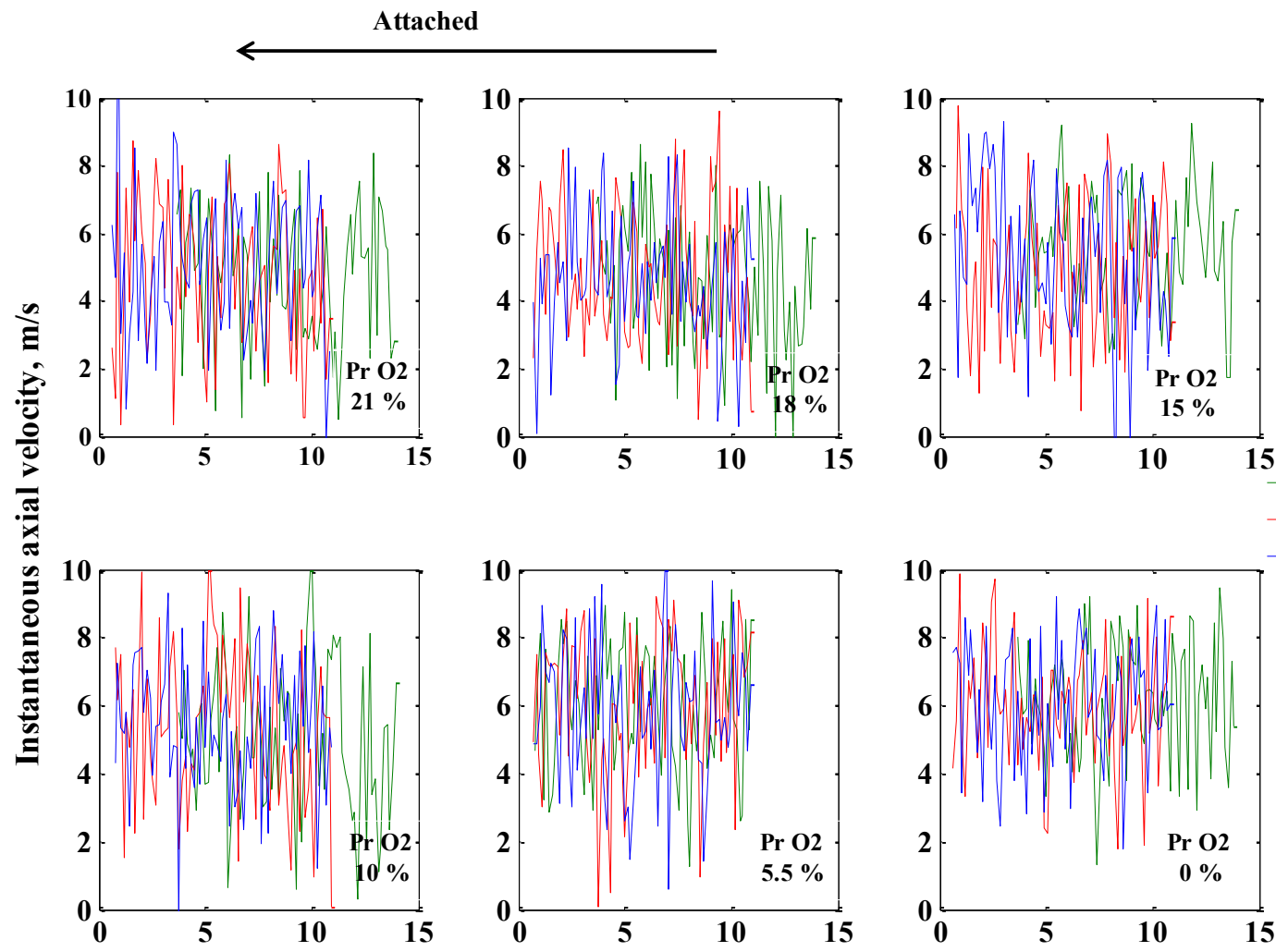

2nd run

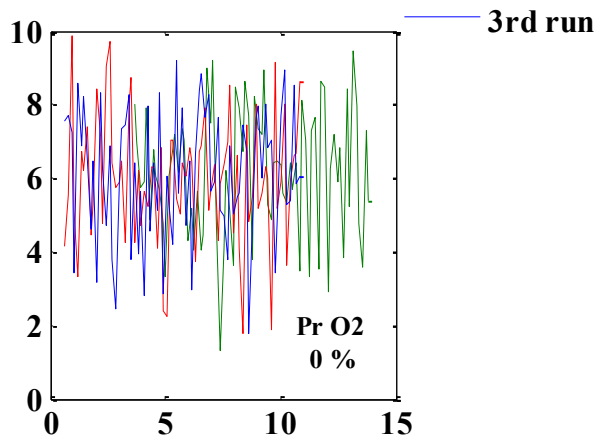

Time, $s$

Detached

Figure 58. Instantaneous axial velocity at a point on the axis $30.1 \mathrm{~cm}$ from the burner tip (far-burner region) at different primary percentage of $\mathrm{O}_{2}$ for three different runs. 

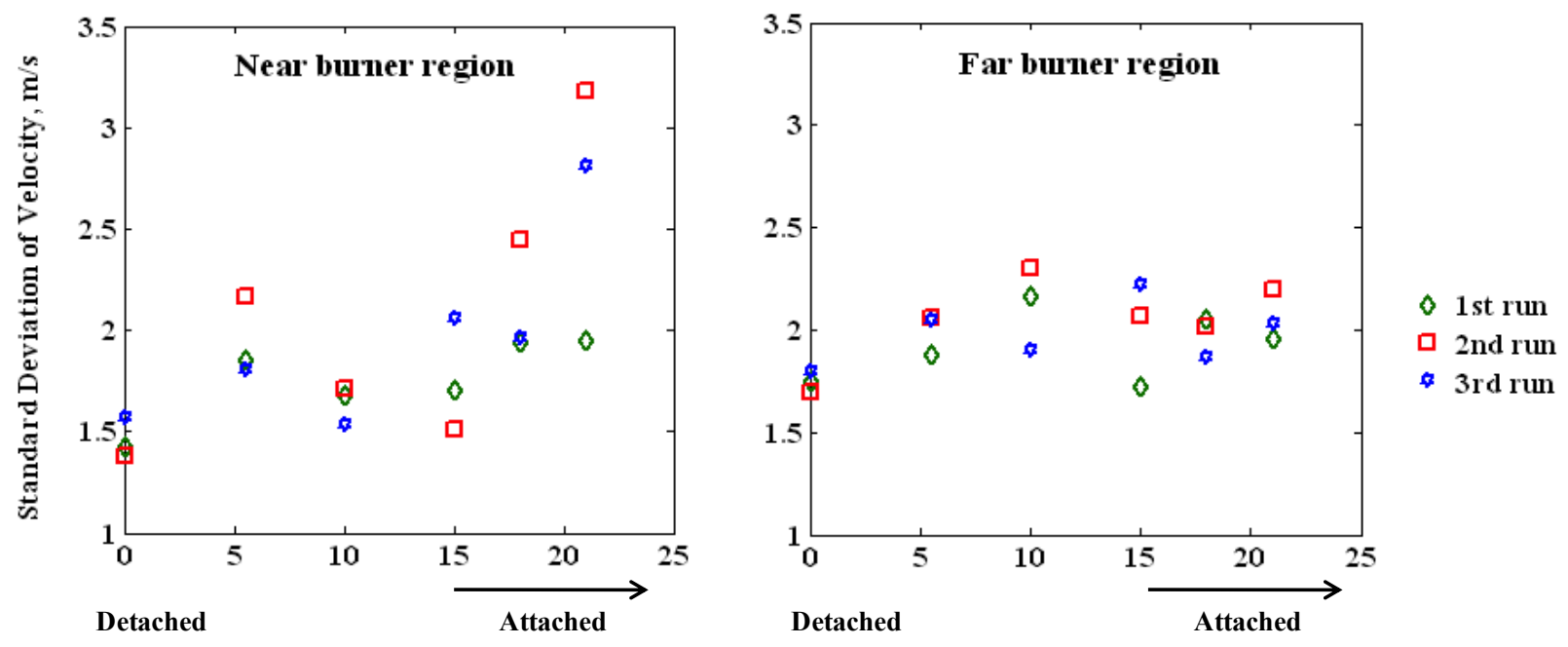

Primary 02, \%

Figure 59. Standard deviation of instantaneous axial velocities for near- and far-burner regions as a function of primary $\mathrm{O}_{2}$.

The time-mean axial velocities along the combustor axis are compared and presented in Figure 60 and Figure 61 for the near- and far-burner regions, respectively. The figures show that the time-mean axial velocity is higher in near the burner region. Additionally, the mean-time axial velocity decreases faster in the near-burner region than in the far-burner region for all concentrations of the primary $\mathrm{O}_{2}$. However, in the far-burner region, the time-mean axial velocity is almost constant with low primary $\mathrm{O}_{2}$ concentration below $10 \%$ as the flames become more detached. 


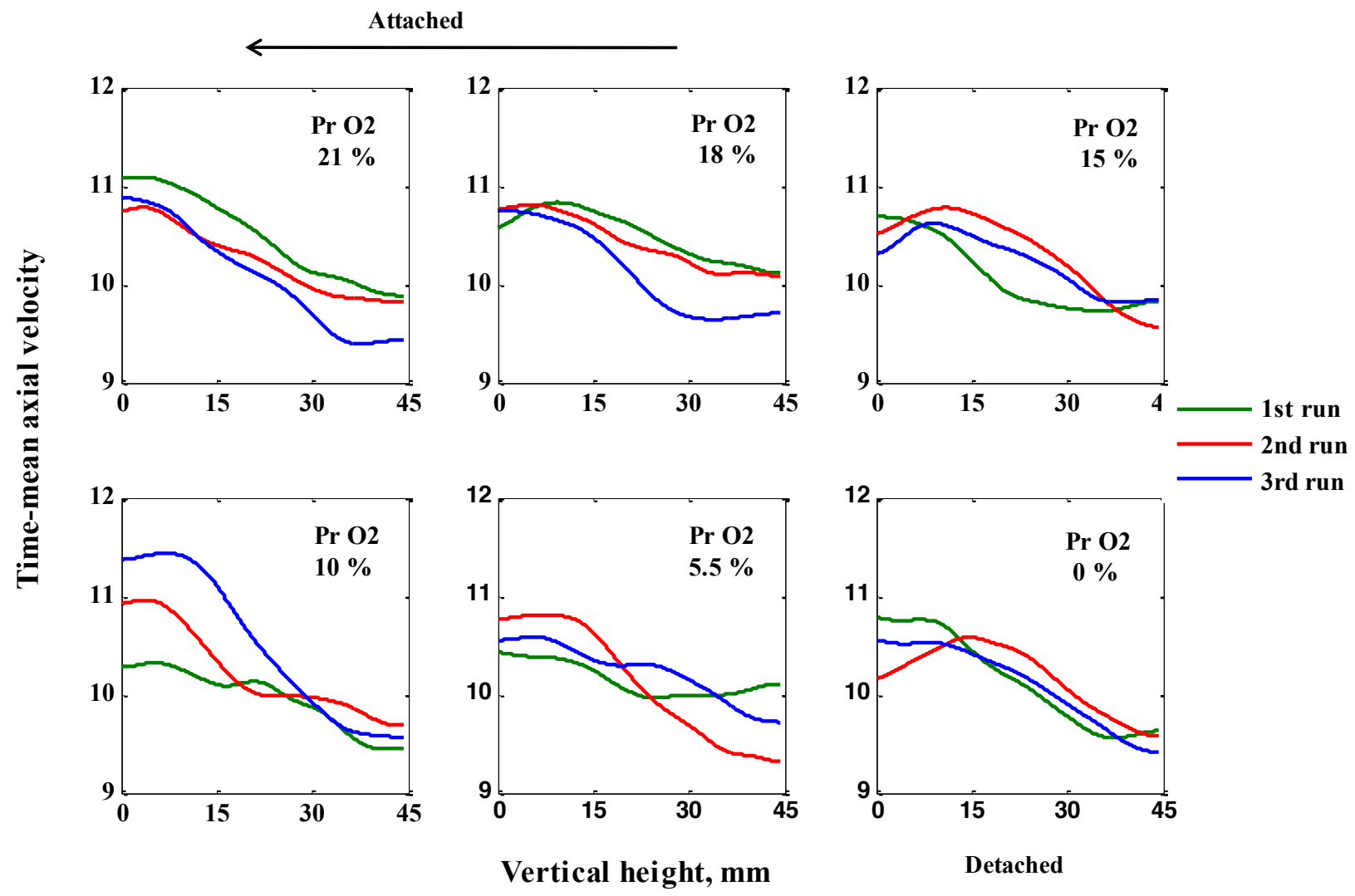

Figure 60. Time-mean axial velocity along the combustor axis at different $\mathrm{PO}_{2} \%$ for the near-burner region. 


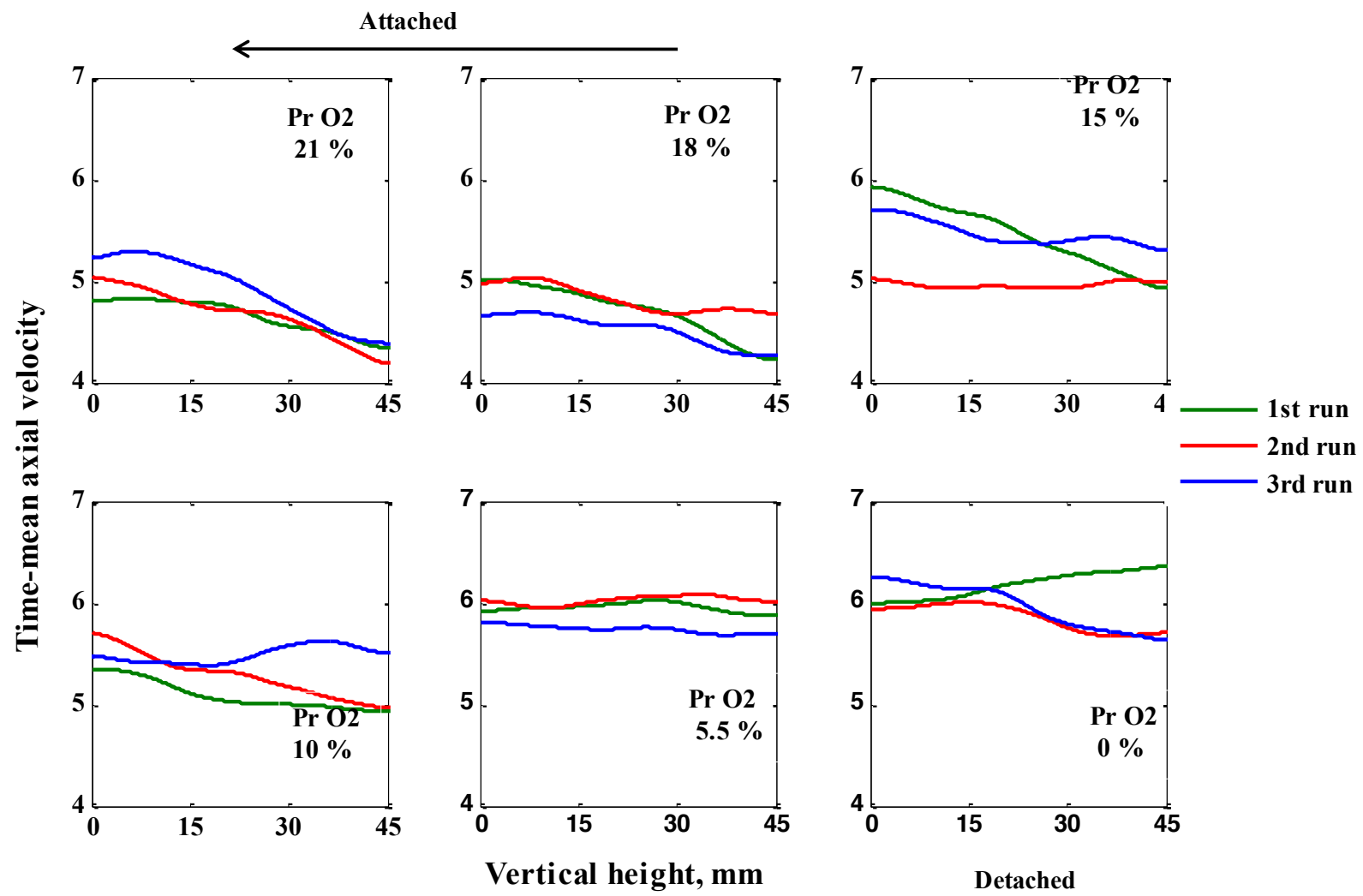

Figure 61. Time-mean axial velocity along the combustor axis at different $\mathrm{P}_{2} \%$ for the far-burner region.

\section{Database of the OFC results}

As part of the work, the results of the OFC measurements were exported as a Matlab data file and as individual text files.

The file 'database.mat' can be loaded into Matlab by typing load('database') in Matlab if your current directory is the directory with the database file in it. The database was created in Matlab 7.11.0.584, but it should be backward compatible with older versions, as long as they support structure arrays.

There are several matrices in the database. Each of these represent data collected from a different experimental setup. All of these matrices are 1X75 size structure arrays - one element for each captured frame. The elements of these contain four fields: each of these fields are 1X1024 lists of either vector positions ( $\mathrm{X}$ and $\mathrm{Y}$ - named 'position X' and 'positionY') or vector directions (U and $\mathrm{V}-$ named 'directionX' and 'directionY').

To visualize a frame with a velocity plot, the function visualize.m can be used which is included with the database. The correct syntax for the function is visualize (experiment, frame) where 'experiment' means the chosen experimental setup and 'frame' means the frame to be plotted. This must be an integer between 1 and 75 . 
As an example, the command visualize(bottom_A_lBa,1) produces the following plot (Figure 62)

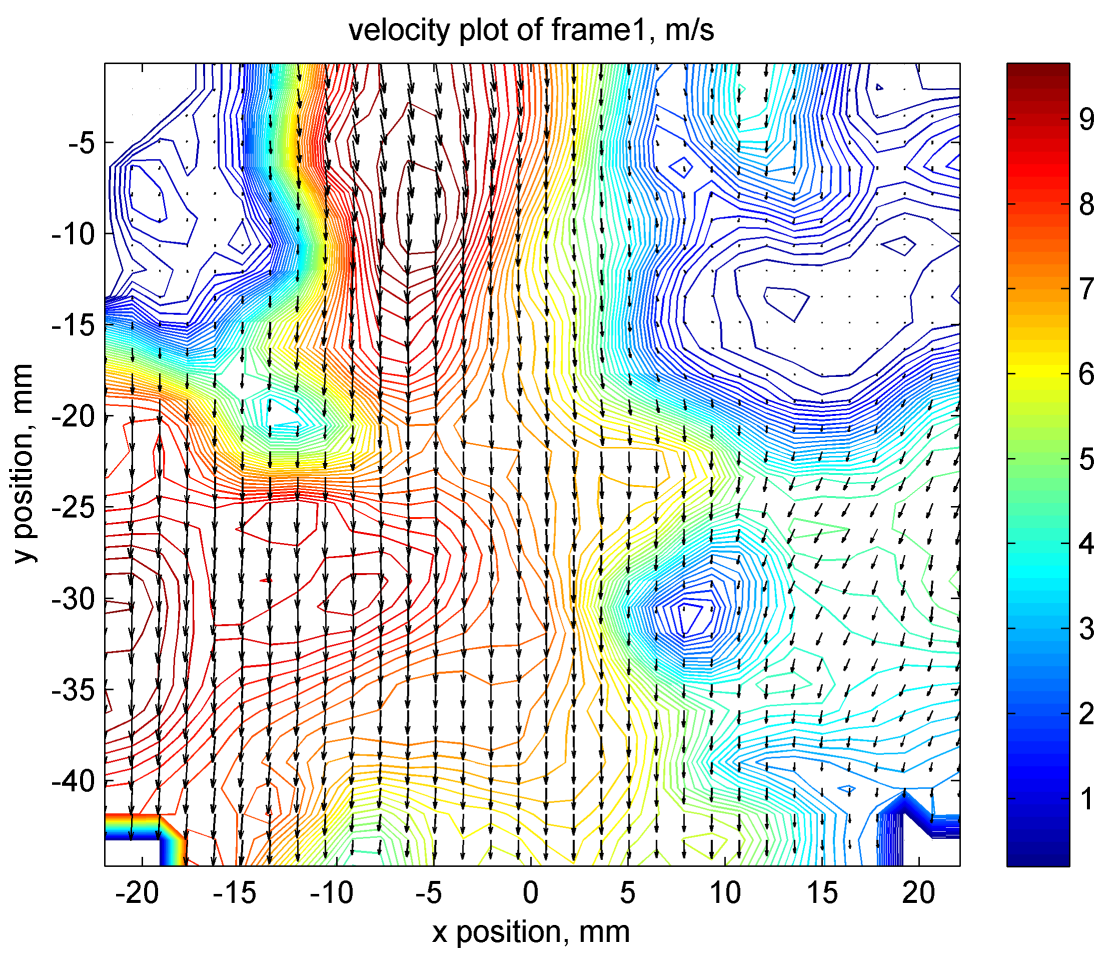

Figure 62. An example output of the 'visualize.m' function.

As can be seen from the plot, all positions are in millimeters and each vector component is in $\mathrm{m} / \mathrm{s}$. The contour plot shows contours of the velocity magnitude map (M), computed by

$$
M_{x, y}=\sqrt{U_{x, y}^{2}+V_{x, y}^{2}}
$$

Two other functions have been included with the database: 'TimeFreq.m' and 'SpaceFreq.m'. The first allows for time frequency analysis of the measured properties at points specified by the user, the second allows for space frequency analysis of a velocity or velocity magnitude profile along a specified horizontal or vertical line in a single frame. Please refer to the help of these functions for more details.

Individual text files. The database is available as a collection of tab delimited text files also. There are several folders, each of these represent an experimental setup. The files in each folder represent data for each captured frame (1-75). The first column in each file is the vector X position in $\mathrm{mm}$, the second column is the $\mathrm{Y}$ position, the third column is the vector $\mathrm{X}$ direction in $\mathrm{m} / \mathrm{s}$ and the last column is the vector $\mathrm{Y}$ direction, also in $\mathrm{m} / \mathrm{s}$. Each row represent a vector $(\mathrm{x}, \mathrm{y}, \mathrm{u}$ and $\mathrm{v})$.

Table 16 shows the operating conditions with the corresponding abbreviations shown in the filenames (.txt) or matrix names (in the .mat file). 
Table 16. Operating conditions and dataset names.

\begin{tabular}{cccccc}
\hline Near-burner region & $\mathrm{xO}_{2}$, primary & Run\# & Far-burner region & xO2, primary & Run\# \\
\hline A_1a & 0.209 & 1 & A_1Ba & 0.209 & 1 \\
A_1b & 0.209 & 2 & A_1Bb & 0.209 & 2 \\
A_1c & 0.209 & 3 & A_1Bc & 0.209 & 3 \\
A_2a & 0.178 & 1 & A_2Ba & 0.178 & 1 \\
A_2b & 0.178 & 2 & A_2Bb & 0.178 & 2 \\
A_2c & 0.178 & 3 & A_2Bc & 0.178 & 3 \\
A_3a & 0.146 & 1 & A_3Ba & 0.146 & 1 \\
A_3b & 0.146 & 2 & A_3Bb & 0.146 & 2 \\
A_3c & 0.146 & 3 & A_3Bc & 0.146 & 3 \\
A_4Ra & 0.1 & 1 & A_4Ba & 0.1 & 1 \\
A_4Rb & 0.1 & 2 & A_4Bb & 0.1 & 2 \\
A_4Rc & 0.1 & 3 & A_4Bc & 0.1 & 3 \\
A_5a & 0.055 & 1 & A_5Ba & 0.055 & 1 \\
A_5b & 0.055 & 2 & A_5Bb & 0.055 & 2 \\
A_5c & 0.055 & 3 & A_5Bc & 0.055 & 3 \\
A_6a & 0 & 1 & A_6Ba & 0 & 1 \\
A_6b & 0 & 2 & A_6Bb & 0 & 2 \\
A_6c & 0 & 3 & A_6Bc & 0 & 3 \\
\hline
\end{tabular}

$\mathrm{xO}_{2}$ corresponds to oxygen concentration expressed in molar fraction.

\section{Uncertainty analysis of PIV data}

To understand the reproducibility of the velocity measurements, six PDFs from the first experiment (three runs) from the bottom region showing the distribution of $\mathrm{X}$ and $\mathrm{Y}$ velocity components are shown in Figure 63 and Figure 64, respectively. The $\mathrm{x}$ velocity component is the velocity perpendicular to the direction of the flame, and the y velocity component is the velocity along the direction of the flame. Similar PDFs have been computed for all experimental runs. Mean and standard deviation values of these PDFs are shown in Table 17. 


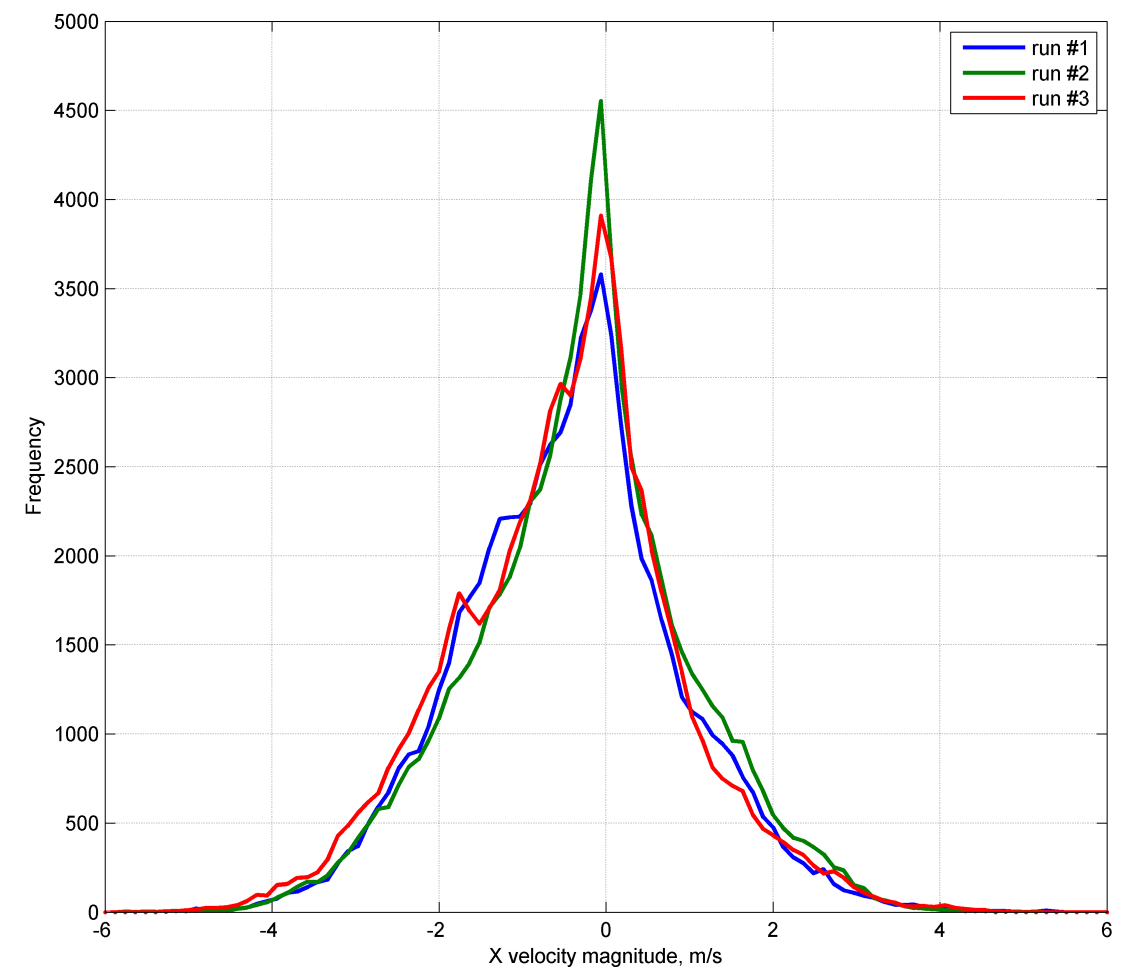

Figure 63. PDFs constructed from $X$ velocity magnitude data from the bottom_A_1 experiment.

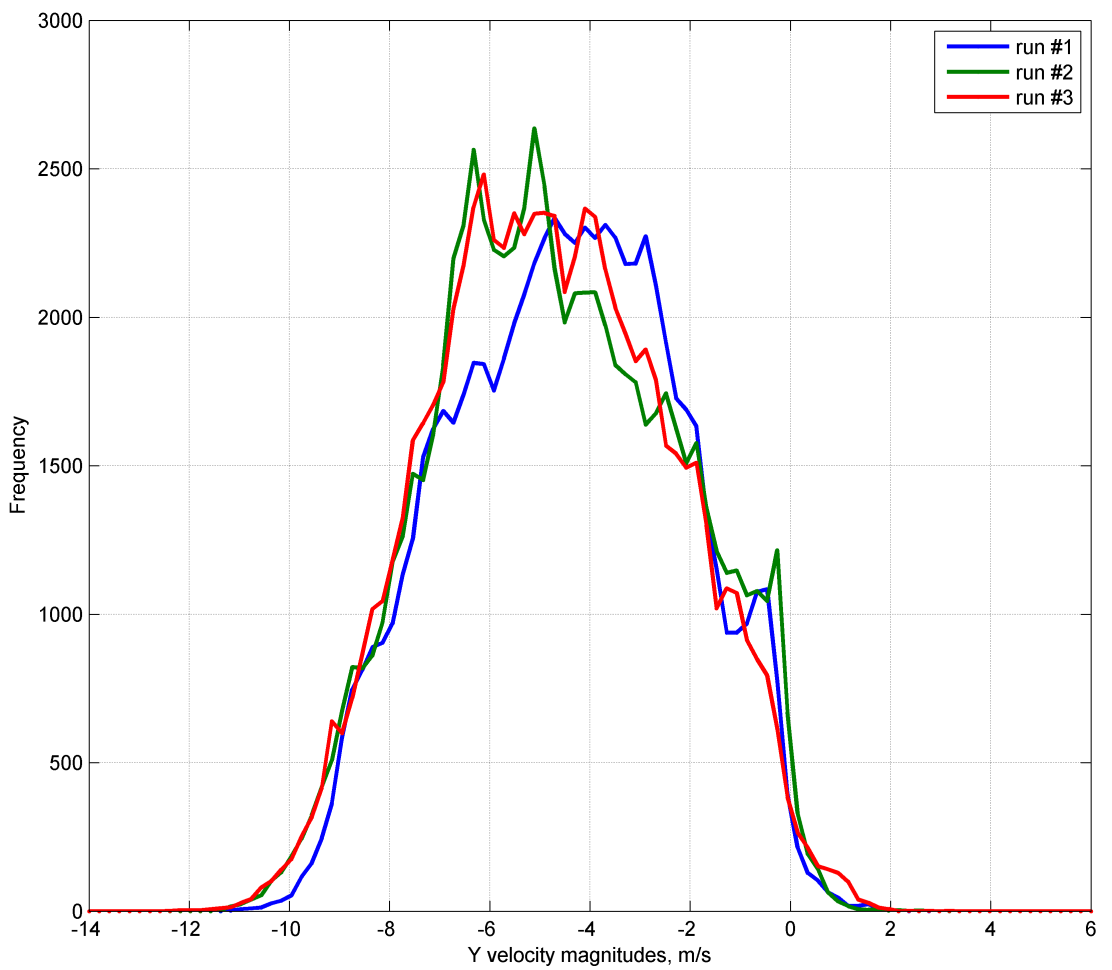

Figure 64. PDFs constructed from Y velocity magnitude data from the bottom_A_1 experiment. 
Table 17. The mean and standard deviation values of $\mathrm{X}$ and $\mathrm{Y}$ components of velocity for all experiments.

\begin{tabular}{cccccccccc}
\hline \multirow{2}{*}{ Top } & \multicolumn{2}{c}{ Mean } & \multicolumn{2}{c}{ Std } & \multicolumn{2}{c}{ Mean } & \multicolumn{2}{c}{ Std } \\
& $\mathbf{X}, \mathbf{m} / \mathbf{s}$ & $\mathbf{Y}, \mathbf{m} / \mathbf{s}$ & $\mathbf{X}, \mathbf{m} / \mathbf{s}$ & $\mathbf{Y}, \mathbf{m} / \mathbf{s}$ & & $\mathbf{X}, \mathbf{m} / \mathbf{s}$ & $\mathbf{Y}, \mathbf{m} / \mathbf{s}$ & $\mathbf{X}, \mathbf{m} / \mathbf{s}$ & $\mathbf{Y}, \mathbf{m} / \mathbf{s}$ \\
\hline A_1a & -0.349 & -9.915 & 1.741 & 3.074 & A_1Ba & -0.363 & -4.383 & 1.036 & 1.617 \\
A_1b & -0.422 & -9.664 & 1.664 & 3.540 & A_1Bb & -0.228 & -4.569 & 1.004 & 1.585 \\
A_1c & -0.412 & -9.510 & 1.735 & 3.475 & A_1Bc & -0.413 & -4.656 & 1.018 & 1.748 \\
A_2a & -0.466 & -9.715 & 1.680 & 3.019 & A_2Ba & -0.252 & -4.531 & 1.393 & 2.390 \\
A_2b & -0.335 & -9.724 & 1.635 & 3.296 & A_2Bb & -0.411 & -4.538 & 1.395 & 2.400 \\
A_2c & -0.467 & -9.434 & 1.599 & 3.188 & A_2Bc & -0.173 & -4.448 & 1.379 & 2.352 \\
A_3a & -0.543 & -8.916 & 1.647 & 3.207 & A_3Ba & -0.301 & -5.323 & 1.384 & 2.370 \\
A_3b & -0.487 & -9.515 & 1.553 & 3.014 & A_3Bb & -0.314 & -4.834 & 1.403 & 2.349 \\
A_3c & -0.526 & -9.365 & 1.539 & 3.231 & A_3Bc & -0.287 & -5.217 & 1.309 & 2.626 \\
A_4Ra & -0.639 & -8.694 & 1.563 & 3.429 & A_4Ba & -0.196 & -4.995 & 1.505 & 2.448 \\
A_4Rb & -0.642 & -8.963 & 1.635 & 3.355 & A_4Bb & -0.154 & -5.237 & 1.361 & 2.486 \\
A_4Rc & -0.595 & -9.037 & 1.549 & 3.530 & A_4Bc & -0.307 & -5.248 & 1.428 & 2.356 \\
A_5a & -0.630 & -8.847 & 1.601 & 3.336 & A_5Ba & -0.275 & -5.780 & 1.275 & 2.183 \\
A_5b & -0.605 & -8.744 & 1.573 & 3.547 & A_5Bb & -0.223 & -5.912 & 1.317 & 2.322 \\
A_5c & -0.599 & -8.904 & 1.503 & 3.451 & A_5Bc & -0.343 & -5.441 & 1.262 & 2.342 \\
A_6a & -0.537 & -8.933 & 1.547 & 3.350 & A_6Ba & -0.026 & -5.779 & 1.332 & 2.209 \\
A_6b & -0.586 & -8.876 & 1.581 & 3.325 & A_6Bb & -0.021 & -5.706 & 1.225 & 1.954 \\
A_6c & -0.633 & -8.896 & 1.510 & 3.288 & A_6Bc & -0.017 & -5.720 & 1.275 & 2.153 \\
\hline
\end{tabular}

Subtask 3.4 - Oxy-Coal Combustion in Circulating Fluidized Beds

For the pilot-scale CFB tests, a western bituminous coal (Utah Skyline) was employed. $\mathrm{SO}_{2}$ and $\mathrm{SO}_{3}$ emissions were measured under both air-fired and oxy-fired scenarios. For air firing, $80 \%$ air was introduced to the CFB by the primary oxidant line, while the rest (20\%) was injected by the secondary oxidant line. Aiming to simulate the same air firing conditions, a wide range of $\mathrm{O}_{2}$ concentrations $(21 \%$, $27 \%$, and $35 \%$ ) for oxy-firing were employed. From these tests results, if $\mathrm{O}_{2}$ concentration obtained $27 \%$ after mixing with recycled flue gas, the average temperature in the fluidized bed was similar to that in air firing. Using the same approach to introduce $\mathrm{O}_{2}$ as the injection of air, $\mathrm{O}_{2}$ was added into recycled flue gas (mainly $\mathrm{CO}_{2}$ ) and was split into two streams. One stream passed through the distributor plate to fluidize the bed material, fuel particles, sulfur capture sorbents (mainly limestone), and the rest was injected via the secondary $\mathrm{O}_{2}$ line located downstream of the distributor plate. An overall concentration of $27 \% \mathrm{O}_{2}$ (wet basis) was used for most tests, while an excess $\mathrm{O}_{2}$ level of $3 \%$ (dry basis) in the exhaust was maintained for all tests.

For tests investigating the efficacy of limestone capture under oxy-firing conditions, limestone was injected continuously by a separate feed auger, to allow independent variation of the $\mathrm{Ca}: \mathrm{S}$ ratio. To maintain consistency, the feed of coal (50 lb/hour) was fixed, while varying the desired ratio of Ca:S. 


\section{Operation considerations for oxy-firing in CFBs}

The performance of air firing and oxy firing is quite different. The bed temperature is one of the most important parameters and has a significant impact on coal combustion. In order to compare bed temperature during oxy-firing to an air-firing basis, a wide $\mathrm{O}_{2}$ concentration range was carried out. For these tests, the bed material used was sand without limestone addition. The furnace was preheated with natural gas overnight because it required a relatively long time to reach the desired operating temperature. The CFB was transitioned to air firing and heated to the operating bed temperature at the start of each testing day. As the operating bed temperature was attained, the CFB was switched to oxy firing from air firing. The heat transfer surface was no different in the air and oxy-firing cases. Slightly positive pressure in the CFB and bag-house minimized air leakage; however, some air was inevitably sucked into the blowers. For this reason, $\mathrm{CO}_{2}$ concentrations in the flue gas exceeded $85 \%$ (dry basis) but were lower than $95 \%$ due to limitation of blower. About $3 \% \mathrm{O}_{2}$ existed in the flue gas (a dry basis).

A series of air-firing tests were carried out to characterize the combustor and acted as a baseline for the oxy-firing testing. The $\mathrm{O}_{2}$ concentration in the flue gas was approximately $3 \%$ (a dry basis). Generally, there were several competing issues that must be considered when shifting from air-firing to oxy-firing. First, the heat capacity of $\mathrm{CO}_{2}$ (-to $1.280 \mathrm{~kJ} / \mathrm{kgK}$ ) was much higher compared to that of $\mathrm{N}_{2}$ (1.187 to 1.204 $\mathrm{kJ} / \mathrm{kgK}$ ) at conventional CFB operating temperatures. If simply replacing $\mathrm{CO}_{2}$ with $\mathrm{N}_{2}$ in air the bed/flame temperature for oxy firing would be much lower than that for air firing. Next, if keeping mass flow rate constant, lower flame/bed temperature would also lead to lower volumetric flow rate. As a result, the gas velocity passing through the distributor plate would decrease at the same cross section area of the CFB. From the above discussion, reduction of flame temperature leads to insufficient fluidization if simply replacing $\mathrm{CO}_{2}$ with $\mathrm{N}_{2}$ in air. As well, an unexpected impact on the solids circulation process was likely. If enhancing $\mathrm{O}_{2}$ concentration for oxy-firing, it seemed to reduce the effect of the higher heat capacity of $\mathrm{CO}_{2}$ (assuming no additional fuel is fired) and will simulate the bed/flame temperature well.

Two strategies for oxy firing to maintain comparable bed temperatures as air firing were explored: the constant flue gas velocity $\left(\mathrm{O}_{2}+\right.$ wet RFG $)$ and constant $\mathrm{O}_{2}$ concentration $\left(\mathrm{O}_{2}+\right.$ dry $\left.\mathrm{RFG}\right)$ based on air firing. The constant velocity cases maintained approximately the same total oxidant flow to the bed $\left(\mathrm{O}_{2}+\right.$ wet RFG) as the air-firing configuration. In this scenario $\left(\mathrm{O}_{2}+\right.$ wet $\left.\mathrm{RFG}\right), \mathrm{H}_{2} \mathrm{O}$ vapor was not supposed to be removed from the recycled flue gas so that $\mathrm{SO}_{\mathrm{x}}, \mathrm{NO}_{\mathrm{x}}$, and most of $\mathrm{H}_{2} \mathrm{O}$ still came back to the CFB. If the strategy $\left(\mathrm{O}_{2}+\right.$ dry $\left.\mathrm{RFG}\right)$ was performed, most condensable gases $\left(\mathrm{SO}_{3}, \mathrm{H}_{2} \mathrm{SO}_{4}\right)$ and easily soluble gas species were precluded as $\mathrm{H}_{2} \mathrm{O}$ vapor removal. For the constant flue $\mathrm{O}_{2}$ concentration strategy, the total stoichiometric ratio was controlled so the $\mathrm{O}_{2}$ concentration in the flue was the same as that based on air firing $\left(\sim 3 \% \mathrm{O}_{2}\right.$, dry $)$.

Although $\mathrm{O}_{2}$ concentration is typically reported on a dry basis, the combustion environment depended on the actual (wet basis) $\mathrm{O}_{2}$ concentration and thus the actual concentration is reported here. Also, experimental data on a wet basis can help us to understand well the effect of flue gas recycling on $\mathrm{SO}_{\mathrm{x}}$ because $\mathrm{SO}_{\mathrm{x}}$ was not removed by external forces.

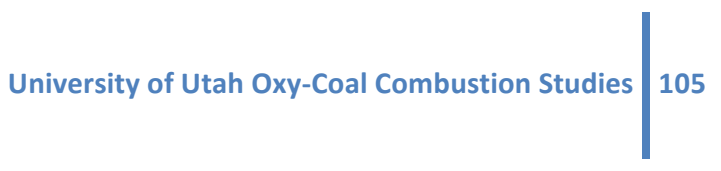




\section{Effect of $\mathrm{O}_{2}$ concentration on the bed temperature}

In these tests, one simple assumption was that the heat removal and carbon burnout was constant for oxyfiring. Hence, the measured temperatures might be expected to be higher in a slightly positive pressure than estimated from the heat and mass balances owing to added heat release over the air baseline. It is important to note that $\mathrm{O}_{2}$ concentrations of $\sim 21 \%$ on a dry basis, as are often reported, are actually equal to only $18 \%$ on a wet basis. Based on these data $\mathrm{O}_{2}$ concentrations of $\sim 27 \%$ based on a wet recycled flue gas would yield a similar temperature to the air case if $\mathrm{O}_{2}$ in the flue gas was held constant. As Figure 65 shows, the profile of bed temperatures for oxy firing with a wide range of $\mathrm{O}_{2}$ concentration $(21 \%, 27 \%$ and $35 \%$ ) were examined, as well as air firing. First, heat and mass balances for the air case were used to estimate the heat removal in the bed based on the average bed temperature (defined as the average of Sections 1-5). The heat and mass balances were then repeated for oxy-firing with a wide range of $\mathrm{O}_{2}$ concentrations. From the profile of bed temperatures based on air firing, the distribution of bed temperature seems to be even in each section (1-5) and transition section. This ranged from 800 to $820 \mathrm{C}$, and is consistent with the optimized CFB operating temperature. Also, it suggests our CFB design was excellent. When switching to oxy firing, the bed temperature profile with $27 \% \mathrm{O}_{2}$ concentration (wet basis) for oxy firing is slightly higher that that based on air firing, and almost close to air firing, which shows the exact simulated environment we wanted. Accordingly, the following tests for oxy firing will be suggested to be performed at $27 \% \mathrm{O}_{2}$ concentration (wet basis), and are convincing to compare the test results for oxy firing with that air firing.

Not surprisingly, as shown in Figure 66, $\mathrm{O}_{2}$ concentrations also have a significant impact on the average bed temperature. Figure 66 showed a clear trend that the average bed temperature increases with an increasing of $\mathrm{O}_{2}$ concentration. As $\mathrm{O}_{2}$ concentration reaches $35 \%$, the bed temperature (above $1000 \mathrm{C}$ ) is much higher than on an air-firing basis. As well, the bed temperature (lower than $750 \mathrm{C}$ ) is somewhat lower than that for air firing if $21 \% \mathrm{O}_{2}$ (wet basis) is used. Both them $(21 \%, 35 \%)$ are out of range for an optimized CFB operating temperature. Overall, operating at 27\% $\mathrm{O}_{2}$ concentration (wet basis) for oxy firing would provide comparable temperatures to air firing. It is also important to note that these tests used wet flue gas recycle. 


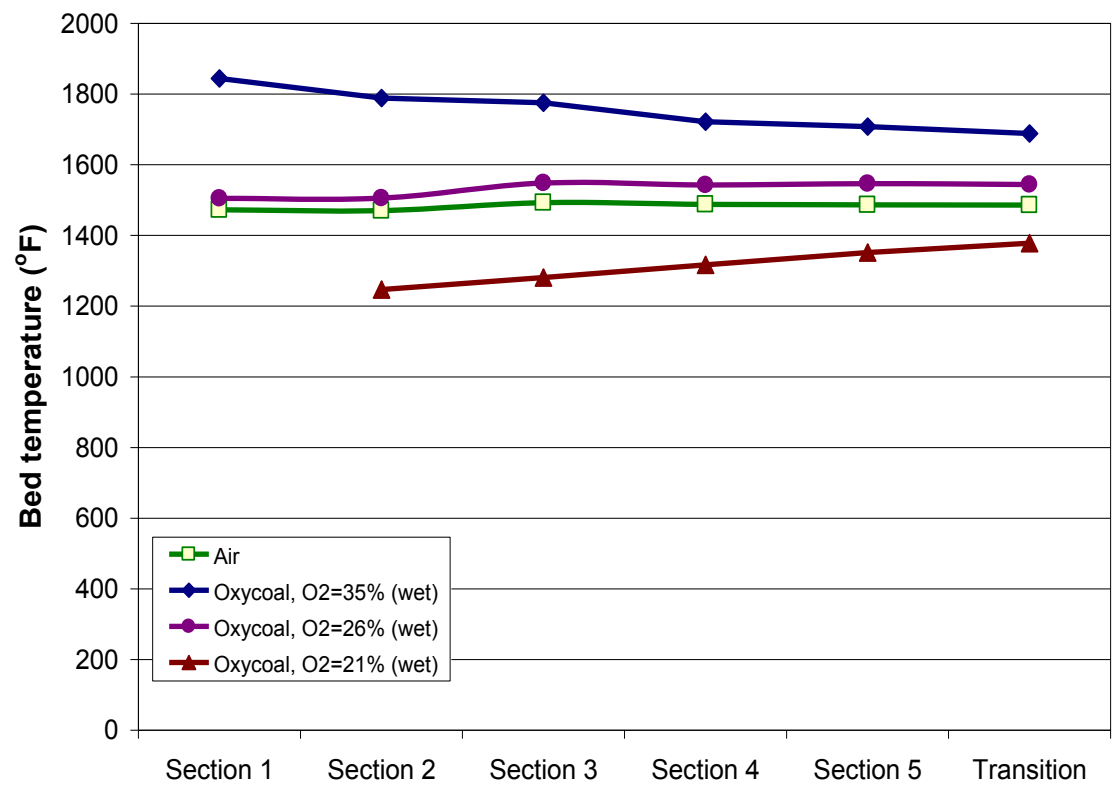

Figure 65. Temperature profile of CFB using Utah bituminous coal for air-firing and oxy-firing.

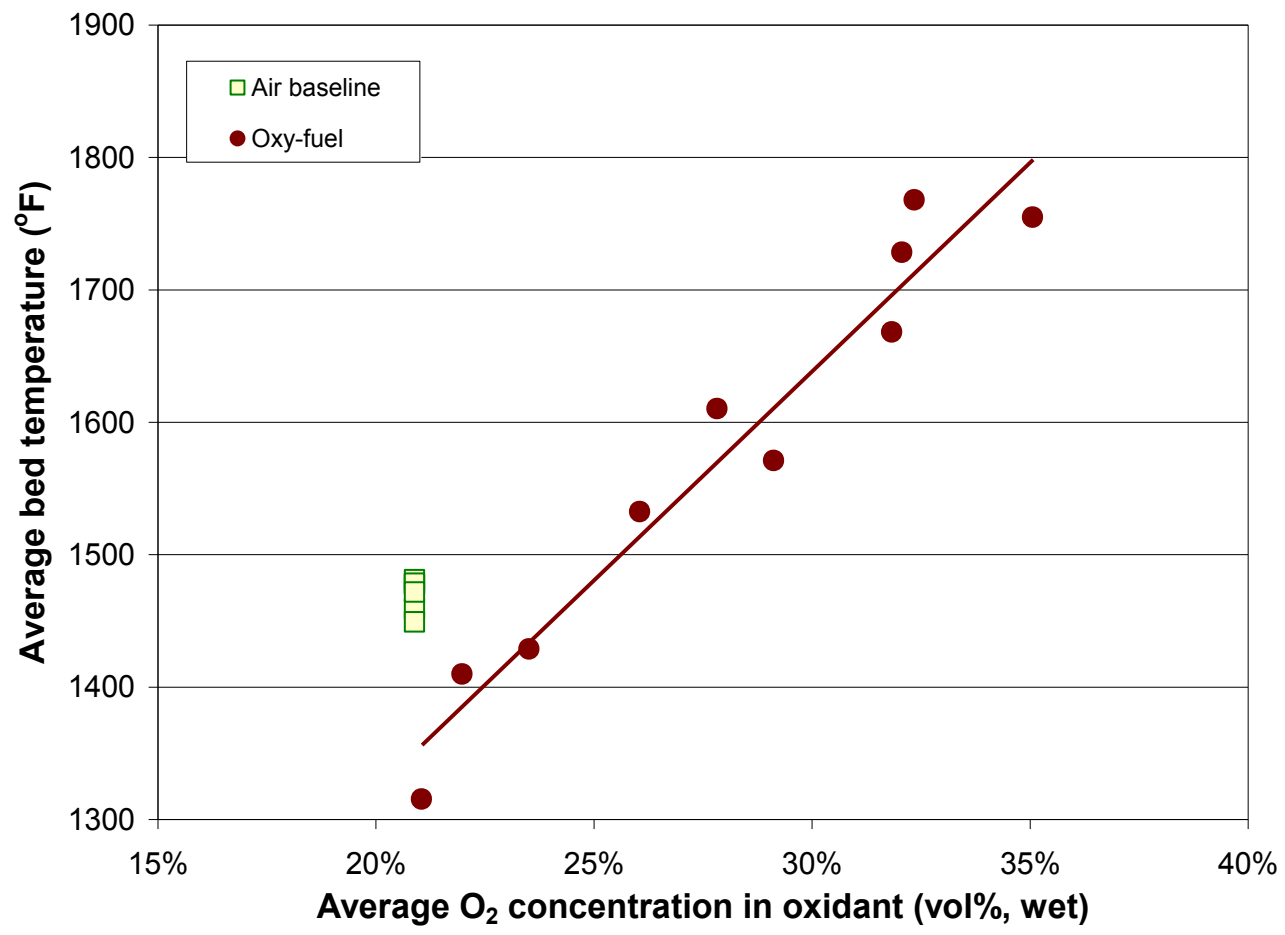

Figure 66. The effect of $\mathrm{O}_{2}$ concentration on the profile of bed temperature for oxy firing. 


\section{Effect of air vs. oxy-firing on species concentration profiles}

Gaseous emissions profiles are shown in Figure 67 and Figure 68 for air and oxy-firing conditions. The trends for both conditions are similar. CO starts out high as the fuel burns in the bed and is reduced after the secondary oxidant is introduced. The $\mathrm{CO}$ then goes back up as the entrained fuel is burned in the upper sections of the CFB before dropping back off at the exit.

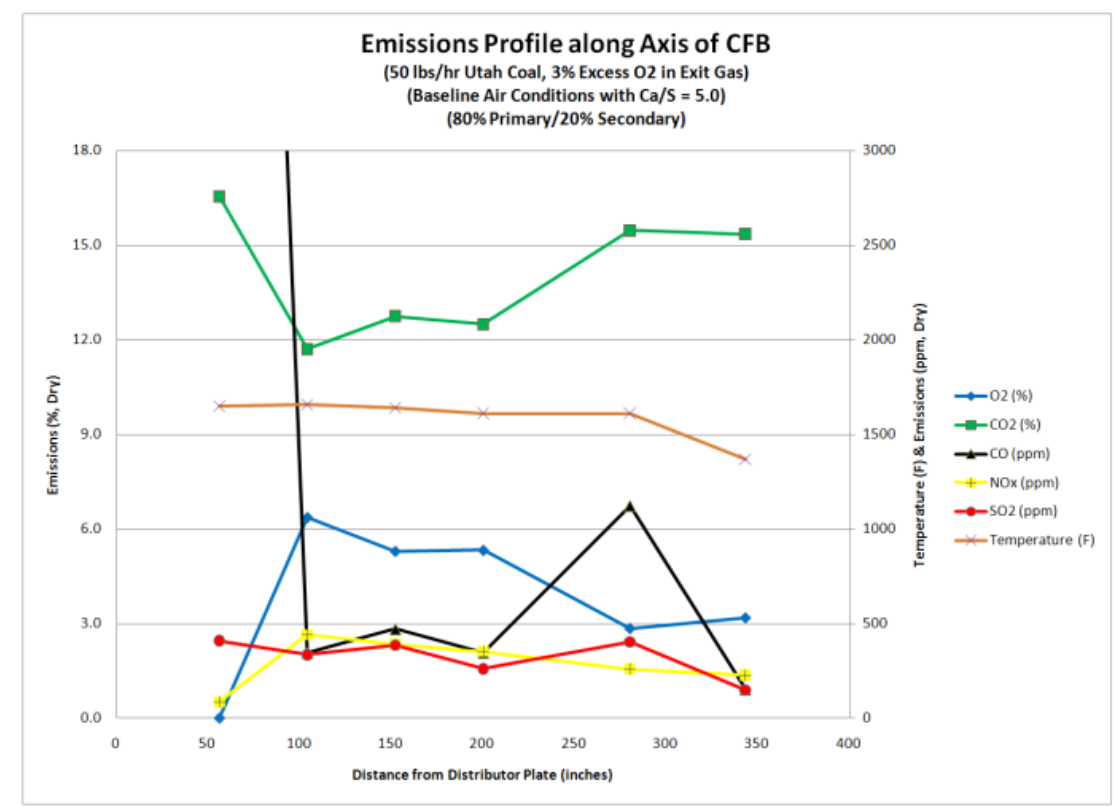

Figure 67. Emission profiles measured under air-fired conditions in the $330 \mathrm{~kW} \mathrm{CFB}$ combustor. 


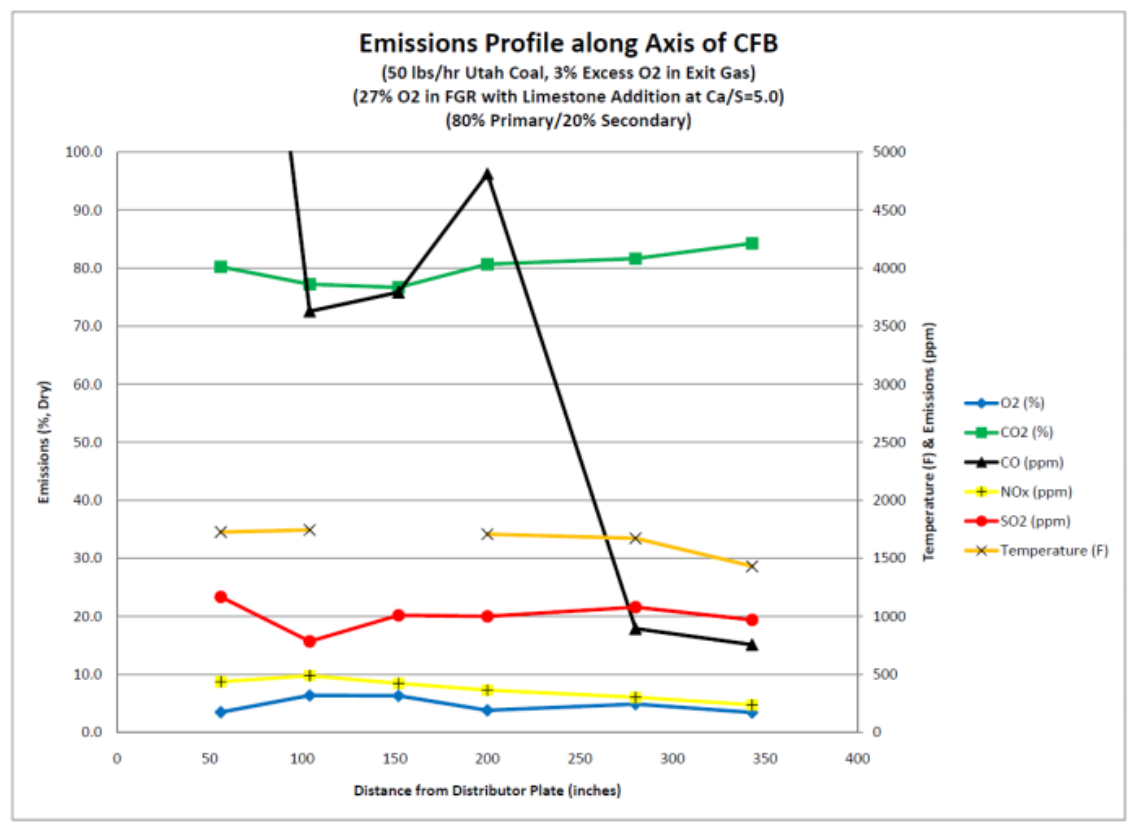

Figure 68. Emission profiles measured under oxy-fired conditions in the $330 \mathrm{~kW} \mathrm{CFB}$ combustor.

\section{SO $_{\mathrm{x}}$ Emissions in Oxy-coal CFB Combustion}

$\mathrm{SO}_{2}$ and $\mathrm{SO}_{3}$ emissions were measured in detail as a function of operating conditions to provide insight into sulfur behavior in air- vs. oxy-firing with a wet recycled flue gas, and the effect of limestone injection was also examined. Two types of $\mathrm{SO}_{2}$ analyzers (UV and IR) were used to quantify $\mathrm{SO}_{2}$ concentration, and the CCM method described in the approach section was used for $\mathrm{SO}_{3}$ measurement. The CCM equipment also allowed for quantification of $\mathrm{SO}_{2}$, and comparisons between the CCM results and $\mathrm{SO}_{2}$ analyzer data were consistent.

Oxygen was mixed with recycled flue gas and was split between the distributor plate (80\%) and a secondary oxidant injection location $(20 \%)$ at the same height as the loop seal particle reinjection location. An overall oxygen concentration of $27 \% \mathrm{O}_{2}$ (wet basis) was used for all tests reported below, which provided an excess $\mathrm{O}_{2}$ level of $3 \%$ (dry basis) in the exhaust.

Initial testing indicated some variations in $\mathrm{SO}_{2}$ emissions under different operating conditions, even in the absence of sorbents such as limestone. Many coals contain quantities of $\mathrm{Ca}$ or other alkali metals that can provide native sulfur capture, and the Utah coal used in these tests exhibited clearly measurable in-bed capture. Although many different operating conditions were studied, the primary operating parameter that affected this native in-bed capture was bed temperature, as shown in Figure 7. As shown, native capture occurred under both air- and oxy-fired conditions, and correlated well with bed temperature.

An additional test indicated the potential instability of this native capture. The CFB was operated for an extended period of time at $1500 \mathrm{~F}$ such that the ash material was loaded with captured sulfur. The bed 
temperature was then increased rapidly to $1800 \mathrm{~F}$, which is a temperature that does not support significant sulfur capture, as shown in Figure 69. The measured $\mathrm{SO}_{2}$ concentration in the exhaust increased rapidly until the analyzers were off-scale, where they remained for 15-20 minutes, before the $\mathrm{SO}_{2}$ concentration finally decreased to detection levels again, but at a new, higher $\mathrm{SO}_{2}$ concentration that was representative of the equilibrium level of capture at the higher temperature. Thus, the bed had become loaded with sulfur, but the compounds were not stable at this higher temperature and released the sulfur inventory when the bed heated up. Note that this experiment was performed in the absence of any added sorbent material, and thus only reflects the behavior of the accumulated coal ash.

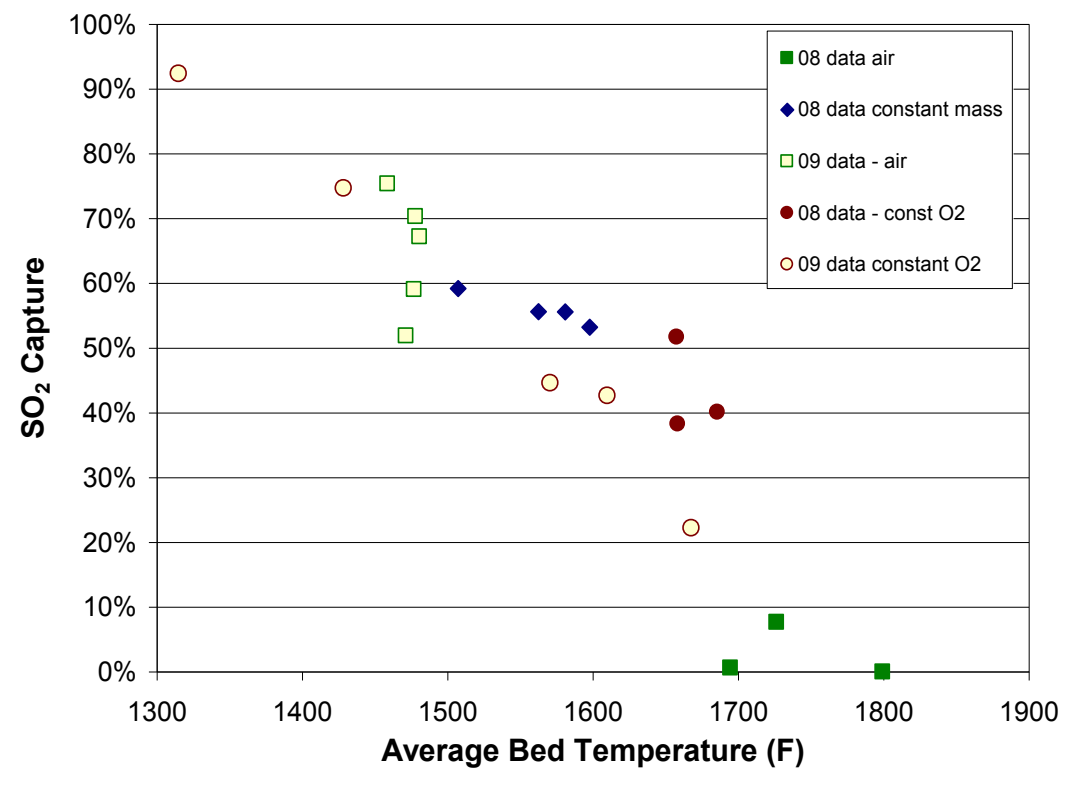

Figure 69. The effect of bed temperature on the $\mathrm{SO}_{2}$ emissions for oxy-firing and air-firing.

$\mathrm{SO}_{2}$ and $\mathrm{SO}_{3}$ concentrations under oxy-firing conditions were significantly higher than air-fired conditions, as shown in Figure 70 and Figure 71, as would be expected with flue gas recycle. Note that the error shown in these figures and all subsequent figures represents $+/$ - one standard deviation. The addition of limestone, with Ca:S molar ratios ranging from 0 to 10 , resulted in decreases in $\mathrm{SO}_{2}$ concentration for both air- and oxy-firing. The addition of limestone did not exhibit a clear trend on $\mathrm{SO}_{3}$ concentrations, as the concentrations appeared to be essentially unchanged (within the scatter of the data) over the range of limestone addition rates and operating conditions investigated.

Normalized mass emissions (mass per unit energy input) of $\mathrm{SO}_{2}$ and $\mathrm{SO}_{3}$ are shown in Figure 72 and Figure 73. On a mass basis, the actual emissions of $\mathrm{SO}_{2}$ and $\mathrm{SO}_{3}$ from the CFB are similar under both airand oxy-firing conditions for the coal and conditions investigated. $\mathrm{SO}_{2}$ emissions still show a clear trend of decreasing emissions with increasing limestone addition, as shown in Figure 72. The influence of limestone injection on $\mathrm{SO}_{3}$ formation, however, was difficult to assess from the data. Ca:S ratios of 0, 2.5, 
3.5, 5.0 and 10.0. There was significant variability in the $\mathrm{SO}_{3}$ emissions at each injection ratio. Thus, $\mathrm{SO}_{3}$ emissions were essentially constant over the range of $\mathrm{Ca}: \mathrm{S}$ ratios and operating conditions investigated.

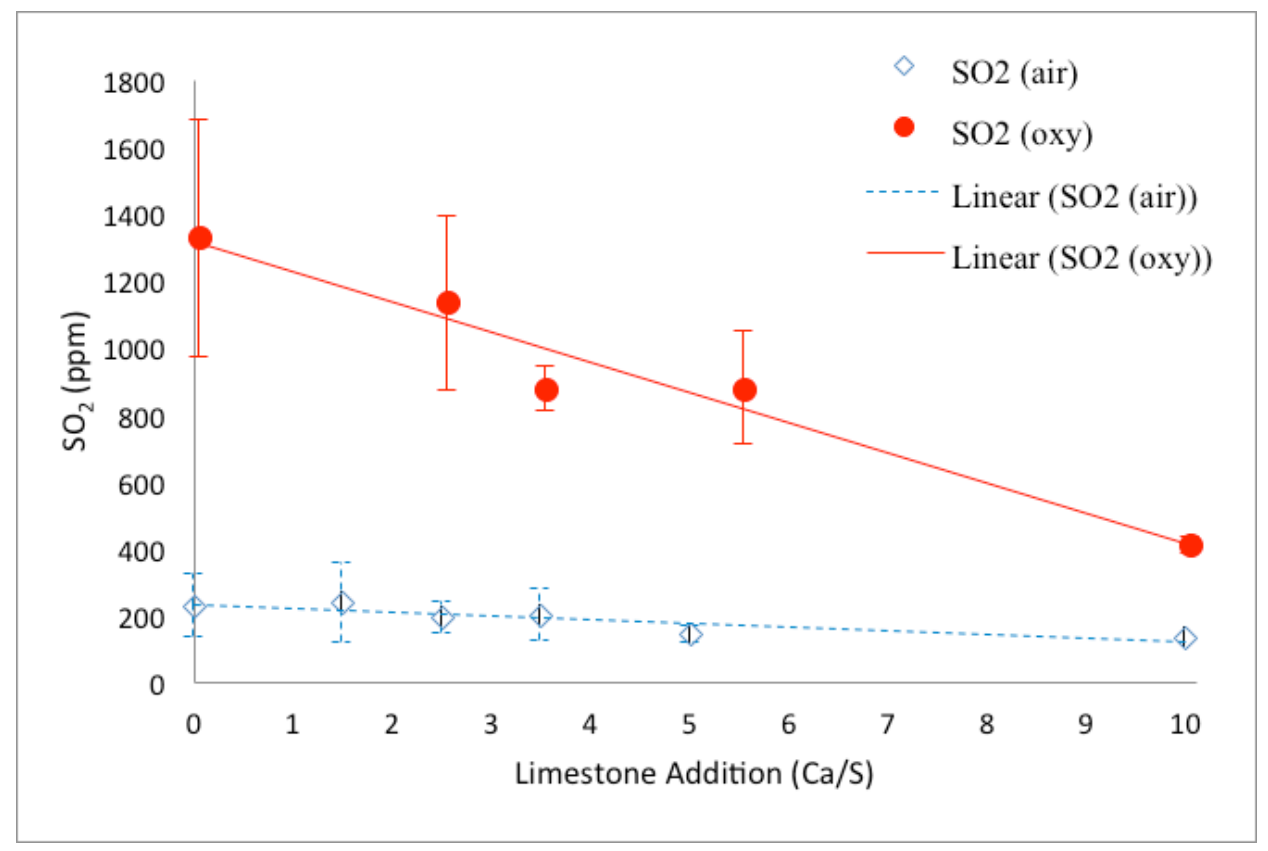

Figure 70. $\mathrm{SO}_{2}$ emissions based on concentration (ppm) with different $\mathrm{Ca}: \mathrm{S}$ ratio for air-firing and oxyfiring (50 lbs/hr Utah coal, $3 \%$ excess $\mathrm{O}_{2}$ in exit flue gas, $80 \%$ primary $/ 20 \%$ secondary).

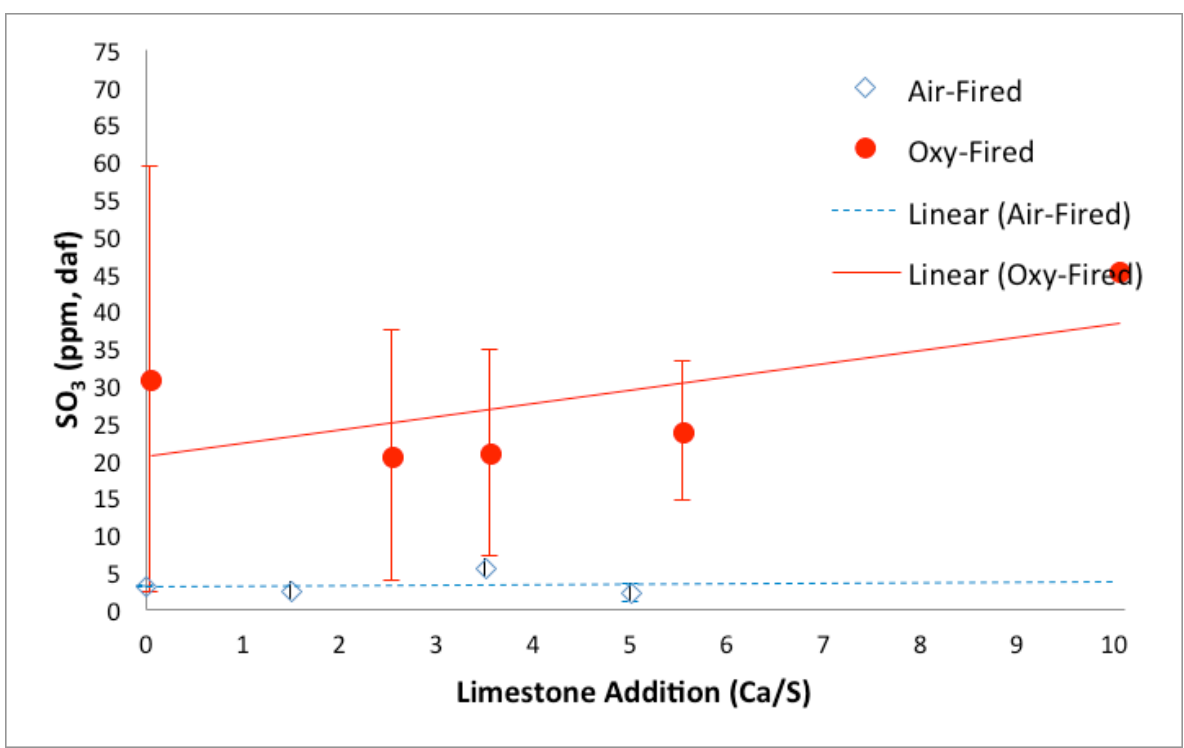

Figure 71. $\mathrm{SO}_{3}$ emissions based on concentration (ppm) with different $\mathrm{Ca}: \mathrm{S}$ ratio for air-firing and oxyfiring (50 lbs/hr Utah coal, $3 \%$ excess $\mathrm{O}_{2}$ in exit flue gas, $80 \%$ primary $/ 20 \%$ secondary). 


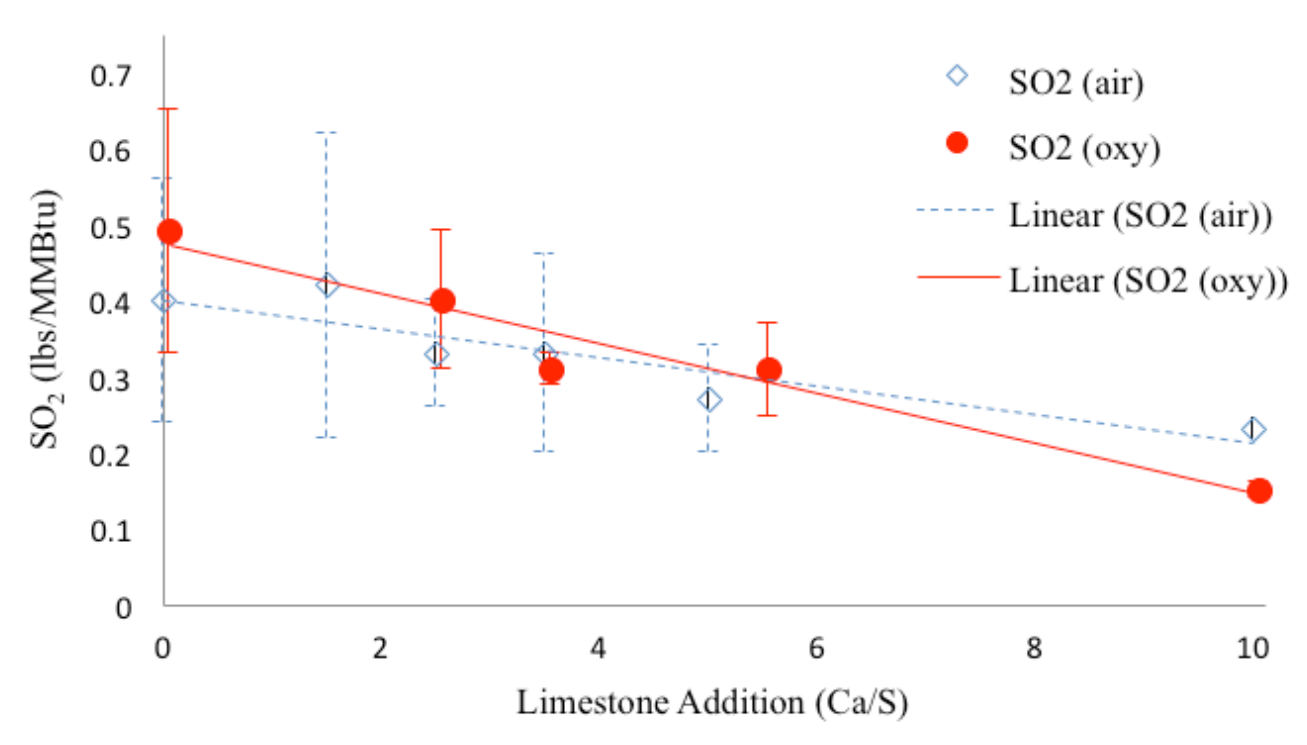

Figure 72. $\mathrm{SO}_{2}$ emissions based on mass (lbs/MMBtu) with different $\mathrm{Ca}: \mathrm{S}$ ratio for air-firing and oxyfiring (50 lbs/hr Utah coal, $3 \%$ excess $\mathrm{O}_{2}$ in exit flue gas, $80 \%$ primary $/ 20 \%$ secondary).

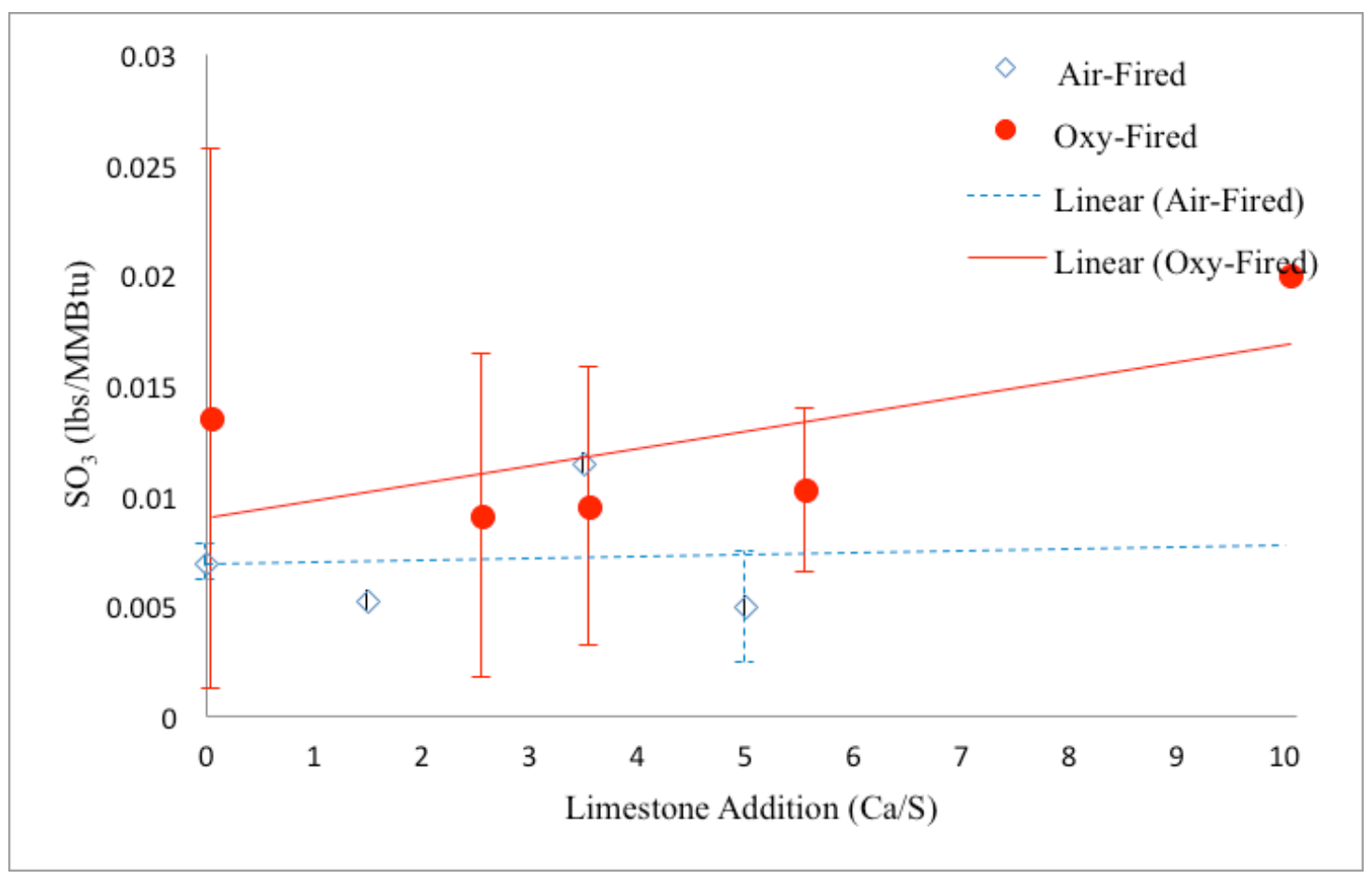

Figure 73. $\mathrm{SO}_{3}$ emissions based on mass (lbs/MMBtu) with different $\mathrm{Ca}: \mathrm{S}$ ratio for air-firing and oxyfiring (50 lbs/hr Utah coal, $3 \%$ excess $\mathrm{O}_{2}$ in exit flue gas, $80 \%$ primary $/ 20 \%$ secondary). 


\section{Uncertainty Analysis}

An uncertainty analysis was performed for the pilot-scale CFB experiment and included assessment of errors arising from both the operating and measurement equipment, as well as other potential sources of error. The flow rates, temperatures, pressures, and gaseous emissions averages and uncertainties are shown in Tables 2 and 3 for both air and oxy-firing conditions. For example, the Section 1 (bed) temperature under oxy-fired conditions was $1627 \pm 33{ }^{\circ} \mathrm{F}$ over 20 data points. Table 18 also includes the accuracies of the equipment used to obtain the individual data points as reported by the equipment manufacturers. As can be seen in the tables, the flow rates, temperatures, and pressures have fairly good accuracies and the standard deviation between tests is relatively low. This is also the case for the $\mathrm{O}_{2}, \mathrm{CO}_{2}$, $\mathrm{NO}$, and $\mathrm{H}_{2} \mathrm{O}$ analyses. There is considerable variability in the $\mathrm{CO}$ analysis, which is probably due to presence of significant amounts of coal fines in the as-fed coal, and these coal fines would be entrained immediately by the fluidizing gas and conveyed into the downstream regions of the CFB where they could generate $\mathrm{CO}$.

As noted previously, during the experimental testing limestone was injected in varying amounts to compare the effects of $\mathrm{SO}_{2}$ and $\mathrm{SO}_{3}$ reductions under air-fired and oxy-fired conditions. Figure 65 shows the $\mathrm{SO}_{2}$ concentrations as a function of calcium to sulfur ratio $(\mathrm{Ca}: \mathrm{S})$. There is a strong linear correlation between the $\mathrm{SO}_{2}$ concentration and limestone addition with the trend line falling within the error of most data points. The error shown in this figure and all subsequent figures represents $+/$ - one standard deviation. Although the concentration of $\mathrm{SO}_{2}$ is much higher for the oxy-fired conditions than for air-fired conditions on a ppm basis, Figure 66 shows that both oxy-fired and air-fired have similar overall emissions on a mass basis, and both curves fall within the error bars of either condition. The $\mathrm{SO}_{3}$ trend is less defined, as shown in Figure 65 and Figure 66. The concentration of $\mathrm{SO}_{3}$ is definitely higher under oxy-firing conditions on a ppm basis and could possibly be higher on a mass basis as well. Both curves fall within the error bars of the oxy-fired data points, so it is difficult to draw definitive conclusions given the uncertainties. 
Table 18. CFB equipment uncertainties.

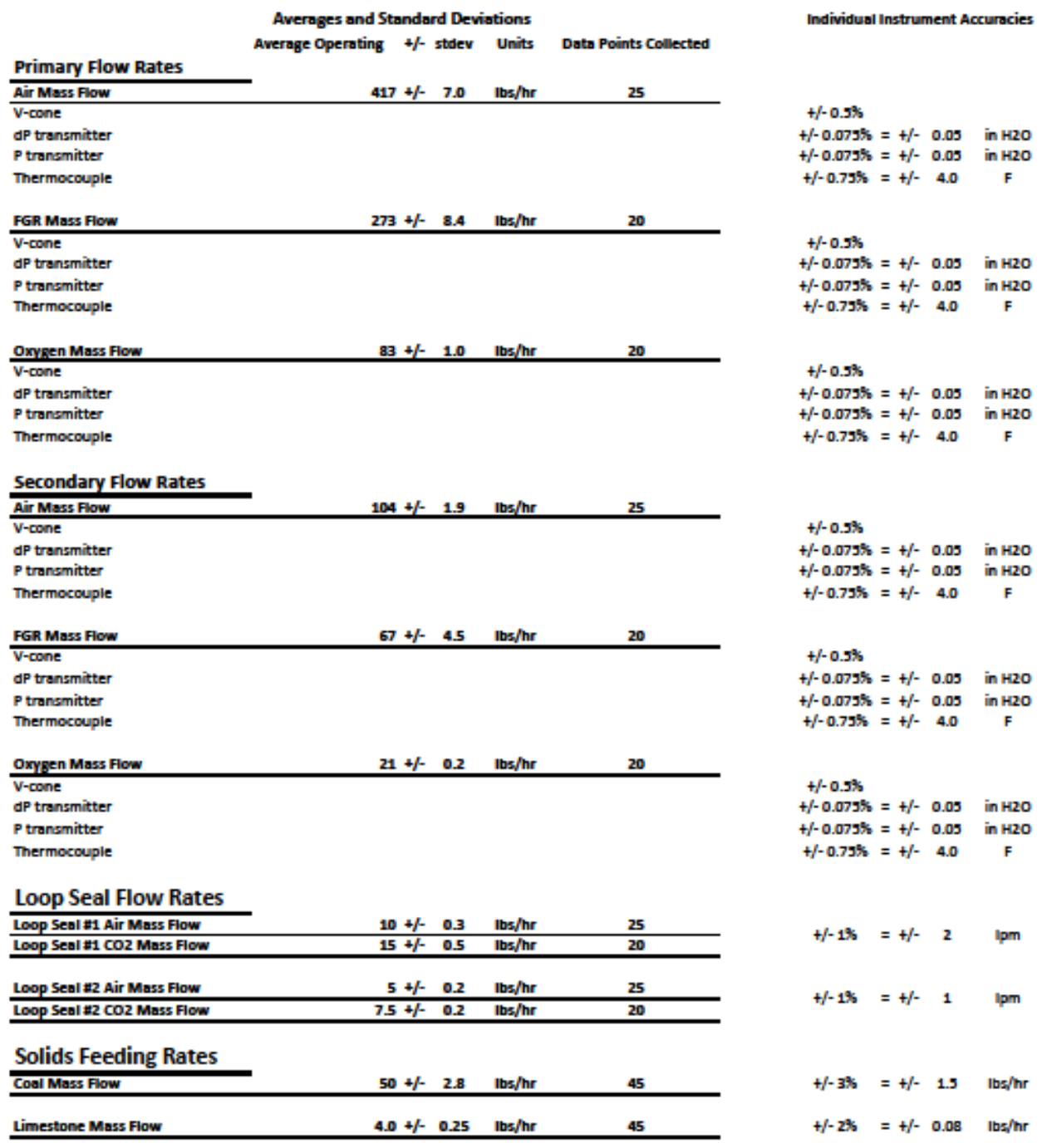


CFB equipment uncertainties (continued).

\begin{tabular}{|c|c|c|c|c|}
\hline & Averages and Stando & rd Devi & iations & \\
\hline & Average Operating $\quad+$ - & stdev & Units & Data Points Collected \\
\hline System Pressures & & & & \\
\hline Plenum Pressure (air-fired) & $29.1+1-$ & 1.6 & in $\mathrm{H}_{2} \mathrm{O}$ & 25 \\
\hline Plenum Pressure (oxy-fired) & $26.0+\%$ & 2.0 & in $\mathrm{H} 2 \mathrm{O}$ & 20 \\
\hline Bed Pressure (air-fired) & $2.3+\%$ & 0.8 & in $\mathrm{H}_{2} \mathrm{O}$ & 25 \\
\hline Bed Pressure (axy-fired) & $1.3+\%$ & 0.4 & in $\mathrm{H}_{2} \mathrm{O}$ & 20 \\
\hline Cyclone Pressure (air-fired) & $2.7+\%$ & 0.4 & in $\mathrm{H}_{2} \mathrm{O}$ & 25 \\
\hline Cyclone Pressure (oxy-fired) & $2.2+1$ & 0.6 & in $\mathrm{H} 2 \mathrm{O}$ & 20 \\
\hline Loop Seal Pressure (air-fired) & $10.1+\%$ & 0.6 & in $\mathrm{H}_{2} \mathrm{O}$ & 25 \\
\hline Loop Seal Pressure (axy-fired) & $8.3+1-$ & 1.1 & in $\mathrm{H} 2 \mathrm{O}$ & 20 \\
\hline System Temperatures & & & & \\
\hline Primary Stream (plenum iniet) & $600+\%$ & 2 & $\mathbf{F}$ & 45 \\
\hline Section 1 (air-fired) & $1446+/-$ & 80 & $\mathbf{F}$ & 25 \\
\hline Section 1 (oxy-fired) & $1627+\%$ & 33 & $\mathbf{F}$ & 20 \\
\hline Section 2 (air-fired) & $1525+\%$ & 67 & $\mathbf{F}$ & 25 \\
\hline Section 2 (oxy-fired) & $1697+\%$ & 27 & $\mathbf{F}$ & 20 \\
\hline Section 3 (air-fired) & $1536+\%$ & 62 & $\mathbf{F}$ & 25 \\
\hline Section 3 (oxy-fired) & $1704+\%$ & 29 & $\mathbf{F}$ & 20 \\
\hline Section 4 (air-fired) & $1533+\%$ & 67 & $\mathbf{F}$ & 25 \\
\hline Section 4 (oxy-fired) & $1660+/-$ & 26 & $\mathbf{F}$ & 20 \\
\hline Section 5 (air-fired) & $1527+/-$ & 60 & $\mathbf{F}$ & 25 \\
\hline Section 5 (oxy-fired) & $1686+\%$ & 33 & $\mathbf{F}$ & 20 \\
\hline Transition (air-fired) & $1516+/-$ & 59 & $\mathbf{F}$ & 25 \\
\hline Transition (axy-fired) & $1669+\%$ & 38 & $\mathbf{F}$ & 20 \\
\hline Loop Seal (air-fired) & $1428+1-$ & 49 & $\mathbf{F}$ & 25 \\
\hline Loop Seal ary-fired & $1493+7-$ & 43 & $F$ & 20 \\
\hline Cyclone Outbet (sir-fired) & $1324+7$ & 46 & $\mathbf{F}$ & 25 \\
\hline Cyclone Outlet (oxy-fired) & $1436+1-$ & 29 & $\mathbf{F}$ & 20 \\
\hline Gas Analyzers (daf) & & & & \\
\hline 02 (air-fired) & $2.9+\%$ & 0.6 & $\$ 02$ & 25 \\
\hline 02 (oxy-fired) & $3.1+\%$ & 0.5 & 5,02 & 20 \\
\hline $\mathrm{CO} 2$ (air-fired) & $14.9+7$ & 1.3 & $5 \mathrm{co2}$ & 25 \\
\hline $\mathrm{CO} 2$ (axy-fired) & $86.5+1$ & 3.5 & $5 \mathrm{cos}$ & 20 \\
\hline Co (air-tired) & $447+\%$ & 349 & $\mathrm{ppm}$ co & 25 \\
\hline co (oxy-fired) & $718+\%$ & 414 & ppm CO & 20 \\
\hline No (airffired) & $140+\%$ & 55 & ppm No & 25 \\
\hline NO (oxy-fired) & $202+\%$ & 60 & Ppm NO & 20 \\
\hline $\mathrm{SO2}$ (air-fired) & $203+/-$ & 84 & $\mathrm{ppm} \mathrm{SO2}$ & 25 \\
\hline SO2 (any-fired) & $968+/-$ & 342 & $\mathrm{ppm} \mathrm{SO2}$ & 25 \\
\hline SO3 (air-fired) & $3.0+\%$ & 1.5 & $\mathrm{ppm} \mathrm{SO3}$ & 8 \\
\hline 503 (axy-fired) & $26+\%$ & 16 & $\mathrm{ppm} \mathrm{SO3}$ & 12 \\
\hline H2O(oxy-fired) & $30.3+7$ & 2.4 & 8420 & 20 \\
\hline
\end{tabular}

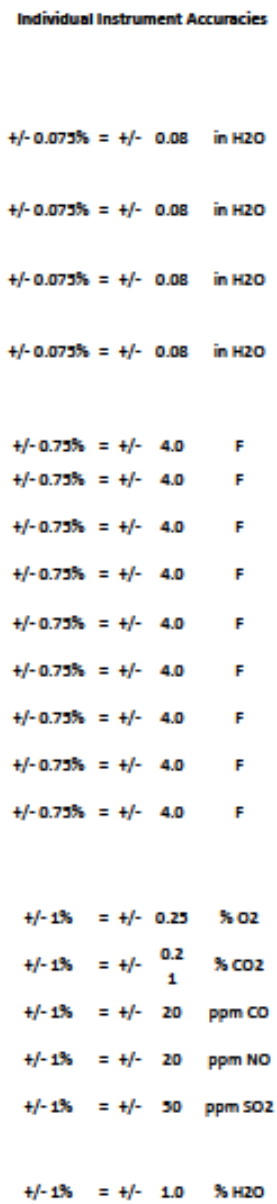

\section{Subtask 3.5 - Single-Particle Oxy-CO $2{ }_{2}$ Combustion}

\section{FTIR spectra and calibration curve}

A typical Fourier transform infrared spectroscopy (FTIR) spectrum of $\mathrm{SO}_{2}$ is shown in Figure 74. There are two main absorbance regions: one region (1) is located between $1294 \mathrm{~cm}^{-1}$ and $1421 \mathrm{~cm}^{-1}$, and the other (region 2) is from $1087 \mathrm{~cm}^{-1}$ to $1209 \mathrm{~cm}^{-1}$. Obviously, the absorbance in region 1 is much stronger than that in region 2. To avoid overlapping with other species, the wavelength region from $1319 \mathrm{~cm}^{-1}$ to $1363 \mathrm{~cm}^{-1}$ is used. 


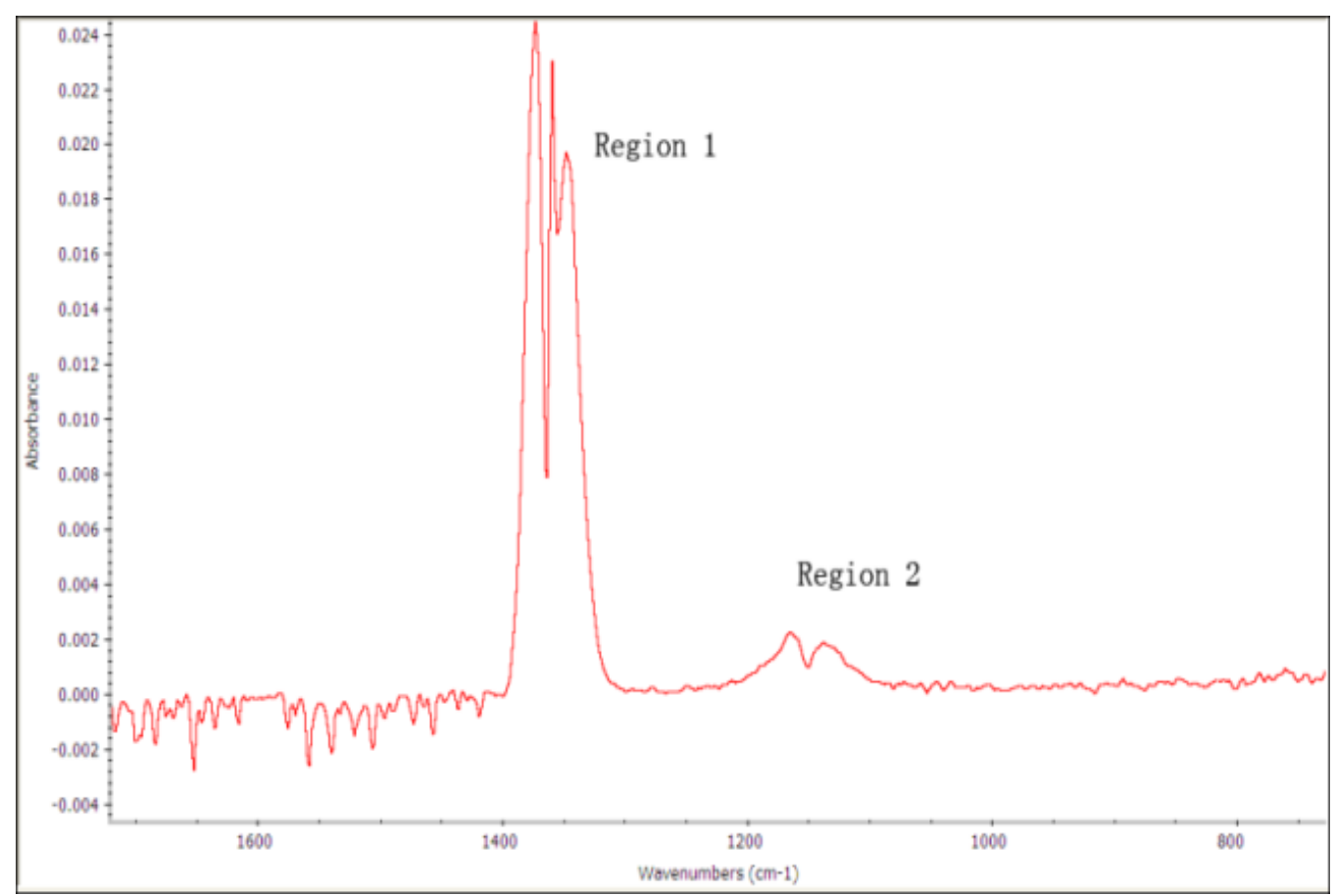

Figure 74. $\mathrm{SO}_{2}$ spectra by FTIR with a $\mathrm{SO}_{2}$ concentration of $1000 \mathrm{ppm}$.

$\mathrm{CO}_{2}$ spectra have a large absorbance peak area $\left(2281 \mathrm{~cm}^{-1}\right.$ to $\left.2404 \mathrm{~cm}^{-1}\right)$, compared with the CO absorbance peak area $\left(2086 \mathrm{~cm}^{-1}\right.$ to $\left.2281 \mathrm{~cm}^{-1}\right)$ as shown in Figure 75. There is no overlap area between $\mathrm{SO}_{2}, \mathrm{CO}$ and $\mathrm{CO}_{2}$, so gas-species concentrations can be measured simultaneously.

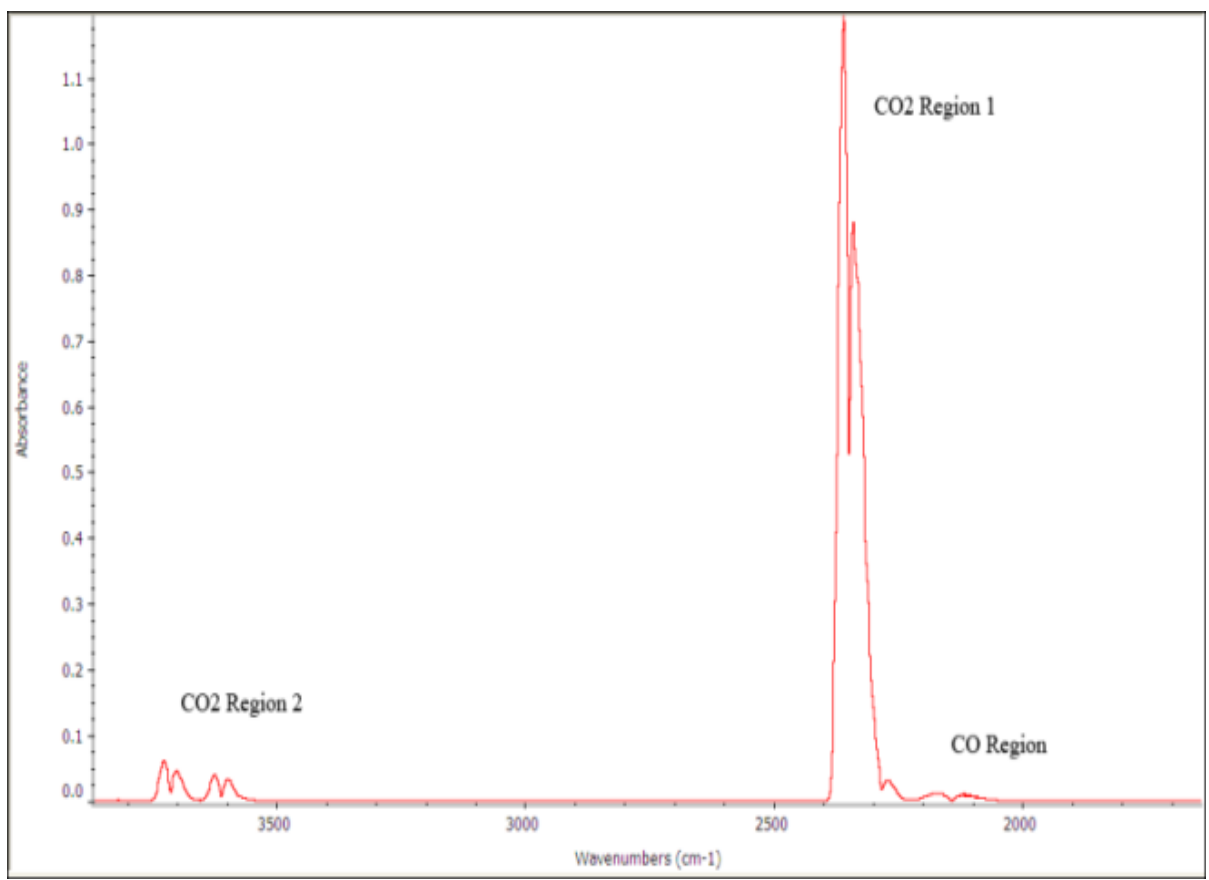

Figure $75 . \mathrm{CO}_{2}-\mathrm{CO}$ spectra by FTIR. 
Calibration curves for $\mathrm{SO}_{2}$ were evaluated at room temperature. $\mathrm{SO}_{2}$ calibration gas flowed through the gas cell. The concentration of $\mathrm{SO}_{2}$ calibration gas, which was balanced with $\mathrm{N}_{2}$ or $\mathrm{CO}_{2}$, is $1000 \mathrm{ppm}$, and it was mixed with $\mathrm{N}_{2}$ or $\mathrm{CO}_{2}$ by mass flow controller to attain various concentrations of $\mathrm{SO}_{2}$. Three spectra were taken for each condition. Figure 76 illustrates the calibration curve of $\mathrm{SO}_{2}$ in $\mathrm{N}_{2}$ or $\mathrm{CO}_{2}$ environments. Both calibration curves were highly linear, with an $\mathrm{R}^{2}$ value greater than 0.999 .

The equation of the calibration curve for $\mathrm{SO}_{2}$ balanced with $\mathrm{N}_{2}$ :

$\mathrm{SO}_{2}($ ppm $)=1859 * \mathrm{SO}_{2}($ area $)+21.6, R^{2}=0.999$.

The equation of calibration curve for $\mathrm{SO}_{2}$ balancedCO $\mathrm{C}_{2}$ :

$\mathrm{SO}_{2}(\mathrm{ppm})=1847.1 * \mathrm{SO}_{2}($ area $)-9.9, R^{2}=0.999$.

Figure 76 also shows that the effect of $\mathrm{N}_{2}$ or $\mathrm{CO}_{2}$ on the $\mathrm{SO}_{2}$ absorbance spectra is very similar.

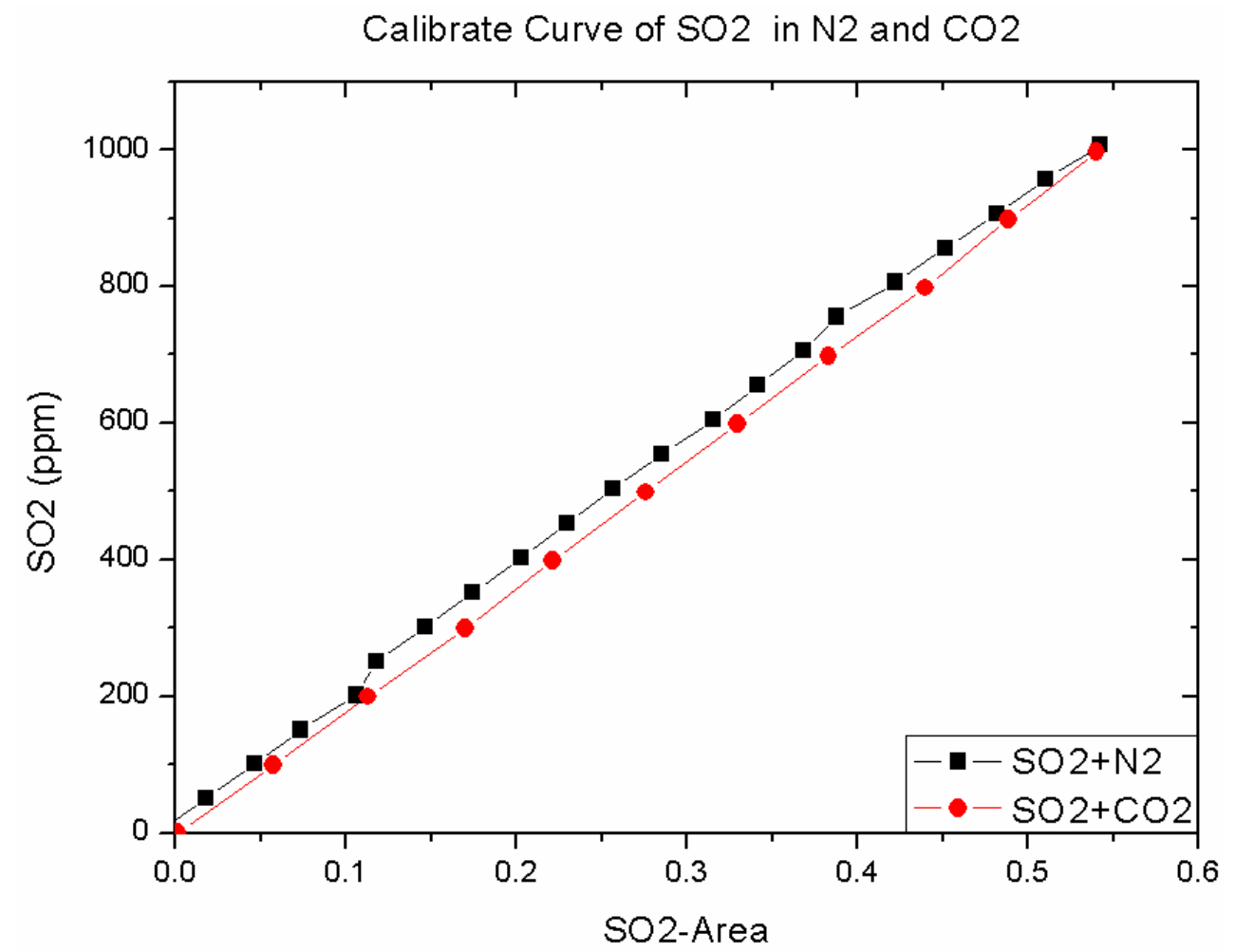

Figure 76. Calibration curve for $\mathrm{SO}_{2}$, balance $\mathrm{N}_{2}$ or $\mathrm{CO}_{2}$.

\section{$\mathrm{SO}_{2}$ emissions under oxy-fuel combustion and air-combustion conditions}

The emissions of $\mathrm{SO}_{2}$ in oxy-fuel combustion and air-combustion are quite different in the bench-scale fluidized bed and pilot-scale CFB (Subtask 3.4) with flue gas recycling. High concentrations of $\mathrm{CO}_{2}$ 
appear to have no effect on $\mathrm{SO}_{2}$ emissions in the bench-scale fluidized bed. On the contrary, in the pilotscale with flue gas recycling yields different $\mathrm{SO}_{2}$ emissions under oxy-fuel combustion and aircombustion conditions. The pilot-scale CFB shows higher concentrations of $\mathrm{SO}_{2}(\mathrm{ppm})$ but a lower mass emission rate of $\mathrm{SO}_{2}(\mathrm{mg} / \mathrm{MJ})$, and the fate of sulfur in the pilot-scale doesn't seem to be consistent with the results of bench-scale fluidized bed.

\section{$\mathrm{SO}_{2}$ emissions in the bench-scale fluidized bed}

The experiments of $\mathrm{SO}_{2}$ emission experiments in the bench-scale fluidized bed were carried out at three $\mathrm{O}_{2}$ concentrations $(10 \%, 20 \%$ and $30 \%)$ and temperatures $(765-902 \mathrm{C})$. Single coal particle combustion showed the transient nature of $\mathrm{SO}_{2}$ evolution. The distribution of sulfur content in each single coal particle was not uniform. In order to reduce the effect of the variation in coal particles, each experimental condition was repeated five times. The error bars for each experimental condition showed the experimental data's fluctuation. In this way, we can compare $\mathrm{SO}_{2}$ emissions at specific $\mathrm{O}_{2}$ concentrations, bed temperatures and experimental conditions to determine the effect of $\mathrm{CO}_{2}$ on the $\mathrm{SO}_{2}$ emissions.

As Figure 77 shows, $99 \%$ of the $\mathrm{SO}_{2}$ was released within 60 seconds, while burning out the fixed carbon required 3 to 8 minutes, depending on the experimental conditions. Sulfur evolution is much more rapid than carbon evolution in single coal particle combustion. The emissions of $\mathrm{SO}_{2}$ indicated clearly its transient nature. At the initiation of the combustion reaction, the sulfur emissions were pretty low due to the low coal particle temperature. The coal particle rapidly heated up from the furnace wall and surrounding hot gas phase. When the ignition temperature was achieved, combustion heat generation caused rapid heating of the coal particle. The emission rates for $\mathrm{SO}_{2}$ reaches a maximum value between 6 to 12 seconds. With the combustion process occurring, after that, the emission rate of $\mathrm{SO}_{2}$ decreased because sulfur was consumed from the coal particle.

Each subplot in Figure 77 shows the comparison of $\mathrm{SO}_{2}$ emissions between oxy-fuel combustion and air combustion. It clearly indicates there was little difference in the $\mathrm{SO}_{2}$ emissions.
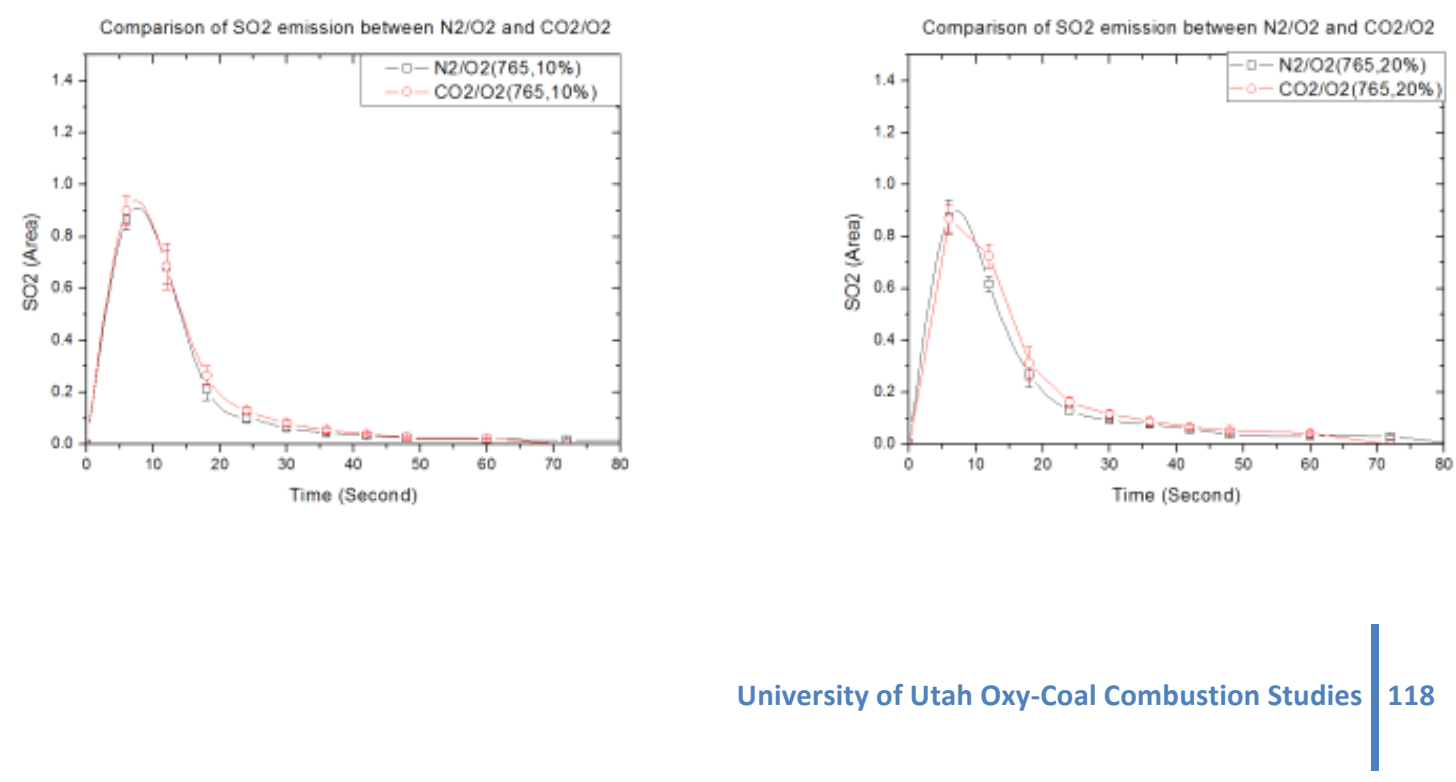

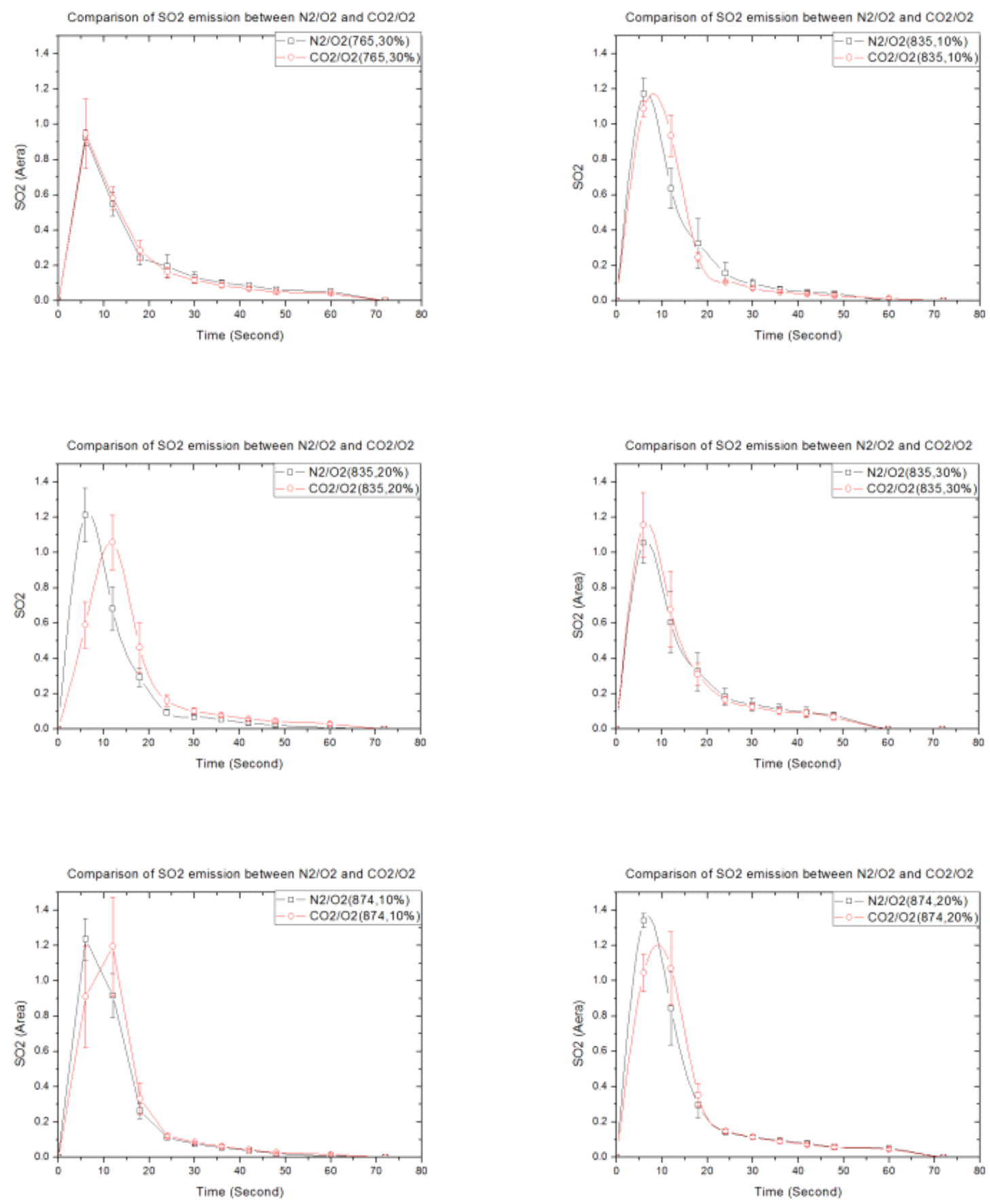

University of Utah Oxy-Coal Combustion Studies 

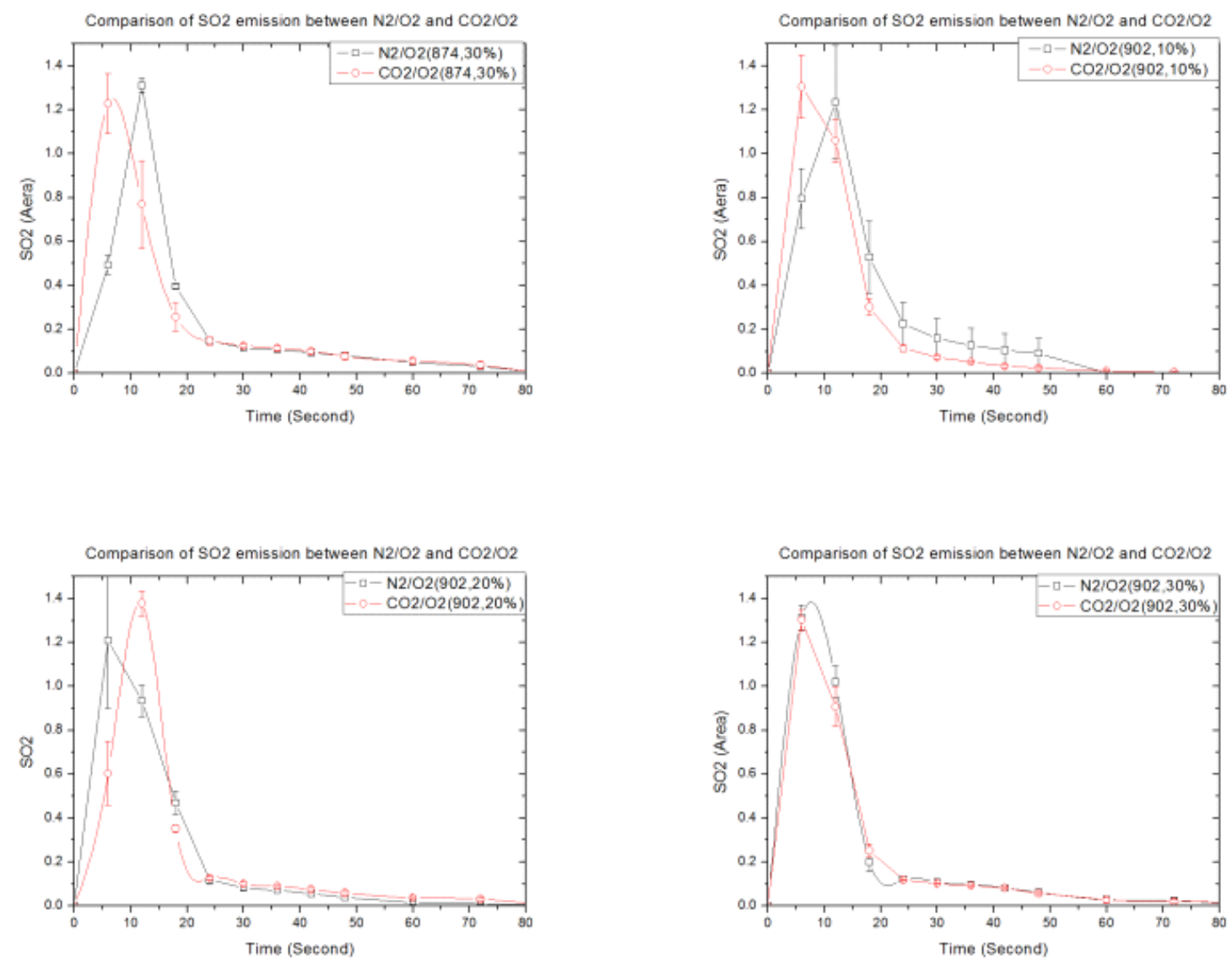

Figure 77. $\mathrm{SO}_{2}$ emissions in oxy-fuel combustion and air combustion from a single particle fluidized bed.

The effect of temperature on $\mathrm{SO}_{2}$ emissions. The effect of temperature on $\mathrm{SO}_{2}$ emission is illustrated in the 6 sub-plots of Figure 78. A wide range of fluidized bed operating temperatures (765C to $902 \mathrm{C}$ ) is investigated at various $\mathrm{O} 2$ concentrations $(10 \%, 20 \%, 30 \%)$. Each condition was repeated 5 times.

As Figure 78 shows, the temperature appears to have an important influence on $\mathrm{SO}_{2}$ emissions, which increases dramatically with an increase of the temperature. Approximately, $80 \%-90 \%$ of the sulfur in the coal particle is released in the first $30 \mathrm{~s}$. The rate of $\mathrm{SO}_{2}$ emission achieves maximum in the first 5-6 s.

Figure 79 gives the profile of the integrated $\mathrm{SO}_{2}$ emission versus reaction time under $30 \% \mathrm{O}_{2}$ and a temperature of $765 \mathrm{C}$. Based on the rate of $\mathrm{SO}_{2}$ emissions we see three reaction regions: slow sulfur release, fast sulfur release, and a final slow release region. In the first slow region, the carbon and sulfur reaction was very slow due to the low coal-particle temperature. In addition, kinetics control in this region. In the fast region, the coal particle was heated up by the walls of the fluidized bed and the surrounding hot gas to achieve the ignition temperature. As the coal particle's temperature rapidly increases, fixed carbon 
and sulfur inside coal particle can react with $\mathrm{O}_{2}$ rapidly, and the rate of $\mathrm{SO}_{2}$ emission reaches the maximum. Finally, in the second slow region (after $12 \mathrm{~s}$ ), the sulfur in the coal is consumed, and then the $\mathrm{SO}_{2}$ emissions decrease rapidly. According to preliminary experiments, the evolution of sulfur is much faster than that of carbon.

It is a real challenge faced by researchers attempting to develop new theories to explain the differences between carbon and sulfur evolution. In order to explain the sulfur release rate, we develop our own diffusion-control theory. There are two assumptions in our theory in this theory.

1. Single coal particle combustion after ignition is diffusion controlled. Hence, $\mathrm{O}_{2}$ exists in a very thin surface layer, and $\mathrm{O}_{2}$ concentration is very low inside coal particles, as Figure 80 illustrates.

2. Solid phases, such as fixed carbon, inorganic sulfur, etc., cannot diffuse outside the coal particle, while the gases can move between the coal particle and external environment.

3. Since diffusion dominates, there is a lack of $\mathrm{O}_{2}$ inside the coal particle. Thus, fixed carbon and solid sulfur has no possibility to react with $\mathrm{O}_{2}$ until the outer layer of the coal particle is burned out.

The physical and chemical properties of fixed carbon, inorganic and organic sulfur are shown in Table 4. Fixed carbon can be vaporized above $4827 \mathrm{C}$ in the absence of $\mathrm{O}_{2}$. However, coal particle combustion cannot achieve such a high temperature, even adiabatic combustion. Hence, fixed carbon inside a coal particle has no opportunity to react with $\mathrm{O}_{2}$ unless the outside carbon layer has burned out. On the contrary, sulfur shows different chemical and physical properties. Organic sulfur can be vaporized below 400-500C, hence it can diffuse to the coal particle surface with volatile matter. In addition, inorganic sulfur is usually comprised of $\mathrm{FeS}, \mathrm{FeSO}_{4}$, and $\mathrm{FeS}_{2}$. These can decompose into sulfur and iron compounds at $\mathrm{T}=400 \mathrm{C}, 1194 \mathrm{C}, 1188 \mathrm{C}$, respectively. Normally, the coal particle combustion temperature is higher than $1194 \mathrm{C}$. The sublimation of monomer sulfur takes place easily at $\mathrm{T}=446 \mathrm{C}$. Hence, gaseous sulfur passes into the zone where $\mathrm{O}_{2}$ is present very quickly after ignition. As discussed above, organic or inorganic sulfur inside a coal particle can react with $\mathrm{O}_{2}$ by diffusing as gas phase. Thus, evolution of sulfur can be much faster than that of fixed carbon due to the different conversion temperatures (solid state to gaseous state).
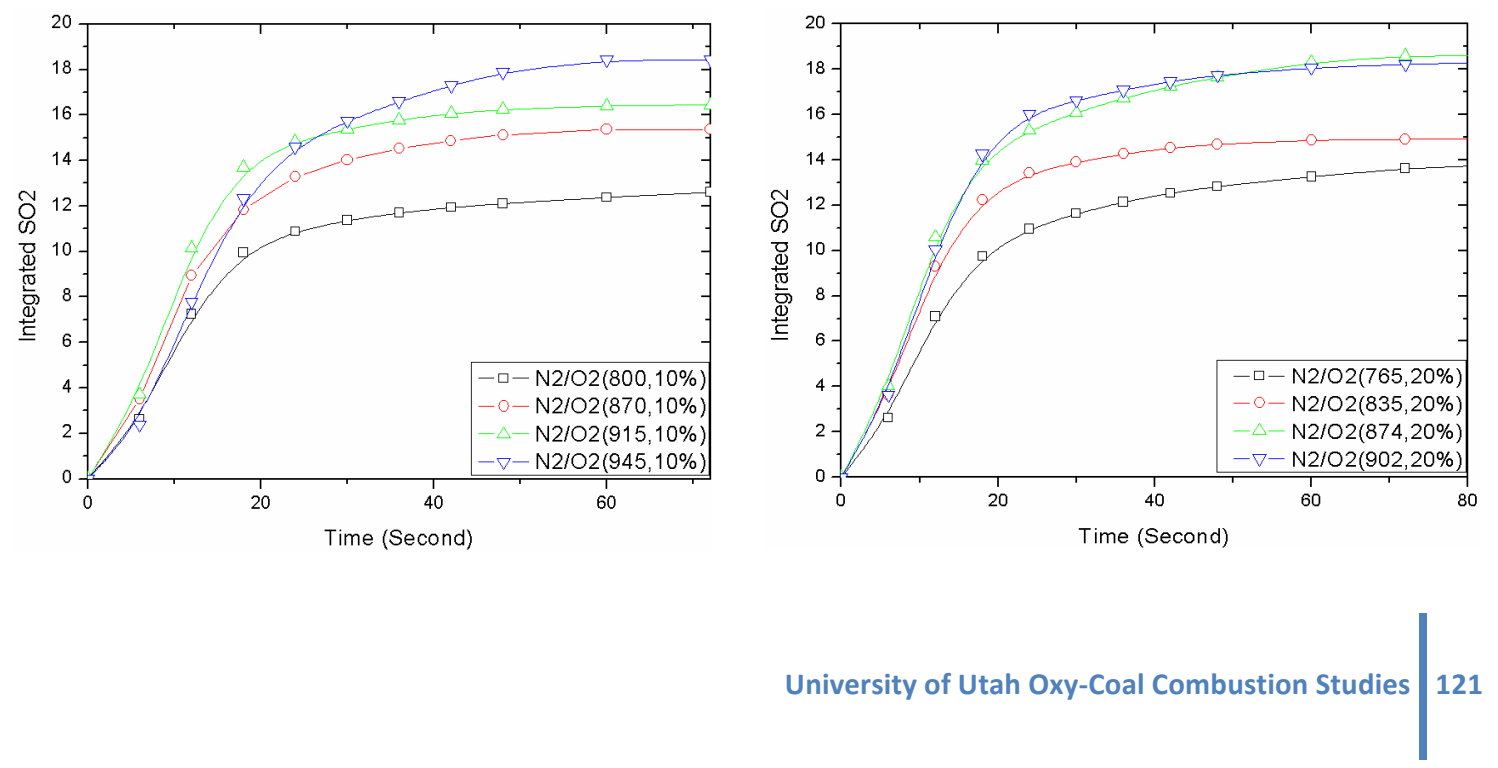

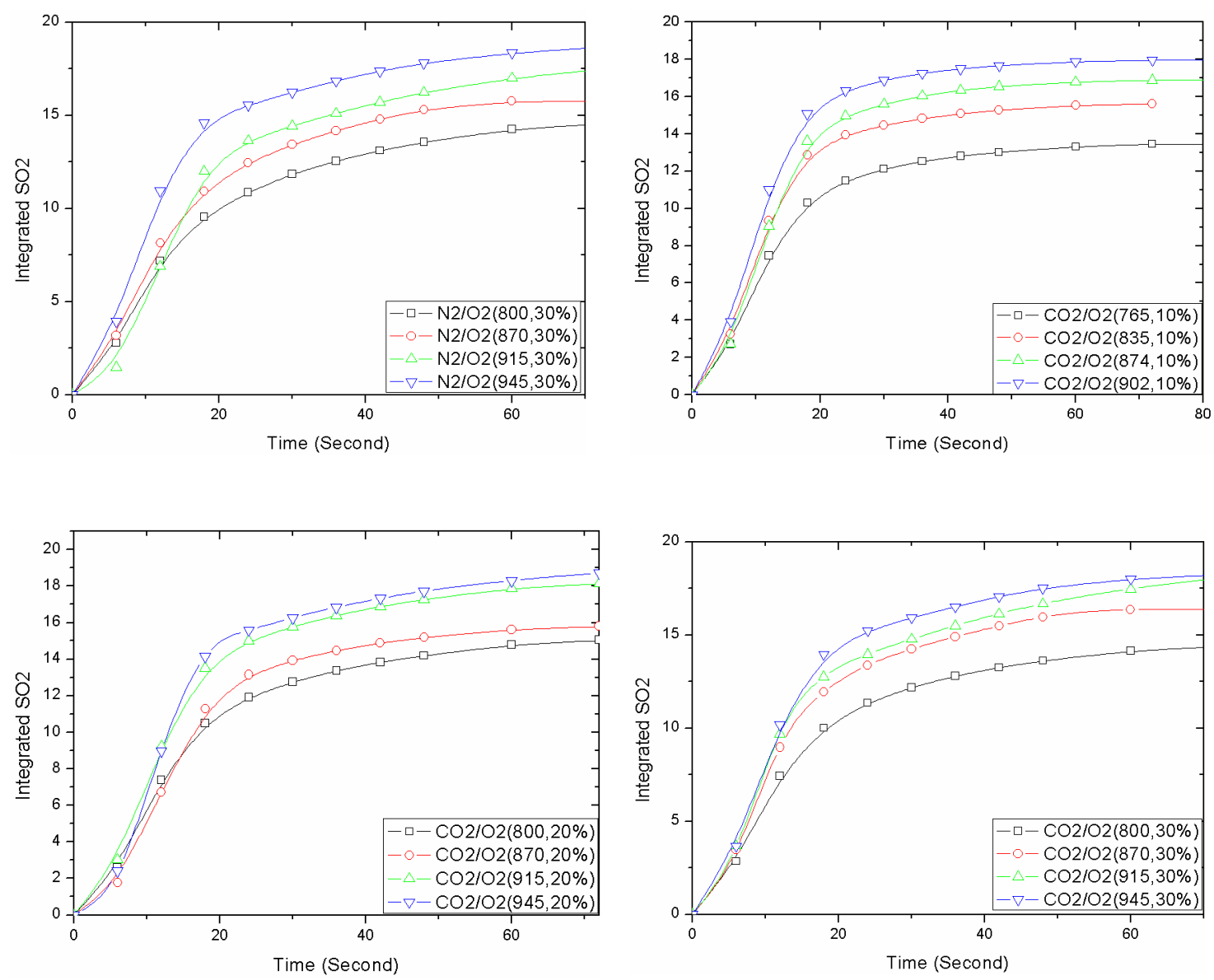

Figure 78. The evolution of $\mathrm{SO}_{2}$ with an increasing temperature in bench-scale fluidized bed. 


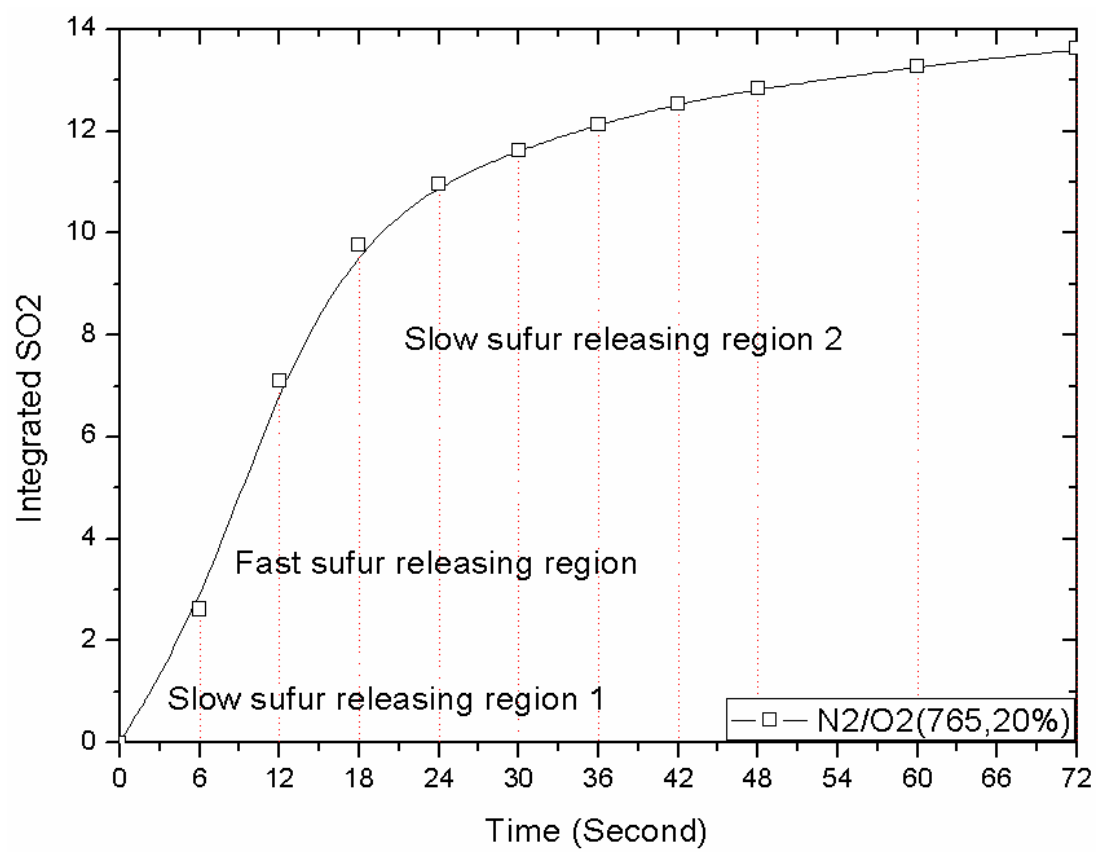

Figure 79. Three sulfur releasing regions in single coal particle.

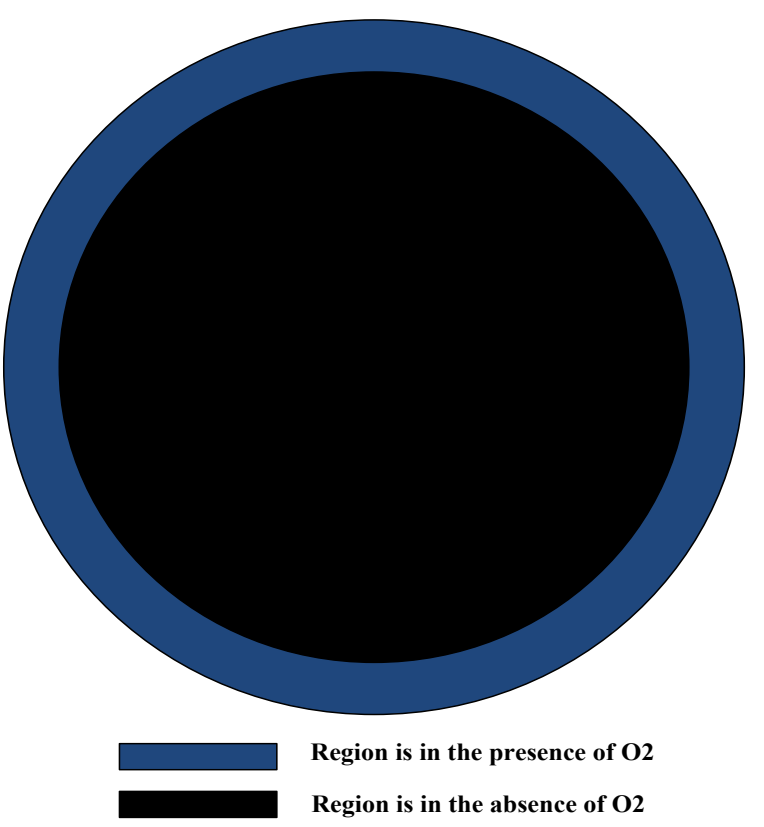

Figure 80. Schema of diffusion control domination in single coal particle combustion. 
Table 19. Physical and chemical property of fix carbon and organic and inorganic sulfur.

\begin{tabular}{|c|c|c|c|}
\hline \multicolumn{4}{|c|}{$\begin{array}{l}\text { Boiling or decomposition } \\
\text { temperature }\end{array}$} \\
\hline \multicolumn{2}{|c|}{ Fixed carbon } & $\begin{array}{c}4827.0 \mathrm{C}(5100.15 \mathrm{~K}, \\
\left.8720.6^{\circ} \mathrm{F}\right)\end{array}$ & $C(s) \rightarrow C(g)$ \\
\hline \multicolumn{2}{|c|}{ Monomer sulfur } & $\begin{array}{c}444.60 \mathrm{C}(717.75 \mathrm{~K} \\
\left.832.28^{\circ} \mathrm{F}\right)\end{array}$ & $S(s) \rightarrow S(g)$ \\
\hline \multicolumn{2}{|c|}{ Organic sulfur } & Less than $500 \mathrm{C}$ & \\
\hline $\begin{array}{l}\text { Inorganic } \\
\text { sulfur }\end{array}$ & $\begin{array}{c}\mathrm{FeSO}_{4} \\
\mathrm{FeS}\end{array}$ & $\begin{array}{c}400 \mathrm{C} \\
1194 \mathrm{C}\end{array}$ & $2 \mathrm{FeSO}_{4}(\mathrm{~s}) \rightarrow \mathrm{Fe}_{2} \mathrm{O}_{3}(\mathrm{~s})+\mathrm{SO}_{2}(\mathrm{~g})+\mathrm{SO}_{3}(g)$ \\
\hline & $\mathrm{FeS}_{2}$ (pyrite) & $1177-1188 \mathrm{C}$ & $\mathrm{FeS}_{2}(\mathrm{~S}) \rightarrow \mathrm{FeS}+\mathrm{S}(\mathrm{g})$ \\
\hline
\end{tabular}

Calculation of $\mathrm{SO}_{2}$ emissions by chemical equilibrium program. The chemical equilibrium calculation (CEA program developed by NASA) is employed to evaluate the effect of temperature on $\mathrm{SO}_{2}$ emissions in the presence of $\mathrm{CO}_{2}$ or $\mathrm{N}_{2}$. Illinois \#6 coal is used as the fuel in the CEA calculations. Also, the parameters of simulation are the same as the bench-scale experiment's operational conditions. A wide range of temperatures (600-1000 C) are simulated, as well as different types of combustion environments $\left(\mathrm{CO}_{2} / \mathrm{O}_{2}\right.$ and $\left.\mathrm{N}_{2} / \mathrm{O}_{2}\right)$.

As Figure 81 shows, $\mathrm{SO}_{2}$ emissions are the same in oxy-fuel combustion and air combustion, and both plots exactly overlap. The results of the equilibrium simulation are consistent with experimental results from the bench-scale fluidized bed. To some extent, the equilibrium model can give a possible proof of $\mathrm{SO}_{2}$ emissions on a mass basis decreasing in pilot-scale CFB oxy-fuel combustion due to flue gas recycling instead of high concentration $\mathrm{CO}_{2}$.

The effect of temperature on $\mathrm{SO}_{2}$ emissions is also examined using the CEA program. It is clear that $\mathrm{SO}_{2}$ emissions increase with an increase in temperature. As Figure 81 shows, the effect of temperature on $\mathrm{SO}_{2}$ emission is more sensitive in the low temperature region. With anO $\mathrm{O}_{2}$ concentration of $20 \%, \mathrm{SO}_{2}$ emissions increase from 110 to $440 \mathrm{ppm}$ at the lower temperatures (600-800C), while they increase from 440 to 510 ppm at $800-1000 \mathrm{C}$. Moreover, $\mathrm{O}_{2}$ concentration seems to have a slight effect on $\mathrm{SO}_{2}$ emissions. The effect of $\mathrm{O}_{2}$ on $\mathrm{SO}_{2}$ emission is more sensitive at low temperature $(600 \mathrm{C})$, while there is no difference at $1000 \mathrm{C}$. It is obvious that the effect of temperature is much stronger than that of $\mathrm{O}_{2}$ concentration, which could be neglected. 


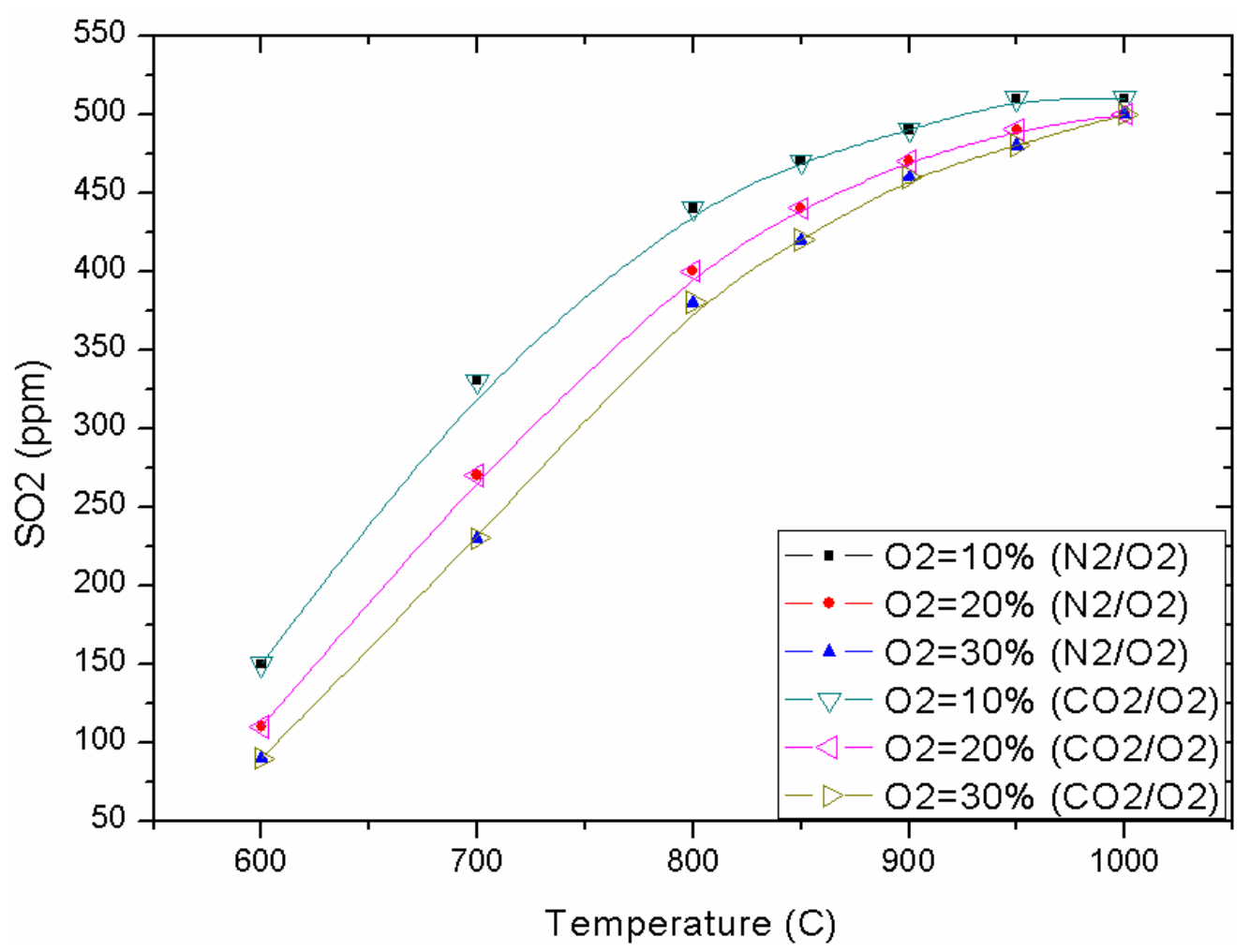

Figure 81.The evolution of $\mathrm{SO}_{2}$ emission with an increasing temperature using equilibrium calculation (CEA).

\section{Sulfur removal by limestone during coal combustion process}

Sulfur removal by directly injecting limestone is advantageous in pollution control for fluidized-bed combustion technology. The ratio of $\mathrm{Ca}: \mathrm{S}$ is more than 2000, so large amounts of limestone ensure enough contact with $\mathrm{SO}_{2}$ being released from coal particles.

$\mathrm{SO}_{2}$ emissions were investigated at low temperature $(765 \mathrm{C}, 835 \mathrm{C})$. Sub-plots in Figure 82 show the trends of $\mathrm{SO}_{2}$ emissions at different $\mathrm{O}_{2}$ concentrations $(10 \%, 20 \%$, and $30 \%)$.It is clear that the efficiency of sulfur removal by limestone in oxy-fuel combustion is much lower than during air combustion. Because the $\mathrm{CO}_{2}$ concentration is very high in the fluidized bed under oxy-fuel conditions it is anticipated that there would be a great suppression of the decomposition of $\mathrm{CaCO}_{3}$ (limestone) thereby reducing the efficiency of sulfur removal by limestone. A very high $\mathrm{Ca}: \mathrm{S}$ ratio is used in an attempt to compensate for low conversion of $\mathrm{CaCO}_{3}$ to $\mathrm{CaO}$ prior to sulfur capture.

As Figure 82 and Figure 83 show, the efficiency of sulfur removal by limestone for air combustion conditions $\left(\mathrm{O}_{2}\right.$ in $\left.\mathrm{N}_{2}\right)$ is lower at high temperature (903C) than at low temperature $(765 \mathrm{C}, 835 \mathrm{C})$. It is highly possible for limestone to sinter at high temperatures $(>900 \mathrm{C})$, which rapidly leads to reducing pore size, and the rate of $\mathrm{SO}_{2}$ diffusion into the limestone particles will decrease very quickly, thereby 
reducing the efficiency of sulfur capture of limestone in air-fired conditions at a reaction temperature of $902 \mathrm{C}$.

However, the efficiency of sulfur capture for oxy-fuel conditions $\left(\mathrm{O}_{2}\right.$ in $\left.\mathrm{CO}_{2}\right)$ is higher at high temperature (902C) than at low temperature (765C). It is anticipated that there would be less suppression of decomposition of $\mathrm{CaCO}_{3}$ in high temperature (902C), due to equilibrium considerations. Thus, greater quantities of $\mathrm{CaO}$ would exist at higher temperature, which would increase the efficiency of sulfur capture for oxy-coal conditions. The impact of sintering at higher temperatures, however, would tend to reduce efficiency.
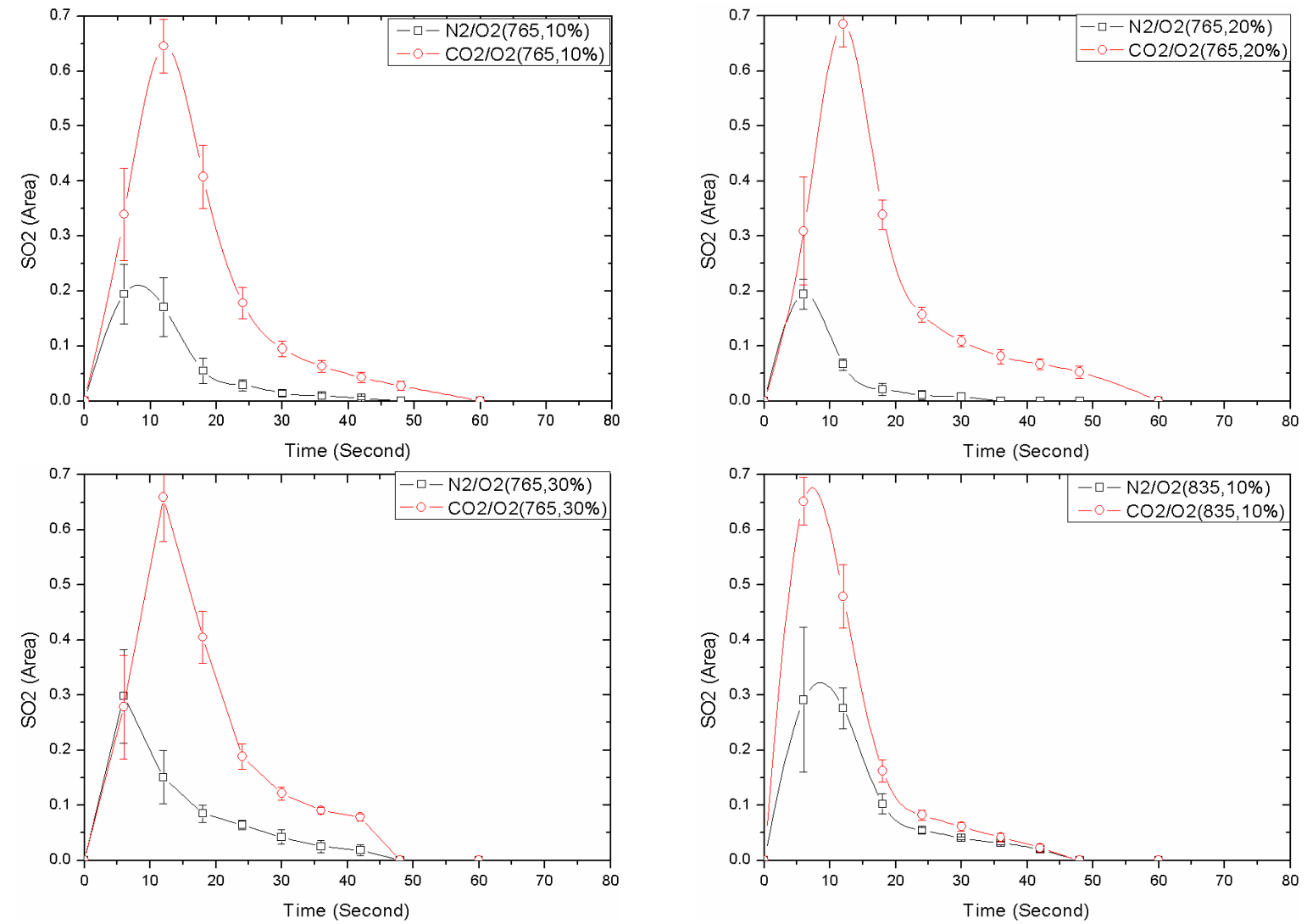

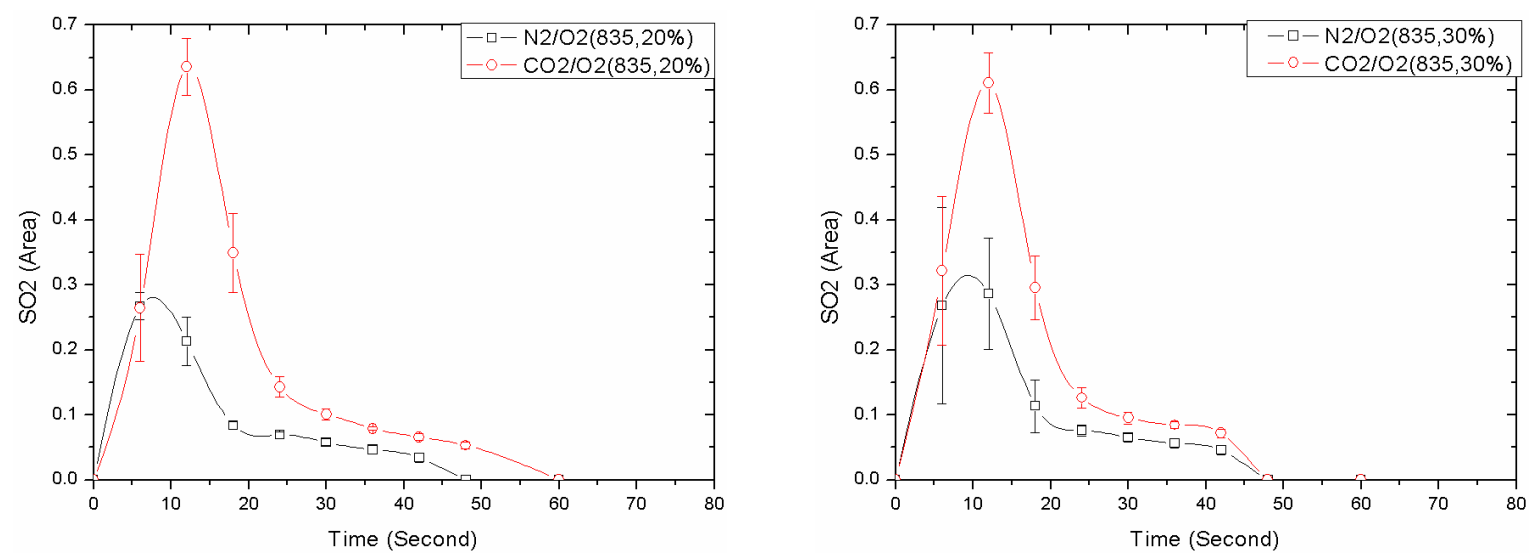

Figure 82. $\mathrm{SO}_{2}$ capture with limestone in oxy-fuel combustion and air combustion in the bench-scale fluidized bed.

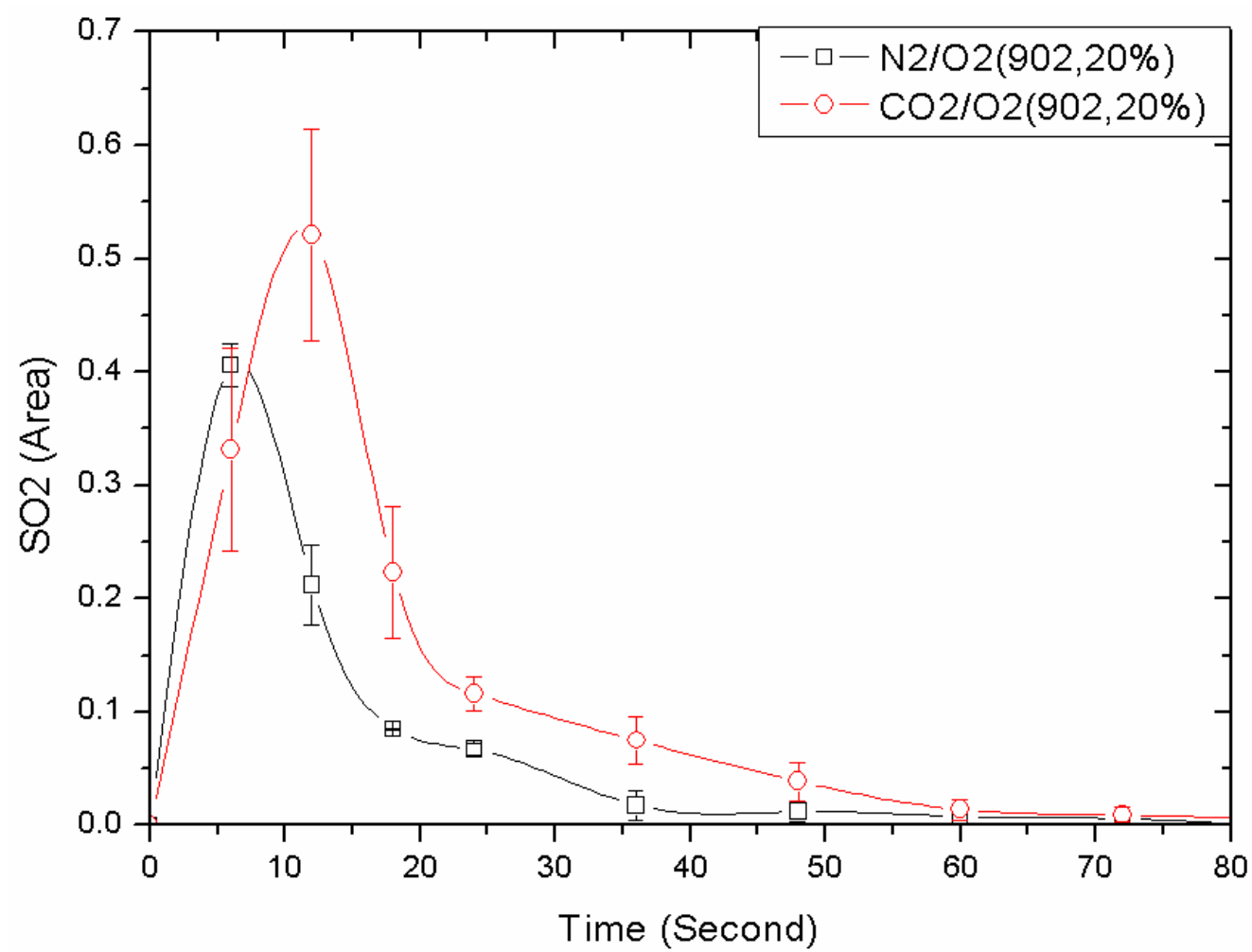

Figure $83 . \mathrm{SO}_{2}$ capture with limestone at $\mathrm{T}=902 \mathrm{C}, \mathrm{O}_{2}=20 \%$.

Sulfation behavior of limestone in $\mathrm{N}_{2} / \mathrm{O}_{2}$ and $\mathrm{CO}_{2} / \mathrm{O}_{2}$

The major limitation of studying sulfur release from a single coal particle is that it is transient and unstable. The sulfation of limestone is determined by the difference between premixed $\mathrm{SO}_{2}(800 \mathrm{ppm})$ and reacted $\mathrm{SO}_{2}$ (in FTIR gas cell). The molar ratio of $\mathrm{SO}_{2}$ to $\mathrm{CaCO}_{3}$ is $1: 1$. If the calibration gas flow rate is $\mathrm{Q}$, reacted $\mathrm{SO}_{2}$ concentration is $\mathrm{c}_{\mathrm{t}}$ at $\mathrm{t}$, and the premixed initial $\mathrm{SO}_{2}$ concentration is $\mathrm{c}_{0}\left(\mathrm{c}_{0}=800 \mathrm{ppm}\right)$, then 
the integration of molar $\mathrm{SO}_{2}$ is illustrated by the following steps. First, the consumption of $\mathrm{SO}_{2}$ by volume can be presented by equation (16).

$$
V_{s O_{2}}^{t}=\int_{0}^{t} Q \cdot\left(c_{o}-c_{t}\right) d t
$$

From the idea gas law, we find total molar $\mathrm{SO}_{2}$ consumed at $\mathrm{t}$

$$
n_{\mathrm{SO}_{2}}^{t}=\frac{P V_{\mathrm{SO}_{2}}^{t}}{R T}
$$

Since the molar relationship between $\mathrm{SO}_{2}$ and $\mathrm{CaCO}_{3}$ is $1: 1$, the weight of $\mathrm{CaCO}_{3}$ is calculated by equations (3) and (4).

$$
\begin{gathered}
n_{\mathrm{SO}_{2}}^{t}=n_{\mathrm{CaCO}_{3}}^{t} \\
m_{\mathrm{CaCO}_{3}}^{t}=M_{\mathrm{CaCO}_{3}} \cdot n_{\mathrm{SO}_{2}}^{t}
\end{gathered}
$$

The sulfation degree is the ratio of the weight $m_{\mathrm{CaCO}_{3}}^{t}$ to $m_{\mathrm{CaCO}_{3}}^{0}$, shown by equation (5)

$$
f_{t}=\frac{m_{\mathrm{CaCO}_{3}}^{t}}{m_{\mathrm{CaCO}_{3}}^{0}}
$$

Combining the above equations, the sulfation degree of limestone is given by the equation (6)

$$
f_{t}=\frac{P M_{\mathrm{CaCO}_{3}}}{R T m_{\mathrm{CaCO}_{3}}^{0}} \int_{0}^{t} Q \cdot\left(c_{o}-c_{t}\right) d t
$$

The degree of sulfation as a function of time for air- and oxy-combustion conditions $\left(\mathrm{O}_{2} / \mathrm{N}_{2}\right.$ and $\mathrm{O}_{2} / \mathrm{CO}_{2}$ atmospheres) is illustrated in Figure 84 and Figure 85. For air-combustion, Figure 84, the reactor temperature had little effect on the degree of sulfation over the range considered. Also, the level of conversion achieved (degree of sulfation) is quite low. After 1 hour, only $15 \%$ of the limestone had been converted to $\mathrm{CaSO}_{4}$. It is well established that due to differences in molar volumes between $\mathrm{CaCO}_{3}$ and $\mathrm{CaSO}_{4}$, significant pore plugging can occur that would limit the degree of sulfation. If the overall rate is limited by particle diffusion, then the reaction would tend to take place near the particle surface. The pores would become blocked after only a limited outer layer of the particle had reacted to form $\mathrm{CaSO}_{4}$. The low degree of sulfation shown in Figure 84 is consistent with this hypothesis. In addition, the very limited dependence on temperature would also indicate more of a diffusion-controlled regime.

The degree of sulfation for the oxy-combustion condition is shown in Figure 85, and reveals a clear dependence on temperature. Also, the level of sulfation achieved is quite low. After 1 hour, only 10\%-16\% of the limestone was involved in $\mathrm{SO}_{2}$ capture. A more detailed comparison of these sulfation rates is provided in Figure 86 and Figure 87. At the lowest temperature (765C), it is clear that the rate of sulfation in the presence of $\mathrm{CO}_{2}$ is much less than in the presence of $\mathrm{N}_{2}$. After about 1 hour, the sulfation degree of limestone under oxy-combustion conditions is about $10 \%$, while the sulfation degree of limestone in air combustion is about $15 \%$.In addition, there are significantly higher levels of sulfation for $\mathrm{CO}_{2} \mathrm{vs} . \mathrm{N}_{2}$ at the higher reactor temperature tested $(874 \mathrm{C})$. After 1 hour, the conversion of limestone can reach $16 \%$,

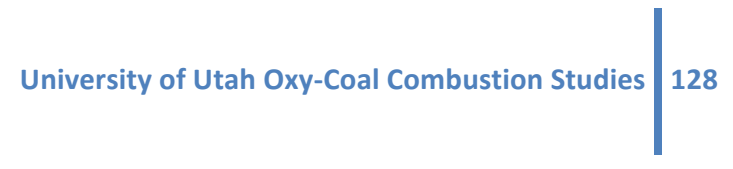


which is higher than at the same condition for the air combustion, while the sulfation efficiency of limestone is lower than in the initial sulfation process for air combustion.

The sulfation mechanism of limestone in oxy combustion and air combustion $(\mathrm{T}=874 \mathrm{C})$ is shown in more detail in Figure 88. The concentration of $\mathrm{SO}_{2}$ represents the transient sulfation kinetic rate of limestone. The sulfation degree is the integration of $\mathrm{SO}_{2}$ concentration and reaction time. As the $\mathrm{SO}_{2}$ concentration shows, the transient sulfation kinetics rate in oxy combustion is much lower than in air combustion before the transformation point A (580 s). After point A, the sulfation rate of limestone in oxy-combustion is higher compared to air combustion. Even though the transient kinetics of limestone is higher in oxy combustion environment after point A (580 s), the transition point B for the sulfation degree of limestone is delayed until $2000 \mathrm{~s}$.

It appears that the sulfation is dominated by a different mechanism in the presence of $\mathrm{CO}_{2}$ as compared with $\mathrm{N}_{2}$, since very different sulfation behavior is observed for the same operating conditions. It is likely that air-combustion and oxy-combustion conditions result in indirect and direct sulfation mechanisms. Also, it appears that the indirect sulfation mechanism is in a diffusion-controlled regime for the conditions evaluated, as there is very little temperature sensitivity and the conversion is low, consistent with the earlier discussion of pore plugging on the outside of the particle. The direct sulfation mechanism may be in a kinetically controlled regime, since the temperature dependence is much more pronounced and the degree of sulfation at the highest temperature tested is significantly greater for the $\mathrm{CO}_{2}$ case. In $\mathrm{N}_{2} / \mathrm{O}_{2}$, if the kinetic rate for the $\mathrm{SO}_{2}-\mathrm{CaO}$ (indirect) reaction is relatively fast, then pore diffusion limits would become blocked very quickly allowing only a limited outer layer of the particle to react to form $\mathrm{CaSO}_{4}$ and would limit overall conversion. In $\mathrm{CO}_{2} / \mathrm{O}_{2}$, if the kinetic rate for the $\mathrm{SO}_{2}-\mathrm{CaCO}_{3}$ (direct) reaction is slow, pore diffusion is not as limiting and the reaction to form $\mathrm{CaSO}_{4}$ could take place throughout more of the particle. This would allow the formation of $\mathrm{CaSO}_{4}$ over a larger surface area and allow greater reaction time prior to pore plugging. At higher temperatures, the $\mathrm{SO}_{2}-\mathrm{CaCO}_{3}$ rate would be increased to yield greater conversion. 


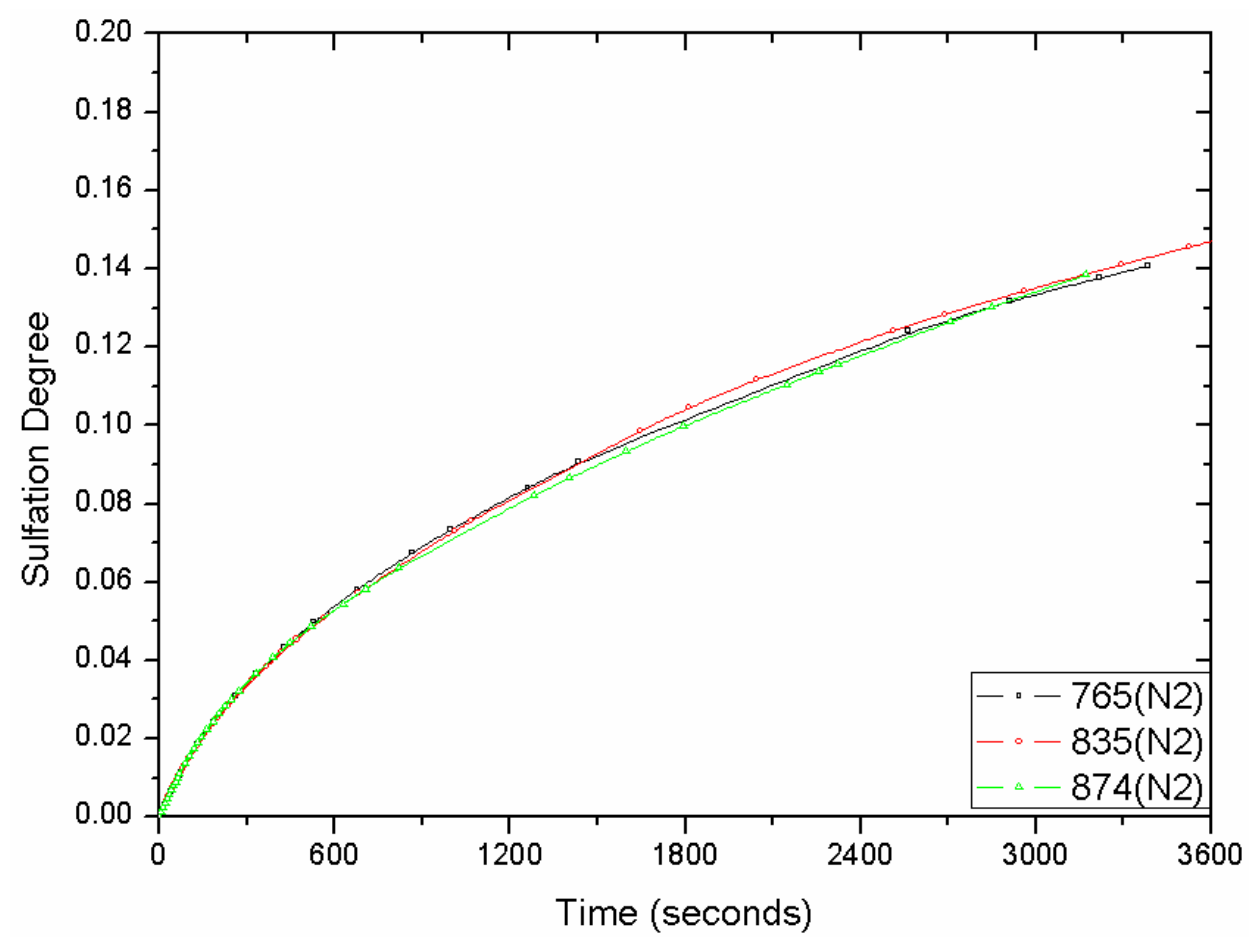

Figure 84. Effect of temperature on the sulfation degree of limestone under $\mathrm{N}_{2} / \mathrm{O}_{2} / \mathrm{SO}_{2}$ condition.

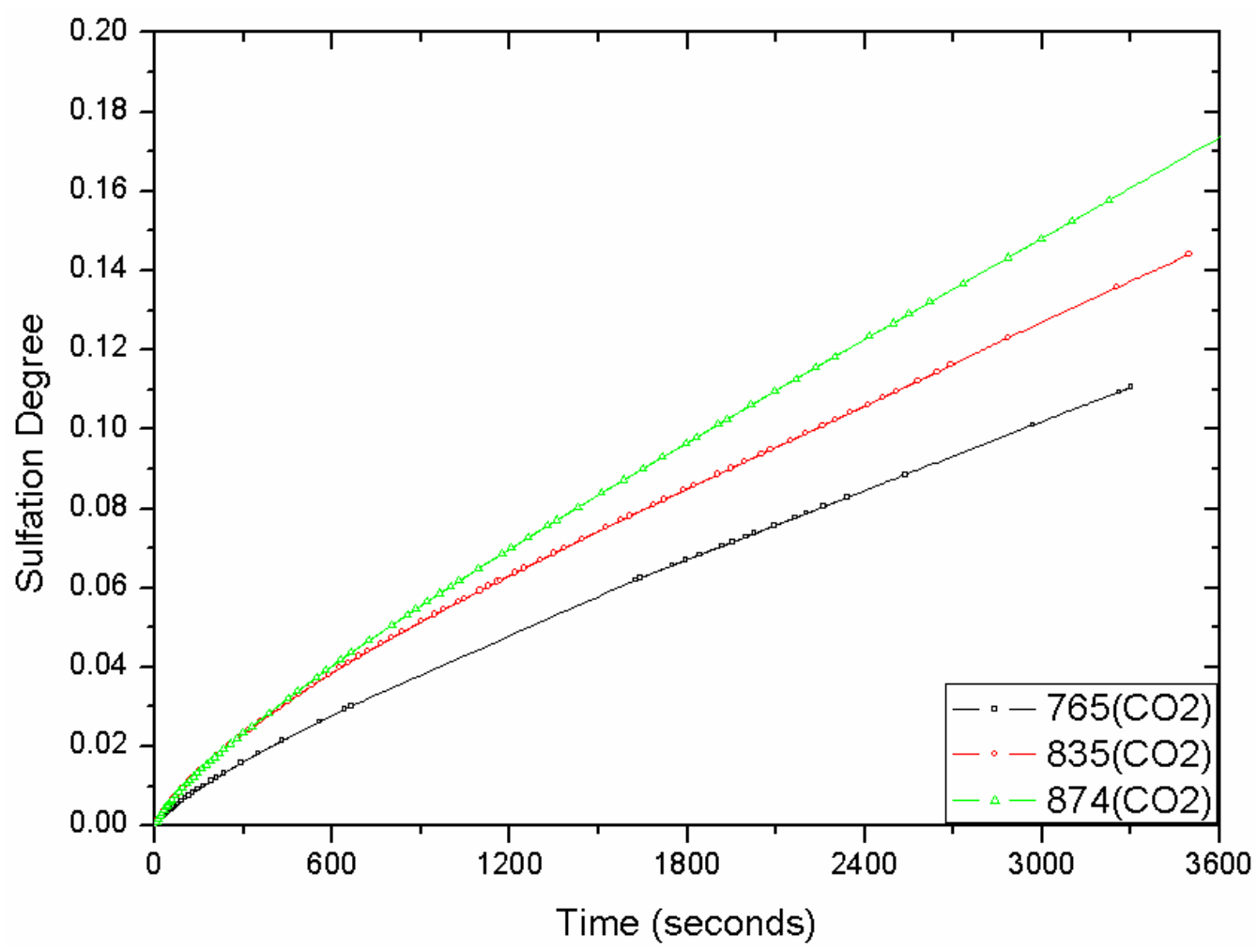

Figure 85. Effect of temperature on the sulfation degree of limestone under $\mathrm{CO}_{2} / \mathrm{O}_{2} / \mathrm{SO}_{2}$ conditions. 


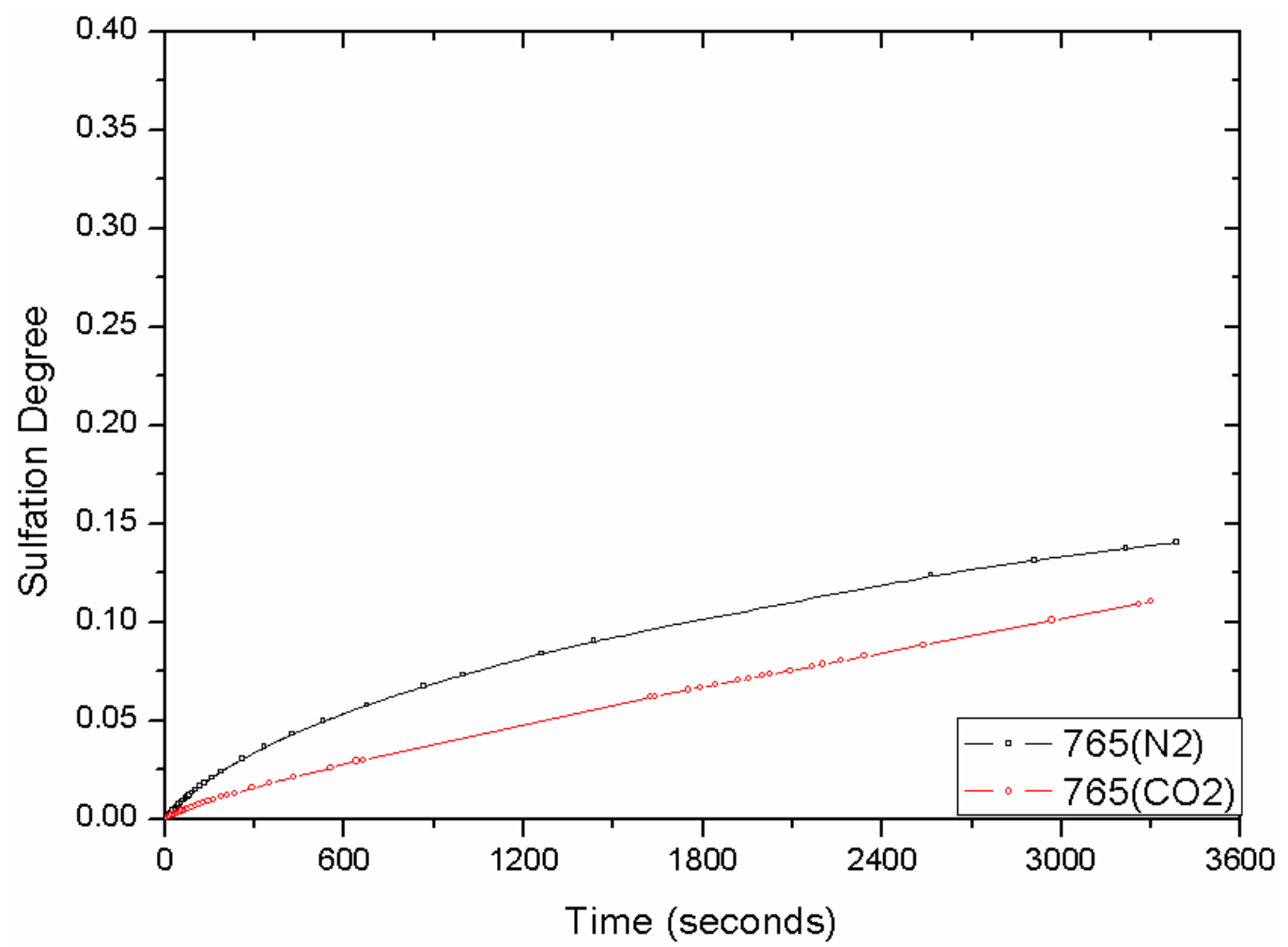

Figure 86. Comparison of sulfation degree of limestone between $\mathrm{N}_{2} / \mathrm{O}_{2} / \mathrm{SO}_{2}$ and $\mathrm{CO}_{2} / \mathrm{O}_{2} / \mathrm{SO}_{2}$ at $\mathrm{T}=765 \mathrm{C}$.

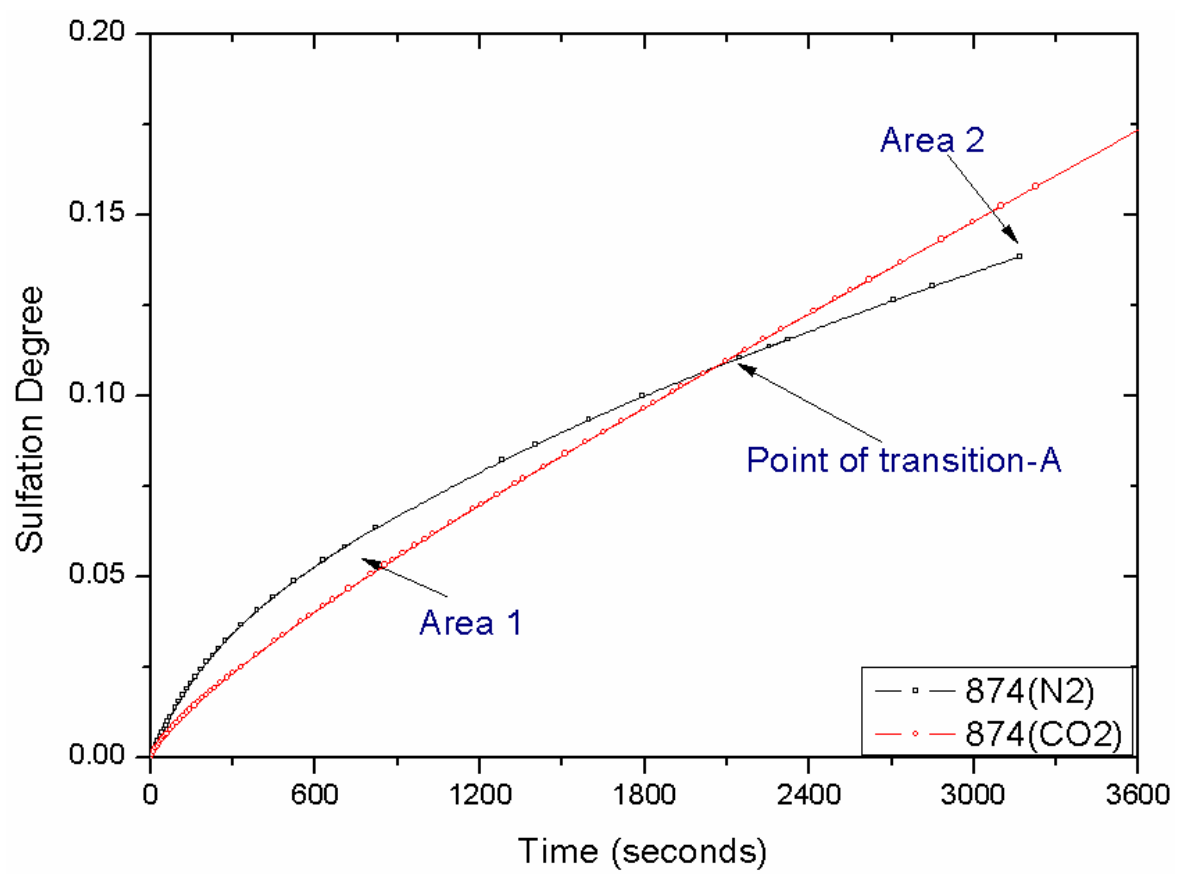

Figure 87. Comparison of the sulfation degree of limestone between $\mathrm{N}_{2} / \mathrm{O}_{2} / \mathrm{SO}_{2}$ and $\mathrm{CO}_{2} / \mathrm{O}_{2} / \mathrm{SO}_{2}$ at $\mathrm{T}=874 \mathrm{C}$. 


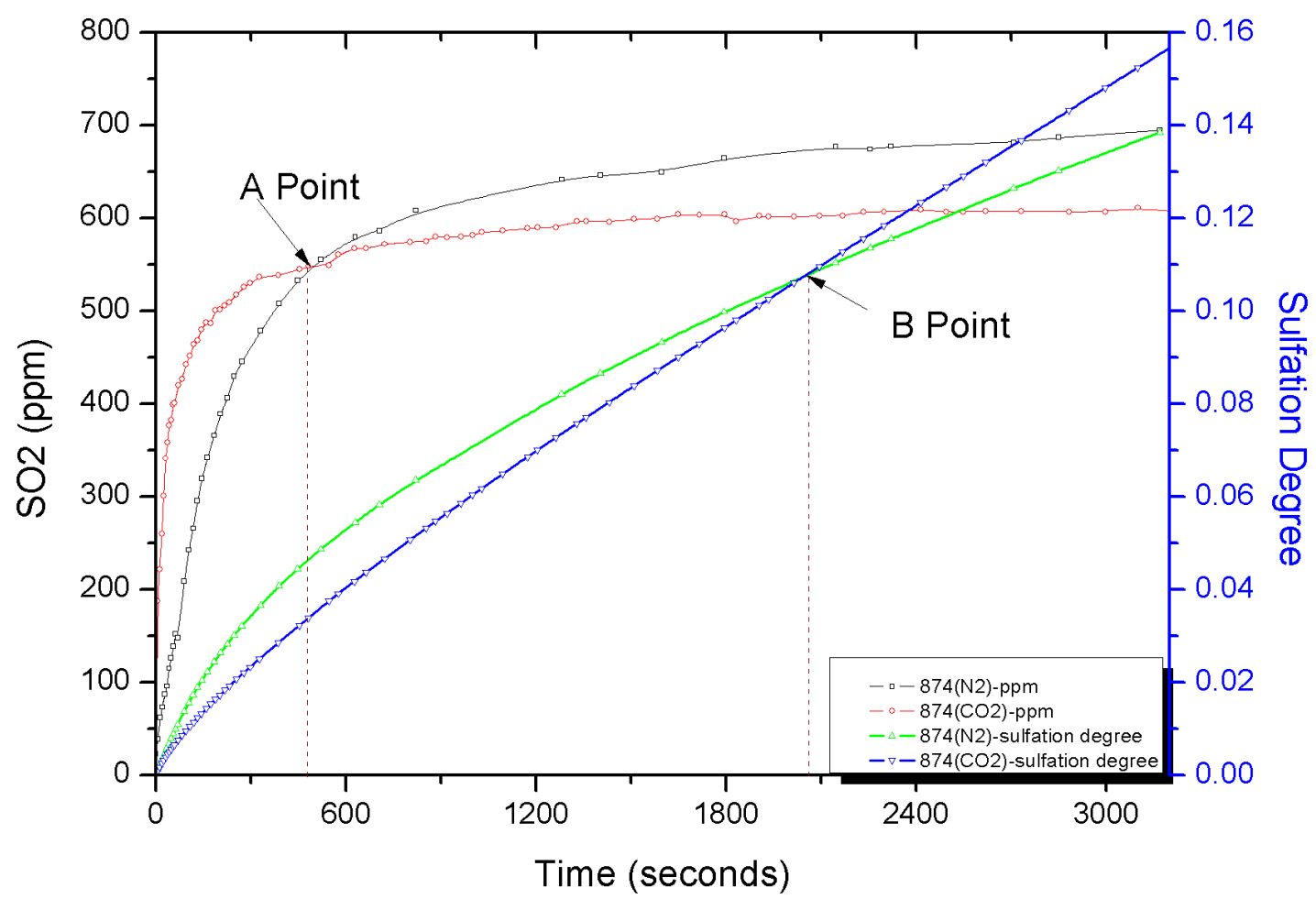

Figure 88. Sulfation degree of limestone and $\mathrm{SO}_{2}$ concentration at $\mathrm{T}=874 \mathrm{C}$.

\section{Model results and discussion}

Several simulation cases illustrate our model's applications. These include diffusion dominated, reaction dominated and diffusion-reaction dominated cases. Then, the ignition of the coal particle is investigated by the simulation. Finally, the fixed carbon consumption shows the shrinking of the core during the coal combustion process.

\section{Diffusion control and kinetics control}

Which mechanisms dominate, to a large extent, depends on particle size and temperature. The diffusioncontrol mechanism occurs at high temperature and large particle sizes. On the contrary, kinetics control tends to occur at low temperature and small particle sizes. Usually, pulverized coal combustion appears to be kinetics controlled. On the contrary, fluidized-bed combustion seems to be diffusion controlled. Furthermore, the type of mechanism changes during the combustion process. For instance, in pulverized coal combustion diffusion control dominates before ignition, while kinetics control takes place after ignition.

Here, different size particles (15 micron and 1500 micron) are investigated. The temperatures of the furnace wall (wall radiation temperature) and gas surrounding the coal particle are $1300 \mathrm{~K}$. In Figure 89, 
Figure 90, Figure 91, Figure 92 , the following results of simulation show the profile of temperature and mass species $\left(\mathrm{CO}, \mathrm{CO}_{2}, \mathrm{O}_{2}\right)$ for 15 micron and 1500 micron particle sizes during $\mathrm{t}=0.2$ second.

The simulation results (15 microns) clearly show kinetics control. All of the parameters (temperature, mass species concentrations) will distribute evenly along the particle radius. In a similar manner, the simulation results show gradients along the particle radius for larger particle size (1500 microns). The highest temperature is located at the particle surface due to the external heat source and chemical heat generation. Then the inside of the coal particle will be heated by internal heat conduction. Since the time used from the simulation is only 0.2 second, temperature profiles show significant gradients.

For small size particles the temperature of the whole particle increases to $1000 \mathrm{~K}$ in $0.03 \mathrm{~s}$. In addition, steady state can be achieved in $0.12 \mathrm{~s}$ as the temperature in the whole particle achieves more than $1400 \mathrm{~K}$. Also, for large particle sizes, the temperature of the coal particle surface is about $420 \mathrm{~K}$ after $0.19 \mathrm{~s}$, while the temperature in the coal particle center is still not hot. From the above comparisons, we see the heating rate of the small particle is much faster than for the large particle.

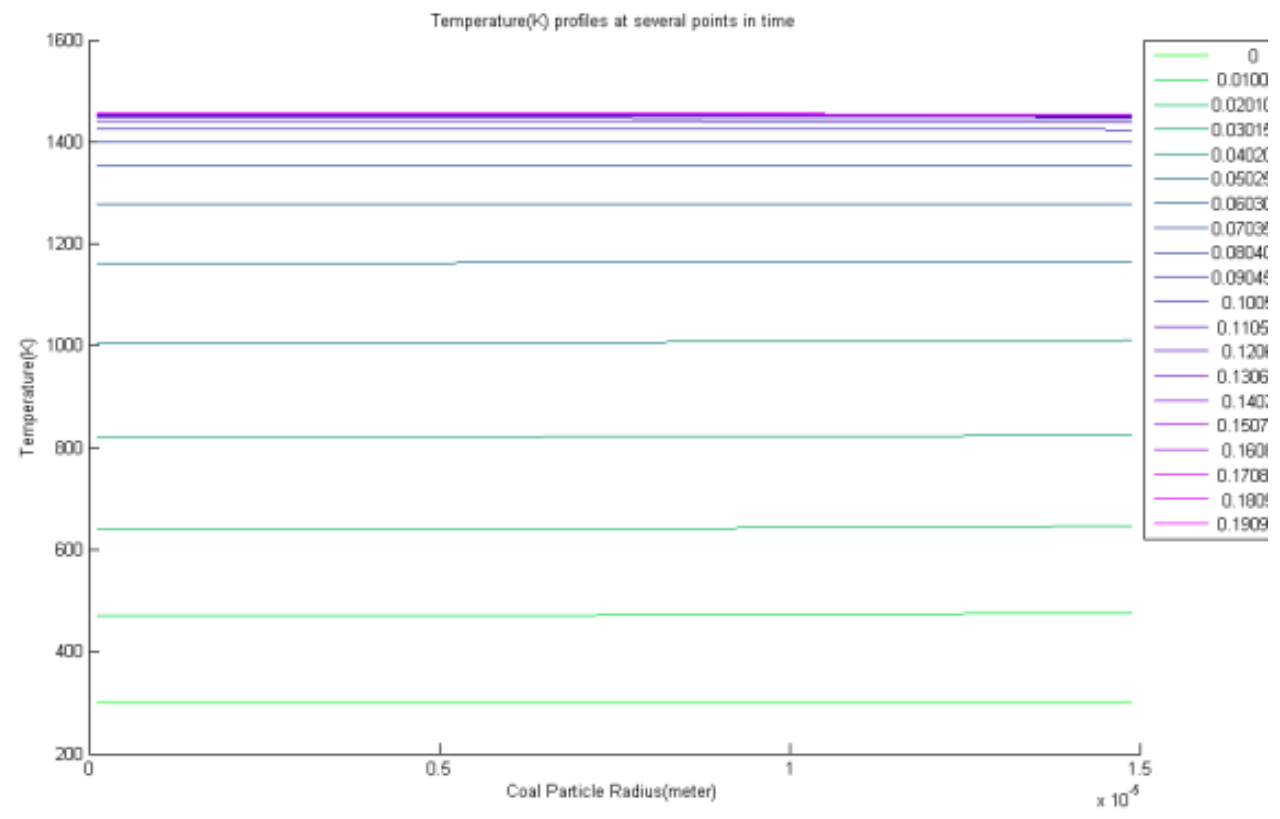




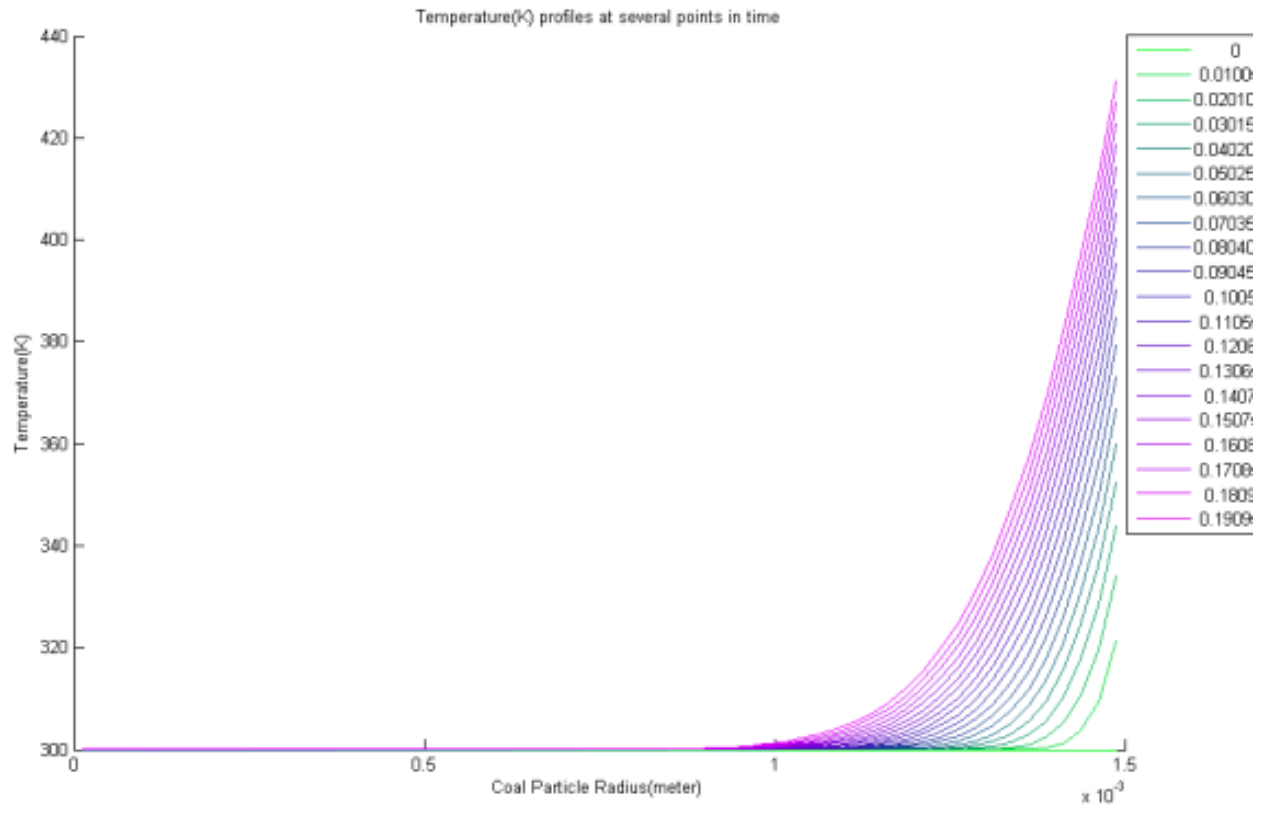

Figure 89. The effect of particle sized on evolution of temperature (top-50 microns; bottom-1500 microns).

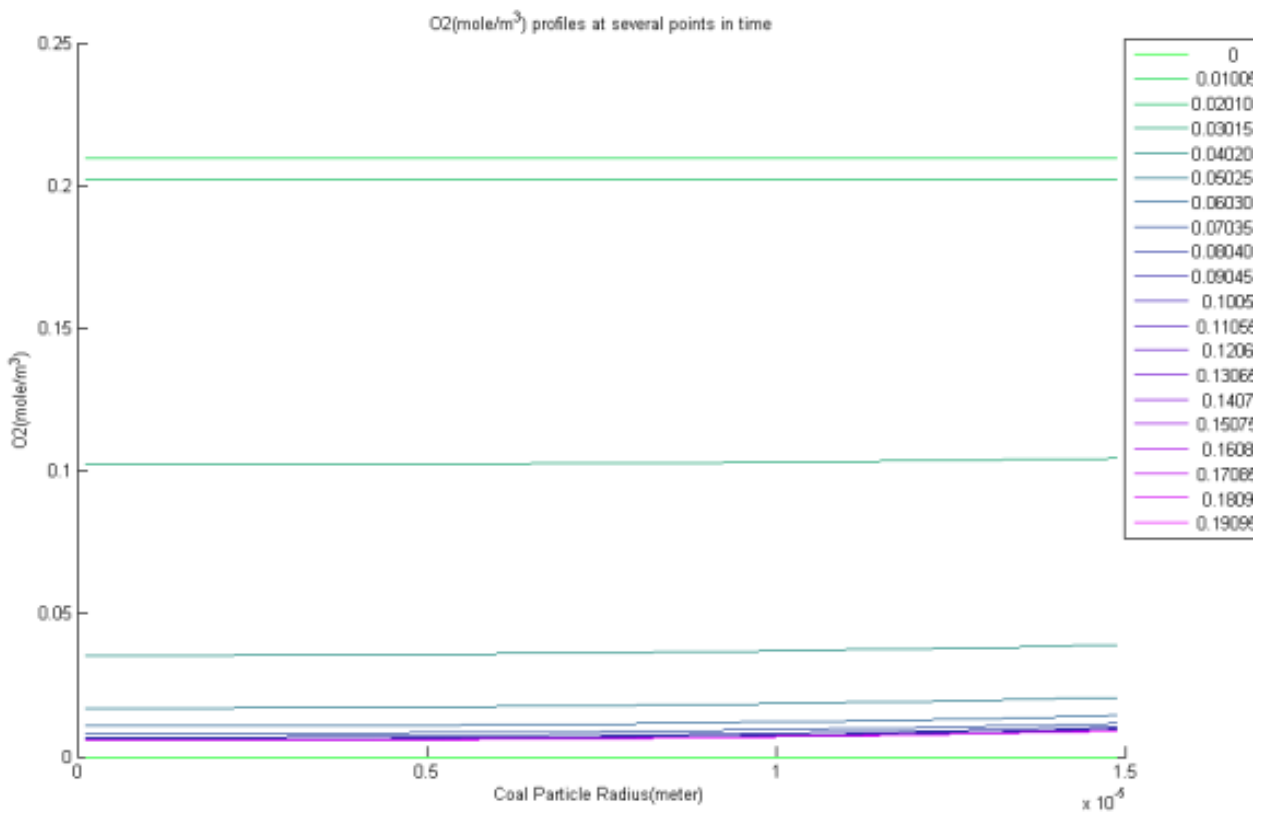




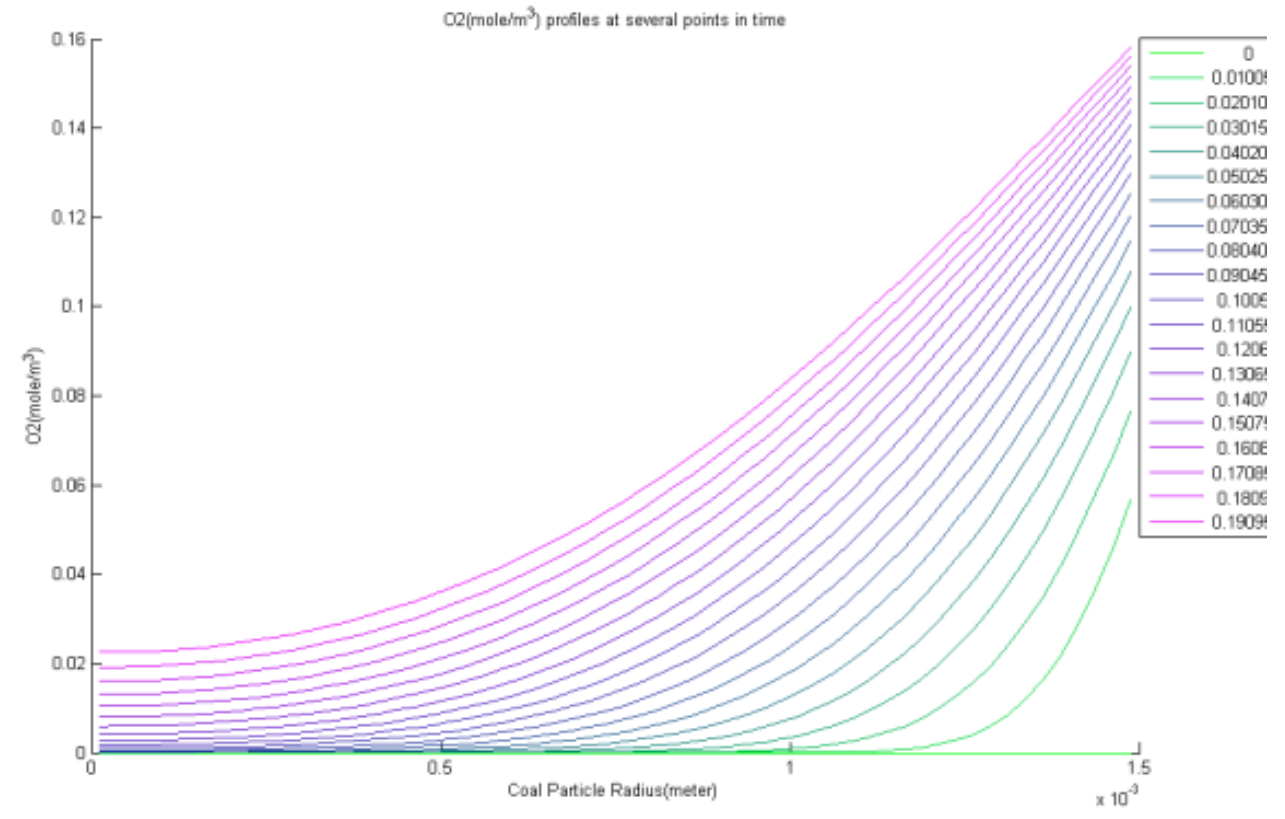

Figure 90. The effect of particle sized on evolution of $\mathrm{O}_{2}$ (top-50 microns; bottom-1500 microns).

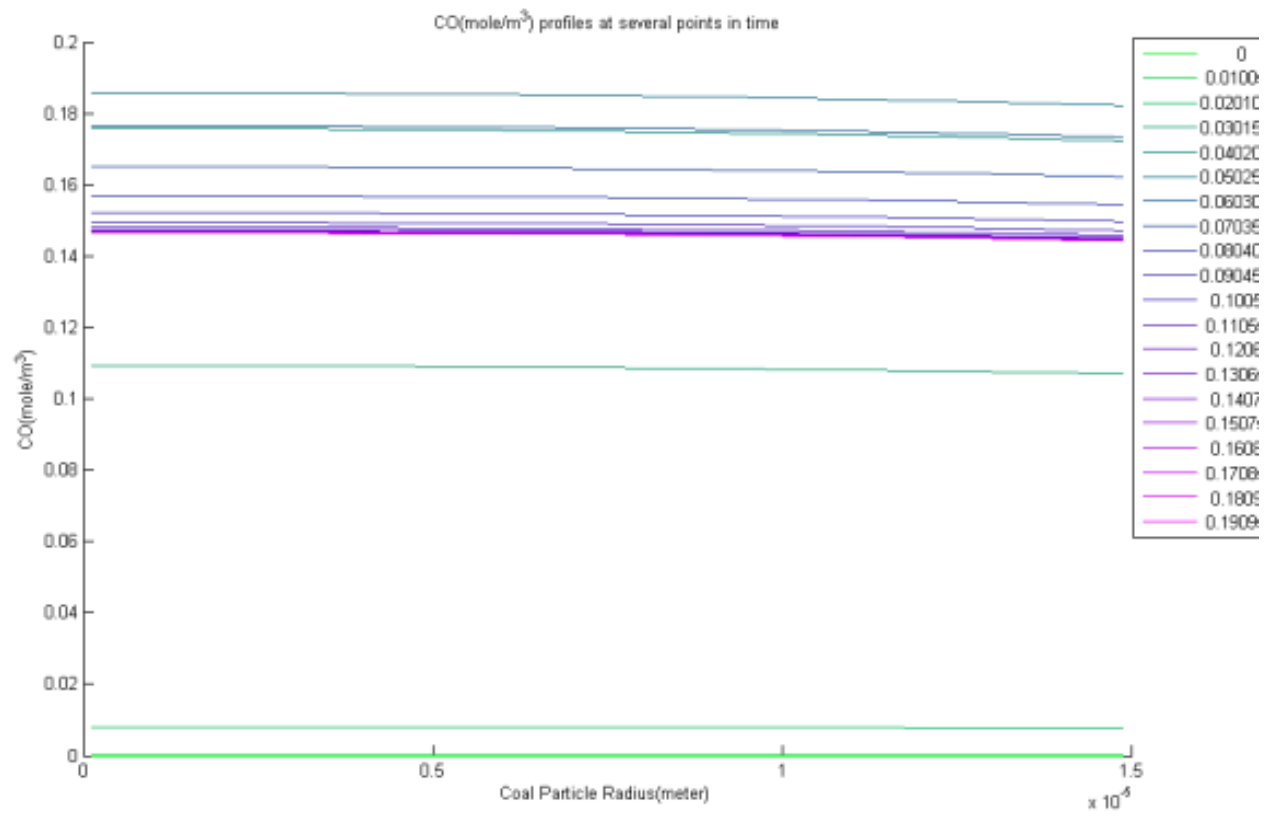




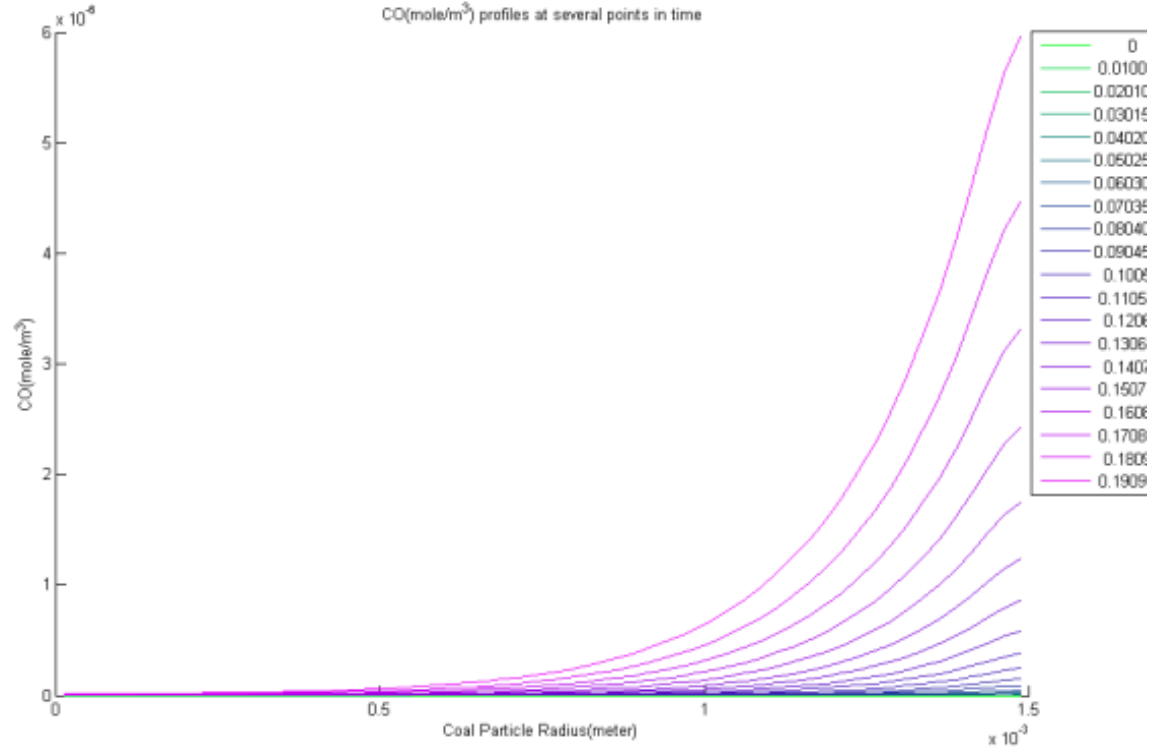

Figure 91. The effect of particle sized on evolution of CO (top-50 microns; bottom-1500 microns). 

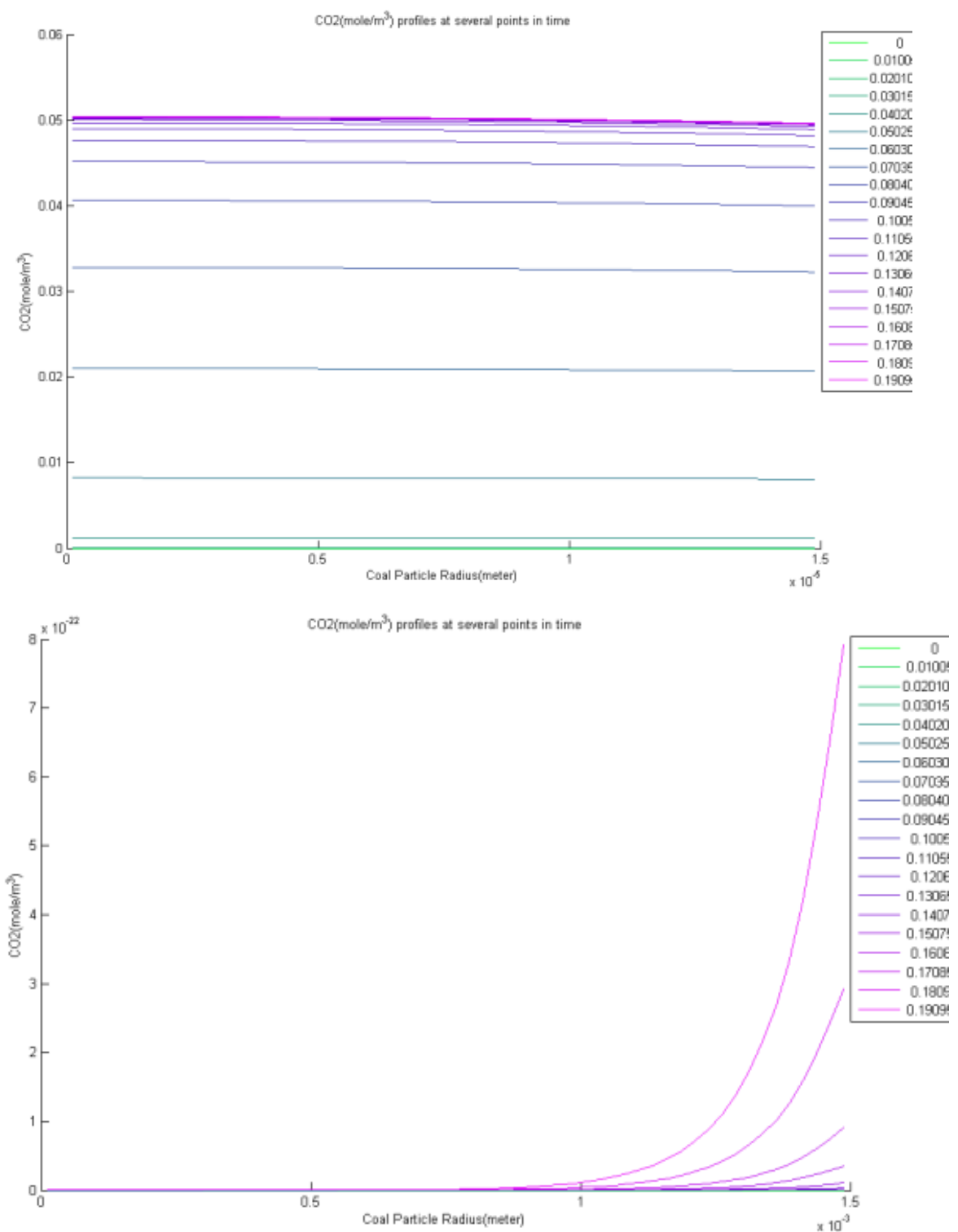

Figure 92. The effect of particle sized on evolution of $\mathrm{CO}_{2}$ (top-50 microns; bottom-1500 microns).

The evolution of fixed carbon in gas-solid model

As Figure 93 shows, The evolution of fixed carbon shows clear evidence of diffusion control in $150 \mathrm{~s}$. Obviously, the fixed carbon is burned out layer by layer from outside to inside. The combustion evolution of fixed carbon has a sharp layer, which is a well known assumption in the shrinking-core particle model. Hence, the shrinking core particle model is only one of the special applications for the general gas-solid model. 


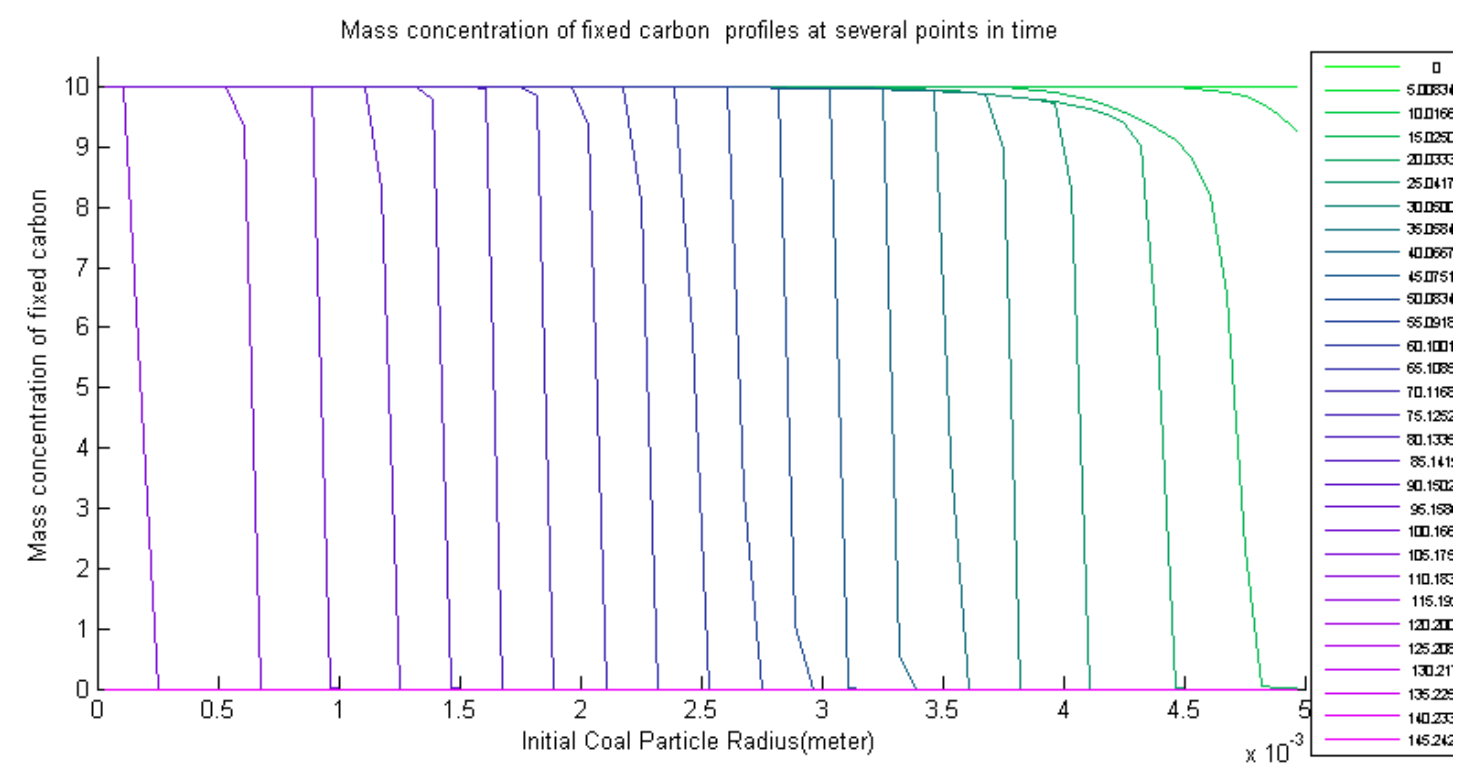

Figure 93. The evolution of fixed carbon in single coal particle combustion model.

Subtask 3.6 - Ash Partitioning Mechanisms for Oxy-Coal Combustion with Varied Amounts of Flue Gas Recycle

\section{Studies in the drop-tube furnace}

Coal char particle temperature simulation results

All three coals, Utah Skyline, PRB and Illinois \#6 were used for the simulation. A diameter of $65 \mu \mathrm{m}$ was employed for the simulation. The simulated temperature profiles of Utah Skyline combusted at $1373 \mathrm{~K}$ and $1500 \mathrm{~K}$ for both $\mathrm{O}_{2} / \mathrm{N}_{2}$ and $\mathrm{O}_{2} / \mathrm{CO}_{2}$ conditions are shown in Figure 94. 

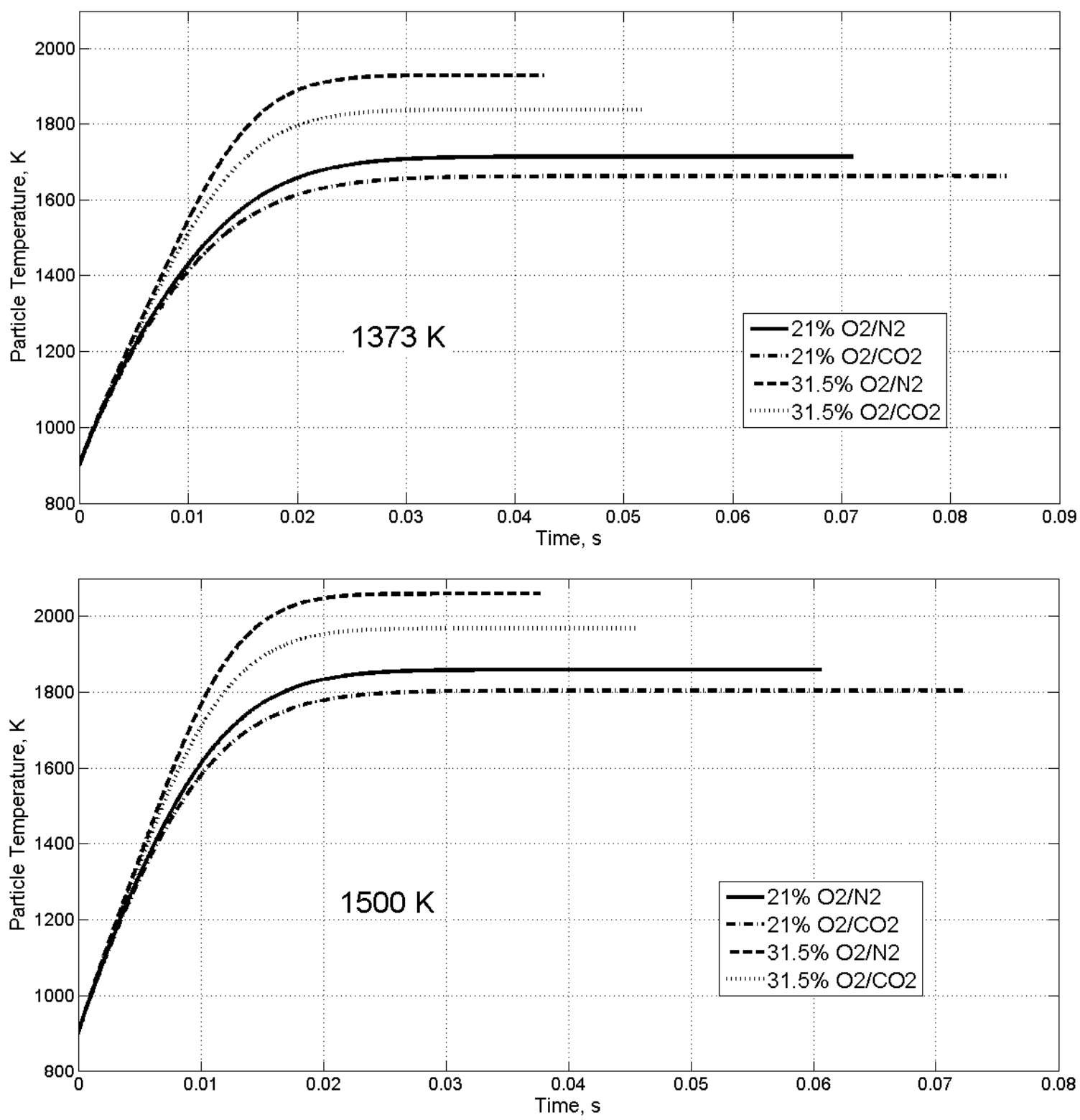

Figure 94. Utah Skyline coal char combustion temperature simulation profiles.

Utah Skyline, PRB and Illinois \#6 simulations showed similar temperature profiles. The simulation results of all three coals are summarized in Table 20.

Utah Skyline coal had the highest heating value, followed by Illinois \#6 and PRB. The simulation results showed that the particle temperature of Utah Skyline was the highest among these three coals at the same 
combustion conditions. Both increasing the furnace wall temperature and increasing oxygen concentration in the combustion gas increased coal char particle combustion temperature.

Table 20. Coal char combustion peak temperature (K) for particle diameter of $65 \mu \mathrm{m}$.

\begin{tabular}{|c|c|c|c|c|c|c|c|c|c|c|c|c|}
\hline & \multicolumn{4}{|c|}{ Utah Skyline } & \multicolumn{4}{c|}{ PRB } & \multicolumn{4}{c|}{ Illinois \#6 } \\
\hline & $1373 \mathrm{~K}$ & \multicolumn{1}{|c|}{$1500 \mathrm{~K}$} & \multicolumn{2}{c|}{$1373 \mathrm{~K}$} & \multicolumn{1}{c|}{$1500 \mathrm{~K}$} & \multicolumn{2}{c|}{$1373 \mathrm{~K}$} & \multicolumn{2}{c|}{$1500 \mathrm{~K}$} \\
\hline $\begin{array}{c}\mathrm{O}_{2} \\
\text { Ratio }\end{array}$ & $21 \%$ & $31.5 \%$ & $21 \%$ & $31.5 \%$ & $21 \%$ & $31.5 \%$ & $21 \%$ & $31.5 \%$ & $21 \%$ & $31.5 \%$ & $21 \%$ & $31.5 \%$ \\
\hline $\mathrm{O}_{2} / \mathrm{N}_{2}$ & 1710 & 1930 & 1860 & 2060 & 1610 & 1780 & 1760 & 1920 & 1680 & 1880 & 1830 & 2010 \\
\hline $\mathrm{O}_{2} / \mathrm{CO}_{2}$ & 1660 & 1840 & 1800 & 1970 & 1580 & 1710 & 1730 & 1850 & 1630 & 1800 & 1780 & 1930 \\
\hline
\end{tabular}

Replacing the $\mathrm{N}_{2}$ in the combustion air with $\mathrm{CO}_{2}$ resulted in a decrease in temperature, especially at the higher $\mathrm{O}_{2}$ concentrations. The most likely reasons are that the heat transfer coefficient of $\mathrm{N}_{2}$ is higher than that of $\mathrm{CO}_{2}$, and the mass diffusivity of $\mathrm{O}_{2}$ in $\mathrm{CO}_{2}$ is lower than that of $\mathrm{O}_{2}$ in $\mathrm{N}_{2}$. Both reasons lead to a lower particle burning temperature and an increase in the burn out time of $\mathrm{O}_{2} / \mathrm{CO}_{2}$ combustion compared to $\mathrm{O}_{2} / \mathrm{N}_{2}$ conditions.

\section{Measurements of PSDs with the SMPS/APS and BLPI}

Figure 95 illustrates the PSD results of Utah Skyline combusted under $21 \% \mathrm{O}_{2}$ combined with $\mathrm{CO}_{2}$ at a furnace temperature of $1500 \mathrm{~K}$. The PSDs obtained from SMPS and APS instruments are compared to gravimetric determination of fly ash samples segregated and collected using a BLPI. The PSDs comprised 15 valid scans from the SMPS/APS and five BLPI measurements. These distributions were computed based on the method originally developed by Markowski and Ensor for reporting impactor results (Markowski and Ensor 1977). Both SMPS/APS and BLPI data agreed well within one standard deviation. The standard deviation indicates the variation in PSD at each particle size. The PSDs agreed well in the region where SMPS and APS overlap. The combined PSDs covered the ultrafine mode, fine mode and coarse modes, from $14.3 \mathrm{~nm}$ up to $20 \mu \mathrm{m}$ (Baxter 1992, Helble and Sarofim 1989, Smith et al. 1979, Linak et al. 2000, Linak et al. 2002). The ultrafine mode ranges from $14.1 \mathrm{~nm}$ to $100 \mathrm{~nm}$; the fine ranges from $100 \mathrm{~nm}$ to $900 \mathrm{~nm}$; and the coarse mode comprises particles greater than $900 \mathrm{~nm}$. The BLPI data showed the same trend as the SMPS/APS data, with some scatter at the smaller particle sizes. This is likely due to the limited sample size for these smaller particles. The graph presents that the PSDs can be obtained from two independent measurements. 


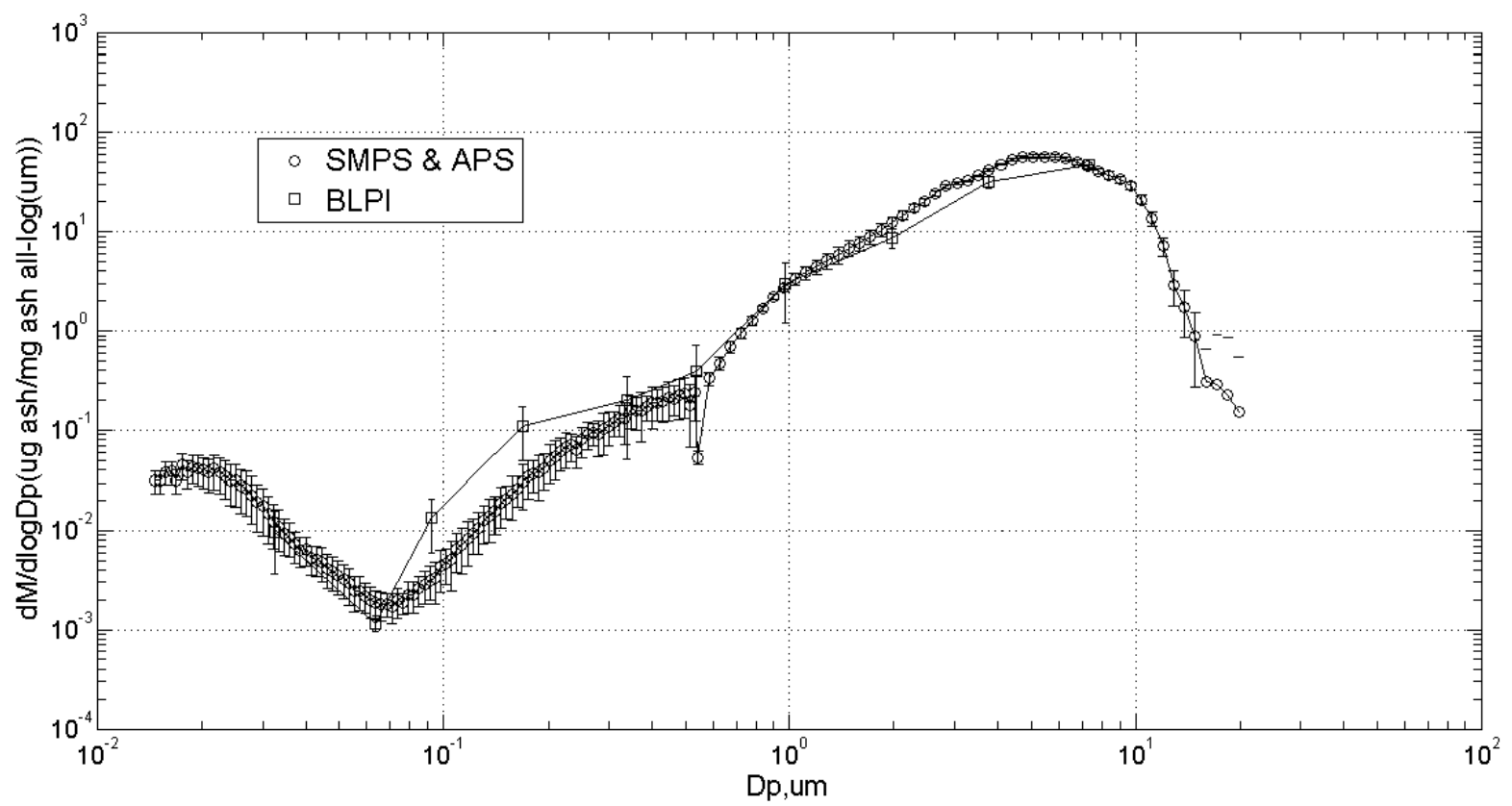

Figure 95. The BLPI and SMPS/APS PSDs of Utah Skyline under $21 \% \mathrm{O}_{2} / \mathrm{CO}_{2}$ at $1500 \mathrm{~K}$.

\section{Ash particle size distribution}

All PSD data for Utah Skyline, PRB and Illinois \#6 were derived from SMPS and APS measurements. The total mass was obtained by integrating the PSDs. Mean sizes and mass distributions of ultrafine, fine and coarse modes are shown in Table 21. The mean particle size under $\mathrm{O}_{2} / \mathrm{CO}_{2}$ combustion conditions was smaller in the ultrafine and fine particle modes as compared with $\mathrm{O}_{2} / \mathrm{N}_{2}$ combustion conditions, except Illinois \#6. The most remarkable differences in mass distribution were in the ultrafine mode and fine modes over different conditions; coarse modes were not affected by different combustion conditions. Similar results were found in Sheng et al. (2007). 
Table 21. Total collected mass distribution.

\begin{tabular}{|c|c|c|c|c|c|c|c|c|c|}
\hline & & & & Ult & fine mode & & e mode & & se mode \\
\hline & $\begin{array}{c}\text { Furnace } \\
\text { Temp }\end{array}$ & & & $\begin{array}{c}\text { Mean } \\
\text { Dp } \\
(\mu \mathrm{m})\end{array}$ & $\begin{array}{l}\text { Mass conc } \\
\text { (mg/g_ash) }\end{array}$ & $\begin{array}{c}\text { Mean } \\
\text { Dp } \\
(\mu \mathrm{m})\end{array}$ & $\begin{array}{l}\text { Mass conc } \\
\text { (mg/g_ash) }\end{array}$ & $\begin{array}{c}\text { Mean } \\
\text { Dp } \\
(\mu \mathrm{m})\end{array}$ & $\begin{array}{l}\text { Mass conc } \\
\text { (mg/g_ash) }\end{array}$ \\
\hline \multirow{8}{*}{$\begin{array}{l}\text { Utah } \\
\text { Sky }\end{array}$} & \multirow{4}{*}{$1373 \mathrm{~K}$} & \multirow{2}{*}{$21 \%$} & $\mathrm{O}_{2} / \mathrm{N}_{2}$ & 0.023 & 1.11 & 0.318 & 13.95 & 3.996 & 984.94 \\
\hline & & & $\mathrm{O}_{2} / \mathrm{CO}_{2}$ & 0.020 & 0.16 & 0.313 & 3.51 & 4.237 & 996.33 \\
\hline & & \multirow{2}{*}{$31.5 \%$} & $\mathrm{O}_{2} / \mathrm{N}_{2}$ & 0.035 & 9.18 & 0.322 & 7.52 & 4.033 & 983.30 \\
\hline & & & $\mathrm{O}_{2} / \mathrm{CO}_{2}$ & 0.028 & 2.13 & 0.296 & 4.34 & 4.317 & 993.21 \\
\hline & \multirow{4}{*}{$1500 \mathrm{~K}$} & \multirow{2}{*}{$21 \%$} & $\mathrm{O}_{2} / \mathrm{N}_{2}$ & 0.028 & 1.29 & 0.352 & 5.53 & 4.542 & 993.18 \\
\hline & & & $\mathrm{O}_{2} / \mathrm{CO}_{2}$ & 0.023 & 0.83 & 0.343 & 4.28 & 4.657 & 994.89 \\
\hline & & \multirow{2}{*}{$31.5 \%$} & $\mathrm{O}_{2} / \mathrm{N}_{2}$ & 0.046 & 12.59 & 0.383 & 12.95 & 4.821 & 974.46 \\
\hline & & & $\mathrm{O}_{2} / \mathrm{CO}_{2}$ & 0.029 & 7.63 & 0.321 & 21.49 & 4.696 & 970.87 \\
\hline \multirow{8}{*}{ PRB } & \multirow{4}{*}{$1373 \mathrm{~K}$} & \multirow{2}{*}{$21 \%$} & $\mathrm{O}_{2} / \mathrm{N}_{2}$ & 0.056 & 6.27 & 0.39 & 1.58 & 3.874 & 992.15 \\
\hline & & & $\mathrm{O}_{2} / \mathrm{CO}_{2}$ & 0.032 & 1.52 & 0.329 & 1.39 & 4.271 & 997.09 \\
\hline & & \multirow{2}{*}{$31.5 \%$} & $\mathrm{O}_{2} / \mathrm{N}_{2}$ & 0.075 & 14.19 & 0.435 & 2.39 & 3.312 & 983.42 \\
\hline & & & $\mathrm{O}_{2} / \mathrm{CO}_{2}$ & 0.055 & 4.43 & 0.382 & 1.15 & 3.763 & 994.42 \\
\hline & \multirow{4}{*}{$1500 \mathrm{~K}$} & \multirow{2}{*}{$21 \%$} & $\mathrm{O}_{2} / \mathrm{N}_{2}$ & 0.053 & 6.03 & 0.351 & 1.84 & 3.936 & 991.95 \\
\hline & & & $\mathrm{O}_{2} / \mathrm{CO}_{2}$ & 0.034 & 2.99 & 0.336 & 2.63 & 4.411 & 994.38 \\
\hline & & \multirow{2}{*}{$31.5 \%$} & $\mathrm{O}_{2} / \mathrm{N}_{2}$ & 0.067 & 10.75 & 0.379 & 2.69 & 3.651 & 986.56 \\
\hline & & & $\mathrm{O}_{2} / \mathrm{CO}_{2}$ & 0.045 & 3.41 & 0.342 & 2.08 & 4.136 & 994.51 \\
\hline \multirow{8}{*}{ IL\#6 } & \multirow{4}{*}{$1373 \mathrm{~K}$} & \multirow{2}{*}{$21 \%$} & $\mathrm{O}_{2} / \mathrm{N}_{2}$ & 0.028 & 16.44 & 0.333 & 11.27 & 3.972 & 972.30 \\
\hline & & & $\mathrm{O}_{2} / \mathrm{CO}_{2}$ & 0.025 & 8.82 & 0.353 & 7.60 & 4.36 & 983.58 \\
\hline & & \multirow{2}{*}{$31.5 \%$} & $\mathrm{O}_{2} / \mathrm{N}_{2}$ & 0.041 & 56.47 & 0.354 & 16.97 & 4.065 & 926.56 \\
\hline & & & $\mathrm{O}_{2} / \mathrm{CO}_{2}$ & 0.030 & 17.03 & 0.349 & 13.33 & 5.305 & 969.64 \\
\hline & \multirow{4}{*}{$1500 \mathrm{~K}$} & \multirow{2}{*}{$21 \%$} & $\mathrm{O}_{2} / \mathrm{N}_{2}$ & 0.027 & 6.72 & 0.863 & 97.71 & 5.672 & 895.58 \\
\hline & & & $\mathrm{O}_{2} / \mathrm{CO}_{2}$ & 0.024 & 4.45 & 0.913 & 100.64 & 6.138 & 894.92 \\
\hline & & \multirow{2}{*}{$31.5 \%$} & $\mathrm{O}_{2} / \mathrm{N}_{2}$ & 0.037 & 14.19 & 0.787 & 92.32 & 6.068 & 893.49 \\
\hline & & & $\mathrm{O}_{2} / \mathrm{CO}_{2}$ & 0.036 & 15.05 & 0.841 & 72.34 & 6.229 & 912.61 \\
\hline
\end{tabular}

Total mass of each sample $=$ ultrafine $_{\text {mass }}{ }^{a}+$ fine mass $^{b}+$ coarse mass $^{c}=1000 \mathrm{mg} / \mathrm{g} \_$ash. Dp: particle diameter.

Utah Skyline results. The simulation results showed that increasing the $\mathrm{O}_{2}$ concentration increased the particle combustion temperature by about $200 \mathrm{~K}$ in an $\mathrm{O}_{2} / \mathrm{N}_{2}$ combustion environment and by $150 \mathrm{~K}$ for an $\mathrm{O}_{2} / \mathrm{CO}_{2}$ combustion environment at a furnace temperature of $1500 \mathrm{~K}$. The temperature increase due to $\mathrm{O}_{2}$ was more pronounced at the lower furnace temperature, approximately $200 \mathrm{~K}$. 
The PSDs of Utah Skyline from SMPS and APS measurements are shown in Figure 96. The PSD for a $31.5 \% \mathrm{O}_{2} / \mathrm{N}_{2}$ environment always had the highest ultrafine particle yield (Table 4, Figure 4). A small effect from furnace temperature was observed except at the lower particle temperature. The change in the $\mathrm{O}_{2}$ concentration significantly changed the ultrafine and fine PSDs. The yields of ultrafine and fine particles increased with increasing $\mathrm{O}_{2}$ concentrations in both $\mathrm{O}_{2} / \mathrm{N}_{2}$ and $\mathrm{O}_{2} / \mathrm{CO}_{2}$ environments. The mean particle size in the ultrafine mode under $\mathrm{O}_{2} / \mathrm{N}_{2}$ combustion conditions had a mean size of $0.045 \mu \mathrm{m}$ for a $31.5 \% \mathrm{O}_{2}$ concentration and $0.25 \mu \mathrm{m}$ for a $21 \% \mathrm{O}_{2}$ concentration. A shift to smaller mean ultrafine and fine particle sizes was observed for $\mathrm{O}_{2} / \mathrm{CO}_{2}$ at both $\mathrm{O}_{2}$ concentrations.

Under the conditions studied, $\mathrm{CO}_{2}$ always reduced vaporization for Utah Skyline coal. At the same $\mathrm{O}_{2}$ concentration, combustion in a $\mathrm{CO}_{2}$ environment produced fewer ultrafine particles than in an $\mathrm{O}_{2} / \mathrm{N}_{2}$ environment. The simulated particle temperature of $31.5 \% \mathrm{O}_{2} / \mathrm{N}_{2}$ at $1373 \mathrm{~K}$ was similar to that of $31.5 \%$ $\mathrm{O}_{2} / \mathrm{CO}_{2}$ at $1500 \mathrm{~K}$ (Table 3). Their mean particle sizes in the ultrafine mode were similar. The yield of ultrafine particles in $\mathrm{O}_{2} / \mathrm{N}_{2}$ was $9.18 \mathrm{mg} / \mathrm{g} \_$ash, while that of $\mathrm{O}_{2} / \mathrm{CO}_{2}$ was $7.63 \mathrm{mg} / \mathrm{g}$ ash. This result supports the $\mathrm{CO}_{2}$ effect hypothesis very well. The $\mathrm{CO}_{2}$ effect was expected in Utah Skyline combustion because Utah Skyline has high content of silicon and aluminum (Table 1), which are classified as refractory metallic elements. Simulated particle temperatures at $31.5 \% \mathrm{O}_{2} / \mathrm{CO}_{2}$ and $1373 \mathrm{~K}$ and $21 \%$ $\mathrm{O}_{2} / \mathrm{N}_{2}$ at $1500 \mathrm{~K}$ were similar. However, experimental results showed that higher $\mathrm{O}_{2}$ concentrations yielded larger quantities of ultrafine particles, which reflects higher vaporization rates even though $\mathrm{CO}_{2}$ was present. Therefore, the ultrafine yield was highest for a $\mathrm{N}_{2}$ environment and the higher $\mathrm{O}_{2}$ concentration. A decrease ultrafine yield was always shown in $\mathrm{CO}_{2}$ environment. The shape of the coarse particle PSD was almost identical for all combustion conditions at the same furnace temperature. For the fine particles, the highest particle number was also for $\mathrm{N}_{2}$ conditions. 

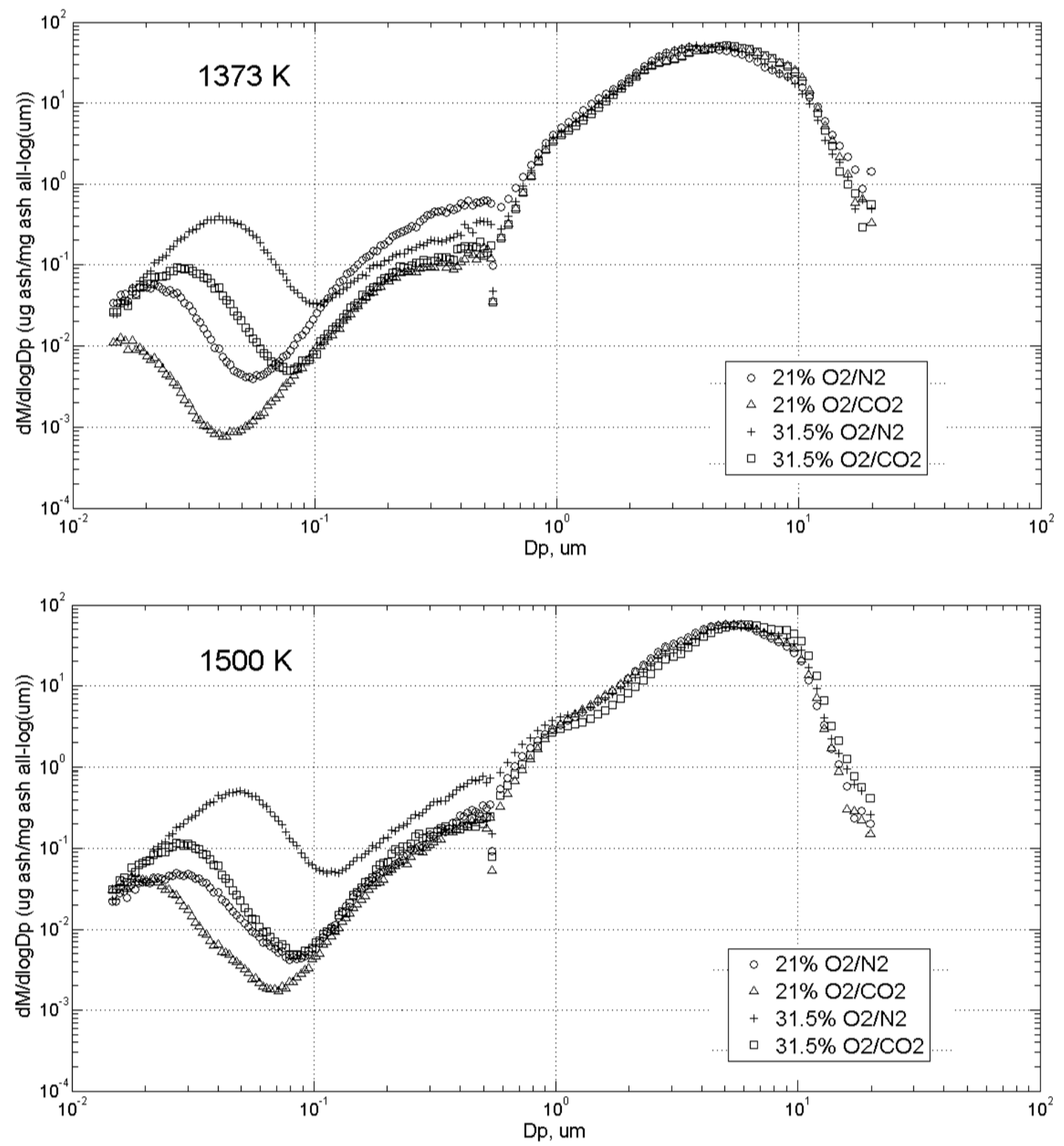

Figure 96. PSDs of Utah Skyline at $1373 \mathrm{~K}$ and $1500 \mathrm{~K}$.

Figure 97 shows the results from the BLPI and EDS analysis. The PSD shapes are the same as SMPS/APS data. The mass distributions of larger particles were in similar positions for all combustion conditions. As previously discussed, Utah Skyline contains a high silicon content. The mass fraction of Si was highest in the coarse mode (from 1.98 to $7.33 \mu \mathrm{m}$ ). The yields of $\mathrm{Si}$ were highest under the $31.5 \%$ $\mathrm{O}_{2} / \mathrm{N}_{2}$ condition, followed by $31.5 \% \mathrm{O}_{2} / \mathrm{CO}_{2}, 21 \% \mathrm{O}_{2} / \mathrm{N}_{2}$ and $21 \% \mathrm{O}_{2} / \mathrm{CO}_{2}$. This is the same order as the 
predicted particle temperatures from the simulation (order is high to low). . Both the $\mathrm{O}_{2}$ concentration and combustion environment $\left(\mathrm{CO}_{2}\right.$ versus $\left.\mathrm{N}_{2}\right)$ had significant effects on Utah Skyline coal ash formation, as reflected in the detailed elemental distribution.
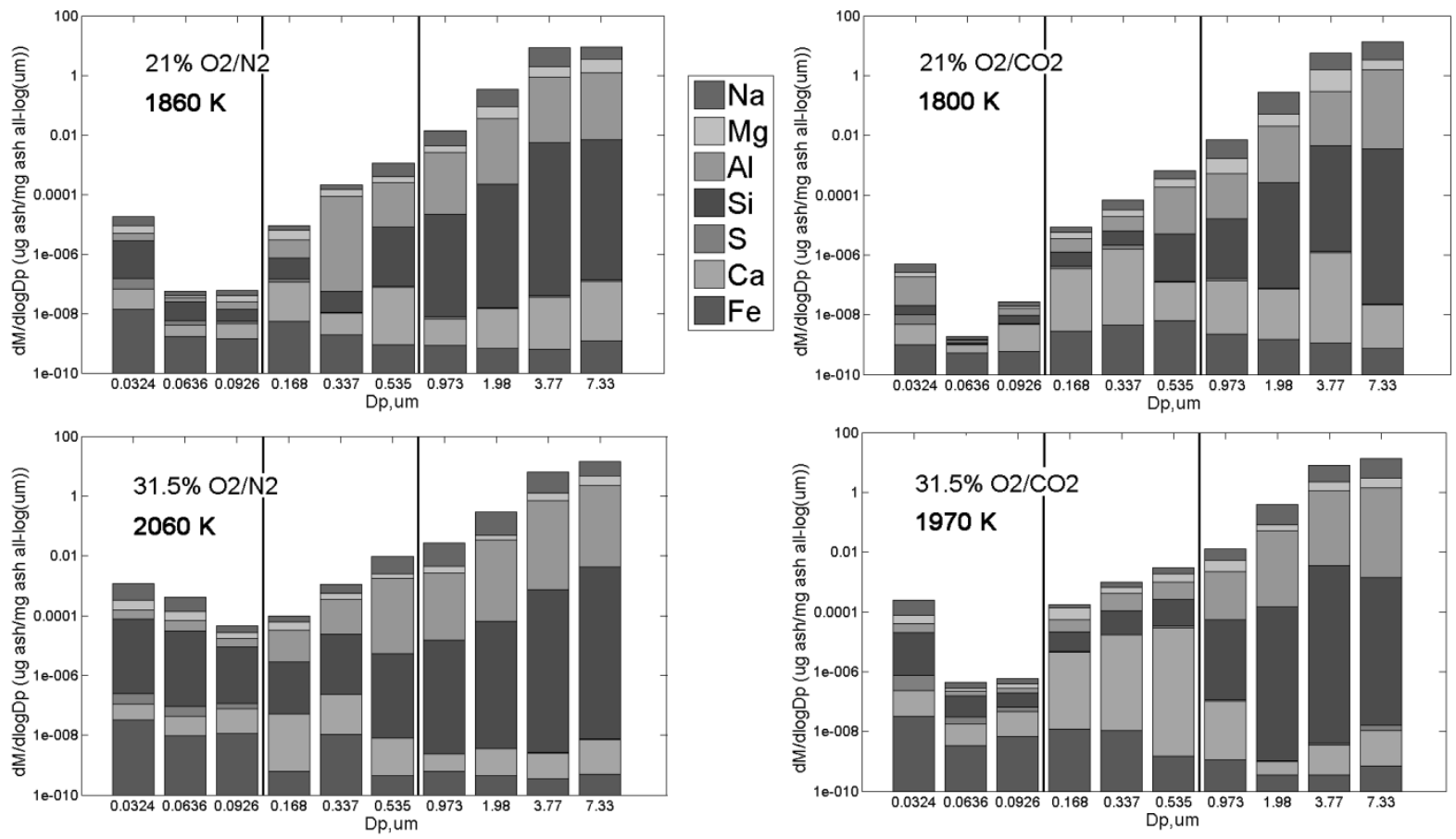

Figure 97. Elemental mass fraction size distribution of Utah Skyline at $1500 \mathrm{~K}$. Temperatures are predicted maximums from the simulation.

$P R B$ results. Figure 98 shows that the PRB coal exhibited similar results to the Utah Skyline coal: significant differences in ultrafine and fine mode versus coarse mode. The mean size of the ultrafine particle mode under $\mathrm{O}_{2} / \mathrm{N}_{2}$ combustion conditions was $0.07 \mu \mathrm{m}$ for $31.5 \% \mathrm{O}_{2}$ and $0.05 \mu \mathrm{m}$ for $21 \% \mathrm{O}_{2}$ conditions. The $\mathrm{O}_{2} / \mathrm{CO}_{2}$ environment resulted in ultrafine particles with a smaller mean particle size, although their mean sizes were higher than Utah Skyline coal. The $31.5 \% \mathrm{O}_{2} / \mathrm{N}_{2}$ condition always had the highest mass concentration of ultrafine and fine particles.

The simulated particle combustion temperatures for PRB coal were lower than those of Utah Skyline coal. 

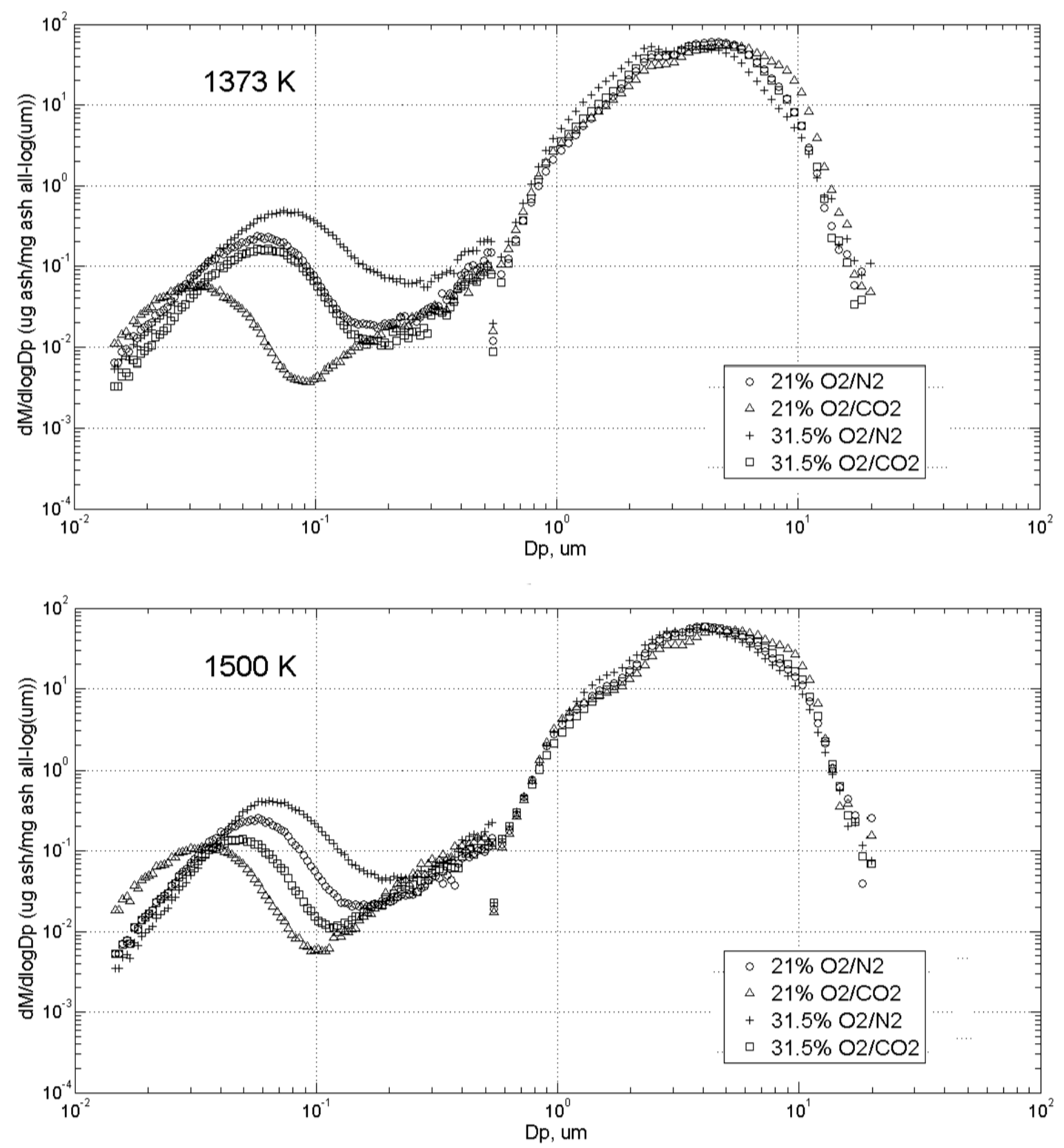

Figure 98. PSDs of PRB at $1373 \mathrm{~K}$ and $1500 \mathrm{~K}$.

Increasing the oxygen concentration from $21 \%$ to $31.5 \%$ increased the predicted particle combustion temperature by about $150 \mathrm{~K}$ in $\mathrm{O}_{2} / \mathrm{N}_{2}$ environment and by $130 \mathrm{~K}$ in $\mathrm{O}_{2} / \mathrm{CO}_{2}$ environment. The change in the $\mathrm{O}_{2}$ concentration significantly changed the PSDs. The yields of ultrafine and fine particles increased with increasing $\mathrm{O}_{2}$ concentration for both $\mathrm{O}_{2} / \mathrm{N}_{2}$ and $\mathrm{O}_{2} / \mathrm{CO}_{2}$ combustion environments. The simulated 
temperature of $21 \% \mathrm{O}_{2} / \mathrm{N}_{2}$ at $1500 \mathrm{~K}$ had a similar result to that of $31.5 \% \mathrm{O}_{2} / \mathrm{N}_{2}$ at $1373 \mathrm{~K}$ : A higher yield of ultrafine particles at the higher $\mathrm{O}_{2}$ concentration condition.

The simulated particle combustion temperature for $31.5 \% \mathrm{O}_{2} / \mathrm{CO}_{2}$ was $1850 \mathrm{~K}$ as compared to $1775 \mathrm{~K}$ for $31.5 \% \mathrm{O}_{2} / \mathrm{N}_{2}$. The yield of ultrafine $\mathrm{PM}$ in the $\mathrm{CO}_{2}$ environment was less than that in the $\mathrm{N}_{2}$ environment. This result suggested that $\mathrm{CO}_{2}$ effect hypothesis was well supported. The lower yield of ultrafine PM in the $\mathrm{CO}_{2}$ environment was also found at lower temperature. However, the $\mathrm{CO}_{2}$ effect was less pronounced at low temperature.

The shapes of the coarse particle curves were similar for all combustion conditions at the same furnace temperatures. Some differences associated with temperature were evident in this mode.

The size-segregated elemental composition from PRB combustion is shown in Figure 99. PRB coal has a high content of calcium and silicon, and $\mathrm{Ca}$ is the predominant ash compound. $\mathrm{Ca}$ is more easily vaporized than $\mathrm{Si}$, and PSDs changes are probably a result of temperature changes. The yield of calcium oxide showed the same trend as the predicted particle combustion temperatures and ash total mass concentrations. Therefore, the elemental analysis of $\mathrm{PRB}$ ash also supports the effect of $\mathrm{O}_{2}$ concentration and the effect of $\mathrm{CO}_{2}$ in ash formation during coal combustion.
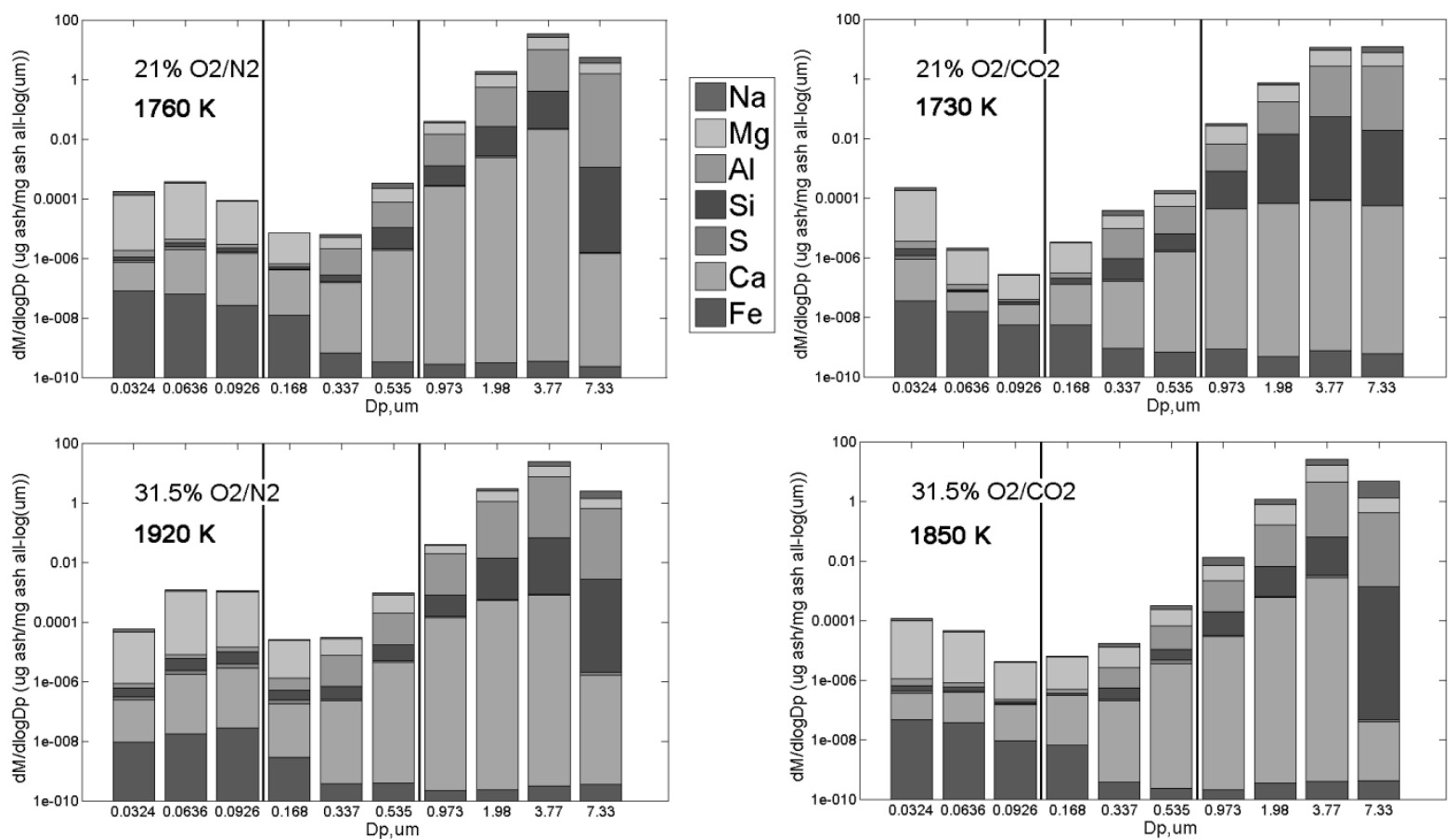

Figure 99. Elemental mass fraction size distribution of PRB at $1500 \mathrm{~K}$. Temperatures are predicted maximums from the simulation. 
Illinois \#6 results. The PSDs of Illinois \#6 are shown in Figure 100. All of the Illinois \#6 PSDs showed the three modes most clearly among the three coals. Ash from Illinois \#6 also showed the greatest fraction of ultrafine and fine particles compared to the other two coals. Significant differences in mass concentration associated with ash formation behavior were observed in ultrafine and fine mode. The mean size of the ultrafine particles showed the particle temperature effect more clearly at $1373 \mathrm{~K}$ than at 1500 $\mathrm{K}$. The mean particle diameter of the ultrafine mode for $\mathrm{O}_{2} / \mathrm{N}_{2}$ combustion was $0.04 \mu \mathrm{m}$ for $31.5 \% \mathrm{O}_{2}$ and $0.028 \mu \mathrm{m}$ for $21 \% \mathrm{O}_{2}$. The mean sizes of ultrafine particles from $\mathrm{O}_{2} / \mathrm{CO}_{2}$ combustion were about the same as $\mathrm{O}_{2} / \mathrm{N}_{2}$ conditions. The coarse mode PSDs were similar at the same furnace temperature. The ultrafine, fine and coarse particles at same $\mathrm{O}_{2}$ concentration conditions had similar yields in both $\mathrm{N}_{2}$ and $\mathrm{CO}_{2}$ environments, except for the ultrafine mode at a furnace temperature $1373 \mathrm{~K}$.
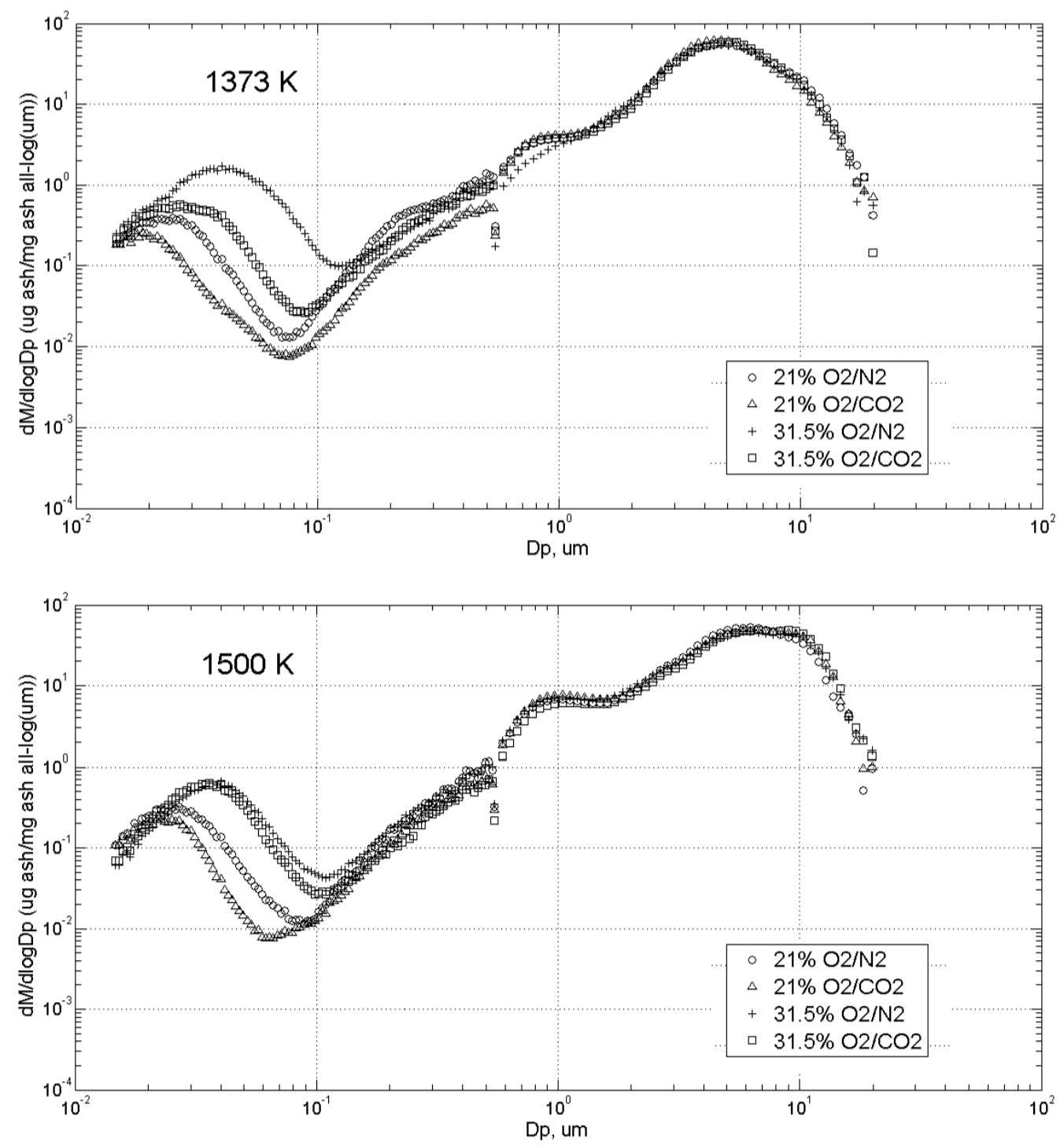

Figure 100. PSDs of Illinois \#6 at $1373 \mathrm{~K}$ and $1500 \mathrm{~K}$. 
The simulated particle combustion temperatures of Illinois \#6 showed that increasing the $\mathrm{O}_{2}$ concentration from $21 \%$ to $31.5 \%$ increased the predicted particle combustion temperature by about 200 $\mathrm{K}$ under $\mathrm{O}_{2} / \mathrm{N}_{2}$ combustion conditions and by $150 \mathrm{~K}$ in $\mathrm{O}_{2} / \mathrm{CO}_{2}$ combustion conditions. In the experimental studies, the increase in the $\mathrm{O}_{2}$ concentration increased the yield of ultrafine PM even with $\mathrm{CO}_{2}$ present. For example, the simulated particle combustion temperature for $21 \% \mathrm{O}_{2} / \mathrm{N}_{2}$ at $1500 \mathrm{~K}$ was similar to that of $31.5 \% \mathrm{O}_{2} / \mathrm{CO}_{2}$ at $1373 \mathrm{~K}$. In this $31.5 \% \mathrm{O}_{2} / \mathrm{CO}_{2}$ environment, ash yield was 17.03 $\mathrm{mg} / \mathrm{g}$ _ash, much higher than $21 \% \mathrm{O}_{2} / \mathrm{N}_{2}$ with $6.72 \mathrm{mg} / \mathrm{g}$ ash.

In addition, the $\mathrm{CO}_{2}$ effect was observed at lower temperatures. The predicted particle combustion temperature at $21 \% \mathrm{O}_{2} / \mathrm{N}_{2}$ and $21 \% \mathrm{O}_{2} / \mathrm{CO}_{2}$ at $1373 \mathrm{~K}$ were similar. The environment of $\mathrm{O}_{2} / \mathrm{N}_{2}$ yielded $16.437 \mathrm{mg} / \mathrm{g} \_$ash, compared to $8.824 \mathrm{mg} / \mathrm{g}$ a ash for an $\mathrm{O}_{2} / \mathrm{CO}_{2}$ environment.

The size-segregated elemental composition of Illinois \#6 ash is shown in Figure 101. Illinois \#6 has high content of sulfur silicon and iron. The ultrafine and fine particle modes had large concentrations of sulfur, with almost no sulfur in the coarse mode. This suggested the formation of sulfates during the coal combustion. More sulfur was found at lower $\mathrm{O}_{2}$ conditions, both in $\mathrm{N}_{2} / \mathrm{CO}_{2}$ environments. Si and $\mathrm{Fe}$ in mass distributions showed more dependence on $\mathrm{O}_{2}$ concentration versus the combustion environment $\left(\mathrm{N}_{2} / \mathrm{CO}_{2}\right)$ for all stage samples, which was consistent with the PSDs.
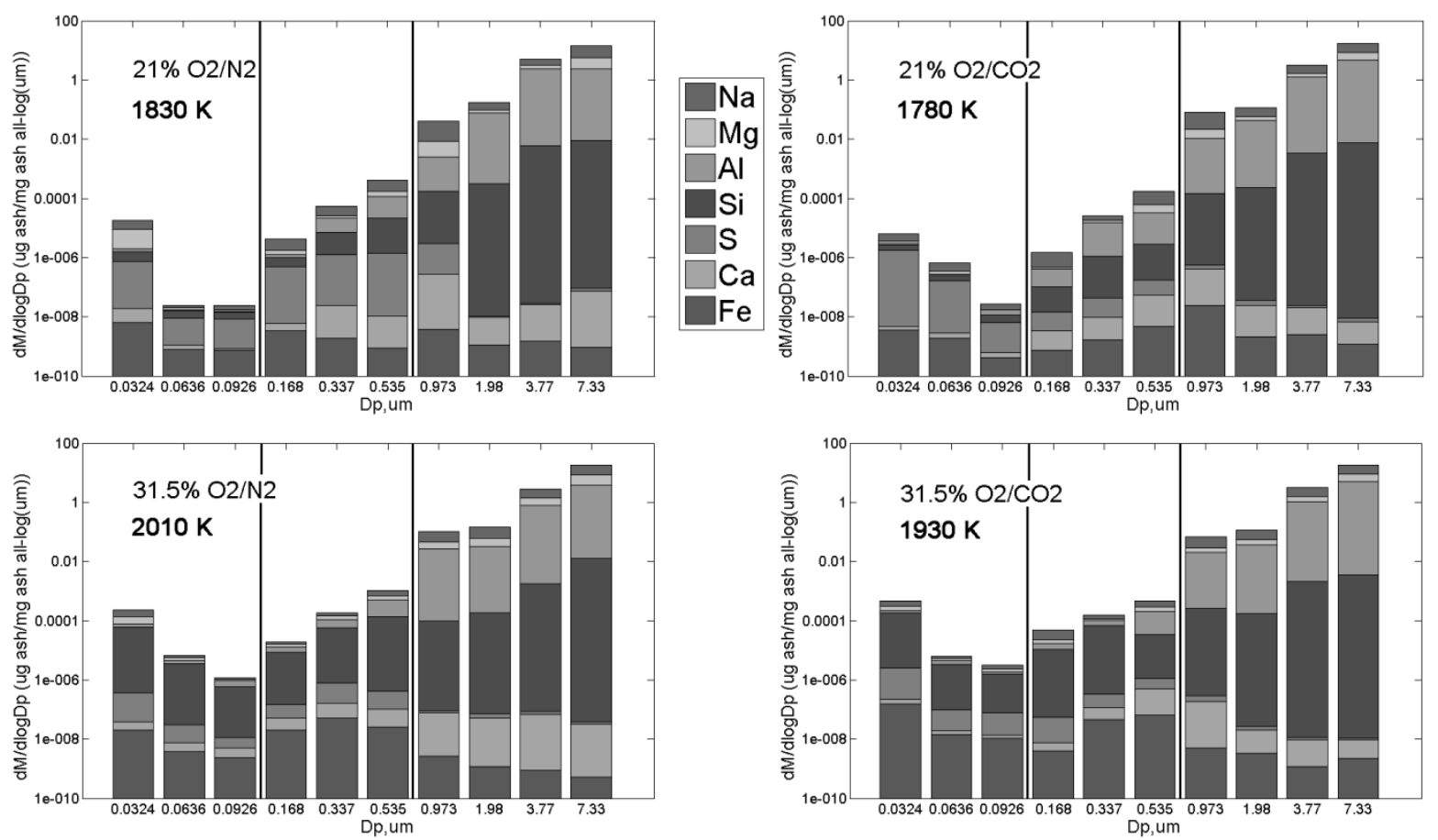

Figure 101. Elemental mass fraction size distribution of Illinois \#6 at $1500 \mathrm{~K}$. Temperatures are predicted maximums from the simulations. 


\section{Morphology of ash particulates}

Ash particulate samples collected from the BLPI system were used to determine morphology. Utah Skyline, PRB and Illinois \#6 coals combusted under 31.5\% $\mathrm{O}_{2}$ with $\mathrm{CO}_{2}$ and $\mathrm{N}_{2}$ atmosphere at $1500 \mathrm{~K}$ were studied.

Figure 102 shows SEM images of ash samples on stage 1, stage 7 and stage 10 for all three coals; these stages have a $50 \%$ aerodynamic cutoff diameter of $0.0324 \mu \mathrm{m}, 0.973 \mu \mathrm{m}$ and $7.33 \mu \mathrm{m}$, respectively. The images of stage 1 at a magnification of 250,000 showed that the particles were coagulated. The particles on stage 7 and stage 10 showed the typical spherical shape of coal ashes. There were no differences in shape for all three coals ash particles, for the different combustion environments $\left(\mathrm{O}_{2} / \mathrm{N}_{2}\right.$ and $\left.\mathrm{O}_{2} / \mathrm{CO}_{2}\right)$ or for the different $\mathrm{O}_{2}$ concentrations. This spherical surface looked smooth and had approximately the appropriate collection diameters for each stage. However, smaller size particles were found adhered to some large particles surfaces on stage 7 and 10 .

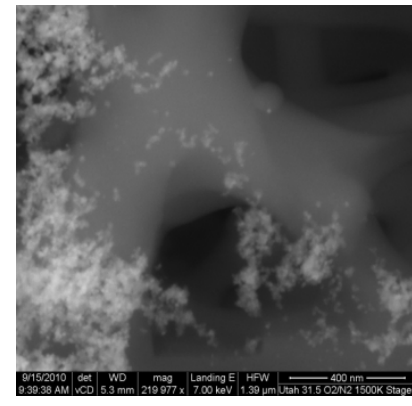

(a) Utah Skyline Stage 1
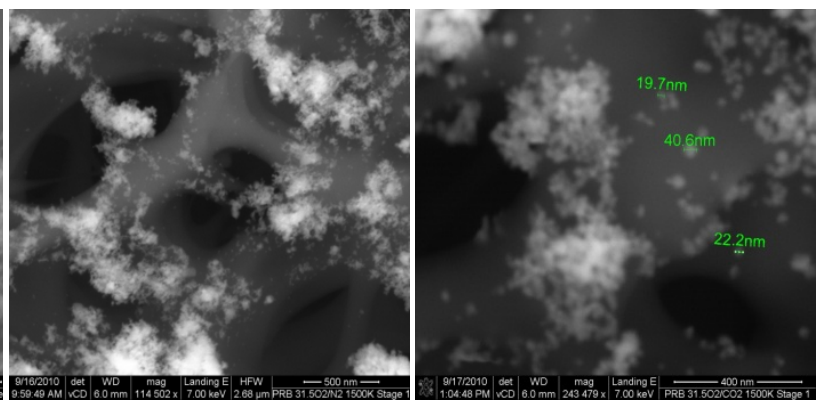

(b) PRB stage 1

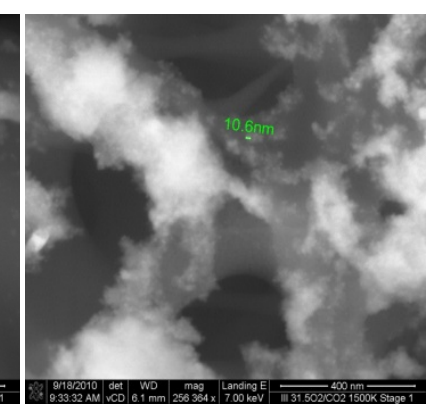

(c) Illinois \#6 stage 1

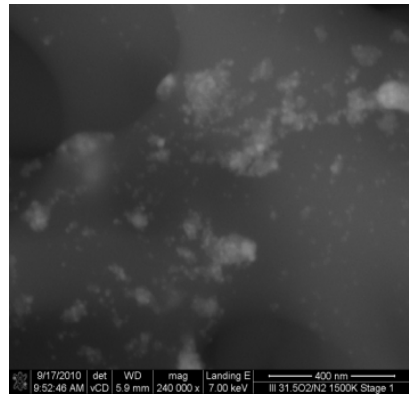




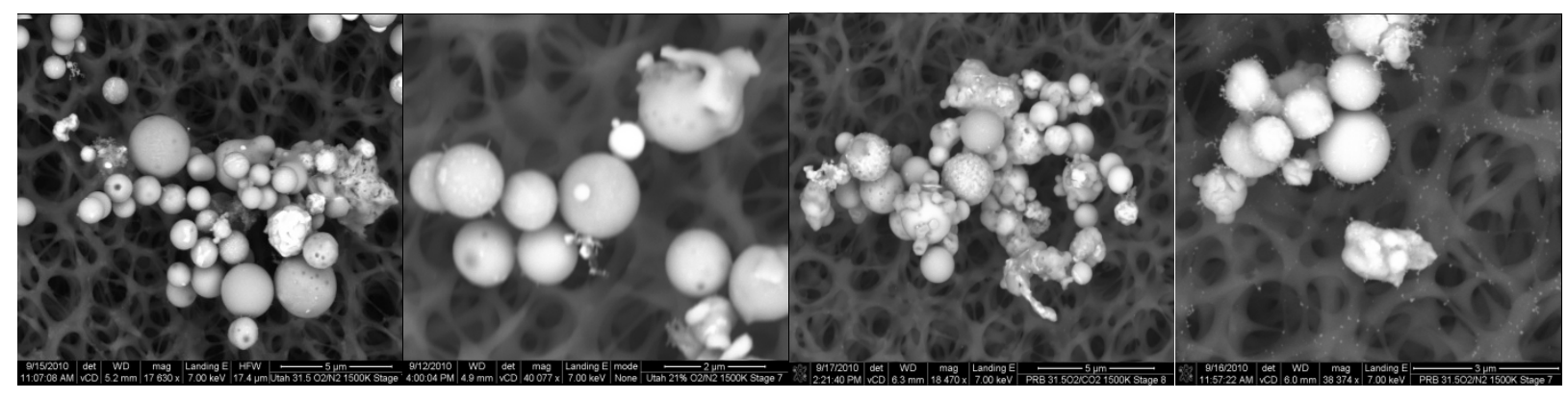

(a) Utah Skyline Stage 7

(b) PRB stage 7

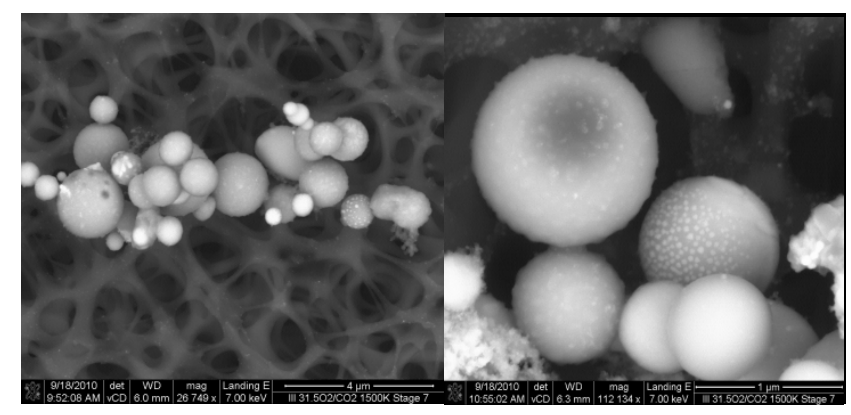

(c) Illinois \#6 stage 7

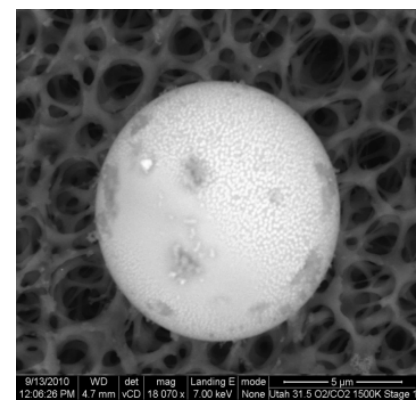

(a) Utah Skyline Stage 10

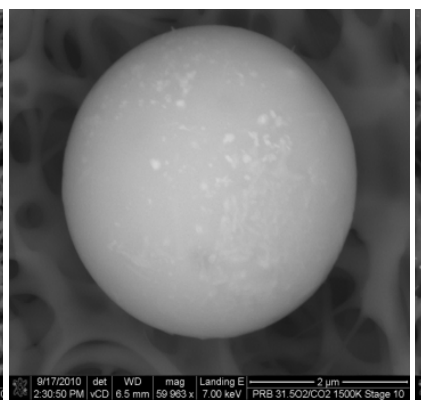

(b) PRB stage 10
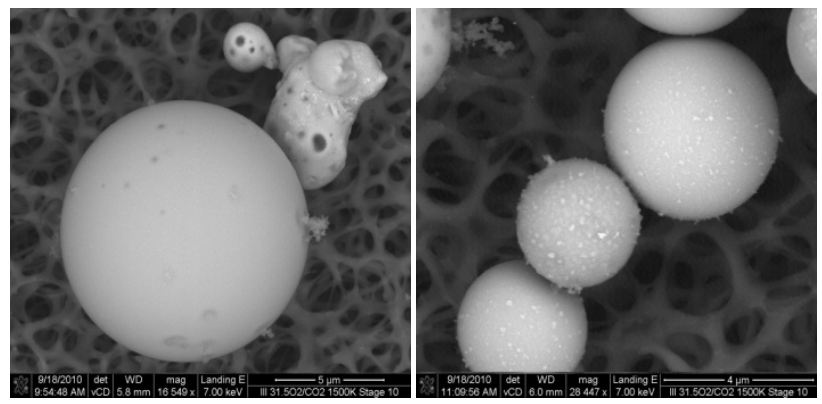

(c) Illinois \#6 stage 10

Figure 102. Morphology of Utah Skyline, PRB and Illinois \#6 combusted under $31.5 \% \mathrm{O}_{2} / \mathrm{CO}_{2}$ and $31.5 \% \mathrm{O}_{2} / \mathrm{N}_{2}$ conditions at $1500 \mathrm{~K}$. 


\section{Studies in the OFC}

As noted above, data are presented to compare the effects of once-through $\mathrm{CO}_{2}$ (simulating super clean FGR) and those of dirty FGR for a single oxygen concentration $\left(32 \% \mathrm{O}_{2}\right)$. Effects for three coals are presented, with varied clean up strategies depending on the coal as described in Figure 21 - Figure 23.

\section{Ultrafine particle size distributions}

Figure 103 shows ultra-fine PSDs for the three coals, each burned $32 \% \mathrm{O}_{2} 68 \% \mathrm{CO}_{2}$ or FGR, as the oxidant, for once-through $\mathrm{CO}_{2}$, cleaned FGR (according to Figure 21 - Figure 23, and dirty FGR. Figure 104 shows the same data replotted to highlight the important differences due to differences in coal.

\section{Utah}

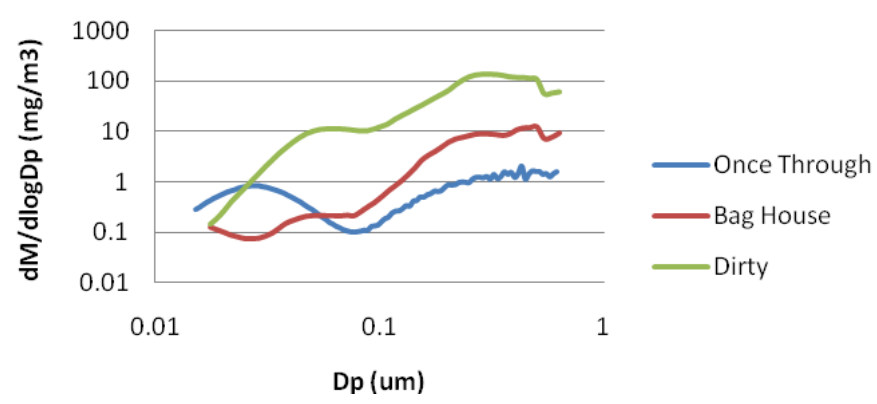

PRB

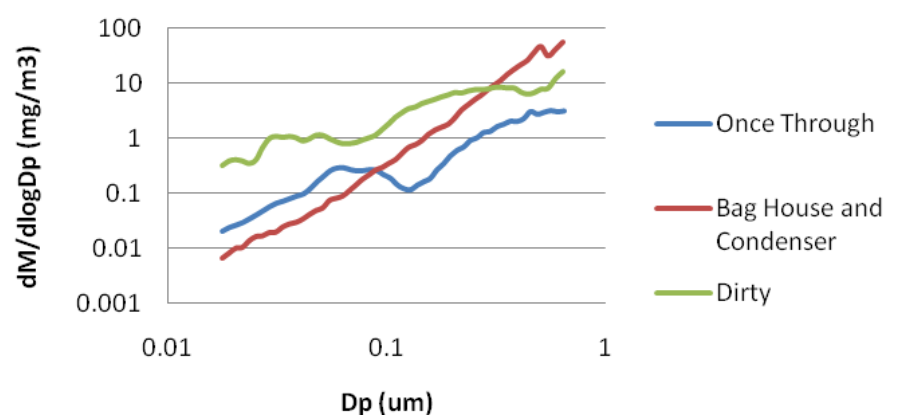




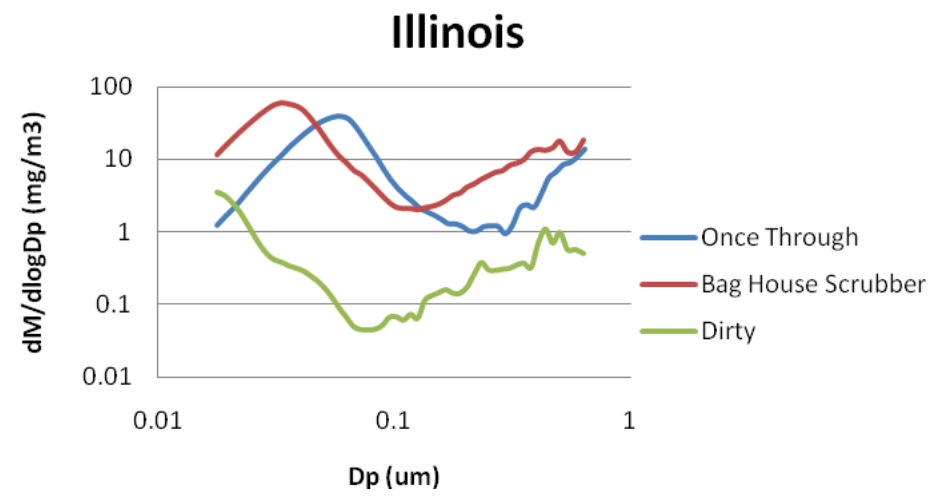

Figure 103. Ultrafine PSDs for once-through $\mathrm{CO}_{2}$ and cleaned and dirty FGR as diluent for oxidant.

Data clearly show that for Utah and PRB coals ultra-fine particle concentrations are significantly higher for dirty and "cleaned" FGR compared to those with once-through $\mathrm{CO}_{2}$. However, for the Illinois coal the dirty FGR appeared to produce lower particle concentrations, possibly because of removal mechanisms in the oversized hot recycle blower.

The importance of coal composition is highlighted on Figure 104, and this supports the importance of considering coal composition effects when investigating ash partitioning mechanisms under oxy-coal combustion conditions. Experiments with solely a single coal can lead to erroneous conclusions in general. Therefore it was essential and more valuable to explore coal composition effects, prior to investigating ash partitioning at higher inlet $\mathrm{O}_{2}$ levels, which, in any case, was not possible during the project because of operational difficulties.

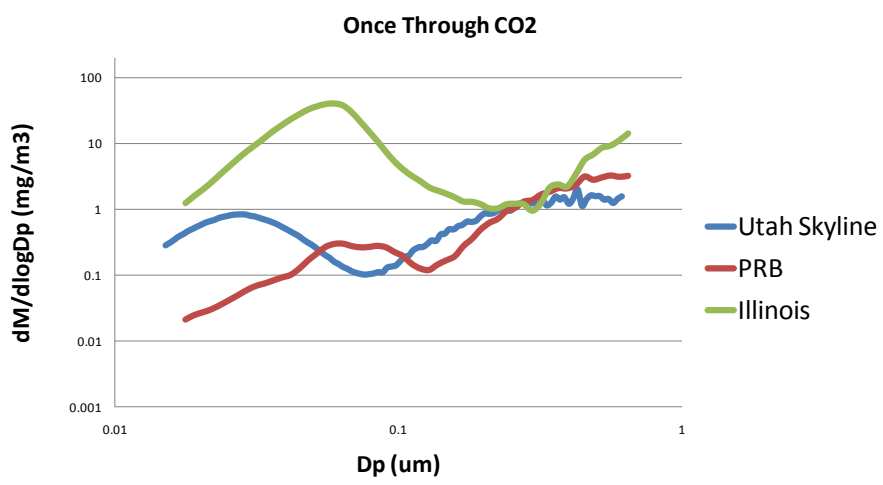



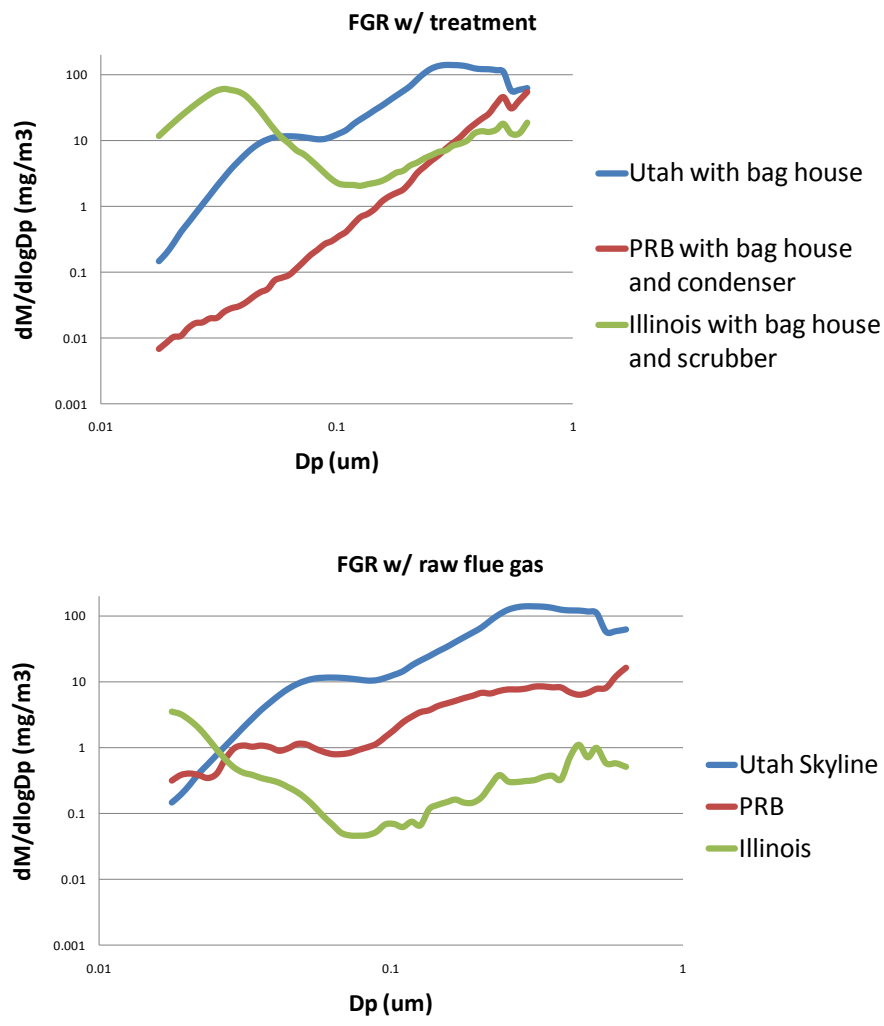

Figure 104. Same data as in Figure 103, showing effects of coal composition.

\section{Ash partitioning results}

The BLPI described in previous reports was used to classify and collect fly ash particles $<15.7 \mu \mathrm{m}$. All the size-segregated ash samples $>0.16 \mu \mathrm{m}$ were subjected to EDS analysis. The analyzed major and minor oxides included $\mathrm{Na}_{2} \mathrm{O}, \mathrm{MgO}, \mathrm{Al}_{2} \mathrm{O} 3, \mathrm{SiO}_{2}, \mathrm{P}_{2} \mathrm{O}_{5}, \mathrm{SO}_{3}, \mathrm{~K} 2 \mathrm{O}, \mathrm{CaO}, \mathrm{TiO}_{2}$, and $\mathrm{Fe}_{2} \mathrm{O}_{3}$. The size distributions of the oxides in the ash samples of the Utah coal, the Illinois coal, and the PRB coal are illustrated in, Figure 105 - Figure 107, respectively.

For the Utah coal, in the studied size range, it seems that varying flue gas composition has insignificant impacts on the size distributions of $\mathrm{Al}_{2} \mathrm{O}_{3}$ (c) and $\mathrm{SiO}_{2}$ (d), but does have effects on the size distributions of other oxides, although definite conclusions cannot be made at this point. The interesting results are the size distributions of $\mathrm{SO}_{3}(\mathrm{f})$. For both cases, the content of $\mathrm{SO}_{3}$ increases with decreasing particle size. This is consistent with the vaporization and heterogeneous condensation/reaction theory. Compared to the "Cleaned FGR" case, the fly ash from the "Dirty FGR" case contains higher contents of $\mathrm{SO}_{3}$, especially in the small size range. It is likely because the fly ash from the "Dirty FGR" case contains a larger fraction of fine particulates that can absorb sulfur oxides. 


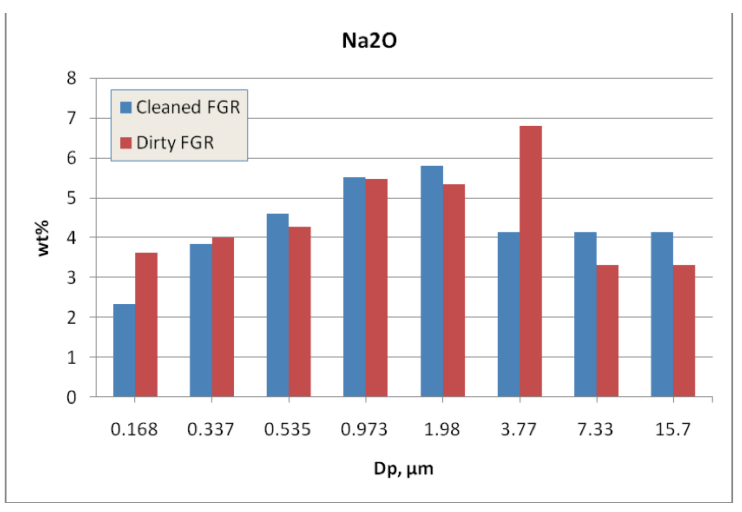

(a)

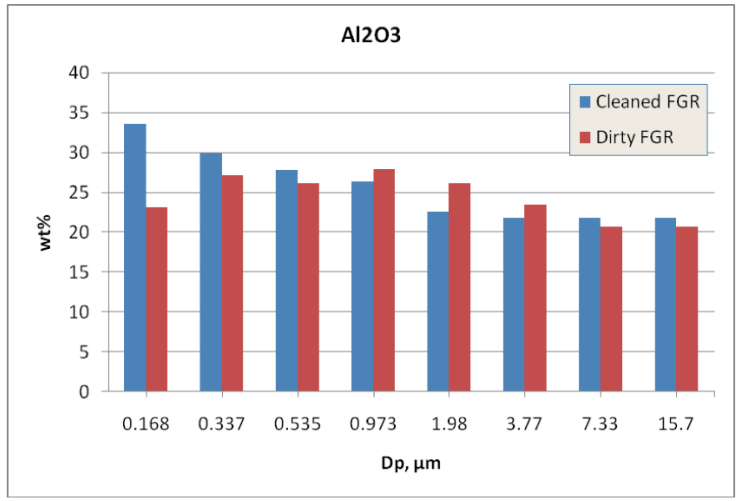

(c)

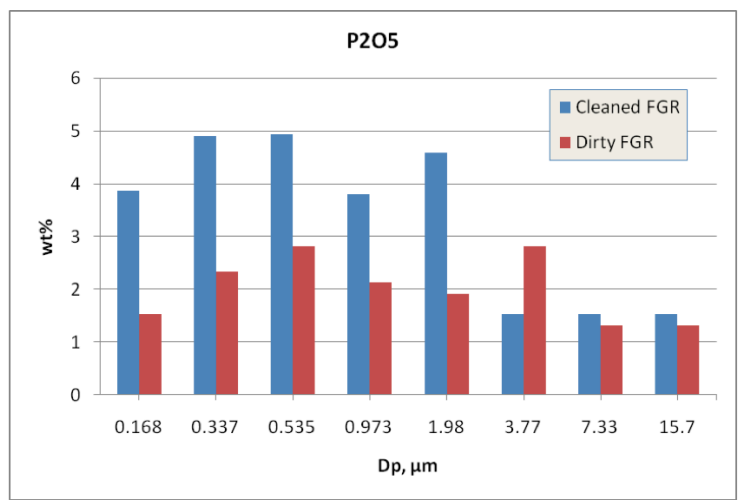

(e)

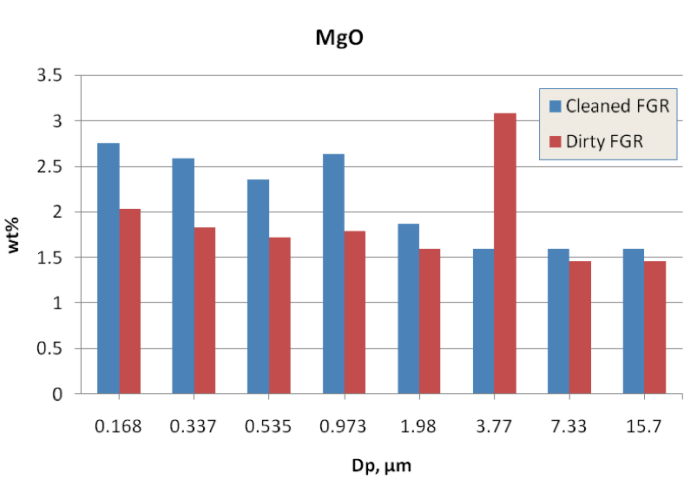

(b)

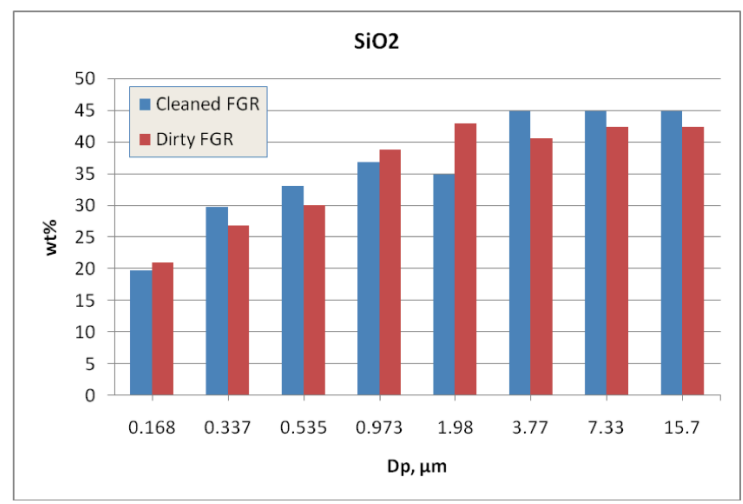

(d)

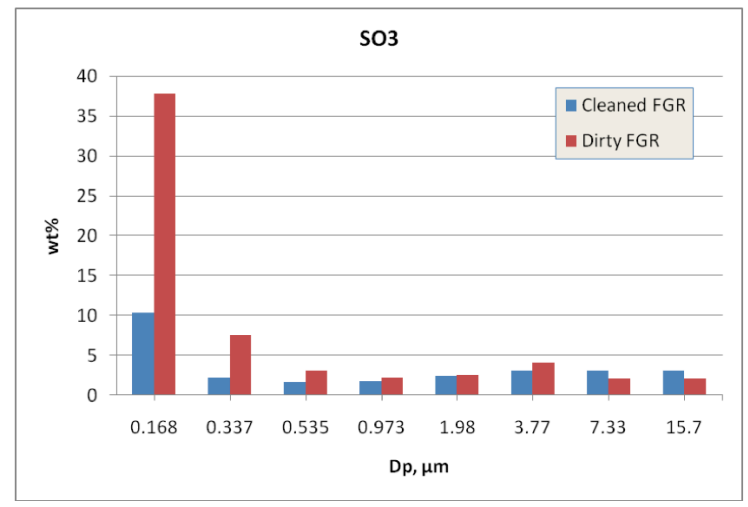

(f) 


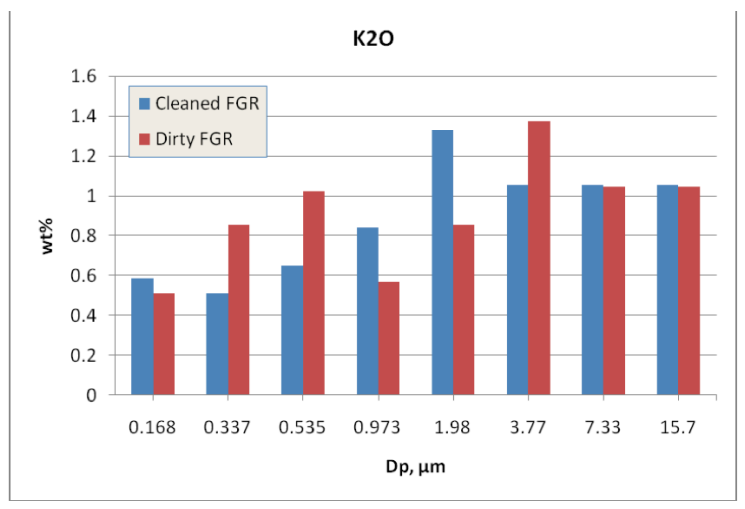

(g)

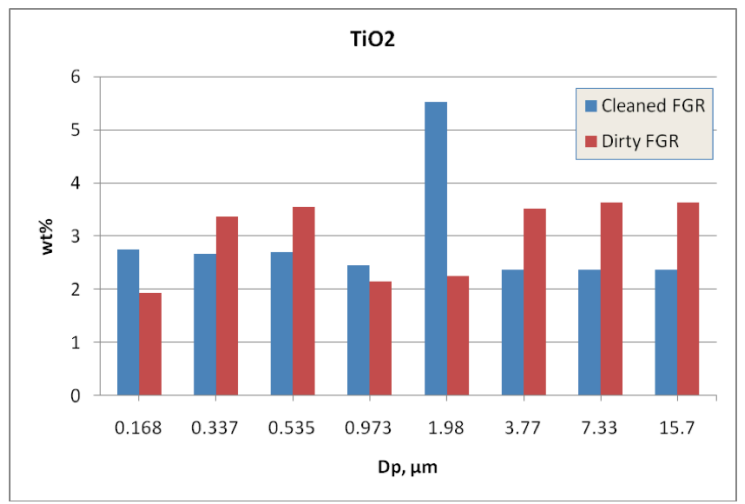

(i)

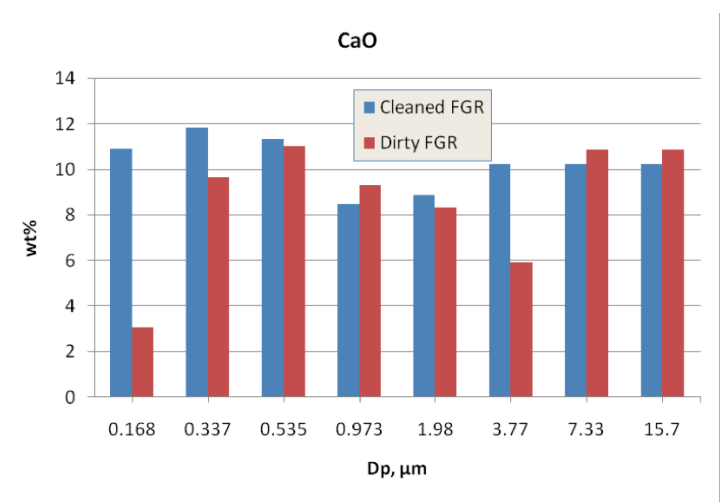

(h)

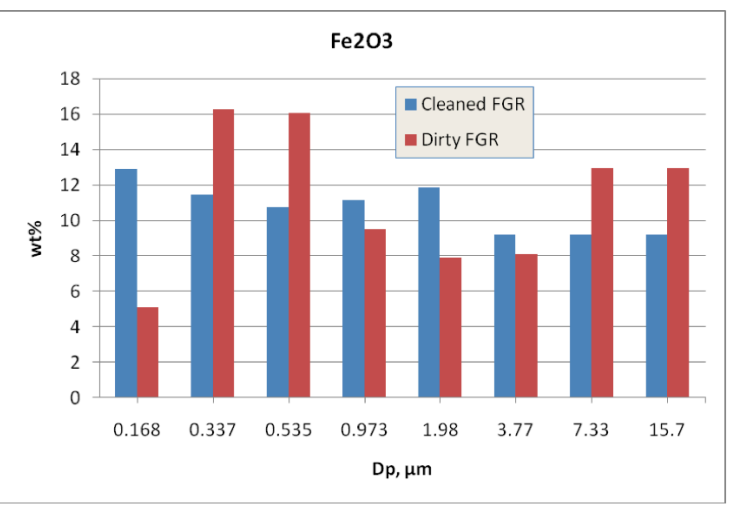

(j)

Figure 105. Size distributions of the oxides in the Utah coal ash.

For the Illinois coal, the size distributions of $\mathrm{Al}_{2} \mathrm{O}_{3}, \mathrm{SiO}_{2}$, and $\mathrm{SO}_{3}$ for the "Cleaned FGR" case are not significantly different from those for the "Dirty FGR" case, while differences in other oxide size distributions can be observed (Figure 106). The underlying mechanisms need further clarification. 


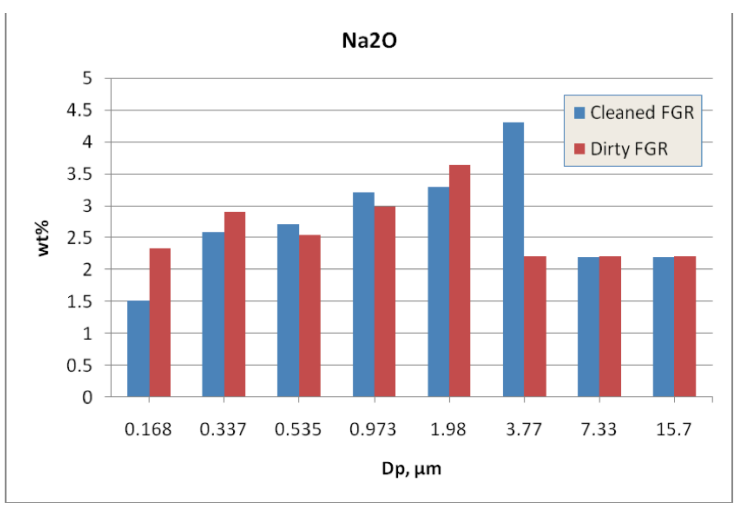

(a)

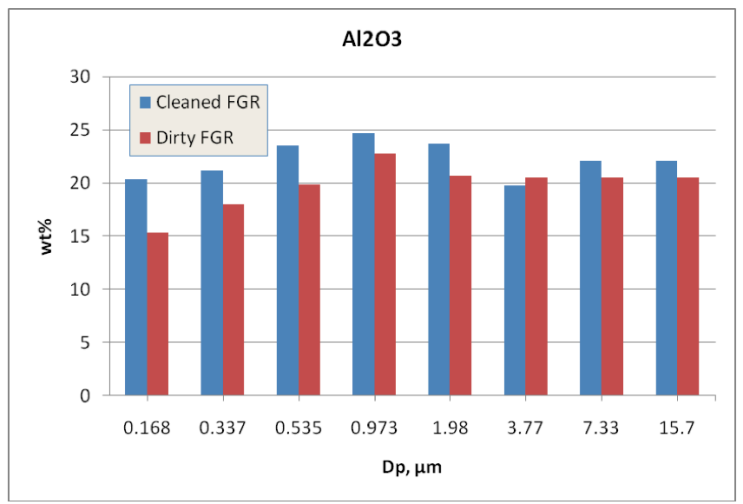

(c)

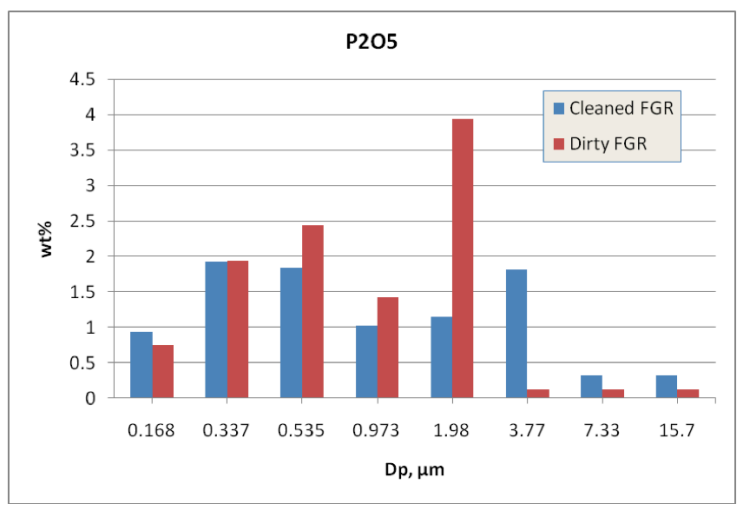

(e)

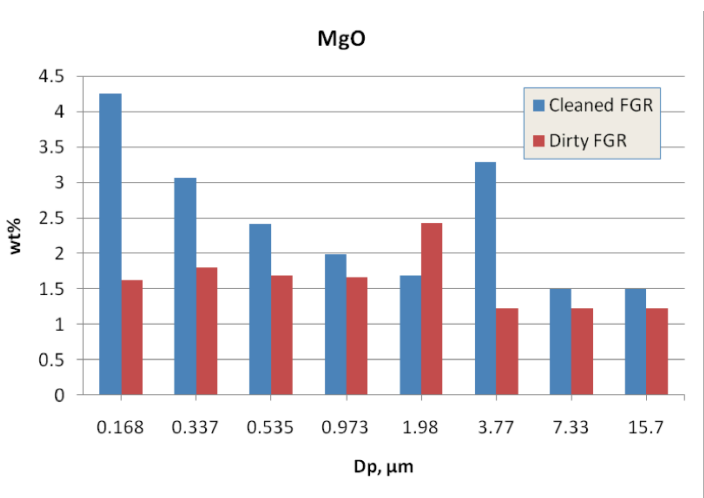

(b)

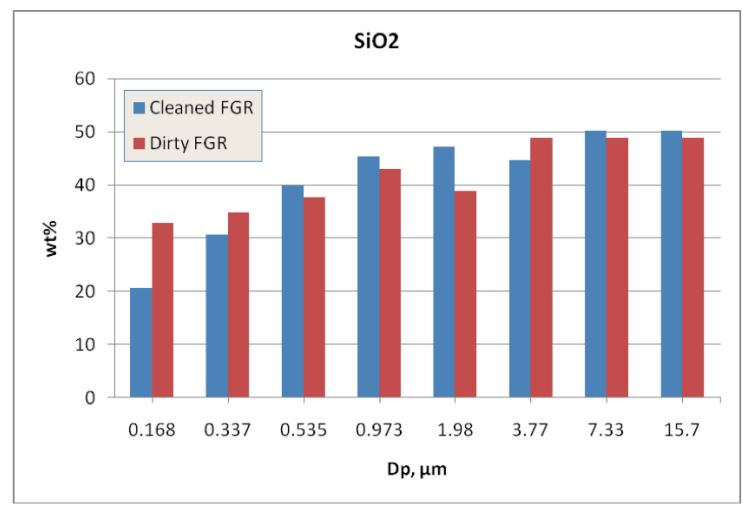

(d)

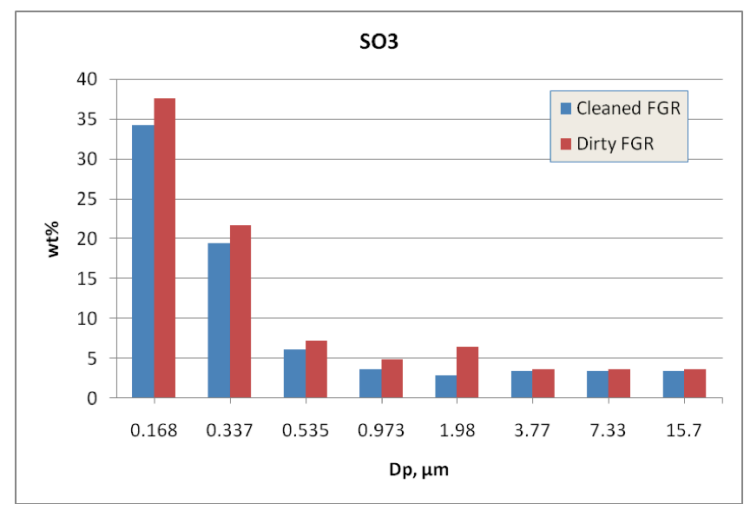

(f) 


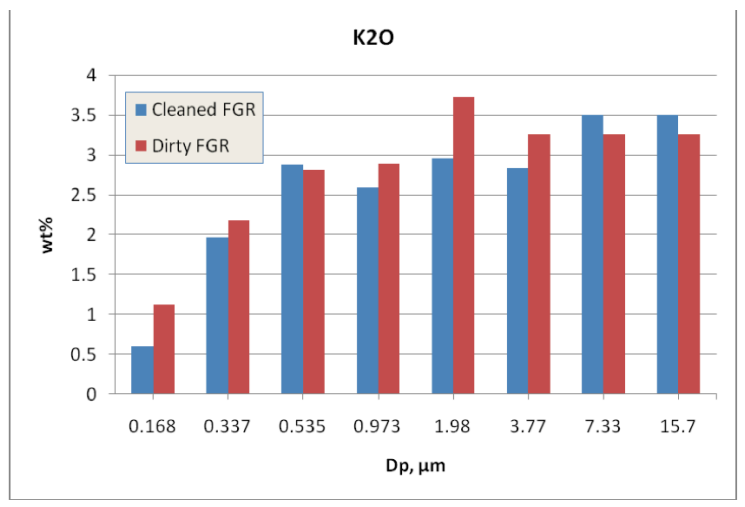

(g)

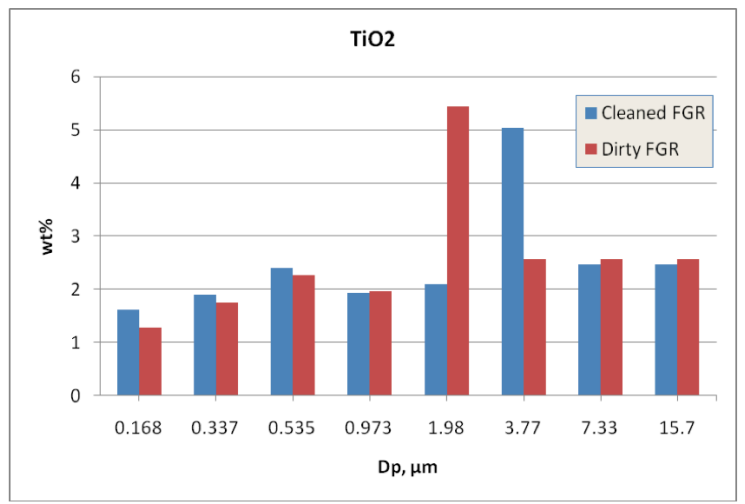

(i)

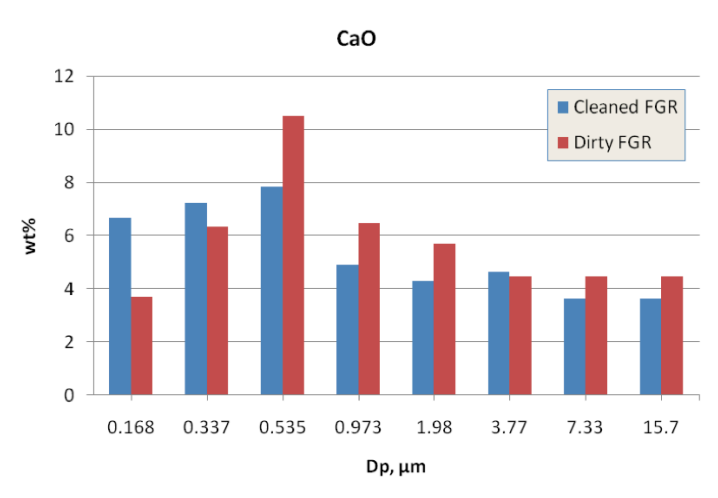

(h)

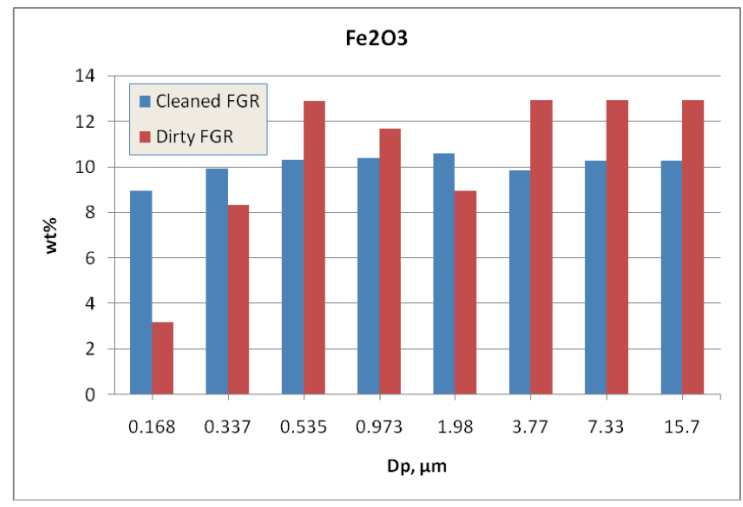

(j)

Figure 106. Size distributions of the oxides in the Illinois coal ash.

In contrast to the Utah and Illinois coals, the PRB coal ash composition seems not to be so significantly affected by varying flue gas composition (Figure 107). It indicates that the impacts of FGR on ash chemistry may also be dependent on coal type. However further verification is necessary. 


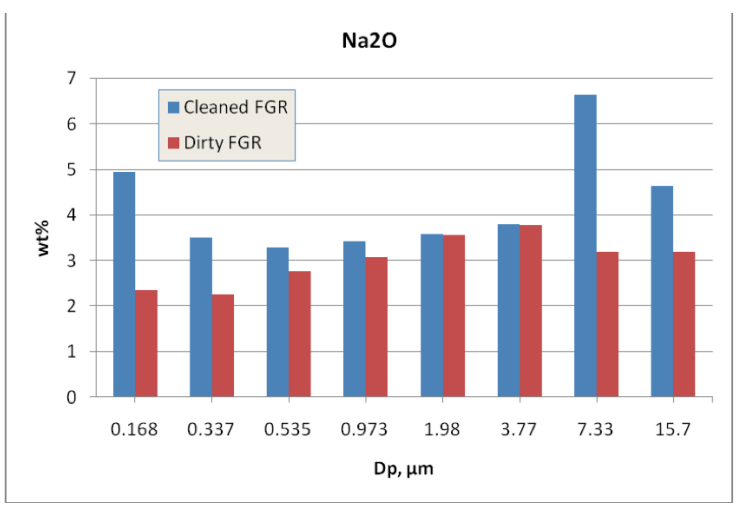

(a)

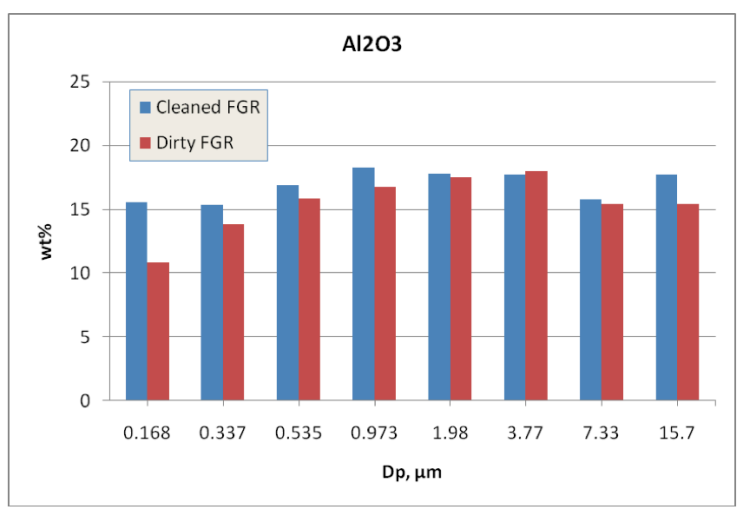

(c)

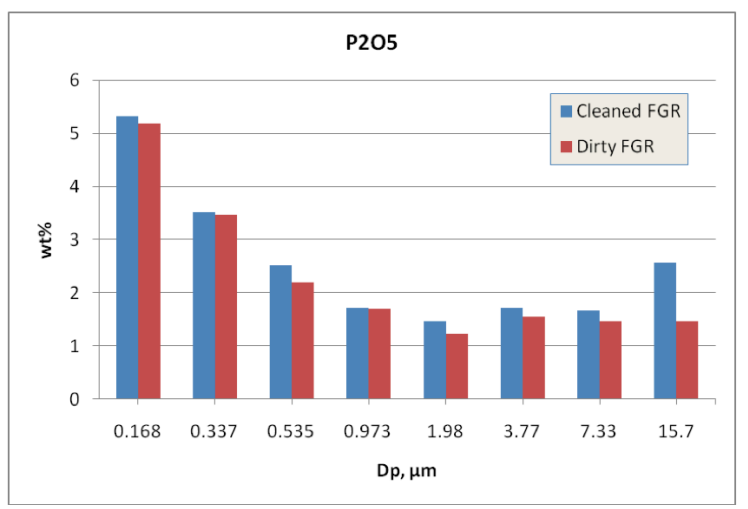

(e)

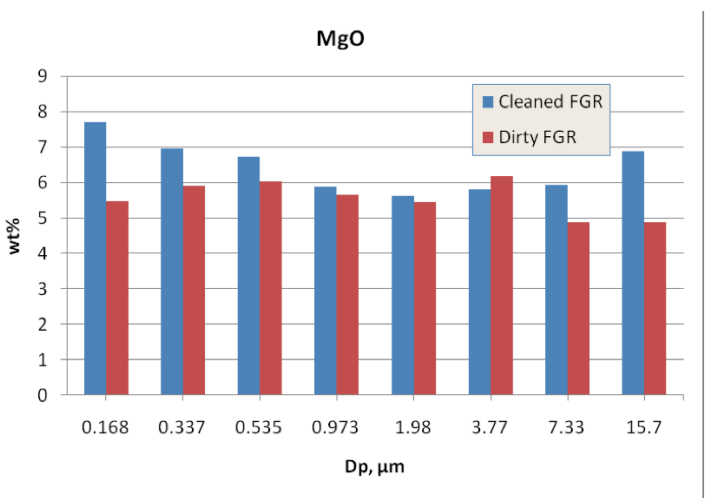

(b)

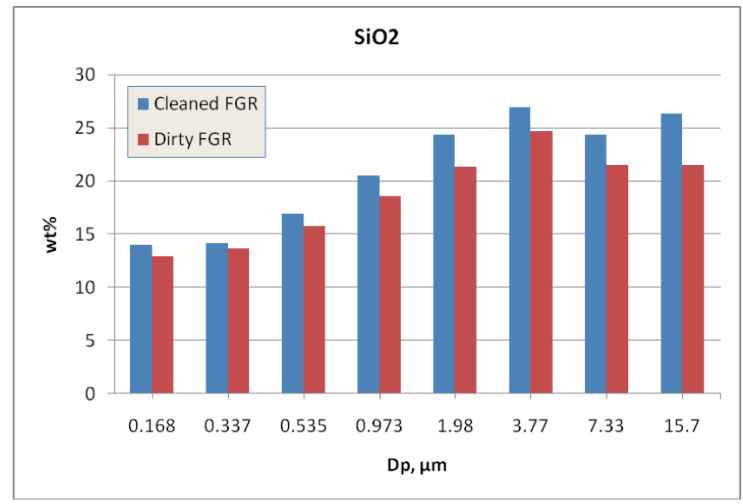

(d)

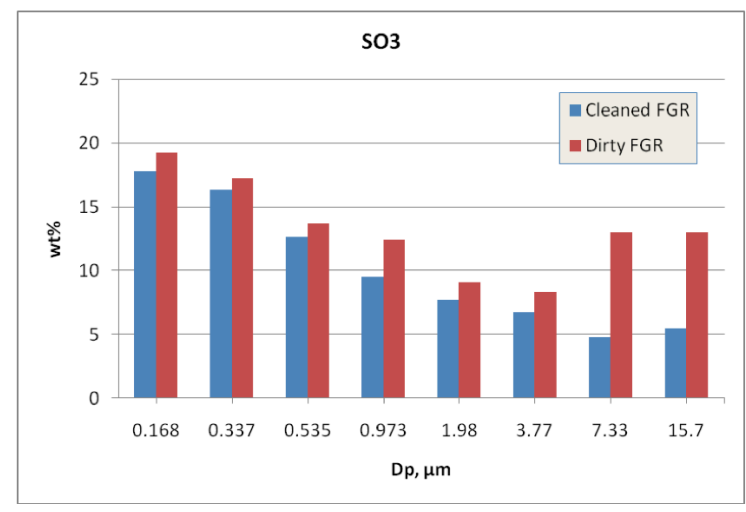

(f) 


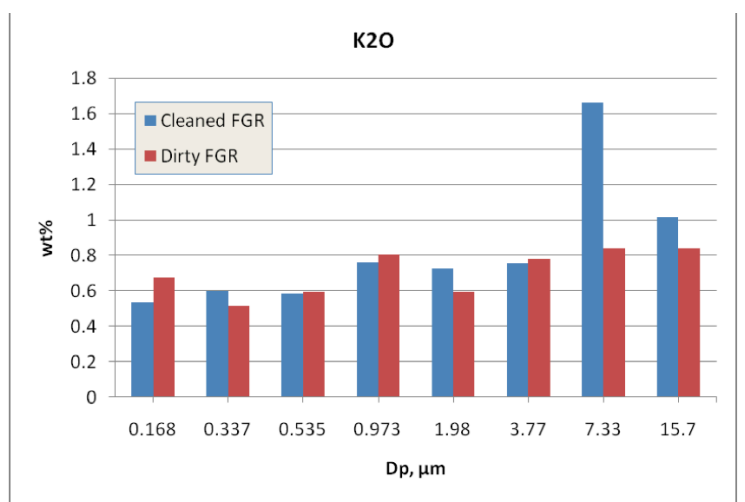

(g)

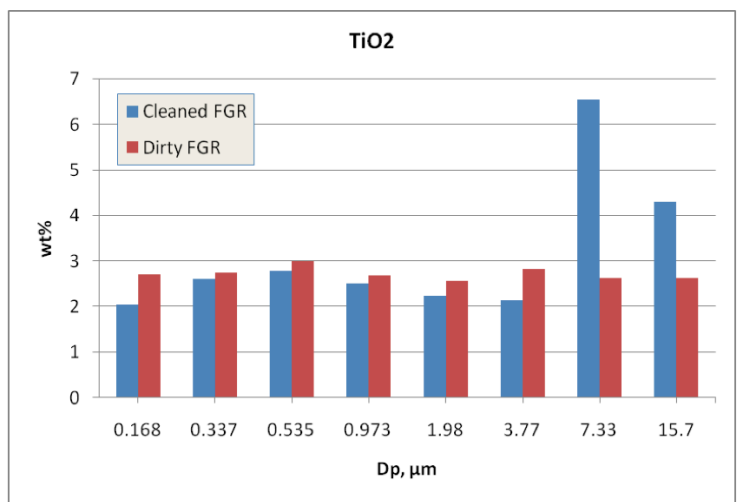

(i)

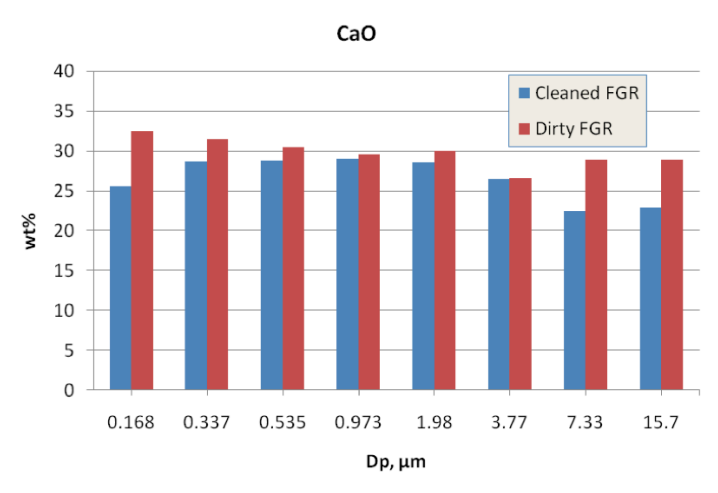

(h)

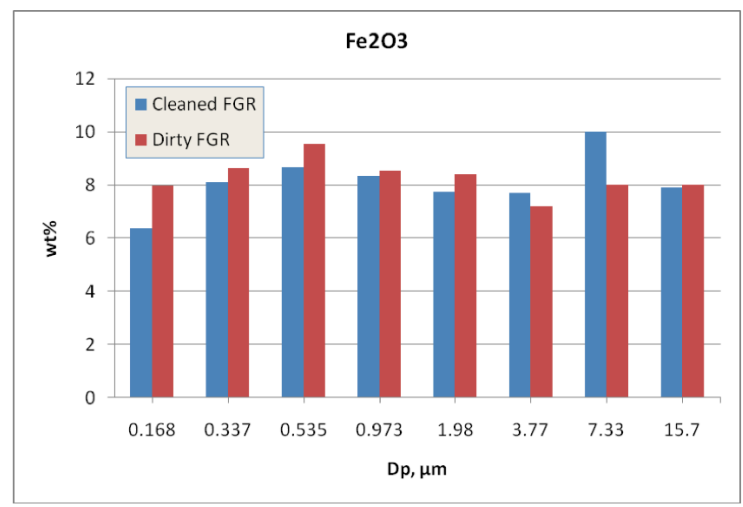

(j)

Figure 107. Size distributions of the oxides in the PRB coal ash.

\section{CONCLUSIONS}

During this project, the investigators moved toward the ultimate goal of developing a predictive capability with quantified uncertainty bounds for pilot-scale, single-burner, oxy-coal operation. This validation research brings together multi-scale experimental measurements and computer simulations, with a particular focus on ignition, coal flame stability, ash partitioning and ash deposition under pulverized oxy-coal conditions, with a smaller companion effort on application of circulating fluidized beds to oxycoal combustion conditions. Conclusions from the individual subtasks follow:

Oxy-coal combustion large eddy simulations. The LES with DQMOM approach proved to be a valid tool to perform accurate simulations of particle-laden flows. A validation study on a coaxial jet and showed that for several operating conditions, simulations were able to predict both gas and particle velocities with a maximum error of $12 \%$. Simulations also proved able to replicate particle clustering and particle segregation. The different LES simulations of oxy-coal flames showed that the code could model 
complex ignition phenomena. The predicted flame stand-off distance is sensitive to wall temperature but not to the partial pressure of oxygen in the primary. The observed trend of stand-off distance decreasing with increasing primary $\mathrm{P}_{\mathrm{O} 2}$ may come from an unidentified phenomenon, but could also result from uncertainties in the experimental operating conditions such as the temperature of the walls. Simulations also dismissed the possibility of heterogeneous ignition in those conditions.

Near-field aerodynamics of oxy-coal flames. An important conclusion from the oxygen-injection tests conducted so far was that all the oxygen could be injected separately as undiluted pure oxygen, with dilution by separately injected $\mathrm{CO}_{2}$ (flue gas) occurring downstream to modulate the peak flame temperature. This strategy employed triple concentric axial burners and led to attached long flames with low $\mathrm{NO}_{\mathrm{x}}$. Special tests on the replacement of the fluid transporting the coal in the primary jet suggested that the coal jet ignition in coaxial turbulent diffusion flames was controlled by molecular diffusion of oxygen through the primary transporting fluid.

Advanced diagnostics for oxy-coal combustion. The PIV technique was able to provide velocity fields of coal particles in a pulverized coal flame in a lab-scale burner. The evaluation of coal particle velocities for various coal particle sizes, global equivalence ratios of the system and height (location) in the flame revealed that the mean axial velocity of the coal particles increased vertically in the flame, and the lower sections of the flame are more stable than the upper regions of the flame. Regardless of the fluctuation of the flame, especially in upper portions of the flame, there was no specific periodicity over the PIV run time, as detected by the power spectrum of velocity. In general terms, the mean axial velocity increases as the equivalence ratio increases and larger coal particle sizes in the flame result in a decrease in the mean axial velocity of the coal particles.

The PIV methodology proved successful in investigating coal flames in the large scale $100 \mathrm{KW}$ downflow oxy-fired combustor. The velocity fields are more complex, and the fluctuations in the axial velocity are much greater than those of the lab-scale, and reflect the greater levels of turbulence at this scale. The PIV results show a decrease in velocity far from the burner due to turbulent jet decay and an increase in the velocity fluctuations far from the burner due to an increase in turbulent eddies. In general, the fluctuations increase with increasing primary $\mathrm{O}_{2}$ concentration.

Oxy-coal combustion in circulating fluidized beds. The results of experiments performed in a pilot-scale CFB facility under air- and oxy-fired conditions using a Utah bituminous coal revealed: (1) Under oxyfired conditions, an $\mathrm{O}_{2}$ concentration of $27 \%$ (a wet basis) in recycled wet flue gas provided an average bed temperature in the fluidized bed similar to that in air firing. $\mathrm{O}_{2}$ concentrations as low as $21 \%$ or as high as $35 \%$ (wet basis) resulted in bed temperatures that are outside of an acceptable range for optimized CFB operation. (2) Native capture of $\mathrm{SO}_{2}$ by coal ash is possible under both air- and oxy-fired conditions. The performance was primarily a function of bed temperature, with sulfur capture decreasing with increasing bed temperature. (3) $\mathrm{SO}_{2}$ and $\mathrm{SO}_{3}$ emissions on a concentration basis (ppm) for oxy-firing were much higher than that for air firing, while $\mathrm{SO}_{2}$ and $\mathrm{SO}_{3}$ emissions based on mass (lbs/MMBtu) in were not significantly different between air- and oxy-firing. (4) Tests performed on limestone addition,

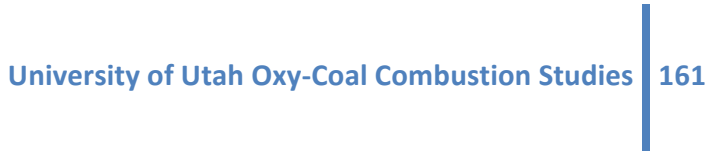


with $\mathrm{Ca}: \mathrm{S}$ molar ratios ranging from 0 to 10 , showed a relationship between $\mathrm{SO}_{2}$ emissions (ppm) and the molar ratio of $\mathrm{Ca}: \mathrm{S}$ and $\mathrm{SO}_{2}(\mathrm{ppm})$. However, this appears negligible within the range of error of the data.

Single-particle oxy-CO $\mathrm{CO}_{2}$ combustion. The single-particle CFB experiments in the absence of flue gas recycling showed no significant difference in $\mathrm{SO}_{2}$ formation between air- and oxy- firing conditions. For lower temperatures, air-firing conditions provide greater capture efficiency, but at higher temperatures oxy-firing conditions can become more effective. Furthermore, the sulfation mechanisms are quite different for air- vs. oxy- firing, with trade-offs between pore blockage due to different sulfation mechanisms and re-carbonation. The initial results from the general gas-solid model, based on coupled governing equations, illustrate the effect of particle size on combustion evolution: smaller particles favor kinetics control while the diffusion control occurs in the larger particle, as expected. The shrinking-core particle model functions as a special application in the general gas-solid model developed here.

Ash partitioning mechanisms for oxy-coal combustion. The drop-tube studies of the effect of furnace temperature, coal type and gas composition on ash formation revealed that combustion in an $\mathrm{O}_{2} / \mathrm{CO}_{2}$ environment yielded smaller mean particle sizes in the ultrafine and fine modes when compared to an $\mathrm{O}_{2} / \mathrm{N}_{2}$ combustion environment with same $\mathrm{O}_{2}$ concentration. The yields of particulates from $\mathrm{O}_{2} / \mathrm{CO}_{2}$ combustion were less than those from $\mathrm{O}_{2} / \mathrm{N}_{2}$ combustion for all three coals. The studies suggested that $\mathrm{CO}_{2}$ significantly reduced ash particle formation by decreasing refractory oxide vaporization and somewhat by decreasing temperature. The simulation results indicated that increasing the furnace temperature and $\mathrm{O}_{2}$ concentration enhanced the ash particle generation due to increased predicted particle combustion temperature.

The experiments in the OFC showed that ash partitioning mechanisms depend strongly on the composition of the recycled flue gas (i.e. using once-through $\mathrm{CO}_{2}$ to simulate FGR is not realistic) and on the coal composition. Varying recycled flue gas composition can have effects on ash PSDs and also sizesegregated ash composition, but the extent of the effects may depend on coal type as well. Ultrafine particles concentrations are significantly higher under FGR conditions, compared to once-through $\mathrm{CO}_{2}$, even with a bag-house installed.

\section{List of Peer-Reviewed Publications}

Morris, W. J., Yu, D., Wendt, J.O.L. "Soot, Unburned Carbon and Ultrafine Particle Emissions from Airand Oxy-coal Flames" Proc. Combust. Inst. 33, 3415-3421 (2011).

Yu, D., Morris, W.J., Erickson, R, Wendt, J.O.L., Fry, A., Senior, C.L. "Ash and deposit formation from oxy-coal combustion in a $100 \mathrm{~kW}$ test furnace" Int, J, Greenhouse Gas Control, 5S, S159S167(2011).

Zhang, J., Kelly, K.E., Eddings, E.G., Wendt, J.O.L., "Ignition in 40kW Co-axial Turbulent Diffusion Oxy-Coal Flames" Proc. Combust. Inst. 33, 3375-3382 (2011).

Zhang, J., Kelly, K.E., Eddings, E.G., Wendt, J.O.L. "CO2 effects on near field aerodynamic phenomena in 40kW, co-axial, oxy-coal, turbulent diffusion flames" Int, J, Greenhouse Gas Control, 5S, S47S57(2011). 


\section{REFERENCES}

Ahn, J.; Okerlund, R.; Fry, A.; Eddings, E. G. Sulfur trioxide formation during oxy-coal combustion. Int. J. Greenhouse Gas Control. 2011, 5, S-1, S127-S135.

Attar, A. Chemistry, thermodynamics and kinetics of reactions of sulphur in coal-gas reactions: A review. Fuel. 1978, 57, 201-212.

Bachmann, J. D.; Damber, R. J.; Caldwell, J. C.; Edwards, C.; Koman, P. D. Review of the National Ambient Air Quality Standards for Particulate Matter: Policy Assessment of Scientific and Technical Information. Office of Air Quality Planning and Standards, Research triangle park, NC, 1996.

Badzioch, S.; Gregory, D. R.; Field, M. A. Investigation of the temperature variation of the thermal conductivity and thermal diffusivity of coal. Fuel. 1964, 43, 267-280.

Baxter, L. L. Char fragmentation and fly ash formation during pulverized-coal combustion. Combust. Flame. 1992, 90 (2), 174-184.

Beér, J. M. High efficiency electric power generation: The environmental role. Prog. Energy Combust. Sci. 2007, 33, 107-134.

Bouillard, J. X.; Lyczkowsky, R. W.; Gidaspow, D. Porosity distribution in a fluidized bed with an inmersed obstacle. AICHE J. 1989, 35 (6), 908-922.

Brennen, C. E. Fundamentals of Multiphase flows; Cambridge University Press: California, 2003.

Budilarto, S. An experimental study on effects of fluid aerodynamics and particle size distribution in particle-laden jet flows. ETD Collection for Purdue University, 2003.

Buhre, B. J. P.; Elliott, L. K.; Sheng, C. D.; Gupta, R. P.; Wall, T. F. Oxy-fuel combustion technology for coal-fired power generation. Prog. Energy Combust. Sci. 2005, 31 (4), 283-307.

Can, G.; Salatino, P.; Scala, F. A single particle model of the fluidized bed combustion of a char particle with a coherent ash skeleton: Application to granulated sewage sludge. Fuel Proc. Technol. 2007, 88, 577-584.

Carslaw, H. S.; Jaeger, J. C. Conduction of Heat in Solids; Oxford Univ Press, 1959.

Croiset, E.; Thambimuthu, K. V. $\mathrm{NO}_{\mathrm{x}}$ and $\mathrm{SO}_{2}$ emissions from $\mathrm{O}_{2} / \mathrm{CO}_{2}$ recycle coal combustion. Fuel. 2001, 80, 2117-2121.

Dam-Johansen, K.; Stergaard, K. High-temperature reaction between sulphur dioxide and limestone--I. Comparison of limestones in two laboratory reactors and a pilot plant. Chem. Eng. Sci. 1991, 46, 827837.

Dam-Johansen, K.; Stergaard, K. High-temperature reaction between sulphur dioxide and limestone--II. An improved experimental basis for a mathematical model. Chem. Eng. Sci. 1991, 46, 839-845.

Dockery, D. W.; Pope, C. A.; Xu, X.; Spengler, J. D.; Ware, J. D.; Fay, M. E.; et al. An association between air pollution and mortality in six U.S. cities. New England J. Med. 1993, 329, 1753-1759.

Drew, D. A. Mathematical modeling of two-phase flows. Annu. Rev. Fluid Mech. 1983, 15 (1), 261-291.

Fan, R.; Marchisio, D. L.; Fox, R. O. Application of the direct quadrature method of moments to polydisperse gas-solid fluidized beds. Powder Technol. 2004, 139 (1), 7-10.

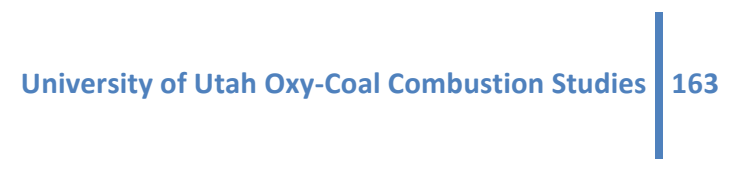


Fuertes, A. B.; Velasco, G.; Fuente, E.; Alvarez, T. Study of the direct sulfation of limestone particles at high CO2 partial pressures. Fuel Process. Technol. 1994, 38, 181-192.

Field, M. A. (1969). Rate of combustion of size-graded fractions of char from a low-rank coal between $1200^{\circ} \mathrm{K}$ and $2000^{\circ} \mathrm{K}$. Combust. Flame, 13, 237-248.

Gavalas, G. R. (1981). Analysis of char combustion including the effect of pore enlargement. Combust. Sci. Tech. , 24 (5-6), 197-210.

Geier, M.; Shaddix, C. R.; Haynes, B. S. Oxy-combustion of pulverized coal: modeling of charcombustion kinetics. 27th Annual International Pittsburgh Coal Conference. Istanbul, Turkey, 2010.

Gibilaro, L. G. Fluidization-Dynamics, the formlation and application of a predictive theory for the fluidized state; Butterworth-Heinemann: Oxford, 2001.

Graham, A. L. (1981). On the viscosity of suspensions of solids spheres. Appl. Sci. Res. 1981, 37, 275286.

Hajaligol, M. R.; Longwell, J. P.; Sarofim, A. F. Analysis and modeling of the direct sulfation of calcium carbonate. Ind. Eng. Chem. Res. 1988, 27, 2203-2210.

Hao Liu, S. K.; Okazaki, K. Drastic SOx removal and influences of various factors in O2/CO2 pulverized coal combustion system. Energy Fuels. 2001, 15, 403-412.

Hao Liu, R. Z.; Gibbs, B. M. Comparisons of pulverized coal combustion in air and in mixtures of $\mathrm{O}_{2} / \mathrm{CO}_{2}$. Fuel. 2005, 84, 833-840.

Haynes, B. S.; Neville, M.; Quann, R. J.; Sarofim, A. F. Factors governing the surface enrichment of fly ash in volatile trace species. J. Colloid Interface Sci. 1982, 87 (1), 266-278.

Helble, J. J.; Sarofim, A. F. Influence of char fragmentation on ash particle size distributions. Combust. Flame. 1989, 76 (2), 183-196.

Hillamo, R. E.; Kauppinen, E. I. (1991). On the performance of the Berner low pressure impactor. Aerosol Sci. Tech. 1991, 14 (1), 33-47.

Hu, G.; Dam-Johansen, K.; Wedel, S.; Hansen, J. P. Review of the direct sulfation reaction of limestone. Prog. Energy Combust. Sci. 2006, 32, 386-407.

$\mathrm{Hu}, \mathrm{Y}$.; Naito, S.; Kobayashi, N.; Hasatani, $\mathrm{M} . \mathrm{CO}_{2}, \mathrm{NO}_{\mathrm{x}}$ and $\mathrm{SO}_{2}$ emissions from the combustion of coal with high oxygen concentration gases. Fuel. 2000, 79, 1925-1932.

Iisa, K; Hupa, M.; Yrjas, P. Product layer diffusion in the sulphation of calcium carbonate. Symp. (Int.) Combust. 1992, 1349-1356.

Illerup, J. B.; Dam-Johansen, K.; Lundén, K. High-temperature reaction between sulfur dioxide and limestone--VI. The influence of high pressure. Chem. Eng. Sci. 1993, 48, 2151-2157.

Jain, A. K. Determination of sulfuric acid vapor or mist and sulfur dioxide emissions from Kraft recovery furnaces. National Council of the Paper Industry for Air and Stream Improvement, Inc., 1997.

Jiang, J.; Wendt, J.O.L. Effects of Partial Pressure of Oxygen on the Stability of Axial, Oxycoal, Turbulent Diffusion Flames, Topical Report for Task 8, Utah Clean Coal Program, July 2009.

Kang, S.-G.; Helble, J. J.; Sarofim, A. F.; Beér, J. M. Time-resolved evolution of fly ash during pulverized coal combustion. Symp. (Int.) Combust. 1989, 22 (1), 231-238.

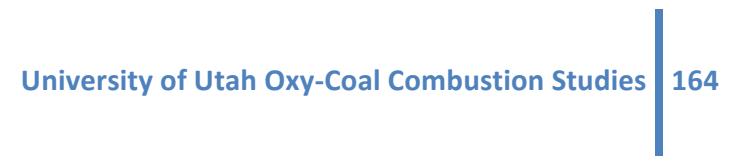


Kauppinen, E. I.; Pakkanen, T. A. Coal combustion aerosols: a field study. Environ. Sci. Technol. 1990, 24 (12), 1811-1818.

Kiga, T.; Takano, S.; Kimura, N.; Omata, K.; Okawa, M.; Mori, T.; Kato, M. Characteristics of pulverized-coal combustion in the system of oxygen/recycled flue gas combustion. Energy Convers. Manage. 1997, 38, 129-134.

Klostermann, M. Efficiency Increase of the oxyfuel process by waste heat recovery considering the effects of flue gas treatment. 3rd workshop of the IEA GHG international oxy-combustion network. Yokohama, Japan, 2008.

Koornneef, J.; Junginger, M.; Faaij, A. Development of fluidized bed combustion--An overview of trends, performance and cost. Prog. Energy Combust. Sci. 2007, 33, 19-55.

Levenspiel, O. Chemical reaction engineering; Wiley: New York, 1962.

Linak, W. P., Miller, C. A., \& Wendt, J. O. (2000). Comparison of Particle Size Distributions and Elemental Partitioning from the Combustion of Pulverized Coal and Residual Fuel Oil. J. Air Waste Manage. Assoc., 20, 1532-1544.

Linak, W. P.; Miller, C. A.; Seames, W. S.; Wendt, J. O.; Ishinomori, T.; Endo, Y.; et al. On trimodal particle size distributions in fly ash from pulverized-coal combustion. Proc. Combust. Inst. 2002, 29 (1), 441-447.

Liu, H.; Katagiri, S.; Kaneko, U.; Okazaki, K. Sulfation behavior of limestone under high $\mathrm{CO}_{2}$ concentration in $\mathrm{O} 2 / \mathrm{CO} 2$ coal combustion. Fuel. 2000, 79, 945-953.

Liu, H.; Okazaki, K. Simultaneous easy $\mathrm{CO} 2$ recovery and drastic reduction of SOx and NOx in O2/CO2 coal combustion with heat recirculation [small star, filled]. Fuel. 2003, 82, 1427-1436.

Marchisio, D. L., \& Fox, R. O. (2005). Solution of population balance equations using direct quadrature method of moments. Journal of Aerosol Science, 36, 43-73.

Markowski, G. R.; Ensor, D. S. A procedure for computing particle size dependent efficiency for control devices from cascade impactor data. Proceedings of the 70th Annual Meeting of the Air Pollution Control Assoc. Toronto, 1977.

Murphy, J. J.; Shaddix, C. R. Combustion kinetics of coal chars in oxygen-enriched environments. Combust. Flame. 2006, 144, 710-729.

Neville, M.; Quann, R. J.; Haynes, B. S.; Sarofim, A. F. Vaporization and condensation of mineral matter during pulverized coal combustion. Symp. (Int.) Combust. 1981, 18 (1), 1267-1274.

Nsakala, N. Y.; Marion, J.; Bozzuto, C.; Liljedahl, G.; Palkes, M.; Volgel, D.; et al. Engineering feasibility of $\mathrm{CO} 2$ capture on existing US coal-fired power plant. First National Conference on Carbon Sequestration. Washington D.C, 2001.

Pedel, J. Oxy-coal combustion: Large eddy simulation of coaxial jet burner using the direct quadrature method of moments. Research Proposal, 2010.

Quann, R. J. Ash vaporization under simulated pulverized coal combustion conditions. Ph.D. Thesis, 1982.

Quann, R. J.; Sarofim, A. F. Vaporization of refractory oxides during pulverized coal combustion. Symp. (Int.) Combust. 1982, 19 (1), 1429-1440.

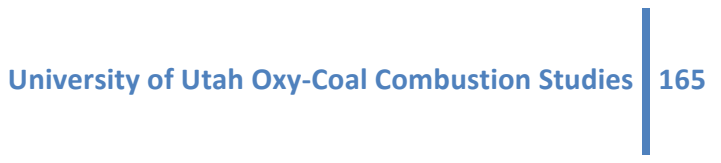


Qiu, K.; Lindqvist, O. Direct sulfation of limestone at elevated pressures. Chem. Eng. Sci. 2000, 55, 3091-3100.

Ramsden, A. R. A microscopic investigation into the formation of fly-ash during the combustion of a pulverized bituminous coal. Fuel 1969, 48, 121-137.

Sánchez, A.; Eddings, E.; Mondragón, F. Fourier Transform Infrared (FTIR) online monitoring of NO, $\mathrm{N}_{2} \mathrm{O}$, and $\mathrm{CO}_{2}$ during oxygen-enriched combustion of carbonaceous materials. Energy Fuels. 2010, $24,4849-4853$.

Sarofim, A. F. Oxy-fuel combustion: progress and remaining issues. 2nd Meeting of the Oxy-Fuel Network, Windsor, CT, USA, 2007.

Sarofim, A. F.; Howard, J. B.; Padia, A. S. The physical transformation of the mineral matter in pulverized coal under simulated combustion conditions. Combust. Sci. Technol. 1977, 16, 187-204.

Selma, B.; Bannari, R.; Proulx, P. Simulation of bubbly flows: Comparison between direct quadrature method of moments (DQMOM) and method of classes (CM). Chem. Eng. Sci. 2010, 65 (6), 19251941.

Senior, C. L.; Flagan, R. C. Ash vaporization and condensation during combustion of suspended coal particle. Aerosol Sci. Technol. 1982, 1, 371-383.

Shadle, L. J.; Ludlow, J. C.; Mei, J. S.; Guenter, C. Circulating Fluid-Bed Technology for Advanced Power Systems. West Virginia, 2002.

Sheng, C.; Li, Y.; Liu, X.; Yao, H.; Xu, M. Ash particle formation during O2/CO2 combustion of pulverized coals. Fuel Process. Technol. 2007, 88 (11-12), 1021-1028.

Silcox, G. D.; Kramlich, J. C.; Pershing, D. W. A mathematical model for the flash calcination of dispersed calcium carbonate and calcium hydroxide particles. Ind. Eng. Chem. Res. 1989, 28, 155160.

Smith, R. D.; Campbell, J. A.; Nielson, K. K. Concentration dependence upon particle size of volatilized elements in fly ash. Environ. Sci. Technol. 1979, 13 (5), 553-558.

Snow, M. J. H.; Longwell, J. P.; Sarofim, A. F. Direct sulfation of calcium carbonate. Ind. Eng. Chem. Res. 1988, 27, 268-213.

Spartinos, D. N.; Vayenas, C. G. Kinetics of sulphation of limestone and precalcined limestone. Chem. Eng. Proc. 1991, 30, 97-106.

Stanger, R.; Wall, T. Sulphur impacts during pulverised coal combustion in oxy-fuel technology for carbon capture and storage. Prog. Energy Combust. Sci. 2010, In Press, Corrected Proof.

Suriyawong, A.; Gamble, M.; Lee, M.-H.; Axelbaum, R.; Biswas, P. Submicrometer particle formation and mercury speciation under O2-CO2 coal combustion. Energy Fuels. 2006, 20 (6), 2357-2363.

Szekely, J.; Evans, J. W.; Sohn, H. Y. Gas-solid reactions; Academic Press, 1976.

Toftegaard, M. B.; Brix, J.; Jensen, P. A.; Glarborg, P.; Jensen, A. D. Oxy-fuel combustion of solid fuels. Prog. Energy Combust. Sci. 2010, 36, 581-625.

Tognotti, L.; Longwell, J. P.; Sarofim, A. F. The products of the high temperature oxidation of a single phar particle in an electrodynamic balancea. Symp. (Int) Combust. 1991, 23, 1207-1213.

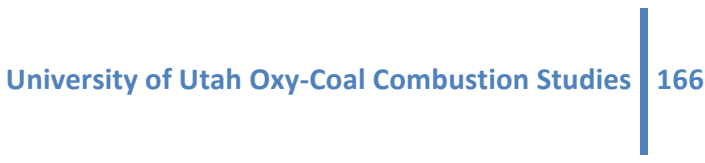


Tullin, C.; Nyman, G.; Ghardashkhani, S. Direct sulfation of calcium carbonate: the influence of carbon dioxide partial pressure. Energy Fuels. 1993, 7, 512-519.

Wall, T.; Liu, Y.; Spero, C.; Elliott, L.; Khare, S.; Rathnam, R.; Zeenathal, F.; Moghtaderi, B.; Buhre, B.; Sheng, C.; Gupta, R.; Yamada, T.; Makino, K.; Yu, J. An overview on oxyfuel coal combustion-State of the art research and technology development. Chem. Eng. Res. Des. 2009, 87, 1003-1016.

Woycenko, D. M; van de Kamp, W. L..; Roberts, P. A. Combustion of pulverised coal in a mixture of oxygen and recycled flue gas; Summary of the APG research program. International Flame Research Foundation (IFRF). Ijmuiden, The Netherlands, 1995.

Yamada, T. Pilot scale experiments giving direct comparison between air and oxy firing of coals and implication for large scale plan design. 2nd Workshop of the IEA international oxy-combustion research network. Hilton Garden Inn, Windsor, USA, 2007.

Yeoh, G. H.; Tu, J. Computational Techniques for Multiphase Flows; Elsevier, Ed.; ButterworthHeinemann: Oxford, UK, 2010.

Zevenhoven, R.; Yrjas, P.; Hupa, M. Sulfur dioxide capture under PFBC conditions: the influence of sorbent particle structure. Fuel. 1998, 77, 285-292.

Zhang, J; Kelly, K; Eddings, E; Wendt, J. Ignition in 40kW co-axial turbulent diffusion oxy-coal jet flames. Proc. Combust. Inst. 2010.

Zhang, J. Oxy-coal Combustion: Stability of Coaxial Pulverized Coal Flames in O2/CO2 Environments, PhD Thesis, University of Utah, December 2011.

Zheng, L.; Furimsky, E. Assessment of coal combustion in $\mathrm{O}_{2}+\mathrm{CO}_{2}$ by equilibrium calculations. Fuel Proc. Technol. 2003, 81, 23-34.

Zhong, Q. Direct sulfation reaction of $\mathrm{SO}_{2}$ with calcium carbonate. Thermochimica Ataca. 1995, 260, 125-136. 